\title{
Estimation of biomass, volume and growth of subtropical forests in Shitai County, China
}

\author{
Dissertation \\ to obtain the Ph.D degree from the Faculty of Forest Science and Forest \\ Ecology, \\ Georg-August-University Göttingen
}

By

Xiaolu Tang

Born in Neijiang, Sichuan Province, China 

Supervisor:

1. Referee/examiner:

2. Referee/examiner:

3. Examiner:

Date of oral examination: 22 July, 2015.
Prof. Dr. Christoph Kleinn

Prof. Dr. Christoph Kleinn

Prof. Dr. Juan Gabriel Álvarez González

Prof. Dr. Christian Ammer 



\section{Acknowledgements}

First of all, I would like to express my deep and great thanks to my supervisor Prof. Dr. Christoph Kleinn for (1) continuous support and trust in me; (2) great patience for my language. His encouragement and friendly guidance provide me the substantial basis for my $\mathrm{PhD}$ study. I can always recall his careful, insightful and tireless improvements of my first manuscript for many times. It is also my great honor and pleasure to work under his careful guidance and I had a really great time during my $\mathrm{PhD}$ study.

I also would like to extend my great thanks to Prof. Dr. Juan Gabriel Álvarez González from Universidad de Santiago de Compostela for his inexhaustible guidance in growth model development, careful and thoughtful review.

I also would like to express my great thanks to Prof. Dr. Christian Ammer for accepting the burden to review and improve my thesis even though overly busy as Dean of the Faculty of Forest Sciences and Forest Ecology.

Great and deep thanks are also given to my master supervisor - Shaohui Fan from International Centre for Bamboo and Rattan, his continuous understanding and support encourage me to go ahead.

Great thanks to Dr. Fengying Guan from International Centre for Bamboo and Rattan for sharing the data and inviting me as co-author in her manuscript.

I am thankful to Prof. Yuanchang Lu from Chinese Academy of Forestry for his kind support of the implementation of our project, and Prof. Yunhe He from Zhengjiang University of Agriculture and Forestry for kind support to vegetation survey.

I am grateful to all my colleagues and friends: Dr. Lutz Fehrmann, Dr. Hans Fuchs, Dr. Haijun Yang, M.Sc. Sabine Schreiner, M.Sc. Dengkui Mo, Dr. César Pérez Cruzado, Dr. Philip Beckschäfer, Dr. Paul Magdon, M.Sc. Dian Melati, M.Sc. Almut Niebuhr, M.Sc.Yanti Sarodja, M.Sc. Ramon Trucios Caciano, M.Sc. Nils Nölke, M.Sc. Collins B. Kukunda, M.Sc. Henning Aberle from Chair of Forest Inventory and Remote Sensing; Dr.Torsten Vor and Dr. Na Lin from Silviculture and Forest Ecology of the Temperate Zones; Dr. David I. Forrester, M.sc. Rubén Guisasola from Freiburg University.

Sincere thanks to Governor Genjie Li from Shitai government, Director Xiaoping Wang, Director Anguo Fan, Mr. Bailing Ding, Miss. Yue'e Chu from Shitai Forest Bureau, Mr. Xiaozhu Wang and Mr. Hongbing Ruan from Jitan Town, and some others from different forest stations.

I am deeply in debt to my parents, parents in laws and my brother for their selfless love. I am immensely grateful to my wife, her continuous love, support and accompany always encourage me.

Sincerely

Xiaolu Tang 


\section{Table of Contents}

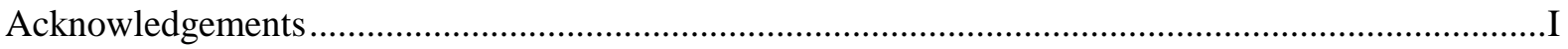

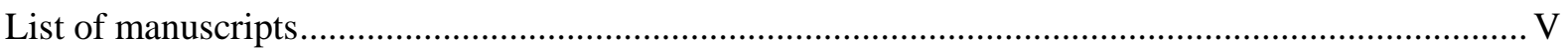

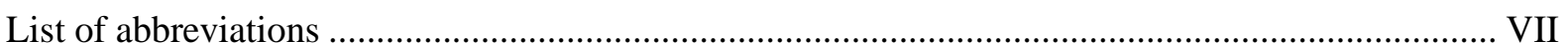

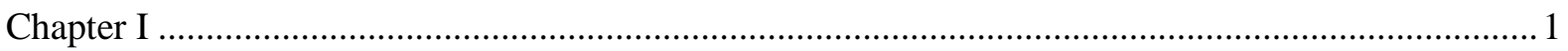

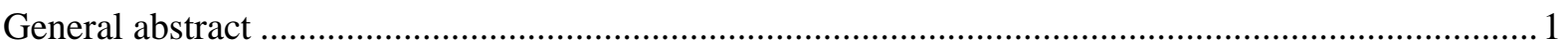

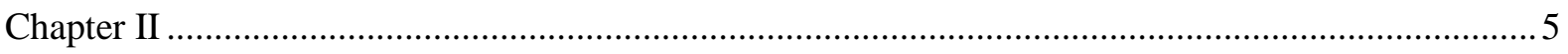

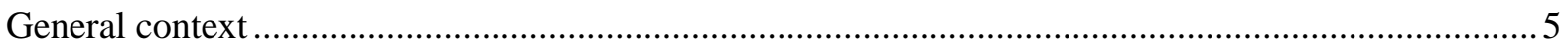

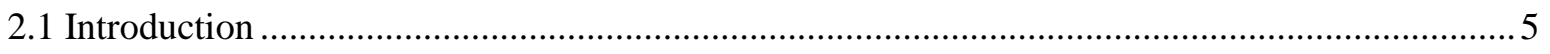

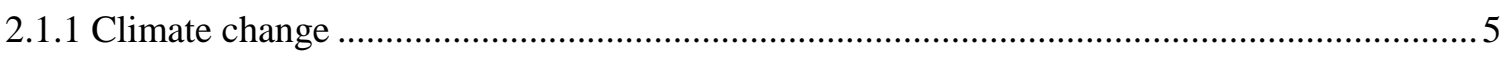

2.1.2 Forest sector in climate change

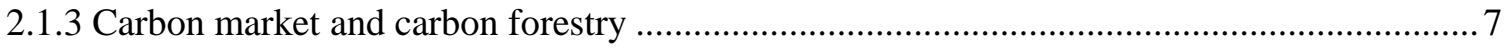

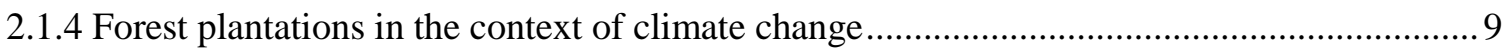

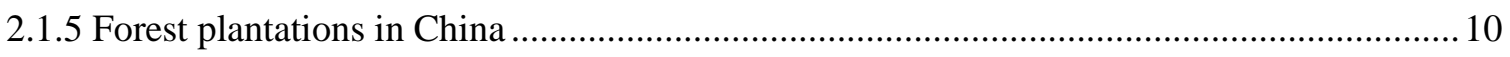

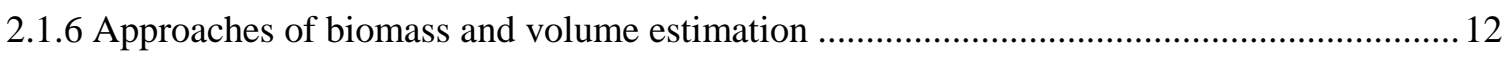

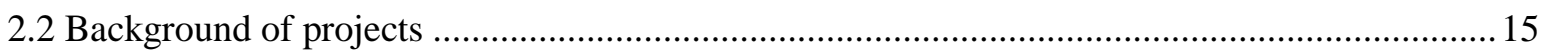

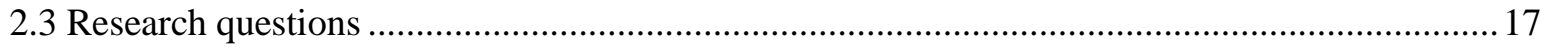

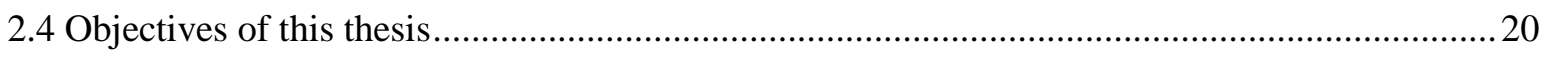

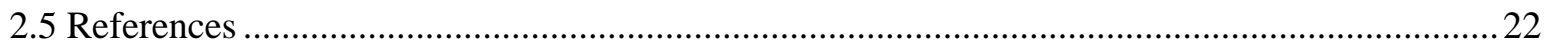

Chapter III: Estimation of aboveground biomass dynamics using generalized algebraic difference approach in Cunninghamia laceolata and Castanopsis sclerophylla forests in subtropical China ......29 Chapter IV: Development of a compatible taper function and stand-level merchantable volume model

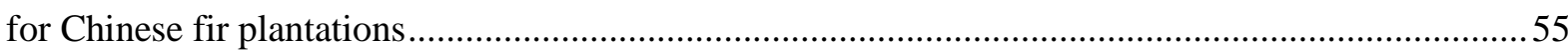

Chapter V: Development of stand density management diagrams for Chinese fir plantations .77

Chapter VI: Changes in soil carbon and nitrogen stocks followed the conversion from secondary forest to Chinese fir and Moso bamboo plantations.

Chapter VII: Inventory-based estimation of forest biomass in Shitai County, China - A comparison of five methods 
Curriculum Vitae 


\section{List of manuscripts}

I. Estimation of aboveground biomass dynamics using generalized algebraic difference approach in Cunninghamia laceolata and Castanopsis sclerophylla forests in subtropical China (submitted to Forestry, first author out of 10 co-authors, $1 / 10$ ).

II. Development of a compatible taper function and stand-level merchantable volume model for Chinese fir plantations (under review in PloS one, 1/6)

III. Development of stand density diagram for Chinese fir plantations (accepted by Forestry, $1 / 6)$

IV. Changes in soil carbon and nitrogen stocks following the conversion from secondary forest to Chinese fir and Moso bamboo plantations (Catena, 2/5)

V. Inventory-based estimation of forest biomass in Shitai County, China - A comparison of five methods (submitted to Annals of Forest Research, 1/6).... 


\section{List of abbreviations}

AGB aboveground biomass

BA basal area

BEF biomass expansion factor

CBEF continuous biomass expansion factor

CER certified emission reduction

CDM Clean Development Mechanism

CF Chinese fir

$\mathrm{CO}_{2} \quad$ carbon dioxide

ETS emission trading schemes

FAO food and agriculture organization

FMI forest management inventory

GADA generalized algebraic difference approach

GDP gross domestic product

HB hardwood broadleaved forest

IPCC Intergovernmental Panel on Climate Change

LUI/FI land use inventory and forest inventory

MB mean biomass

MBEF mean biomass expansion factor

MP masson pine

$\mathrm{N} \quad$ nitrogen

NCBEF national continuous biomass expansion factor

SOC soil organic carbon

SB softwood broadleaved forest

SDMD stand density management diagram

SI stand inventory

UNFCCC United Nations Framework Convention on Climate Change 



\section{Chapter I}

\section{General abstract}

Global climate change caused by increased carbon dioxide $\left(\mathrm{CO}_{2}\right)$ and other greenhouse gases has become one of the most urgent worldwide environmental topics of the $21^{\text {st }}$ century and alleviating climate change has become a core research interest. Forests cover $30 \%$ of total global surface and their role in alleviating global climate change has been highlighted because forests act as a continuous carbon sink of 1.9-2.6 Pg C $\left(1 \mathrm{Pg}=10^{15} \mathrm{~g}\right)$ per year.

China is one of the biggest countries worldwide with large area of forests, and China's forests act as an important role in alleviating climate change. Plantation forests, as one important forest type in China, have reached an area of 61.7 million ha until 2008 due to massive plantation establishment activities in the past several decades, which amount to $29 \%$ of the global plantation area. From 1950 to 2011, plantations in China sequestered $1.686 \mathrm{Pg} \mathrm{C}$ by net uptake into biomass and soil organic carbon. Therefore, China's plantations have made a considerable contribution to reduce atmospheric carbon. However, the stand quality of plantations is relatively low due to the short rotations and a lack of appropriate management. Mean standing volume in plantations is $49 \mathrm{~m}^{3} \mathrm{ha}^{-1}$, which is much lower than the world average of $130.7 \mathrm{~m}^{3} \mathrm{ha}^{-1}$ according to $7^{\text {th }}$ national forest inventory in China. This suggests a huge potential to increase carbon sequestration in China's plantations through forest management and thereby alleviate future climate change.

To improve the management of China's plantations, the objectives of this thesis, as a case study, were to provide a methodological basis for stand management of Chinese fir plantations and to develop a method to efficiently estimate regional biomass in Shitai County, China in context of carbon forestry. This thesis contains five main chapters that are prepared as manuscripts. Specifically, firstly, the aboveground biomass (AGB, including stem, branch and leaf biomass) and its dynamics were estimated in a Chinese fir plantation (Cunninghamia lanceolata) and a Castanoposis sclerophylla forest using the generalized algebraic difference approach (GADA) and biomass allometric models. GADA models were developed for both Chinese fir and Castanoposis sclerophylla to predict the diameter at any age of each individual tree. Secondly, a compatible taper function based on Fang et al. (2000) and a stand-level merchantable volume model were developed for Chinese fir plantations to estimate merchantable and total volume at the tree- and stand-levels. Thirdly, stand density management diagrams (SDMDs) were proposed to optimize stand management of Chinese fir plantations for different management purposes. Fourthly, soil organic carbon was analysed to examine the effects of land use change from secondary forest to Chinese fir and Moso bamboo plantations on soil organic carbon (SOC) and nitrogen (N) stocks. Finally, regional biomass was estimated based on 
inventory data using five different methods, which is expected to contribute to optimize the selection of methods for efficient regional biomass estimation.

This thesis was a part of the Lin4carbon project, which aimed to develop and optimize integrated methodological approaches for the estimation of biomass and carbon stock and improve forest management in China. Forest inventories were conducted to deliver actual estimates of volume, biomass and carbon stock and provide information about the feasibility and costs of sampling and plot designs. To achieve these objectives, three different inventory scales were established: (1) a land use and forest inventory (LUI/FI) that produced information over the whole extent of the sampling frame based on a $3 \times 3 \mathrm{~km}$ systematic grid; (2) a forest management inventory (FMI) for those stands with forest management information with a $500 \times 500 \mathrm{~m}$ systematic grid, and (3) a stand inventory of selected stands (SI) with a $100 \times 100 \mathrm{~m}$ systematic grid. A nested plot design with an inner radius of 6 $\mathrm{m}$ and outer radius of $10 \mathrm{~m}$ was used. A total of 258 plots were established, 74 of which were dominated by Chinese fir plantations.

In the SI plots, a total of 103 trees of different dominance classes of the five main species were felled for stem analysis and biomass allometric model construction. This included 46 Chinese fir trees. The stems were cut into sections at heights of $0.3 \mathrm{~m}, 1.3 \mathrm{~m}, 3 \mathrm{~m}$ and $2 \mathrm{~m}$ intervals thereafter up to the treetop. Cross-sectional stem discs (about $5 \mathrm{~cm}$ thick) were collected at each of these heights, as well as one disc at ground level.

In chapter III, GADA models based on stem analysis of 18 C. lanceolate and 15 C. sclerophylla trees were developed. The application of the GADA model yielded a very good performance in terms of diameter prediction for each individual tree. Combining the allometric models, estimated AGB increased with stand age, increasing from $69.4 \pm 7.7$ (mean \pm standard error) in 2010 to $102.5 \pm 11.4$ $\mathrm{Mg} \mathrm{ha}^{-1}$ in 2013 for Chinese fir plantations, compared to $136.9 \pm 7.0$ in 2010 to $154.8 \pm 8.0 \mathrm{Mg} \mathrm{ha}^{-1}$ in 2013 for C. sclerophylla forests. AGB increment was $10.6 \pm 1.2$ for 2010-2011, $11.0 \pm 1.2$ for 20112012 and $11.5 \pm 1.3 \mathrm{Mg} \mathrm{ha}^{-1} \mathrm{a}^{-1}$ for 2012-2013 for C. lanceolate, respectively. They were significantly higher than those of $C$. sclerophylla forests with $5.8 \pm 0.3,5.9 \pm 0.3$ and $6.3 \pm 0.4 \mathrm{Mg} \mathrm{ha}^{-1} \mathrm{a}^{-1}$. Stems contributed $76 \%$ to total AGB and AGB increment, highlighting the importance of stems in ecosystem biomass stocks. By combining biomass allometric models, stand-level AGB dynamics were successfully estimated, which can contribute to our understanding of net primary production and carbon sequestration dynamics in these forest ecosystems.

Based on a statistical sample of $n=46$ non-forked Chinese fir trees, a compatible taper function proposed by Fang et al. (2000) and a stand-level merchantable volume model were developed for Chinese fir plantations in chapter IV. A second-order continuous autoregressive error structure corrected the inherent serial autocorrelation of different observations in a given tree. The taper function and volume equations were fitted simultaneously after autocorrelation correction. The model 
developed by Fang et al. (2000) fitted the data well and had a very good performance in terms of diameter and individual tree volume prediction. The stand-level merchantable volume equation based on the ratio approach was developed using basal area, dominant height, quadratic mean diameter and top diameter (ranging from 0 to $30 \mathrm{~cm}$ ) as independent variables. The high correlation between measured and predicted total and merchantable stand volume from this model highlighted the efficiency of stand-level merchantable model in stand-level merchantable volume and total stand volume estimation. Lastly, a total stand-level volume table using stand basal area and dominant height was proposed for local forest managers to simplify the stand volume estimation.

To provide a simple tool that guide the stand management for different management purposes, SDMDs for stand volume, stem biomass and total AGB were developed for Chinese fir plantations in chapter V. The number of the trees per ha was set on the $y$-axis and dominant height was set on the $x$ axis, while stand volume, stem biomass or AGB was presented on the isolines. To develop the SDMD, a system of four equations was fitted simultaneously using the data collected from 74 inventory plots. The relative spacing index was used to characterize the growing stock. Two practical examples with the same management target were also proposed to explain the use of SDMD for stand management optimization. The proposed SDMDs can be an easy tool for local forest managers to estimate the stand volume, stem biomass and $\mathrm{AGB}$, and could be a reference to determine optimum thinning schedules. It is an effective planning tool based on relatively low input with reliable data.

Conversion of secondary forests to Chinese fir and Moso bamboo plantations represents an important land use change in subtropical China. The effects of this conversion on soil organic carbon (SOC) and nitrogen $(\mathrm{N})$ stocks have been examined in chapter VI. Soil samples were collected from six plots in the Castanopsis sclerophylla forest, five plots in the Chinese fir and three plots in the Moso bamboo plantations. Three profiles starting from the north direction, lying at $0^{\circ}, 120^{\circ}$ and $240^{\circ}$, and $3 \mathrm{~m}$ from the plot center, were sampled in each plot. Soil samples were collected down to $50 \mathrm{~cm}$ in four layers: 0-10 cm, 10-20 cm, 20-30 cm and 30-50 cm. Mineral soil was air-dried at room temperature and sieved through 2-mm and $0.15-\mathrm{mm}$ sieves for total SOC and $\mathrm{N}$ concentration analysis. Over $0-50 \mathrm{~cm}$, SOC and $\mathrm{N}$ stocks in the secondary forests were significantly higher than those of Chinese fir and Moso bamboo plantations with values of 203.68, 127.34 and $118.25 \mathrm{Mg} \mathrm{ha}^{-1}$ for SOC stock and 9.24, 5.10 and $6.35 \mathrm{Mg} \mathrm{ha}^{-1}$ for $\mathrm{N}$ stock. The results indicated that converting the secondary forests to Chinese fir and Moso bamboo plantations significantly decreased the SOC and N stocks at a depth of $0-50 \mathrm{~cm}$. These reductions were associated with prescribed burning, site preparation, belowground metabolism and stand age. Therefore, it is expected that increasing the rotation age (and improving establishment techniques) could not only increase the AGB accumulation, but also increase SOC stock in the Chinese fir plantations. 
Regarding the regional biomass estimation, the forests of the whole study area were divided into Chinese fir plantations (CF), hardwood broadleaved forests (HB), softwood-broadleaved forests (SB) and mason pine (MP) forests according to the criteria of the local forest management inventory in chapter VII. The five methods that were selected, included a continuous biomass expansion factor (CBEF) approach, a mean biomass density (MB) approach, a mean biomass expansion factor (MBEF) approach, national continuous biomass expansion factors (NCBEF) proposed by Fang et al. (2002) and the standard IPCC approach. Because it is impossible to get the true value of the regional biomass, it is assumed, as suggested by many studies (Fang et al. 1998; Guo et al. 2010), that CBEF derived biomass is most realistic since CBEF reflected the changes of BEFs with stand age, stand density and site quality. Based on this assumption, generally, the MBEF approach overestimated forest biomass by $9 \%-16 \%$ while the IPCC approach underestimated forest biomass by 35\%-27\% for different forest types compared to CBEF derived biomass. The MB approach provided the most similar biomass estimate for all forest types and could be an alternative approach when the CBEF equation and biomass expansion factor (BEF) are lacking in the study area. BEF equations were proposed for each forest type with mean BEFs of $0.84 \mathrm{Mg} \mathrm{m}^{-3}$ for CF and MP, $1.18 \mathrm{Mg} \mathrm{m}^{-3}$ and $1.28 \mathrm{Mg} \mathrm{m}^{-3}$ for $\mathrm{HB}$ and $\mathrm{SB}$, respectively. The total biomass derived from MBEF was highest at $1.44 \times 10^{7} \mathrm{Mg}$, followed by $1.32 \times 10^{7} \mathrm{Mg}$ from CBEF, $1.31 \times 10^{7} \mathrm{Mg}$ from NCBEF, $1.25 \times 10^{7} \mathrm{Mg}$ from $\mathrm{MB}$ and $1.16 \times 10^{7} \mathrm{Mg}$ from IPCC. Our results facilitate method selection for regional forest biomass estimation and provide statistical evidence for local government planning to enter the potential carbon market.

Above all, in this thesis different technical topics have been addressed in content of carbon forestry, which were AGB dynamics estimation using GADA models, development of taper function and stand-level merchantable volume, development of stand density management diagram, soil carbon changes after the land use change from secondary forests to Chinese fir plantations and regional biomass estimation. Based on these results, we proposed that improving stand management and increasing rotation age have great potentials in terms of aboveground, belowground and soil carbon sequestration in plantations. This highlights the importance of improving ecosystem carbon stock by stand management and increasing rotation age in content of carbon forestry in alleviating future climate change. 


\section{Chapter II}

\section{General context}

\subsection{Introduction}

\subsubsection{Climate change}

Global climate change, caused by the rising level of carbon dioxide $\left(\mathrm{CO}_{2}\right)$ and other greenhouse gases (Bonan, 2008), has become one of the most urgent worldwide environmental topics of the $21^{\text {st }}$ century and has become a core research interest (Guo et al., 2010; Seo et al., 2013). It is well accepted that the main reason for climate change is the rising atmospheric $\mathrm{CO}_{2}$ concentrations (Houghton, 2007; IPCC, 2007; Scott et al., 2015). Before the industrial revolution, $\mathrm{CO}_{2}$ remained at about $280 \mathrm{ppm}$ (parts per million) for tens of thousands of years; after the mid- $19^{\text {th }}$ century, atmospheric $\mathrm{CO}_{2}$ concentrations increased exponentially due to rapid industrialization and the increasing burning of fossil fuels, and reached $390.5 \mathrm{ppm}$ in 2011 (Stocker et al., 2014). The annual $\mathrm{CO}_{2}$ concentration is still increasing at a speed of $2.0 \mathrm{ppm}$ per year between 2002-2011, which equals 4.0 Pg C (1 Pg $\mathrm{C}=10^{15} \mathrm{~g} \mathrm{C}$ ), and it is predicted to reach between 430 and $530 \mathrm{ppm}$ in 2100 (Stocker et al., 2014). As a result, the global mean surface temperature has increased by $0.85^{\circ} \mathrm{C}$ over the period 1880 to 2012 (Allen et al., 2014). In the $21^{\text {st }}$ century, it is predicted that the global average temperature will rise by 2.5-7.8 ${ }^{\circ} \mathrm{C}$ (range based on median climate response: $3.7-4.8^{\circ} \mathrm{C}$, Allen et al., 2014). These changes in climate can cause serious environmental problems, such as precipitation shifts at various places on earth, an increasing frequency of drought and flooding and changing terrestrial structures and functions. Therefore, measures to alleviate and mitigate climate change have attracted great attentions for both government and scientists in the $21^{\text {st }}$ century.

One characteristic of the climate change challenge is its long-term effects, since the effects of $\mathrm{CO}_{2}$ emissions are cumulative in the atmosphere, thus long-term planning is required to control atmospheric $\mathrm{CO}_{2}$ concentrations to avoid deleterious consequences. Fortunately, many policy-makers and scientists have realized the importance of long-term policy targets of reducing carbon emissions and atmospheric $\mathrm{CO}_{2}$ concentrations. For example, some nations, especially in Europe, have already begun considering substantial long-term $\mathrm{CO}_{2}$ reduction for their policy goals. The European Commission has set a baseline that "by 2050 global emissions must be reduced by up to 50\% compared to 1990, implying reductions in developed countries of $60 \%-80 \%$ by 2050" (EC European Commission, 2007). To achieve this target, the EU will reduce their greenhouse gas emissions by $20 \%$ by 2020 until a comprehensive international agreement is obtained (EC European Commission, 2007). The British government has also confirmed that the country seeks a $60 \%$ reduction of $\mathrm{CO}_{2}$ emissions by 2050 (EC European Commission, 2007). It is worth mentioning that some developing countries have set up voluntary domestic targets for carbon emission reduction independent of the Kyoto 
requirements. For example, in the "Eleventh Five Year Plan" (for the years 2006-2010), China committed to reduce energy intensity [the amount of energy use per unit of gross domestic product (GDP)] by $20 \%$. Thereafter, by the year of 2020 , the Chinese government has promised to further reduce energy intensity by an additional 40\%-45\% per unit of GDP (Planning Division of National Reform and Development Commission, 2006). Globally, IPCC adapts the following sectors - water, agriculture, infrastructure/settlement, human health, tourism, transport and energy, to reduce greenhouse gas emissions (IPCC, 2007). Forest is one of the most important sectors that enables a reduction in $\mathrm{CO}_{2}$ from the atmosphere by fixing atmospheric $\mathrm{CO}_{2}$ into forest biomass through photosynthesis. Therefore, there is a great interest for both policy-makers and scientists to establish new plantations, reduce forest degradation and improve forest management that increase the carbon sequestration from the atmosphere.

\subsubsection{Forest sector in climate change}

The FAO defined "biomass" as dry organic materials both aboveground and belowground, and both living and dead, e.g., trees, crops, grasses, tree litter, roots (FAO, 2010). Forest biomass is an important ecological variable that is measured in many forest inventories because about $50 \%$ dry biomass is carbon (IPCC, 2007). Therefore, forest biomass has become one of the core interests in climate change research (Guo et al., 2010; Seo et al., 2013). Generally, carbon stocks are converted from biomass by multiplying by carbon content. Changes in the amount of forest biomass already affect the global atmosphere by having the potential either to become a larger carbon sink or to become an even larger source in the future (Baneh et al., 2013). For example, deforestation and forest degradation are considered to be major sources of $\mathrm{CO}_{2}$ emissions through combustion of forest biomass, decomposition of remaining plant materials and soil carbon (Van der Werf et al., 2009), which could not only lead to direct carbon emissions, but also destroy future forest carbon sinks. The amount of carbon emission from deforestation and degradation is estimated to be $12 \%-20 \%$ of global anthropogenic $\mathrm{CO}_{2}$ emissions (Van der Werf et al., 2009).

Although forests cover $30 \%$ of the global land surface, amounting to $4.2 \times 10^{9}$ ha (Bonan, 2008), they contain over $80 \%$ of terrestrial vegetation carbon in forest biomass (Dixon et al., 1994; Fang et al., 2014), which are two times the amount of carbon in the atmosphere (Canadell and Raupach, 2008). The annual carbon flux between forests and the atmosphere via photosynthesis and ecosystem respiration amounts to 50\%-90\% of the total carbon fluxes of terrestrial ecosystems (Fang et al., 2014; Malhi et al., 2002). From 1990 to 2007, forests contributed a consistent carbon sink of 1.9-2.6 Pg C per year, accounting for 33\% of carbon emissions from fossil fuel and land use changes (Houghton, 2007; IPCC, 2007; Pan et al., 2011). Therefore, forests play an important role in climate change mitigation. There are four major strategies to mitigate and alleviate climate change in the forests by: (1) increasing forest area through afforestation and reforestation; (2) increasing carbon density at both the stand- and landscape-scales; (3) expanding the use of forest products to reduce and replace fossil 
fuel $\mathrm{CO}_{2}$ emissions, and (4) reducing emissions from deforestation and forest degradation (Canadell and Raupach, 2008).

It is generally recognized that natural forests store more biomass than forest plantations per ha (Pan et al., 2004). However, under human activities, natural forests have been reduced from $46 \%$ of the earth's terrestrial ecosystems in preindustrial times to $28 \%$ (Winjum and Schroeder, 1997). In the last several decades, forest cover suffers significant transitions due to the increase of disturbances, food, fiber demand and increasing population [Fig. 1 (Angelsen, 2007) modified by Kanninen (2007)]. Globally, an estimated forest area of 13 million ha per year were deforested between 2000 and 2010, which results in a 5.2 million ha net forest loss after compensating for afforestation and natural expansion. Most deforestation occurs in tropical countries while most developed countries with temperate and boreal forest ecosystems are experiencing an increase in forest area (FAO, 2011). However, from 2000 to 2005, there was an annual net gain of 1 million ha in forest area in Asia, to which China, India and Viet Nam were major contributors. Asia is the first continent to display a transition from net deforestation to net reforestation since systematic collation of data of global forest resources began in the 20th century (Mather 2007).

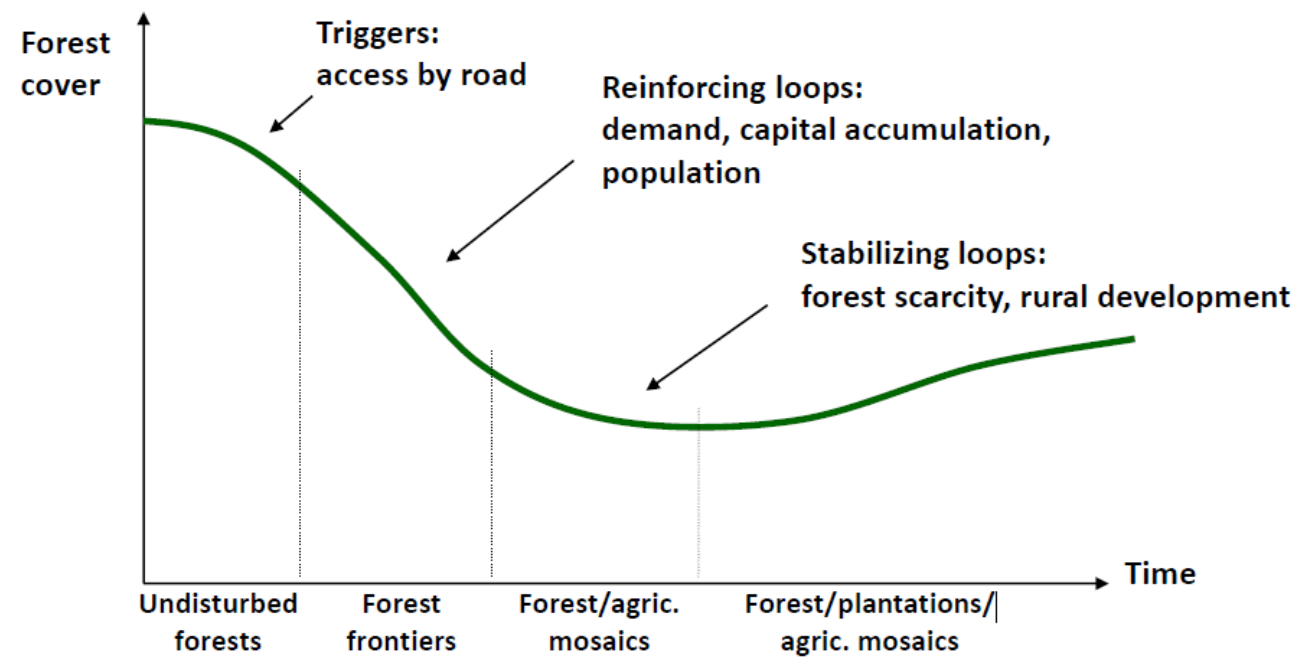

Fig. 1 Forest transition drivers over the time (Angelsen, 2007), modified by Kaninnen (2007).

\subsubsection{Carbon market and carbon forestry}

A carbon market, which is considered by many economists as the most cost-effective route to achieve emission reductions, is the main economic instrument chosen to address the negative excessive greenhouse gas emissions (Delbosc and de Perthuis, 2009; Wang, 2012). A carbon market for ecosystem services has emerged in recent years due to national incentive schemes or international project-driven initiatives. As an important carbon sink, carbon forestry has received great attention due to its special role in mitigating future climate change, increasing forest conservation and local development (Wang, 2012). As a result, a steady increase in the number of projects on carbon forestry 
in developing countries have been conducted under the United Nations Framework Convention on Climate Change (UNFCCC) or under voluntary markets. It is timely to provide empirical evidence from ongoing carbon forestry activities in order to examine their potential to achieve environmental and development outcomes. Emission trading schemes (ETSs) are already in operation in many countries around the world, such as within the European Union, California, and will start in Australia in 2015, Québec, in the Republic of Korea, and several other regions. In 2012, the global carbon market accounted to 10.3 billion $\mathrm{Mg} \mathrm{CO}_{2}\left(1 \mathrm{Mg}=10^{6} \mathrm{~g}\right.$ ), equalling US\$176 billion (Kossoy and Guigon, 2012). Most of the trading comes from EU allowances, reaching 7.9 billion $\mathrm{Mg} \mathrm{CO}_{2}$ and amount to US\$148 billion (Kossoy and Guigon, 2012).

Currently, China is the largest carbon emitter worldwide, amounting to about 2.7 Pg C in 2012 (Le Quéré et al., 2014). The development of carbon markets in China has received great attention from the international community, which is keen to follow the development of a cap-and-trade system in a country not bound by any absolute reduction commitments, and to see what role it will play in China's transition to a low-carbon economy (Liu et al., 2013b; Wang, 2012). Since 2005, China has been involved in the carbon market as an exporter of certified emission reductions (CERs) under Clean Development Mechanism (CDM), under which developed countries provide financial support to projects that cut or reduce greenhouse gas emissions in developing countries and acquire CERs to offset their own emissions and meet their net reduction targets (Lo and Howes, 2014). China is the largest supplier of CERs, currently holding $50 \%$ of the projects registered under the CDM and producing $61 \%$ of the expected CERs from registered projects (Lo and Howes, 2014). The Chinese government has placed a carbon emission trading scheme (ETS) on the national agenda. By 2011, seven pilot sites across China were established, which are in Beijing, Tianjin, Shanghai, Chongqing, Shenzhen, Guangdong and Hubei (Lo, 2013; Wang, 2012). These areas amount to $27.4 \%$ of its national GDP and $18.4 \%$ of the total population in China. These pilot schemes started in 2013 with the short-term goal to establish trans-provincial and trans-regional ETSs in transition to a national scheme by 2015 (Lo, 2013). Potentially, these pilots can be linked to the international ETSs in other regions, e.g. Australia, New Zealand, South Korea, and Japan (Tokyo), eventually creating an AsiaPacific network of carbon trading and making a major progressive move towards an internationally linked carbon market.

Chongqing has clearly announced local offset by carbon forestry under its cap-and-trade system. Carbon forestry has also been highlighted recently in the governments' mandatory agenda. For example, forest coverage is due to increase from $20.36 \%$ in $2006-2010$ to $23 \%$ in 2016-2020, and forest stock volume increase from 13.7 billion $\mathrm{m}^{3}$ in 2006-2010 to 15 billion $\mathrm{m}^{3}$ in 2016-2020 (Wang, 2012). To achieve these goals, many indicators are set for 2015 in terms of land acreage dedicated to forestry and increase of restored desertification, wetland, and natural forestry conservation area. Subsequently, Chinese president Jintao Hu declares that the Chinese government is committed to 
increase its total forest area by 40 million hectares and its forest stock by 1.3 billion $\mathrm{m}^{3}$ from 2006 to 2020 (Gao et al., 2014). Some voluntary emission reduction initiatives in China were also launched in 2009 to foster mitigation activities in the forestry sector. The Panda Standard (PS), China's first thirdparty standard for domestic offset projects, was undertaken by the China Beijing Environment Exchange (CBEEX) and BlueNext at the end of 2009, aiming to establish itself as a widely accepted initiative in mitigation efforts of climate change. As the first transaction, 16800 PS credits-to-be issued from the Bamboo Forestation Project in Yunnan province were acquired by state-owned Franshion Property Company at $¥ 60$ per $\mathrm{Mg} \mathrm{CO}_{2}$ in March 2011 (Wang, 2012). In addition, the China Green Carbon Foundation under the State Forestry Administration (SFA) encourages enterprises, social organizations and individuals to voluntarily take part in the tree plantation and forest protection. Therefore, it is supposed that a carbon market in China has the great potential to use carbon forestry not only for ecological benefits to mitigate climate change, but also economic benefits to forest managers and owners, further improving their initiatives of forest management.

\subsubsection{Forest plantations in the context of climate change}

Plantations act as not only an important role in providing timber production, energy resources, soil and water conservation and restoration of degraded land, but also an important role in carbon sequestration from the atmosphere and mitigating future climate change (Kelty, 2006; Winjum and Schroeder, 1997). Establishing plantations is also recognized as the most effective, hopeful and ecologically friendly practice to increase carbon sequestration in terrestrial ecosystems (Huang et al., 2012). Globally, plantations cover an area of $2.64 \times 10^{9}$ ha until 2010 , amounting to $6.6 \%$ of total forest area (FAO, 2010). Since 1990, the plantation area has increased steadily. For example, plantation area increased more than $3.6 \times 10^{7}$ ha annually from $1990-2000$, with an increase of $5.6 \times 10^{7}$ ha per year from 2000-2005 and 4.2 ×10 7 ha per year from 2005-2010 (FAO, 2010). Although there was a significant increase in plantation area in most the countries, some countries suffered from a loss. The greatest loss in plantation area was found in the Democratic People's Republic of Korea with an annual loss of 17000 ha per year in the last 20 years (FAO, 2010).

Regional and national scale carbon sequestration and its dynamics in plantations have been observed already. For example, plantations in the USA caused an average carbon sequestration of $17 \mathrm{Tg} \mathrm{C}$ per year $\left(1 \mathrm{Tg}=10^{12} \mathrm{~g}\right)$, including $6 \mathrm{Tg} \mathrm{C}$ in the soil and $11 \mathrm{Tg} \mathrm{C}$ per year in forest biomass between 1990 and 2004 (Woodbury et al., 2007). Similarly, carbon sequestration after conversion from marginal croplands to plantations is estimated to be 508-540 Tg C over 20 years and 1018-1080 Tg C over 50 years in Midwestern USA. This could offset 6-8\% of carbon emissions in the region (Niu and Duiker, 2006). Globally, carbon sequestration through afforestation and reforestation is estimated to amount to 69-90 Pg between 1995 and 2050 according to the Land use, Land-use change and Forestry report in 2000 (Watson et al., 2000), which could offset $11 \%$ to $17 \%$ of global carbon emission if an annual figure of $9.5 \mathrm{Pg} \mathrm{C}$ is used (Ciais et al., 2014). Generally, establishing plantations could not 
only increase carbon sequestration in biomass, but also increase SOC stock (Huang et al., 2012; Woodbury et al., 2007). On the other hand, changes in SOC stock remain controversial, and are affected by stand production, soil condition, land use history, forest type and forest management (Paul et al., 2002; Zinn et al., 2002). Most studies indicate SOC stock suffers from initial loss, followed by an increase with the increase of stand age (Cook et al., 2014; Guan et al., 2015; Paul et al., 2002; Turner and Lambert, 2000).

However, forest plantations are irregularly distributed worldwide such that the greatest plantation area was reported in East Asia, Europe and North America, accounting for 75\% of global plantations. In East Asia, plantations make up 35\% of total forest area, and $86 \%$ of them are found in China. In South and Southeast Asia, India, Indonesia, Malaysia, Thailand and Viet Nam established $90 \%$ of the plantations. In Northern Africa, 75\% of the plantation area is found in Sudan (FAO, 2010). Similarly, globally, among the plantation genera, broadleaved plantations, mainly Eucalyptus, make up $40 \%$ of total plantation area, followed by Pinus (20\%) and other conifer genera (Carle et al., 2002). Most of the plantations are established as monocultures due to e.g. simple stand management, resource allocation to the most desirable species, easy harvest operation (Kelty, 2006). However, the importance of establishing mixed plantation has been highlighted in increasing light use efficiency (Nunes et al., 2013), increasing stand production, reducing damage risk and restoring degraded lands (Kelty, 2006).

\subsubsection{Forest plantations in China}

Total forest cover and forest area in China decreased in the 1950s because of large scale forest harvest for mining, and then tended to increase after the 1970s due to massive plantation establishment efforts (Huang et al., 2012). A total area of 130.09 million ha of plantations with an annual average of 2.17 million ha was created between 1950 and 2009. Plantation area cover increased from $0.53 \%$ in 1950 to $10.44 \%$ in 2008 (Huang et al., 2012). As a result, currently China has the largest plantation areas worldwide with an area of 61.7 million ha in 2008 according to the 7th national forest inventory, amounting to $29 \%$ of global plantation areas (FAO, 2010; Jia et al., 2009).

Previous studies have already attempted to estimate the carbon sequestration in China's plantations at regional and national scales for different periods. For example, estimated carbon sequestration by Liu et al. (2008) in newly established plantations under Natural Forest Conservation Program was $21.3 \mathrm{Tg}$ C from 1998 to 2004. Between 1999 and 2003, carbon sequestration in China's plantations amounts to $0.77 \mathrm{Pg} \mathrm{C}$, which is $7 \%$ of that of global plantations (Xu and Li, 2010). Meanwhile, the annual carbon accumulation rate is $0.0217 \mathrm{Pg} \mathrm{C}$ per year, amounting to $12 \%$ of global carbon stock accumulation in plantations ( $\mathrm{Xu}$ and $\mathrm{Li}, 2010)$. Similar report finds that plantations sequestrate $0.45 \mathrm{Pg} \mathrm{C}$ in forest biomass between the mid- 1970s and 1998 (Fang et al., 2001). Nationally, from 1950 until 2009, China's plantations sequestrated 1.686 Pg C by net uptake into biomass and emissions from soil 
(Huang et al., 2012). Furthermore, it is also predicted that carbon sequestration in China's plantations will amount to $3.169 \mathrm{Pg} \mathrm{C}$ by 2050 , including $21.4 \%$ in forest biomass and $78.6 \%$ in soil (Huang et al., 2012). These results suggest that China's plantations have made a considerable contribution to mitigate global climate change (Fang et al., 2001).

Plantations in China are typically established on sites that have rapid growth, easy access to processing facilities and growing markets, and only a few species with good economic benefits are planted (Wei and Blanco, 2014). By species, the largest plantation area is the Chinese fir (Cunninghamia lanceolata) plantations, with an area of 8.54 million ha and accounting to $21.25 \%$ of the total plantation area in China, followed by Populus ( 7.57 million ha and $18.93 \%$ of total plantation area), Pinus massoniana (3.36 million ha and $8.4 \%$ of total plantation area), Larix gmelinii (2.86 million ha and $7.14 \%$ of total plantation area), and Eucalyptus (2.54 million ha and $6.35 \%$ of total plantation area) (Jia et al., 2009). However, most of the plantations are monospecific stands in which the biomass and volume remain at a relatively low level due to relatively poor management. As a result, the mean stand volume in China's plantations is $49 \mathrm{~m}^{3} \mathrm{ha}^{-1}$ with annual increments of $5.13 \mathrm{~m}^{3}$ $\mathrm{ha}^{-1}$ year $^{-1}$ (Jia et al., 2009), which is far lower than the world average $\left(130.7 \mathrm{~m}^{3} \mathrm{ha}^{-1}\right.$ ) (FAO, 2010). This indicates that there is a great potential to increase plantation biomass in China by means of forest management.

Stand management is recognized as an important practice to increase the carbon density of existing plantations (Gao et al., 2014; Liu et al., 2013a). An effective management not only prevents a reduction in net carbon sequestration, but also enhances carbon sequestration (Pan et al., 2011). Traditionally, forest management in plantations is mainly associated with the application of short rotations, monocultures, clear-cut and a high-level of removal of biomass or volume driven by economic benefits. The plantation sites are commonly abandoned after one or two rotation periods to allow natural regeneration to mixed forests (Wei et al., 2012). However, since the 1950s, with the expansion of the plantation area, repeated establishment of plantations by coppicing or new seedlings on the same sites has become normal with a short rotation of 25 years (Wei et al., 2012; Wu, 1984). Due to poor management practices, continuous cultivation of plantations on the same sites or monocultures has resulted in many well-known ecological problems: a decline in production and soil fertility (Bi et al., 2007), biodiversity loss (Wenhua, 2004), increased susceptibility to insects and diseases (Ye et al., 2010), decreased stand stability (Zhou et al., 2011). Wei and Blanco (2014) propose that mixed and sustainably managed plantations could increase carbon sequestration by $67.5 \%$ compared to traditional monospecific Chinese fir plantations. If all monospecific plantations were transferred to mixed plantations within the next 10 years, an additional 260. $22 \mathrm{Tg} \mathrm{C}$ was predicted to be obtained by 2050. Assuming similar sustainable forest management conducted in temperate and boreal plantations, a total of $1.483 \mathrm{Pg} \mathrm{C}$ more could be sequestrated, equalling an annual carbon sequestration rate of $40.08 \mathrm{Tg} \mathrm{C}$ year $^{-1}$ and offsetting $1.9 \%$ of China's carbon emission in 2010 (Wei 
and Blanco, 2014). More importantly, the carbon increase can be maintained in the long-run though the maintenance of soil carbon and timber production with a longer life span after the conversion of monocultures to mixed sustainable plantations. Therefore, sustainable forest management plays an important role in mitigating climate change if the management practices are designed and implemented properly.

If China's plantation area continuously increases with a large area of newly established plantations, urgent improvements in forest management to enhance stand quality by sustainable forest management are required. Although the Chinese government commits to increase new plantations by 40 million ha between 2006 and 2020 (Gao et al., 2014), it may not have the intended impact on carbon sequestration unless an appropriate forest management is implemented (Liu and Yin, 2012). Applying sustainable forest management practices can make a significant difference. Forest management, such as selective harvesting, returning residues to land, reducing human disturbance on soils, choosing nitrogen-fixing tree species, fertilizer application, planting of mixed forests, and fire prevention, have already been implemented in some case studies. However, there is still a long way to go in China because of lacking management knowledge and technical training, especially in remote areas where is difficult to reach.

\subsubsection{Approaches of biomass and volume estimation}

Biomass and volume are the most important management targets for forest managers and forest owners, but a direct measurement is not possible that appropriate approach need to be applied. Generally, individual tree biomass or volume is estimated by allometric models that are developed using easily measured variables, such as diameter at breast height $(d b h, 1.3 \mathrm{~m})$ and total tree height, and scaled to stand-level volume (Aboal et al., 2005; Albert et al., 2014; Cai et al., 2013; Cutini et al., 2013). The allometric models are commonly built based on felled trees (Cutini et al., 2013). When scaling to stand-level biomass or volume, site- and species-specific models are always preferable because these models produce a more suitable fit for a specific species and site where they are developed (Cutini et al., 2013). Although the allometric models have been widely used, they cannot predict the volume of individual sections within a stem or the merchantable volume up to any merchantable height or diameter. Instead, taper functions have been well developed to solve such problems. Taper functions do not only describe stem shapes (Kozak, 1988), but also provide an estimation of: (1) diameter at any height of the stem; (2) total tree volume; (3) merchantable volume and merchantable height at any top diameter and (4) individual volumes for logs between any two heights (Barrio Anta et al., 2007; Kozak, 2004).

A large number of allometric models have been developed to meet various applications in forest types and site conditions. In some studies, allometric models employ $d b h$ as the only variable (Nunes et al., 2013; Paul et al., 2013) because $d b h$ could explain a majority of variations (Albert et al., 2014; Chen 
et al., 2013). In order to improve the precision, tree height is incorporated into the allometric models and the model selection is based on determination coefficients $\left(\mathrm{R}^{2}\right)$ and root-mean-square error (Albert et al., 2014). For example, $d b h$ could explain $91.2 \%$ and $90.6 \%$ of the variability in crown and stem biomass in Eucalyptus nitens, but $d b h$ and tree height could explain $93.8 \%$ and $92.4 \%$ of the variability (González-García et al., 2013). However, it has been recognized that the incorporation of tree height not only increases the accuracy of the allometric models, but also increases in the cost because the tree height should be measured as well. Therefore a balance between the two should be obtained (Wang, 2006).

Besides allometric models, applying biomass expansion factors (BEFs) is another important method to estimate tree- and stand-level biomass. The BEF is defined as the ratio of individual tree or stand biomass and volume (Fang et al., 1998; González-García et al., 2013). Stand-level BEFs of main forest types in China have been proposed by Fang et al. (2001) and Guo et al. (2010). With these BEFs, Zhang et al. (2012) predict that fast-growing Eucalyptus and Acacia plantations in Pearl River Delta sequestrated 1.33-3.92 Tg C over the period of 1989-2003. Similarly, Fang et al (2001) estimate national forest biomass carbon in China increasing from $4.38 \mathrm{Pg} \mathrm{C}$ in 1970 s to $4.75 \mathrm{Pg} \mathrm{C}$ in 1998 using BEF approach.

With the development of remote sensing technology, large-area biomass estimation using remote sensing has increasingly attracted scientific interests (Lu, 2006; Zolkos et al., 2013). It has many advantages in biomass estimation compared with traditional field measurements, such as lower labour intensity and lower cost. The remote sensed data can also provide repetitively of data collection, a summary view, a digital format that allows fast processing of large quantities of data, and the high correlations between spectral bands and vegetation parameters make it the primary source for large area biomass estimation, especially in areas that are difficult to access (Lu, 2006). For example,

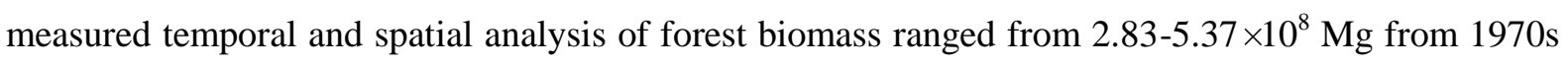
to 2000s in the Changbai Mountains, China (Mao et al., 2011). Similarly, measured biomass carbon in boreal and temperate forest in the northern hemisphere is as large of $61 \times 10^{9} \mathrm{Mg} \mathrm{C}$ in late $1990 \mathrm{~s}$ (Dong et al., 2003). However, remote sensing based-biomass estimation is a complex process affected by many factors, such as atmospheric conditions, mixed pixels, data saturation, insufficient training data, and selected algorithms. Therefore, accurate atmospheric calibration, geometric correction, selection of a suitable vegetation index and image texture, using high resolution images and increasing training data could improve remote sensing-based biomass estimation performance (Lu, 2006).

Comparing aboveground biomass, belowground biomass has been less intensively studied and is a major source of uncertainties in biomass estimation, and has become a research focus in recent decades (Mokany et al., 2006; Vogt et al., 1998; Wang et al., 2008). Excavation, sequential root 
coring and ingrowth cores are the common direct methods to measure root biomass (Vogt et al., 1998). For example, by coring soil, measured fine root biomass ranged from $1.8 \mathrm{Mg} \mathrm{ha}^{-1}$ to $4.3 \mathrm{Mg} \mathrm{ha}^{-1}$ in Scots pine forests differing in ages (Vanninen and Mäkelä, 1999). However, due to time consuming, labour intensive and resultant financial costs, using root/shoot ratio to estimate root biomass has become a core method (Mokany et al., 2006). The ratio varies significantly in different forest types, varying from 0.20 to 3.95 as proposed by IPCC (IPCC, 2003). Based on a review of root/shoot ratios, the mean ratio was 0.23 in China's forest ecosystems (Wang et al., 2014), which is comparable to the global average ratio of 0.26 and the tendency for values to fall between 0.2 and 0.3 (Cairns et al., 1997). 


\subsection{Background of projects}

This study is mainly supported by Lin4carbon project (033L049) funded by Federal Ministry of Education and Research (BMBF), Sino-German Cooperation on Innovative Technologies and Service Capacities of Multifunctional Forest Management (CAFYBB2012013) funded Chinese Academy of Forestry, and the "948 project" of State Forest Administration (2013-4-70) supported by International Centre for Bamboo and Rattan (ICBR). They are conducted in a highly-forested area-Shitai County, in the Southern part of Anhui Province.

China has the largest area of plantation forests globally, with an area of 62 million hectares plantations and 5.4 million hectare of bamboo forests (Jia et al., 2009). The large-scale establishment of plantations has led to a considerable increase of forest cover to 21.63\% in 2013 (State Forestry Adiministration, 2014). In the context of carbon forestry, the remarkable expansion of plantation area, improvement of productivity, increasing average standing stock, resistance and stability of existing forests are formulated in China (Wei and Blanco, 2014). By 2020, the Chinese government has promised to increase new plantations by 40 million ha compared to 2006 (Gao et al., 2014). However, the average of stand volume of Chinese plantations is $49 \mathrm{~m}^{3} \cdot \mathrm{ha}^{-1}$ (Jia et al., 2009). This value is lower than the world average $\left(130.7 \mathrm{~m}^{3} \mathrm{ha}^{-1}\right)$ (FAO, 2010), and far lower than that of $320 \mathrm{~m}^{3} \mathrm{ha}^{-1}$ in Germany (BMELV, 2009). Therefore, reforestation and afforestation initiatives in China can hardly be overrated in qualitative terms, whereas the quality of young and middle-aged forest stands is relatively low. On the other hand, there is much room to increase plantation productivity, stability and ecosystem services with adapted concepts that innovative and sustainable strategies to provide renewable raw materials are growingly required.

The main reasons for the relatively low stand volume of forest plantations in China are: (1) establishing plantations on degraded land principally to restore or maintain important ecosystem services, such as water and erosion protection; (2) a combination of short rotations with frequent site disturbances; (3) the repeated establishment of plantations by sprouts or new seedlings on the same sites; (4) the lack of silvicultural concepts for long-term forest management. As a result, these practices have resulted in a decline in production (Bi et al., 2007), increased susceptibility to insect and diseases (Ye et al., 2010) and decreased stand stability (Zhou et al., 2011).

Germany has rich experiences in forest management. Therefore, Lin4Carbon project is designed to transform the forest management knowledge to China. In Germany, multifunctional forest management strategies, which take the stand productivity and stability over the long-term, have been developed for decades. One potential and often discussed adaptation strategy is "close to nature forestry" as a management principle, which is implemented as the guiding silvicultural principle in the German Federal State of Lower Saxony (Partner State to Anhui Province; associated partner of this 
project) since 1990. Studies on stand treatments, intervention types and tree species mixtures are necessary to evaluate possibilities to transform pure plantations into stable and multifunctional mixed stands.

The improvement or establishment of long-term sustainable forest management strategies is also a necessary step in regards to the reduction of $\mathrm{CO}_{2}$ emissions in China. In this context, a carbon market mechanism on the national level for trading with carbon certificates has been established (Lo and Howes, 2014). This process is highly dependent on the availability of generally accepted methods for forest biomass estimation. For the generation of eligible certificates, reliable estimates of carbon sequestration based on a statistically sound inventory and monitoring concept is as important as the establishment of a suitable trading system. Methodological approaches to the integration of remote sensing information and terrestrial inventory techniques are of high relevance in this context.

The overall objectives of the Lin4Carbon project are to study the possibilities and methodological basis of new technologies and innovative approaches in the context of land use improvement, especially in the management of forests in China. Implementation of multifunctional forest management can improve the ecosystems services and contribute to carbon sequestration. These projects also serve as an example of the improvement of young and middle-aged plantation management for the widely planted Chinese fir plantations in southern China.

Development of sustainable silvicultural management concepts for increasing stand production and ecosystem services will be the priority. In the framework of Lin4Carbon project, an integrated carbon inventory and monitoring system, which considers mixed forests and plantations, will be developed with a focus on the combination of terrestrial inventory and remote sensing.

In the Lin4Carbon project, forest inventories were conducted to deliver actual estimates of volume, biomass and carbon stock and provide information about the feasibility and costs of sampling and plot designs. Three different inventory scales have been established: (1) a land use and forest inventory (LUI/FI) that produces information over the whole extent of the sampling frame based on a systematic grid $3 \times 3 \mathrm{~km}$; (2) a forest management inventory (FMI) for those stands with forest management information with a 500×500 m systematic grid, and (3) a stand inventory of selected stands (SI) with a $100 \times 100 \mathrm{~m}$ systematic grid. During the inventories, many additional variables on forest structures and site conditions were collected to allow an exploratory data analysis and the investigation of possible correlations between management, carbon dynamics and other environmental services. These inventories allow a further adaptation and optimization of the sampling- and plot design based on statistical and practical considerations. 


\subsection{Research questions}

This thesis deals with some specific research questions with final aims of providing methodological base for optimizing stand management for Chinese fir plantations and developing a method to efficiently estimate regional biomass in Shitai County, China. To achieve these goals, the following research questions have been formulated:

\section{(1) Is it possible to estimate AGB increment without repeated measurements? (Chapter III)}

AGB increment is a major part of net primary production (NPP) and is a key element required to understand ecosystem processes (Foster et al., 2014). The dynamics of AGB increment has become a fundamental requirement for evaluating both the capability and potential of forest ecosystems to sequester carbon (Gower et al., 1997). The AGB increment can be always calculated based on the differences in AGB between two points in time based on repeated measurements on inventory plots or permanent plots. However, repeated measurements require long-term planning, labour and cost resources.

As an alternative, tree ring analysis based on complete discs or increment cores offers a retrospective approach to study forest biomass dynamics (Liu et al., 2012; Foster et al., 2014; Woolley et al., 2015). By coring each individual tree in the inventory plots, it can be expanded to estimate stand-level biomass dynamics associated with allometric biomass models (Mund et al., 2002; Liu et al., 2012). However, coring all trees in the inventory plots may be difficult, laborious and harmful to tree growth. Therefore, there is a strong motivation to simplify the work that chapter III aims to deal with:

a. Can growth models using generalized algebraic difference approach be developed to predict the diameter of each individual tree based on the tree ring analysis?

b. Associated with allometric biomass models, can stand-level AGB increment be estimated?

c. As a case study in the Cunninghamia laceolata plantation and Castanopsis sclerophylla forests, is AGB increment of C. lanceolata higher than C. sclerophylla because C. lanceolata is a fast growing species?

(2) How well can the compatible taper function proposed by Fang et al. (2000) perform in Chinese fir plantations? Can stand-level merchantable volume be modelled? (Chapter IV)

Volume is one of the most important management targets for forest managers and forest owners. To estimate the total tree volume, allometic models using diameter at breast height $(1.3 \mathrm{~m}, d b h)$ and total tree height have been widely used (Bi and Hamilton, 1998; Turski et al., 2008; Cutini et al., 2013). Subsequently, individual tree volume can be scaled to stand-level volume using expansion factors. However, those allometric models could not predict merchantable volume at any merchantable height or diameter (Menéndez-Miguélez et al., 2014). Instead, compatible taper functions have been well developed to not only describe the stem shapes (Kozak, 1988), but also provide the estimation of: (1) 
diameter at any height of the stem; (2) total tree volume; (3) merchantable volume and merchantable height at any top diameter and (4) individual volumes for logs between any two heights (Kozak, 2004; Barrio Anta et al., 2007).

Compatible taper functions have been used for decades in many tree species as reviewed by DiéguezAranda et al. (2006). Through comparing different taper functions for different tree species, the compatible taper function proposed by Fang et al. (2000) is regarded as one of the most accurate and flexible functions that has been used for different tree species (Diéguez-Aranda et al., 2006; Barrio Anta et al., 2007; Menéndez-Miguélez et al., 2014). As a result, chapter IV addresses the following questions:

a. How well does the compatible taper function proposed by Fang et al. (2000) perform in diameter and individual tree volume prediction for Chinese fir plantations?

b. Can stand-level merchantable volume be modelled for different top diameter limits?

\section{(3) How can the stand management in the Chinese fir plantations be optimized? (Chapter V)}

Chinese fir represents one of the most important plantation species in China. Stand management is recognized as an important practice to increase production of existing plantations (Liu et al., 2013a; Gao et al., 2014). Traditionally, management in Chinese fir plantation is associated with monoculture, short rotation, clear-cut and high removal of volume or biomass. The plantation sites are commonly abandoned after one or two rotation periods and allow natural restore to the sites by naturally regeneration to mixed forests (Wei et al., 2012). Repeated establishing by sprouts or new seedlings on the same sites with a short rotation of 25 years is commonly observed since the 1950s (Wu, 1984; Wei et al., 2012). As a result, some serious ecological problems are produced, such as a decline in production and soil (Bi et al., 2007), biodiversity loss ( $\mathrm{Li}, 2004$ ), increased susceptibility to insects and diseases (Ye et al., 2010), decreased stand stability (Zhou et al., 2011). Thus, how the management in Chinese fir plantations can be optimized is becoming an emergent topic China in terms of production and sustainability. Chapter V aims to answer:

a. How can the Chinese fir plantations be managed using stand density management diagram?

b. How can the stand management in Chinese fir plantations be optimized for different purposes?

(4) How do SOC and N stocks change after the land-use change from secondary forests to Chinese fir and Moso bamboo plantations? (Chapter VI)

Land use change is the second main reason for $\mathrm{C}$ emissions after fossil fuel combustion, and it is recognized as an important driving force for SOC and N dynamics (Watson et al., 2000b; Fu et al., 2010; Lozano-García and Parras-Alcántara, 2013). China, the largest developing country, has experienced wide land use changes from natural forests to plantations, forests to croplands or intensive land uses due to fast growing of human population and changing lifestyles in the past several decades (Fu et al., 2010). Conversion from secondary forests to Chinese fir and Moso 
bamboo (Phyllostachys heterocycla [Carr] Mitford $c v$. Pubescens) plantations represents one of the most important land use changes in subtropical China. However, the effects of these land use changes on the SOC and N stocks were not observed to our knowledge. Chapter VI is to address:

a. Does the land use change from secondary forests to Chinese fir and Moso bamboo plantations decrease the soil SOC and $\mathrm{N}$ content in top soil of $0-30 \mathrm{~cm}$ ? And soil in $30-50 \mathrm{~cm}$ ?

b. Does the land use change decrease SOC and N stocks?

c. After the land use change, are there any differences in SOC and $\mathrm{N}$ stocks between Chinese fir and Moso bamboo plantations?

(5) Which method is efficient for regional biomass estimation based on the forest inventory data? (Chapter VII)

With the wide spread of continuous forest inventory, regional of biomass estimation is becoming realistic using the inventory data because many reliable variables are recorded, such as tree species, DBH and tree height. Since tree volume is the most reliable estimates in forest inventory data, thus it is possible to build a relationship between tree volume and biomass. Many approaches based on this relationship have been proposed for regional biomass estimates. Constant BEF, continuous BEF and IPCC based BEF approaches have been widely used (Guo et al., 2010; Li et al., 2012). However, different approaches produce great variability in biomass estimates. For example, using continuous $\mathrm{BEF}$, constant BEF and MB approaches, biomass estimates of China's forests ranged from 5.9, 6.2 and 7.7 Pg C in 1999-2003 (Guo et al., 2010), while the actually true value remains unknown. Thus it is proposed that applying constant BEFs values across all age classes and site conditions within a forest type underestimates the forest biomass of younger and less productive stands and overestimates the forest biomass of older and more productive stands (Fang et al., 1998; Goodale et al., 2002). Therefore, using appropriate approaches is becoming increasingly important for accurate estimation for regional forest biomass (Fang et al., 1998), which is itself essential when reporting data to the UNFCCC (IPCC, 2006) and an essential step to enter into the carbon market. Chapter VII will answer:

a. Are national continuous and constant BEFs available in our study area?

b. If the continuous BEF equations are lacking, is there an alternative approach for regional biomass for our study area?

c. Among continuous BEF, constant BEF, NCBEF, MB and IPCC (2003) approaches, which method is optimized for regional biomass estimation based on the forest inventory data? 


\subsection{Objectives of this thesis}

The overall objectives of this thesis were to contribute to provide the methodological basis for optimizing stand management of Chinese fir plantations and to develop an approach to efficiently estimate regional biomass in Shitai County, China. A number of specific technical scientific questions were dealt within five chapters that were created as manuscripts.

(1) To estimate AGB and its dynamics for Cunninghamia laceolata and Castanopsis sclerophylla forests using GADA model and allometric biomass models (chapter III);

(2) To develop a compatible stem taper function based on Fang et al. (2000) and a stand-level merchantable volume for Chinese fir plantations for tree- and stand-level merchantable volume predictions (chapter IV);

(3) To develop stand density management diagrams for stand volume, stem and aboveground biomass for Chinese fir plantations to optimize stand management (chapter V);

(4) To examine the effects of conversion of secondary forests to Chinese fir plantations on soil organic carbon and nitrogen stock (chapter VI);

(5) To develop BEFs equations for different forest type to efficiently estimate regional biomass and optimize methods selection of biomass estimates (chapter VII).

Fig. 2 illustrates the contributions of the five different topics to the process of forest inventory and of stand management in a systematic manner. In this process of forest management, stand biomass and volume are the most important target variables for foresters and managers. During the management process, information and tools to estimate and predict the stand biomass and volume are required. Therefore, this thesis can contribute to stand management from different levels: aboveground level, belowground level and regional level. For aboveground level, the first two chapters (chapter III and IV) contributed to estimate and predict the aboveground biomass and volume using growth models, while chapter $\mathrm{V}$ proposed a SDMD tool to optimize stand management for different management purposes. For belowground level, chapter VI aimed to provide data evidence of the changes of soil organic carbon after land use change from secondary forests to Chinese fir plantations. For regional scale, total biomass (including aboveground and belowground biomass) was estimated by comparing five different approaches in chapter VII. These results are expected to provide data evidence (1) to enter carbon market for local government, and (2) policy decision of improving stand management in terms of stand production and sustainability. 


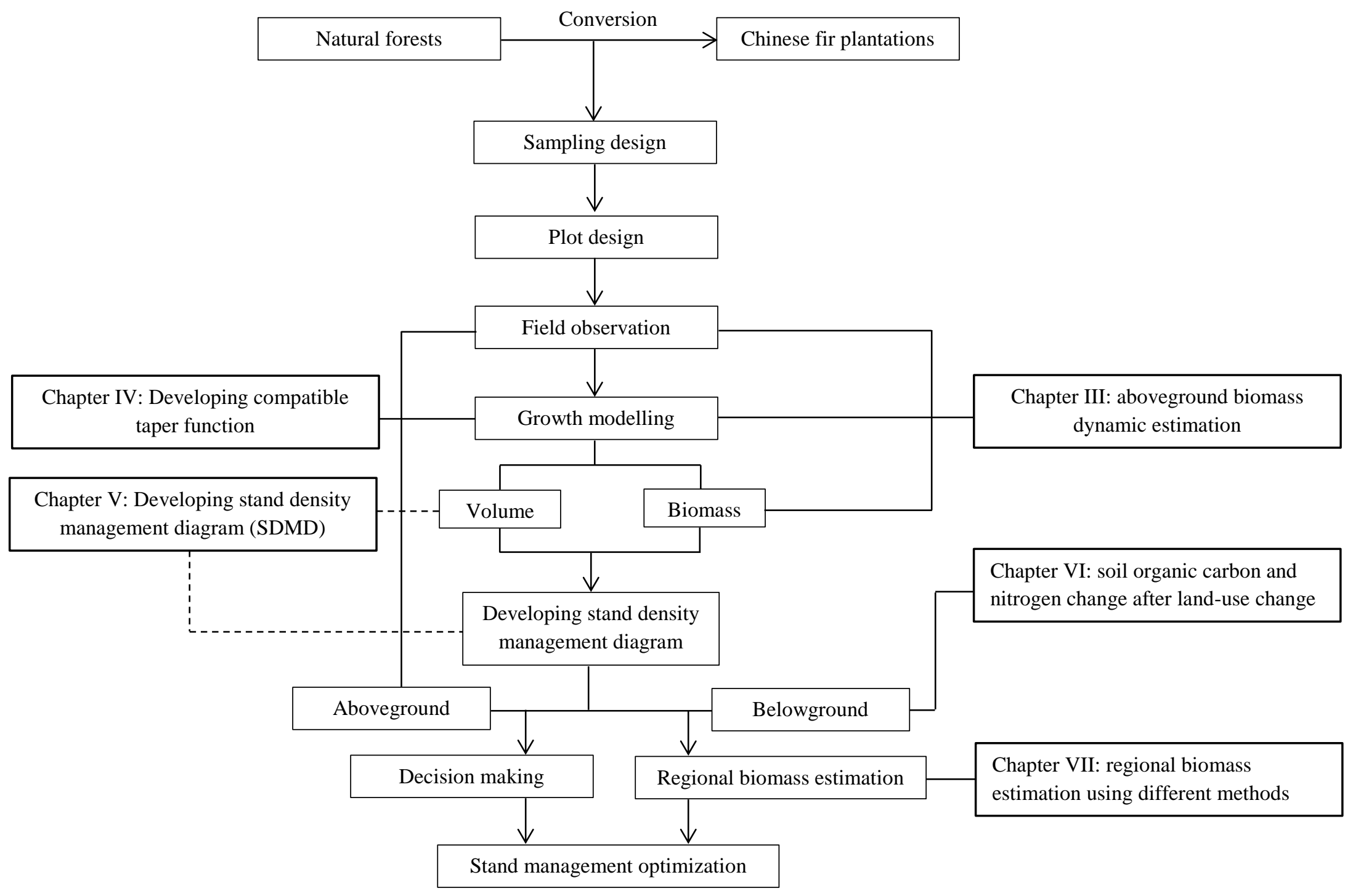

Fig. 2 Contributions of the five different topics to the process of forest inventory and stand management 


\subsection{References}

Aboal JR, Arevalo JR, Fernandez A. 2005. Allometric relationships of different tree species and stand above ground biomass in the Gomera laurel forest (Canary Islands). Flora 200: 264-274.

Albert K, Annighöfer P, Schumacher J, et al. 2014. Biomass equations for seven different tree species growing in coppice-with-standards forests in Central Germany. Scandinavian Journal of Forest Research 29: 1-12.

Allen MR, Barros VR, Broome J, et al. 2014. IPCC Fifth Assessment Synthesis Report-Climate Change 2014 Synthesis Report.

Angelsen A. 2007. Forest cover change in space and time: combining the von Thunen and forest transition theories. World Bank policy research working paper.

Baneh SA, Fallah A, Kalbi S, et al. 2013. Estimation above ground biomass by using a diameter and density parameters (case study: district one of Darabkola forest). International Journal of Biosciences 3: 262-266.

Barrio Anta M, Diéguez-Aranda U, Castedo-Dorado F, et al. 2007. Merchantable volume system for pedunculate oak in northwestern Spain. Annals of Forest Science 64: 511-520.

Bi H, Hamilton F. 1998. Stem volume equations for native tree species in southern New South Wales and Victoria. Australian Forestry 61: 275-286.

Bi J, Blanco JA, Seely B, et al. 2007. Yield decline in Chinese-fir plantations: a simulation investigation with implications for model complexity. Canadian Journal of Forest Research 37: 1615-1630.

BMELV. 2009. Waldbericht der Bundesregierung 2009. Berlin: Bundesministerium für Ernährung Landwirtschaft und Verbraucherschutz.

Bonan GB. 2008. Forests and climate change: forcings, feedbacks, and theclimate benefits of forests. Science 320: 1444-1449.

Cai S, Kang X, Zhang L. 2013. Allometric models for aboveground biomass of ten tree species in northeast China. Annals of Forest Research 56: 105-122.

Cairns MA, Brown S, Helmer EH, et al. 1997. Root biomass allocation in the world's upland forests. Oecologia 111: 1-11.

Canadell JG, Raupach MR. 2008. Managing forests for climate change mitigation. Science 320: 14561457.

Carle J, Vuorinen P, Del Lungo A. 2002. Status and trends in global forest plantation development. Forest Products Journal 52: 12-23.

Chen GS, Yang ZJ, Gao R, et al. 2013. Carbon storage in a chronosequence of Chinese fir plantations in southern China. Forest Ecology and Management 300: 68-76. 
Ciais P, Sabine C, Bala G, et al. 2014. Carbon and other biogeochemical cycles. Climate Change 2013: The Physical Science Basis. Contribution of Working Group I to the Fifth Assessment Report of the Intergovernmental Panel on Climate Change: Cambridge University Press, p465-570.

Cook RL, Binkley D, Mendes JCT, et al. 2014. Soil carbon stocks and forest biomass following conversion of pasture to broadleaf and conifer plantations in southeastern Brazil. Forest Ecology and Management 324: 37-45.

Cutini A, Chianucci F, Manetti MC. 2013. Allometric relationships for volume and biomass for stone pine (Pinus pinea L.) in Italian coastal stands. Iforest-Biogeosciences and Forestry 6: 331-337.

Delbosc A, de Perthuis C. 2009. Carbon markets: the simple facts. Climate Care Series of United Nations Global Compact/Mission Climat of Caisse des Dépôts/University of Paris-Dauphine. Global Compact Office.

Diéguez-Aranda U, Castedo-Dorado F, Álvarez-González JG, et al. 2006. Compatible taper function for Scots pine plantations in northwestern Spain. Canadian Journal of Forest Research 36: 11901205.

Dixon RK, Solomon A, Brown S, et al. 1994. Carbon pools and flux of global forest ecosystems. Science 263: 185.

Dong J, Kaufmann RK, Myneni RB, et al. 2003. Remote sensing estimates of boreal and temperate forest woody biomass: carbon pools, sources, and sinks. Remote Sensing of Environment 84: 393410.

EC European Commission. 2007. Communication from the Commission to the European Parliament, the Council, the European Economic and Social Committee and the Committee of the Regions. $\operatorname{COM}(2007) 780$.

Fang J, Chen A, Zhao S. 2002. Calculating Forest Biomass Changes in China-response. Science 296: 1359.

Fang J, Guo Z, Hu H, et al. 2014. Forest biomass carbon sinks in East Asia, with special reference to the relative contributions of forest expansion and forest growth. Global Change Biology 20: 20192030.

Fang JY, Chen AP, Peng CH, et al. 2001. Changes in forest biomass carbon storage in China between 1949 and 1998. Science 292: 2320-2322.

Fang JY, Wang GG, Liu GH, et al. 1998. Forest biomass of China: An estimate based on the biomassvolume relationship. Ecological Applications 8: 1084-1091.

Fang ZX, Borders BE, Bailey RL. 2000. Compatible volume-taper models for loblolly and slash pine based on a system with segmented-stem form factors. Forest Science 46: 1-12.

FAO. 2010. Global Forest Resources Assessment 2010 Main Report. Rome: FAO.

FAO. 2011. Forestry-Managing forest for future. Rome: Viale delle Terme di Caracalla.

Foster JR, D'Amato AW, Bradford JB. 2014. Looking for age-related growth decline in natural forests: unexpected biomass patterns from tree rings and simulated mortality. Oecologia 175: 363-374. 
Fu X, Shao M, Wei X, et al. 2010. Soil organic carbon and total nitrogen as affected by vegetation types in Northern Loess Plateau of China. Geoderma 155: 31-35.

Gao GL, Ding GD, Zhao YY, et al. 2014. Short Communication. Forestry solutions for mitigating climate change in China. Forest Systems 23: 183-186.

González-García M, Hevia A, Majada J, et al. 2013. Above-ground biomass estimation at tree and stand level for short rotation plantations of Eucalyptus nitens (Deane \& Maiden) Maiden in Northwest Spain. Biomass and Bioenergy 54: 147-157.

Goodale CL, Apps MJ, Birdsey RA, et al. 2002. Forest carbon sinks in the Northern Hemisphere. Ecological Applications 12: 891-899.

Gower ST, Vogel JG, Norman JM, et al. 1997. Carbon distribution and aboveground net primary production in aspen, jack pine, and black spruce stands in Saskatchewan and Manitoba, Canada. Journal of Geophysical Research: Atmospheres 102: 29029-29041.

Guan F, Tang X, Fan S, et al. 2015. Changes in soil carbon and nitrogen stocks followed the conversion from secondary forest to Chinese fir and Moso bamboo plantations. CATENA 133: $455-460$.

Guo ZD, Fang JY, Pan YD, et al. 2010. Inventory-based estimates of forest biomass carbon stocks in China: A comparison of three methods. Forest Ecology and Management 259: 1225-1231.

Houghton RA. 2007. Balancing the Global Carbon Budget. Annual Review of Earth and Planetary Sciences 35: 313-347.

Huang L, Liu J, Shao Q, et al. 2012. Carbon sequestration by forestation across China: Past, present, and future. Renewable and Sustainable Energy Reviews 16: 1291-1299.

IPCC. 2003. Good practice guidance for land use, land-use change and forestry: Institute for Global Environmental Strategies.

IPCC. 2006. IPCC guidelines for national greenhouse gas inventories. IGES, Japan. http://www.ipccnggip.iges.or.jp/public/2006gl/index.html.

IPCC. 2007. Climate Change 2007: Synthesis Report. Contribution of Working Groups I, II and III to the Fourth Assessment Report of the Intergovernmental Panel on Climate Change. 36-41p.

Jia Z, Zhang J, Wang X, et al. 2009. Report for Chinese forest resource-The $7^{\text {th }}$ national forest inventory. Beijing (in Chinese): China Forestry Publishing House.

Kanninen M. 2007. Do trees grow on money?: the implications of deforestation research for policies to promote REDD. Bogor, Indonesia: CIFOR.

Kelty MJ. 2006. The role of species mixtures in plantation forestry. Forest Ecology and Management 233: $195-204$.

Kossoy A, Guigon P. 2012. State and trends of the carbon market 2012. Washington DC, USA: Westland Printers.

Kozak A. 1988. A variable-exponent taper equation. Canadian Journal of Forest Research 18: 13631368. 
Kozak A. 2004. My last words on taper equations. The Forestry Chronicle 80: 507-515.

Le Quéré C, Peters GP, Andres RJ, et al. 2014. Global carbon budget 2013. Earth System Science Data 6: 235-263.

Li HK, Zhao PX, Lei YC, et al. 2012. Comparison on estimation of wood biomass using forest inventory data. Scientia Silvae Sinicae 48: 44-52 (in Chinese with English abstract).

Li W. 2004. Degradation and restoration of forest ecosystems in China. Forest Ecology and Management 201: 33-41.

Liu J, Li S, Ouyang Z, et al. 2008. Ecological and socioeconomic effects of China's policies for ecosystem services. Proceedings of the National Academy of Sciences of the United States of America 105: 9477-9482.

Liu P, Yin R. 2012. Sequestering Carbon in China's Forest Ecosystems: Potential and Challenges. Forests 3: 417-430.

Liu S, Innes J, Wei X. 2013a. Shaping forest management to climate change: An overview. Forest Ecology and Management 300: 1-3.

Liu YC, Zhang YD, Liu SR. 2012. Aboveground carbon stock evaluation with different restoration approaches using tree ring chronosequences in Southwest China. Forest Ecology and Management 263: 39-46.

Liu Z, Guan D, Crawford-Brown D, et al. 2013b. Energy policy: A low-carbon road map for China. Nature 500: 143-145.

Lo AY. 2013. Carbon trading in a socialist market economy: Can China make a difference? Ecological Economics 87: 72-74.

Lo AY, Howes M. 2014. Power and Carbon Sovereignty in a Non-Traditional Capitalist State: Discourses of Carbon Trading in China.

Lozano-García B, Parras-Alcántara L. 2013. Land use and management effects on carbon and nitrogen in Mediterranean Cambisols. Agriculture, Ecosystems \& Environment 179: 208-214.

Lu D. 2006. The potential and challenge of remote sensing - based biomass estimation. International Journal of Remote Sensing 27: 1297-1328.

Malhi Y, Meir P, Brown S. 2002. Forests, carbon and global climate. Philosophical Transactions of the Royal Society of London. Series A: Mathematical, Physical and Engineering Sciences 360: 1567-1591.

Mao X, Fan W-Y, Li M-Z, et al. 2011. Temporal and spatial analysis of forest biomass in Changbai Mountains, Heilongjiang, China. Chinese Journal of Plant Ecology 35: 371-379 (in Chinese with English abtract).

Menéndez-Miguélez M, Canga E, Álvarez-Álvarez P, et al. 2014. Stem taper function for sweet chestnut (Castanea sativa Mill.) coppice stands in northwest Spain. Annals of Forest Science 71: 761-770. 
Mokany K, Raison R, Prokushkin AS. 2006. Critical analysis of root: shoot ratios in terrestrial biomes. Global Change Biology 12: 84-96.

Mund M, Kummetz E, Hein M, et al. 2002. Growth and carbon stocks of a spruce forest chronosequence in central Europe. Forest Ecology and Management 171: 275-296.

Niu X, Duiker SW. 2006. Carbon sequestration potential by afforestation of marginal agricultural land in the Midwestern U.S. Forest Ecology and Management 223: 415-427.

Nunes L, Lopes D, Rego FC, et al. 2013. Aboveground biomass and net primary production of pine, oak and mixed pine-oak forests on the Vila Real district, Portugal. Forest Ecology and Management 305: 38-47.

Pan Y, Birdsey RA, Fang J, et al. 2011. A large and persistent carbon sink in the world's forests. Science 333: 988-993.

Pan YD, Luo TX, Birdsey R, et al. 2004. New estimates of carbon storage and sequestration in China's forests: Effects of age-class and method on inventory-based carbon estimation. Climatic Change 67: 211-236.

Paul KI, Polglase PJ, Nyakuengama JG, et al. 2002. Change in soil carbon following afforestation. Forest Ecology and Management 168: 241-257.

Paul KI, Roxburgh SH, England JR, et al. 2013. Development and testing of allometric equations for estimating above-ground biomass of mixed-species environmental plantings. Forest Ecology and Management 310: 483-494.

Planning Division of National Reform and Development Commission. 2006. National Economic and Social Development Eleventh Five-Year Plan for the Nation and Regions. Beijing: China Market Press. 1698p.

Scott V, Haszeldine RS, Tett SFB, et al. 2015. Fossil fuels in a trillion tonne world. Nature Clim. Change 5: 419-423.

Seo YO, Lee YJ, Lumbres RIC, et al. 2013. Influence of stand age class on biomass expansion factor and allometric equations for Pinus rigida plantations in South Korea. Scandinavian Journal of Forest Research 28: 566-573.

State Forestry Adiministration. 2014. Report for Chinese forest resource-The $8^{\text {th }}$ national forest inventory. Beijing China: China Forestry Publishing House. 94 (in Chinese).

Stocker T, Qin D, Plattner G-K, et al. 2014. Climate change 2013: The physical science basis: Cambridge University Press Cambridge, UK, and New York.

Turner J, Lambert M. 2000. Change in organic carbon in forest plantation soils in eastern Australia. Forest Ecology and Management 133: 231-247.

Turski M, Beker C, Kazmierczak K, et al. 2008. Allometric equations for estimating the mass and volume of fresh assimilational apparatus of standing scots pine (Pinus sylvestris L.) trees. Forest Ecology and Management 255: 2678-2687. 
Van der Werf G, Morton DC, DeFries RS, et al. 2009. $\mathrm{CO}_{2}$ emissions from forest loss. Nature Geoscience 2: 737-738.

Vanninen P, Mäkelä A. 1999. Fine root biomass of Scots pine stands differing in age and soil fertility in southern Finland. Tree Physiology 19: 823-830.

Vogt KA, Vogt DJ, Bloomfield J. 1998. Analysis of some direct and indirect methods for estimating root biomass and production of forests at an ecosystem level. Plant and Soil 200: 71-89.

Wang C. 2006. Biomass allometric equations for 10 co-occurring tree species in Chinese temperate forests. Forest Ecology and Management 222: 9-16.

Wang L, Li L, Chen X, et al. 2014. Biomass allocation patterns across China's terrestrial biomes. PLoS One 9: e93566.

Wang W. 2012. Overview of climate change policies and prospects for carbon markets in China. Les Cahiers de la chaire economie du climate, http://www.chaireeconomieduclimat.org/wpcontent/uploads/2012/07/12-07-10-Cahier-ID-n18-Wang.pdf.

Wang X, Fang J, Zhu B. 2008. Forest biomass and root-shoot allocation in northeast China. Forest Ecology and Management 255: 4007-4020.

Watson RT, Noble IR, Bolin B, et al. 2000a. Land use, land-use change and forestry: a special report of the Intergovernmental Panel on Climate Change: Cambridge University Press.

Watson RT, Noble IR, Bolin B, et al. 2000b. Land use, land-use change, and forestry: a special report of the intergovernmental panel on climate change: Cambridge University Press.

Wei X, Blanco JA. 2014. Significant increase in ecosystem C can be achieved with sustainable forest management in subtropical plantation forests. PLoS One 9: e89688.

Wei X, Blanco JA, Jiang H, et al. 2012. Effects of nitrogen deposition on carbon sequestration in Chinese fir forest ecosystems. Science of the Total Environment 416: 351-361.

Winjum JK, Schroeder PE. 1997. Forest plantations of the world: their extent, ecological attributes, and carbon storage. Agricultural and Forest Meteorology 84: 153-167.

Woodbury PB, Heath LS, Smith JE. 2007. Effects of land use change on soil carbon cycling in the conterminous United States from 1900 to 2050. Global Biogeochemical Cycles 21: GB3006.

Woolley TJ, Harmon ME, O’Connell KB. 2015. Inter-annual variability and spatial coherence of net primary productivity across a western Oregon Cascades landscape. Forest Ecology and Management 335: 60-70.

Wu ZL. 1984. Chinese-fir Beijing: China Forestry Publishing House (in Chinese). 583p.

Xu X, Li K. 2010. Biomass carbon sequestration by planted forests in China. Chinese Geographical Science 20: 289-297.

Ye S-m, Wen Y-g, Yang M, et al. 2010. Correlation analysis on biodiversity and soil physical \& chemical properties of Eucalyptus spp. plantations under successive rotation. Journal of Soil and Water Conservation 24: 246-250,256. 
Zhang H, Guan DS, Song MW. 2012. Biomass and carbon storage of Eucalyptus and Acacia plantations in the Pearl River Delta, South China. Forest Ecology and Management 277: 90-97.

Zhou B, Gu L, Ding Y, et al. 2011. The great 2008 Chinese ice storm: its socioeconomic-ecological impact and sustainability lessons learned. Bulletin of the American Meteorological Society 92: 4760.

Zinn YL, Resck DVS, da Silva JE. 2002. Soil organic carbon as affected by afforestation with Eucalyptus and Pinus in the Cerrado region of Brazil. Forest Ecology and Management 166: 285294.

Zolkos SG, Goetz SJ, Dubayah R. 2013. A meta-analysis of terrestrial aboveground biomass estimation using lidar remote sensing. Remote sensing of environment 128: 289-298. 


\section{Chapter III}

\section{Estimation of aboveground biomass dynamics using generalized algebraic difference approach in Cunninghamia laceolata and Castanopsis sclerophylla forests in subtropical China}

Xiaolu Tang*, Lutz Fehrmann, Fengying Guan, David I Forrester, Rubén Guisasola-Rodríguez, César Pérez-Cruzado, Torsten Vor, Yuanchang Lu, Juan Gabriel Álvarez-González, Christoph Kleinn

Status: submitted to Forestry

Contribution by Xiaolu Tang: $80 \%$

- Design the manuscript

- Collect data

- Analyze data and modelling

- Write and revise manuscript

*Corresponding author: xtang@gwdg.de 
Chapter III: Estimation of aboveground biomass dynamics 


\title{
Estimation of aboveground biomass dynamics by a generalized algebraic difference approach in Cunninghamia laceolata and Castanopsis sclerophylla forests in subtropical China
}

Xiaolu Tang ${ }^{1, *}$, Lutz Fehrmann ${ }^{1}$, Fengying Guan², David I Forrester ${ }^{3}$, Rubén Guisasola-Rodríguez ${ }^{3}$, César Pérez-Cruzado ${ }^{1}$, Torsten Vor ${ }^{4}$, Yuanchang Lu ${ }^{5}$, Juan Gabriel Álvarez-González ${ }^{6}$, Christoph Kleinn ${ }^{1}$

${ }^{1}$ Chair of Forest Inventory and Remote Sensing, Georg-August-Universität Göttingen, Büsgenweg 5, 37077 Göttingen, Germany

${ }^{2}$ Key laboratory of Bamboo and Rattan, International Centre for Bamboo and Rattan, No.8, Futong Dongdajie, Wangjing, Chaoyang District, Beijing 100102, P.R. China

${ }^{3}$ Chair of Silviculture, Faculty of Environment and Natural Resources, Freiburg University, Tennenbacherstr. 4, 79108 Freiburg, Germany

${ }^{4}$ Department of Silviculture and Forest Ecology of the Temperate Zones, Georg-August-Universität Göttingen, Büsgenweg 1, 37077 Göttingen, Germany

${ }^{5}$ Department of Forest Management and Statistics, Institute of Forest Resource Information techniques, Chinese Academy of Forestry, Dongxiaofu 2, Xiangshan Road, 100091 Haidian, Beijing, PR of China

${ }^{6}$ Departamento de Ingeniería Agroforestal, Universidad de Santiago de Compostela. Escuela Politécnica Superior, Campus Universitario, 27002 Lugo, Spain

\begin{abstract}
Cunninghamia lanceolata and Castanopsis sclerophylla are common tree species with a broad geographical distribution throughout subtropical China. The aboveground biomass (AGB, including stem, branch and leaf biomass) and AGB increment in these forests has received little attention even if it is a critical component of monitoring systems aiming at quantifying carbon sequestration by improved forest management. This study aimed to quantify AGB dynamics and AGB increment in $C$. lanceolata and $C$. sclerophylla forests by combining a generalized algebraic difference approach (GADA) for diameter prediction with allometric biomass models. A total of 12 plots for C. lanceolata plantation and 11 plots for C. sclerophylla forest were selected randomly from a $100 \mathrm{~m} \times 100 \mathrm{~m}$ systematic grid in respective forest stands. GADA models performed well in diameter prediction and successfully addressed AGB dynamics for both stands. The mean AGB of the C. lanceolata stand

\footnotetext{
* Corresponding author: xtang@gwdg.de
} 
ranged from $69.4 \pm 7.7 \mathrm{Mg} \mathrm{ha}^{-1}$ in 2010 to $102.5 \pm 11.4 \mathrm{Mg} \mathrm{ha}^{-1}$ in 2013 , compared to $136.9 \pm 7.0 \mathrm{Mg}$ $\mathrm{ha}^{-1}$ in 2010 to $154.8 \pm 8.0 \mathrm{Mg} \mathrm{ha}^{-1}$ in 2013 for C. sclerophylla. There was no significant difference in inter-annual AGB increment for both stands, averaging from $10.6 \pm 1.2 \mathrm{Mg} \mathrm{ha}^{-1}$ year $^{-1}$ to $11.5 \pm 1.3$ $\mathrm{Mg} \mathrm{ha}^{-1}$ year $^{-1}$ for $C$. lanceolata, and $5.8 \pm 0.2 \mathrm{Mg} \mathrm{ha}^{-1} \mathrm{year}^{-1}$ to $6.3 \pm 0.33 \mathrm{Mg} \mathrm{ha}^{-1}$ year $^{-1}$ for $C$. sclerophylla. On average, stems contributed $76 \%$ to total AGB and AGB increment, highlighting the importance of stem for forest ecosystem biomass stocks and production. Significantly higher production efficiency (stem production/leaf area index) and AGB increment was observed in $C$. lancolata compared to $C$. sclerophylla and the average of main forest types in China. The results show the high potential of fast-growing species such as $C$. lanceolata in carbon sequestration due to their high biomass accumulation rate. Dynamic GADA models could overcome the limitations posed by within-stand competition and limited biometric data, and can be applied to study AGB dynamics and AGB increment, and contribute to improving our understanding of net primary production and carbon seqeuestration dynamics in forest ecosystems.

Keywords: aboveground biomass, tree ring analysis, basal area, leaf area index, production efficiency

\subsection{Introduction}

Forest biomass plays an important role in climate change caused by the rising atmospheric $\mathrm{CO}_{2}$ concentrations because trees store around 50\% of carbon in their dry biomass (IPCC, 2007; Bonan, 2008). The estimation of biomass growth dynamics and stocks has become a fundamental requirement for evaluating both the capability and potential of forest ecosystems to sequester carbon (Gower et al., 1997). It represents the net carbon input from the atmosphere to vegetation and it has received great attention during the past few decades (Fang et al., 2003). Due to the practical difficulties in belowground biomass estimation, there has been a focus on aboveground biomass (AGB), and its dynamics have become an important topic in estimating the effects of afforestation, deforestation and the role of improved forest management on the global carbon balance (Zianis and Mencuccini, 2005; Nunes et al., 2013).

AGB increment represents a major part of net primary production (NPP) and is a key element required to understand ecosystem processes (Foster et al., 2014). It can be measured as the difference in AGB between two points in time (Foster et al., 2014). Repeated measurements of inventory plots are commonly used to estimate AGB increment or to calibrate forest growth models that can be used to predict AGB increment (Landsberg and Gower, 1997; Nunes et al., 2013). However, repeated measurements require long-term planning and resources. As an alternative to long-term growth data from inventory plots and growth models, tree ring analysis by coring trees or felling a sample of trees in the inventory plots offers a retrospective approach to study forest biomass dynamics as long as past mortality, thinning or other disturbances are known (Liu et al., 2012; Foster et al., 2014; Woolley et al., 2015). Tree rings could provide reliable data on historical growth rates (Brienen and Zuidema, 
2006). Tree age and the long-term growth rate reflected in the tree ring width could directly be applied to estimate the development of biomass using allometric models. Tree ring analysis has successfully been used to estimate stand level AGB dynamics and carbon sequestration trends (Mund et al., 2002; Liu et al., 2012). For instance, the annual increment of woody biomass estimated by coring individual trees ranged from 1.3 to $4.5 \mathrm{Mg} \mathrm{ha}^{-1} \mathrm{year}^{-1}$ (equaling $0.65-2.25 \mathrm{t} \mathrm{C}^{-1} \mathrm{year}^{-1}$ ) in the main European forest types (Babst et al., 2014). Age-related growth models based on tree ring data from a sample of trees is an alternative to improve the efficiency in AGB increment estimation. Although there are many studies on age-related diameter growth models using generalized algebraic difference approach (GADA) in different forest types (Wu et al., 2001; Tomé et al., 2006; GeaIzquierdo et al., 2008; Palahí et al., 2008), these GADA models are mainly used to predict the diameter growth and few studies focus on AGB and AGB increment (Ogawa, 2012). Studies on AGB increment using GADA models and tree-individual allometric biomass equations in Cunninghamia lanceolata and Castanopsis sclerophylla forests have not yet been observed to our knowledge.

C. lanceolata is one of the most popular plantation tree species in subtropical China with a relatively high timber quality and fast growth (Zhao et al., 2009). In the past few decades, the area of $C$. lanceolata has increased rapidly. According to the $7^{\text {th }}$ national forest inventory of China, it covers an area of 8.54 million ha, which corresponds to $21 \%$ of the total plantation area in China (Jia et al., 2009). C. lanceolata plantations are usually managed in a clear cutting system with a relatively short rotation period of 25 years. Information about AGB increment with a sufficient accuracy over the rotation period is increasingly important to evaluate the carbon sequestration potential in the $C$. lanceolata forests, as well as the carbon market (Zhang et al., 2004).

C. sclerophylla is another important evergreen, shade-tolerant tree species. It is widely distributed across subtropical areas of China from 200 to $1000 \mathrm{~m}$ above sea level, and it is one of the dominant species in evergreen broad-leaved forests (An et al., 2001). C. sclerophylla plays a significant role in water and soil conservation ( $\mathrm{Li}$ et al., 2011). It is also an economically important species as its seeds are used to produce Tofu, which is a staple in the diet of many local residents.

The objectives of this study were to (1): develop GADA models to predict diameter at breast height $(d b h, 1.3 \mathrm{~m})$ at any age for each individual tree in C. lanceolata and C. scleraphylla forests, and (2) estimate AGB dynamics and inter-annual variability in AGB increment using GADA models and allometric biomass models. The results will provide a better understanding of AGB dynamics of the two important species in subtropical China and the application of GADA model in AGB dynamic estimation.

\subsection{Materials and methods}

\subsubsection{Study area}


The study was conducted in the Jitan township of Shitai county $\left(29^{\circ} 59^{\prime}-30^{\circ} 24^{\prime}\right.$ N, $117^{\circ} 12^{\prime}-117^{\circ} 59^{\prime}$ E), in the Southern part of Anhui province, China. It is a mountainous area with a forest cover of about $80 \%$, an elevation range of $50 \mathrm{~m}$ to $1000 \mathrm{~m}$. The region has a mid-subtropical, humid, mountainous climate with distinct seasonality (Geng and Wang, 2011). The recorded annual average temperature is $16{ }^{\circ} \mathrm{C}$ with a variation from $-13.2{ }^{\circ} \mathrm{C}$ to $40.9{ }^{\circ} \mathrm{C}(\mathrm{Lu}, 2010)$. The mean precipitation is $1668 \mathrm{~mm}$ with high inter-annual variability, with about $70 \%$ of annual precipitation occurring from April to September (Geng and Wang, 2011). The average annual sunshine duration is 1704 hours and evaporative capacity is $1256 \mathrm{~mm}(\mathrm{Lu}, 2010)$.
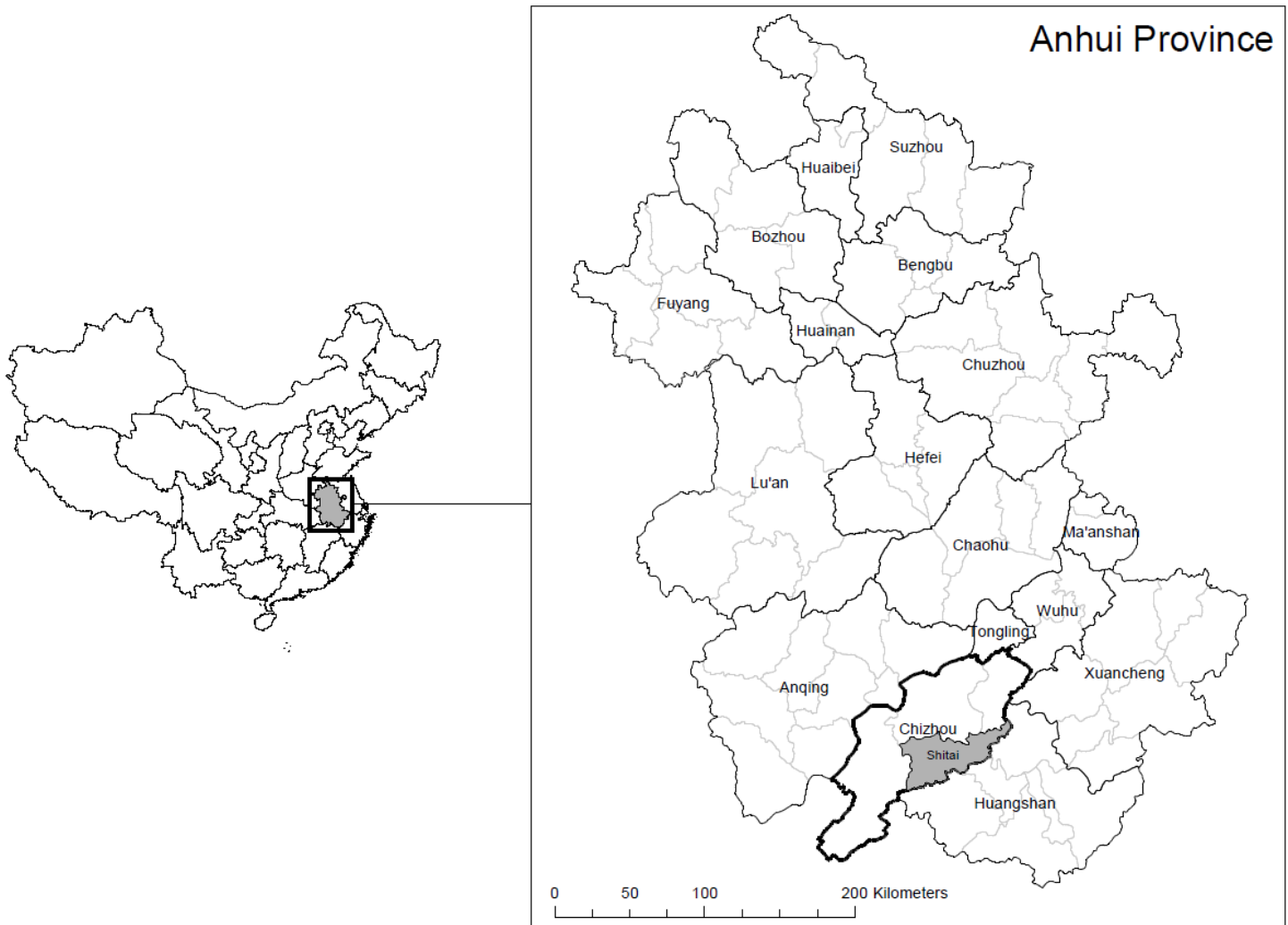

Fig. 1 Location of Shitai County in the southern part of Anhui Province, South-East China.

\subsubsection{Plot design}

One pure Cunninghamia lanceolata stand and one pure Castanopsis sclerophylla stand were selected in our study. In each stand, a systematic base grid of $100 \mathrm{~m} \times 100 \mathrm{~m}$ was established, from which six locations were chosen randomly to establish permanent plots while an additional temporary plot was installed $25 \mathrm{~m}$ north of each permanent plot. Altogether, 12 plots were installed for C. lanceolata and 11 plots for C. sclerophylla. A forest inventory was conducted from March to May 2013. The plot design was a nested circular plot with different horizontal radius for different tree diameter classes. An inner smaller plot of $6 \mathrm{~m}$ radius was used to include trees with a diameter at breast height $(d b h, 1.3$ m) between 10 and $20 \mathrm{~cm}$, while trees with $d b h$ larger than $20 \mathrm{~cm}$ where measured up to a horizontal distance of $10 \mathrm{~m}$. 


\subsubsection{Sample tree selection for biomass, leaf area estimation and stem analysis}

All trees in sample plots were numbered and assigned to three dominance classes - dominant, codominant and suppressed trees. A sample tree representing the average $d b h$ and height in each dominance class was destructively sampled for biomass, leaf area determination and stem analysis in the temporary plots. In total, 18 C. lanceolata and 15 C. sclerophylla trees were felled. Before felling, the $d b h$ was measured to the nearest $0.1 \mathrm{~cm}$ with a diameter tape and the North direction was marked. After the trees were felled, the total tree height and the heights and diameters of all branches were measured.

The stem was cut into different sections at heights of $0.3 \mathrm{~m}, 1.3 \mathrm{~m}, 3 \mathrm{~m}$ and $2-\mathrm{m}$ intervals up to the treetop thereafter. Cross-sectional stem discs (about $5 \mathrm{~cm}$ thick) were cut at each of these heights, as well as one disc at ground level. If there was a branch at the height of the disc, a replacement disc was collected $5 \mathrm{~cm}$ above or below. Live branches (and additional dead branches, if applicable) from each tree were sampled to develop allometric equations for predicting branch and leaf biomass from branch diameter, and hence total tree branch biomass and leaf biomass. For C. sclerophylla, all leaves per sample branch were collected and scanned on an A3 scanner (Epson Expression 10000XL) for leaf area determination. Due to the very high number of small leafs of $C$. lanceolata, a subsample was selected for leaf area determination, as described in detail in Guisasola-Rodríguez (2014).

\subsubsection{Tree ring analysis}

All branches, leaves and discs were dried at $100{ }^{\circ} \mathrm{C}$ to constant weight in the lab. The mean fresh to oven-dried weight ratios of the discs of a given tree were used to convert the whole stem fresh weight into dry biomass. The biomass of each individual tree was the sum of all biomass compartments. After drying, the discs were processed according to standard techniques applied in dendrochronology: the discs were sanded with progressively finer grades of sandpaper (up to 240 grits) to improve the visibility of year rings (Stokes, 1996). The polished discs were rewetted and scanned with 1200 dpi resolution (Epson Expression 10000XL) and visually cross-dated by Lignovision and TSAPwin (LINTAB, RINNTECH, Inc. Freiburg) software. All the discs were cross-dated by matching wide and narrow rings to assign the same calendar year in four directions (East, West, North, and South). Annual diameter increments of each tree were calculated by averaging the cardinal radii and multiplying this value by two. The bark thickness was also measured. The tree diameter calculated from cross-dating was not equal to that measured in the field using a diameter tape due to the irregular growth rate of boles in different directions. Therefore diameters needed to be calibrated according to the procedures proposed by Liu et al. (2012). Finally, age and annual diameter with bark were estimated according to following the processes (Bush and Brand, 2008):

$B R=\frac{B_{T}}{D_{O B}}=\frac{B_{T}}{\left(B_{T}+D_{I B}\right)}$ 
$D_{O B}=\frac{D_{I B}}{(1-B R)}$

Where $B R$ is the bark ratio, $B_{T}$ is the measured bark thickness from tree ring analysis, and $D_{I B}$ and $D_{O B}$ are the diameter inside and outside bark. The $D_{O B}$ was calculated by dividing $D_{I B}$ by $1-B R$. This conversion was required because we developed the allometric models using $D_{O B}$ as the input variable.

\subsubsection{Transition function for $d b h$}

The GADA model was developed based on the model of Bertalanffy (1957), whose integral form can be expressed as:

$Y=a_{1}\left(1-\exp \left(-a_{2} t\right)\right)^{a_{3}}$

Where $Y$ is the target variable; $a_{1}$ is an asymptote or limiting value; $a_{2}$ is a rate parameter, and $a_{3}$ is an initial pattern parameter. To derive a model with both polymorphism and asymptote from Eq. (1), more than one parameter has to be site-specific (Cieszewski and Bailey, 2000; Álvarez-González et al., 2010). Therefore, the asymptote parameter $a_{1}$ and the shape parameter $a_{3}$ are assumed to be dependent on the site, and a site parameter $(X)$ was included into the model (in Eq. 4). To achieve such derivation, the base equation is re-parameterized into a form that is more suitable for the manipulation of these two parameters (using $\exp \left(a_{1}^{\prime}\right)$ instead of $a_{1}$, and taking the natural logarithm of the function) as follows (Álvarez-González et al., 2010):

$Y=\exp \left(a_{1}^{\prime}\right)\left(1-\exp \left(-a_{2} t\right)\right)^{a_{3}}$

$\ln Y=a_{1}^{\prime}+a_{3} \ln \left(1-\exp \left(-a_{2} t\right)\right)$

These site-dependent parameters are conditioned to be consistently proportional to each other's inverse over the site productivity by the following definitions:

$a_{1}^{\prime}=X$ and $a_{3}=b_{2}+\frac{b_{3}}{X}$, while $a_{2}=b_{1}$

Eq. (3) can be expressed as:

$\ln Y=X+b_{2}+\frac{b_{3}}{X} \ln \left(1-\exp \left(-b_{1} t\right)\right)$

The solution of $X$ involves solving roots of a quadratic equation and a selection of the suitable root to substitute into the dynamic equation. The selection process may depend on the equation parameters that in return depend on the data and the domain of the applicable ages (Cieszewski and Bailey, 2000). With the initial condition value $\mathrm{Y}_{0}$ and $t_{0}$, the solution of Eq. (6) is expressed as follows:

$X_{0}=\frac{1}{2}\left(\left(\ln Y_{0}-b_{2} L_{0}\right) \pm \sqrt{\left(\ln Y_{0}-b_{2} L_{0}\right)^{2}-4 b_{3} L_{0}}\right)$

Where $L_{0}=\ln \left(1-\exp \left(-b_{1} t_{0}\right)\right)$ 
In this study, $t_{0}$ is the tree age in the year 2013 derived from the stem analysis, while $Y_{0}$ is the $d b h$ in the year 2013.

According to the tree growth characteristics, the root more likely to be real and positive is selected. Thus after substituting it into Eq. (6), the generalized algebraic difference approach (GADA) formulation applied in our study is as follows:

$Y=Y_{0}\left(\frac{1-\exp \left(-b_{1} t\right)}{1-\exp \left(-b_{1} t_{0}\right)}\right)^{b_{2}+\frac{b_{3}}{X_{0}}}$

Although this model has commonly been applied to calculate site index (Álvarez-González et al., 2010; Sharma et al., 2011) and basal area (Barrio-Anta et al., 2006; Álvarez-González et al., 2010), some authors have successfully applied this model for diameter prediction (Gea-Izquierdo et al., 2008). GADA formulations using different base models such as the log-logistic or the Hossfeld models (Cieszewski, 2002), and for simplicity, the GADA model (Eq. 8) was used because comparing the performance of different GADA models is not the focus of this study and Eq. 8 could achieve our objectives.

\subsubsection{Model fitting}

Data from the stem analyses are expected to have autocorrelated residuals because the database contains multiple observations for each individual tree. This, however, violates the assumption of independent error terms. Therefore, we have corrected the autocorrelation using a modified continuous autoregressive error structure $(\operatorname{mCAR}(x))$. To account for first-order autocorrelation, a mCAR(1) model form can be used which expands the error terms according to Eq. 8 (ÁlvarezGonzález et al., 2010):

$e_{i j}=d_{1} \rho_{1}^{h_{i j}-h_{i j-1}} e_{i j-1}+\varepsilon_{i j}$

where $e_{i j}$ is the $j$ th ordinary residual on the $i$ th individual (i.e., the difference between the observed and the estimated diameters of the tree $i$ at height measurement $j$ ), $d_{1}=1$ for $j>1$ and it is zero for $j=1$, $\rho_{1}$ is the first-order continuous autoregressive parameter to be estimated, and $h_{i j} h_{i j-1}$ is the distance separating the $j$ th from the $j$ th- 1 observations within each tree, $h_{i j}>h_{i j-1} . \varepsilon_{i j}$ is an independent normal random variable with a mean value of zero. To test for the presence of autocorrelation we used the Durbin-Watson test. The modified mCAR(1) error structure was programmed in the MODEL procedure of SAS/ETS ${ }^{\circledR}$ in our study (SAS Institute Inc, 2007), which allows for dynamic updating of the residuals.

Heteroscedasticity could lead to non-minimum variance parameter estimates and unreliable predictor intervals. To avoid this problem, the error variance was assumed to be a power function of the predicted diameter (Huang et al., 2000). The weighting factor $\left(\mathrm{W}_{i}\right)$ was: 
$W_{i}=1 /$ Pred. $\mathrm{d} t_{i}^{k}$

Where $k$ is a constant. Generally, $k=-2,-3 / 2,-1,-1 / 2,1 / 2,1,3 / 2,2$. Since the predicted diameters are initially unknown, weighting is an iterative process. In our study, $k=3 / 2$ showed the best results based on plots of studentized residuals against the predicted diameter.

\subsubsection{Estimation of AGB and AGB increment}

Allometric models are widely used to estimate tree biomass, either for the biomass of different biomass compartments or the tree as a whole (Xiang et al., 2011; González-García et al., 2013). The allometric models for biomass compartment and leaf area of each individual tree are given in appendix Table 1. The stem, branch, leaf biomass and leaf area of all trees was calculated in the inventory plots, and scaled to the reference area of one hectare by considering an expansion factor (32 for $10 \mathrm{~m}$ radius plots and 88 for $6 \mathrm{~m}$ radius plots) for the year 2013. Total AGB of 2013 was calculated as the sum of stem, branch and leaf biomass. Following the same procedure, biomass compartment, total AGB and leaf area of 2012, 2011 and 2010 was calculated using these allometric models and the diameter of each individual tree estimated using Eq. 8. Consequently, AGB increment was calculated as the sum of the biomass increment of stems, branches and leaves of each tree per inventory plot. AGB increment of understory plants was ignored because it is assumed to contribute less than 5\% to total AGB increment for forests and is difficult to measure in the field (Yang et al., 2010). Since a thinning from below took place in 2010 without precise data acquisition (extracted volume, tree heights and $d b h$ ), we only estimated AGB and AGB increment for the period from 2010 to 2013. We also assumed that there was no mortality after the thinning in 2010 , which is consistent with the absence of any dead trees in both stands.

\subsubsection{Data analysis}

Leaf area index (LAI) was calculated as the half of the total leaf area per unit ground surface (Chen and Black, 1992; Jonckheere et al., 2004). Linear regression was applied to examine the relationships between stand basal area and AGB or AGB increment. One-way ANOVA was used to test for significant differences in stand characteristics, biomass compartment, production efficiency (stem biomass production/leaf area index), AGB and AGB increment. Statistical analyses were performed using R (R Core Team, 2014).

\subsection{Results}

\subsubsection{Stand characteristics}

The stand characteristics of the two studied stands are shown in Table 1. Although there was a big difference in age between $C$. lanceolata and $C$. sclerophylla stands, no significant difference was found for mean stand height, basal area and stand volume (all $p>0.05$ ). However, LAI of the $C$. lanceolata stand was $5.4 \pm 0.6 \mathrm{~m}^{-2} \mathrm{~m}^{-2}$, which was significantly lower than that of the $C$. sclerophylla 
stand $(6.9 \pm 0.4 ; p=0.049)$. Mean stand biomass followed the reverse trend such that in the $C$. lanceolata stand was two times of that in the C. sclerophylla stand.

Table 1 Structural characteristics of C. lanceolata and C. sclerophylla forests in 2013

\begin{tabular}{|c|c|c|c|c|c|c|c|c|c|}
\hline Stands & $\begin{array}{l}\text { Sample } \\
\text { trees }\end{array}$ & $\begin{array}{l}\text { Age } \\
\text { (years) }\end{array}$ & $\begin{array}{l}d b h \\
(\mathrm{~cm})\end{array}$ & $\begin{array}{l}\text { Mean H } \\
(\mathrm{m})\end{array}$ & $\begin{array}{l}\mathrm{N} \\
\text { (stem/ha) }\end{array}$ & $\begin{array}{l}\text { BA } \\
\left(\mathrm{m}^{2} \cdot \mathrm{ha}^{-1}\right)\end{array}$ & $\begin{array}{l}\text { LAI } \\
\left(\mathrm{m}^{-2} \cdot \mathrm{m}^{-2}\right)\end{array}$ & $\begin{array}{l}\text { Volume } \\
\left(\mathrm{m}^{3} \cdot \mathrm{ha}^{-1}\right)\end{array}$ & $\begin{array}{l}\text { Mean biomass } \\
\left(\mathrm{Mg} \mathrm{ha}^{-1} \text { year }^{-1}\right)\end{array}$ \\
\hline C. lanceolata & 18 & 17 & $16.2 \pm 0.3 \mathrm{a}$ & $11.6 \pm 0.1 \mathrm{a}$ & $1553 \pm 200 b$ & $33.4 \pm 3.8 \mathrm{a}$ & $5.4 \pm 0.6 \mathrm{a}$ & $200.1 \pm 22.7 \mathrm{a}$ & $6.0 \pm 0.7 b$ \\
\hline C. sclerophylla & 15 & 52 & $19.0 \pm 0.4 \mathrm{a}$ & $11.4 \pm 0.2 \mathrm{a}$ & $990 \pm 77 a$ & $30.1 \pm 1.5 \mathrm{a}$ & $6.9 \pm 0.4 b$ & $202.3 \pm 10.2 b$ & $3.0 \pm 0.0 \mathrm{a}$ \\
\hline
\end{tabular}

$d b h$ is diameter at breast height $(1.3 \mathrm{~m})$; $\mathrm{H}$ is the mean height of stand trees; $\mathrm{N}$ is the number of trees per hectare; BA is the stand basal area; LAI is the leaf area index. Different letter in the same column indicate significant difference $(\mathrm{p}<0.05)$ analysed by the ANOVA.

\subsubsection{Performance of GADA model}

At first, the models were fitted without considering any autocorrelation. There was a strong linear trend in the residuals as a function of lag1 residuals for both stands (Fig. 2 a, b, c, d). This indicated a strong autocorrelation among the multi-observations in each tree. Therefore, a first-order continuous time autoregressive error structure was derived. By considering this autocorrelation, although the trend in residuals as a function of lag1 residuals did not disappear completely, the trend was clearly reduced (Fig. 2 e, f, g, h). The only purpose of eliminating autocorrelation was to improve the statistical interpretation of the model, and it has no practical use unless repeated measurements were conducted in the sample plot (Diéguez-Aranda et al., 2006; Álvarez-González et al., 2010). All parameter estimates were significant at the 0.001 level (Table 2). The GADA model performed very well in predicting the diameter for both stands. We observed an adjusted $\mathrm{R}^{2}$ of 0.94 for the $C$. lanceolata stand and an $\mathrm{R}^{2}$ of 0.96 for the C. sclerophylla stand, with a RMSE of 1.810 and $1.308 \mathrm{~cm}$ for both stands, respectively.

Table 2 Estimated regression coefficients and goodness-to-fit statistics of Eq. (8)

\begin{tabular}{llrrrrr}
\hline Stand & Coefficient & \multicolumn{1}{l}{ Estimate } & \multicolumn{1}{l}{ SE } & \multicolumn{1}{l}{$p$} & RMSE $(\mathrm{cm})^{\text {Adjusted R }^{2}}$ \\
\hline \multirow{4}{*}{ C. lanceolata } & $b_{1}$ & 0.0575 & 0.00340 & $<0.001$ & & \\
& $b_{2}$ & 0.858 & 0.0300 & $<0.001$ & & \\
& $b_{3}$ & 0.441 & 0.0888 & $<0.001$ & 1.810 & 0.935 \\
& $\rho_{1}$ & 1.581 & 0.0626 & $<0.001$ & & \\
C. sclerophylla & $b_{1}$ & 0.0153 & 0.000212 & $<0.001$ & & \\
& $b_{2}$ & 0.261 & 0.0244 & $<0.001$ & & \\
& $b_{3}$ & 2.805 & 0.0879 & $<0.001$ & & \\
& $\rho_{1}$ & 1.670 & 0.00661 & $<0.001$ & & \\
\hline
\end{tabular}

$\rho_{l}$ is the autoregressive parameter; SE means standard error; RMSE is the root mean square error and $\mathrm{R}^{2}$ is the coefficient of determination. 


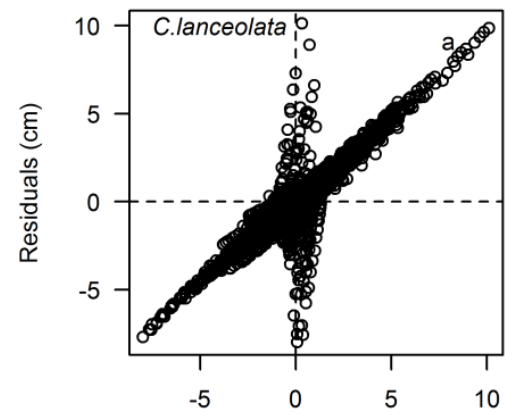

Lag1 residuals $(\mathrm{cm})$

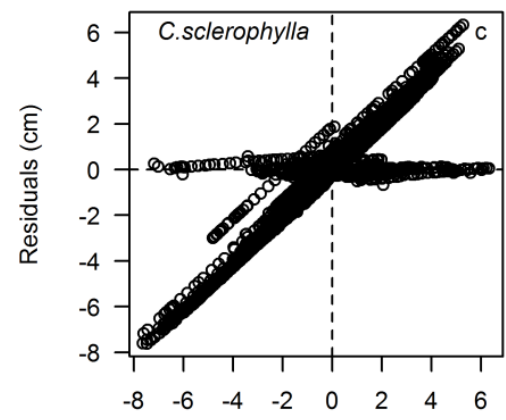

Lag1 residuals $(\mathrm{cm})$

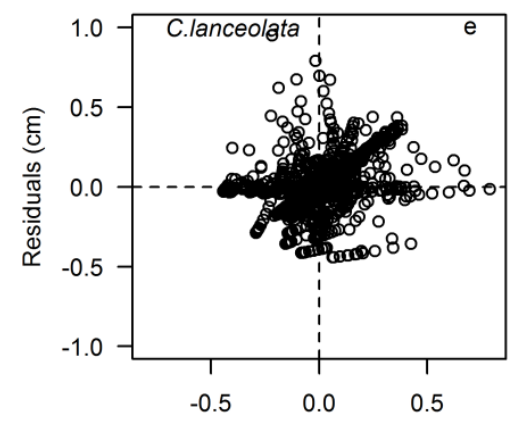

Lag1 residuals $(\mathrm{cm})$

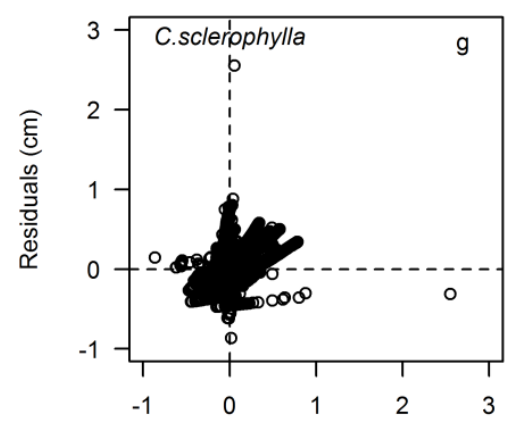

Lag1 residuals (cm)
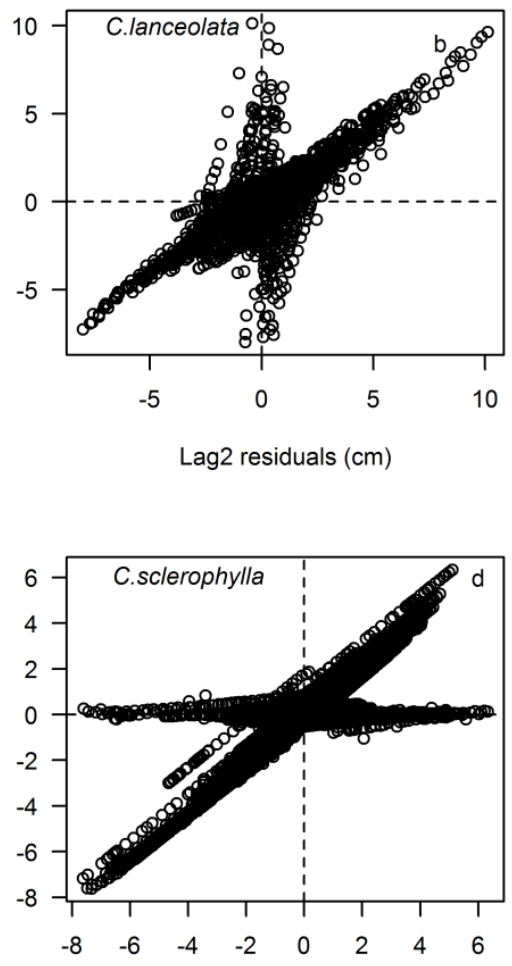

Lag2 residuals $(\mathrm{cm})$

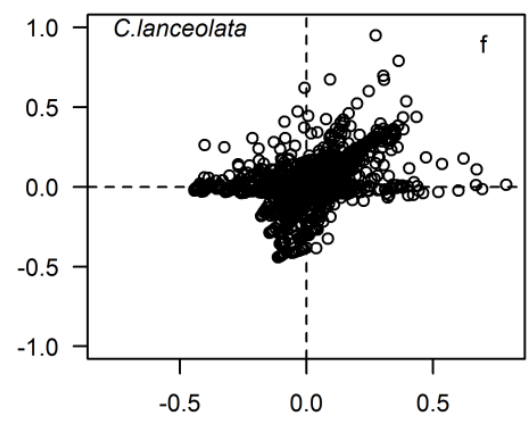

Lag2 residuals $(\mathrm{cm})$

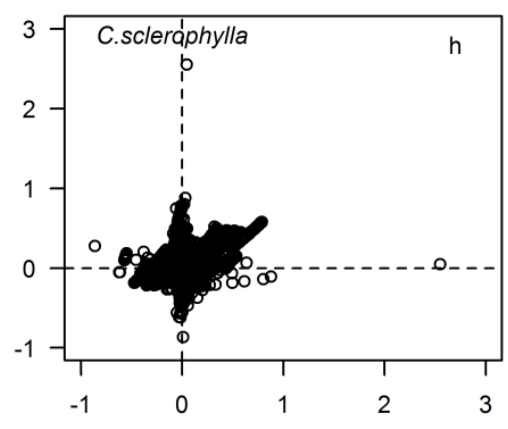

Lag2 residuals $(\mathrm{cm})$

Fig. 2 Residuals against lag1 and lag2 residuals for the GADA model before (a, b, c, d) and after (e, f, $\mathrm{g}, \mathrm{h}$ ) using a first-order continuous time autoregressive error structure for $C$. lanceolata and $C$. sclerophylla forests. 


\subsubsection{AGB and AGB increment}

Table 3 Stem, branch, leaf and total AGB $\left(\mathrm{Mg} \mathrm{ha}^{-1}\right)$ of $C$. lanceolata and C. sclerophylla forests from 2010 to 2013, Mean \pm standard error (percentage of biomass compartment to total AGB).

\begin{tabular}{lllll}
\hline Stands & Stem & Branch & Leaf & Total AGB \\
\hline Biomass 2013 & & & & \\
\hline C. lanceolata & $78.0 \pm 8.7(76.1 \%) \mathrm{a}$ & $14.1 \pm 1.5(13.8 \%) \mathrm{a}$ & $10.4 \pm 1.2(10.1 \%) \mathrm{b}$ & $102.5 \pm 11.4 \mathrm{a}$ \\
C. sclerophylla & $118.5 \pm 6.4(76.5 \%) \mathrm{b}$ & $31.83 \pm 1.5(20.6 \%) \mathrm{b}$ & $4.5 \pm 0.2(2.9 \%) \mathrm{a}$ & $154.8 \pm 8.0 \mathrm{~b}$ \\
Biomass 2012 & & & \\
C. lanceolata & $68.6 \pm 7.7(75.4 \%) \mathrm{a}$ & $12.8 \pm 1.4(14.0 \%) \mathrm{a}$ & $9.6 \pm 1.1(10.5 \%) \mathrm{b}$ & $91.0 \pm 10.1 \mathrm{a}$ \\
C. sclerophylla & $113.3 \pm 6.0(76.3 \%) \mathrm{b}$ & $30.8 \pm 1.5(20.7 \%) \mathrm{b}$ & $4.4 \pm 0.2(2.9 \%) \mathrm{a}$ & $148.5 \pm 7.6 \mathrm{~b}$ \\
Biomass 2011 & & & & \\
C. lanceolata & $60.1 \pm 6.7(75.1 \%) \mathrm{a}$ & $11.3 \pm 1.2(14.1 \%) \mathrm{a}$ & $8.7 \pm 1.0(10.7 \%) \mathrm{b}$ & $80.0 \pm 8.9 \mathrm{a}$ \\
C. sclerophylla & $108.5 \pm 5.8(76.1 \%) \mathrm{b}$ & $29.8 \pm 1.5(20.9 \%) \mathrm{b}$ & $4.3 \pm 0.2(3.0 \%) \mathrm{a}$ & $142.6 \pm 7.3 \mathrm{~b}$ \\
Biomass 2010 & & & & \\
C. lanceolata & $51.9 \pm 5.8(74.8 \%) \mathrm{a}$ & $10.8 \pm 1.0(14.1 \%) \mathrm{a}$ & $7.7 \pm 0.9(11.0 \%) \mathrm{b}$ & $69.4 \pm 7.7 \mathrm{a}$ \\
C. sclerophylla & $103.9 \pm 5.5(75.9 \%) \mathrm{b}$ & $28.7 \pm 1.5(21.0 \%) \mathrm{b}$ & $4.2 \pm 0.2(3.1 \%) \mathrm{a}$ & $136.9 \pm 7.0 \mathrm{~b}$ \\
\hline
\end{tabular}

Different letters in the same column indicate significant differences $(p<0.05)$.

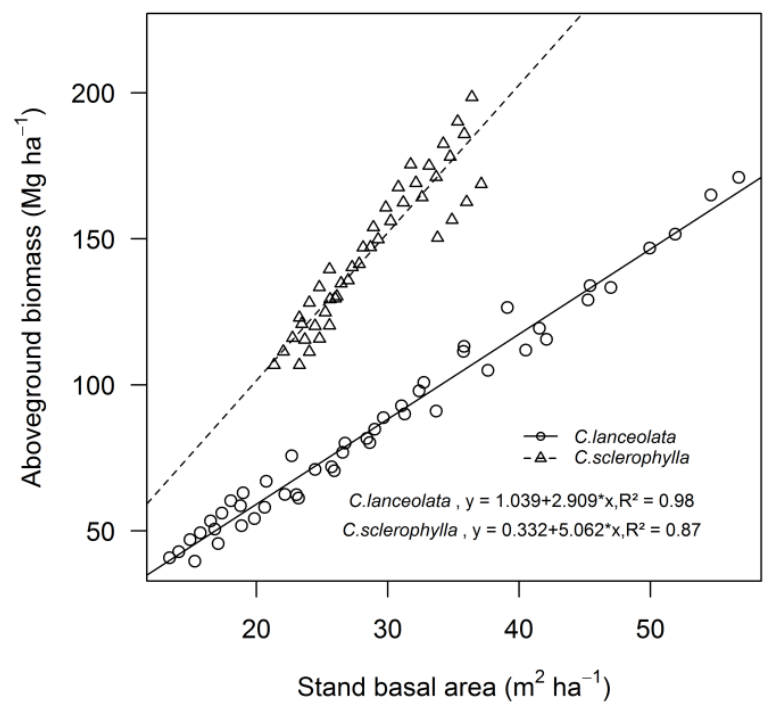

Fig. 3 Relationships between aboveground biomass and stand basal area for C. lanceolata and $C$. sclerophylla forests. The linear regression was applied to fit the model, a significance level of $<0.001$ was achieved for both stands.

Total AGB of $C$. lanceolata was $69.4 \pm 7.7 \mathrm{Mg} \mathrm{ha}^{-1}$ in 2010 , with an increase to $80.0 \pm 8.9,91.0 \pm$ 10.1 and 102.5 $\pm 11.4 \mathrm{Mg} \mathrm{ha}^{-1}$ in 2011, 2012 and 2013, respectively (Table 2). These values were significantly lower than those of the C. sclerophylla stand $(p<0.05)$. Stem biomass contributed 75\%$76 \%$ to total AGB for both stands. Branch and leaf biomass contributed 14\% and 11\% to total AGB for the C. lanceolate stand, compared to $21 \%$ and $3 \%$ for the C. sclerophylla stand. Although the stem and branch biomass of the $C$. lanceolata stand was significantly lower than that of the $C$. sclerophylla 
stand, leaf biomass of $C$. lanceolata was about twice as high as that of $C$. sclerophylla. Total AGB were strongly correlated to stand basal area for both stands (Fig. 3).
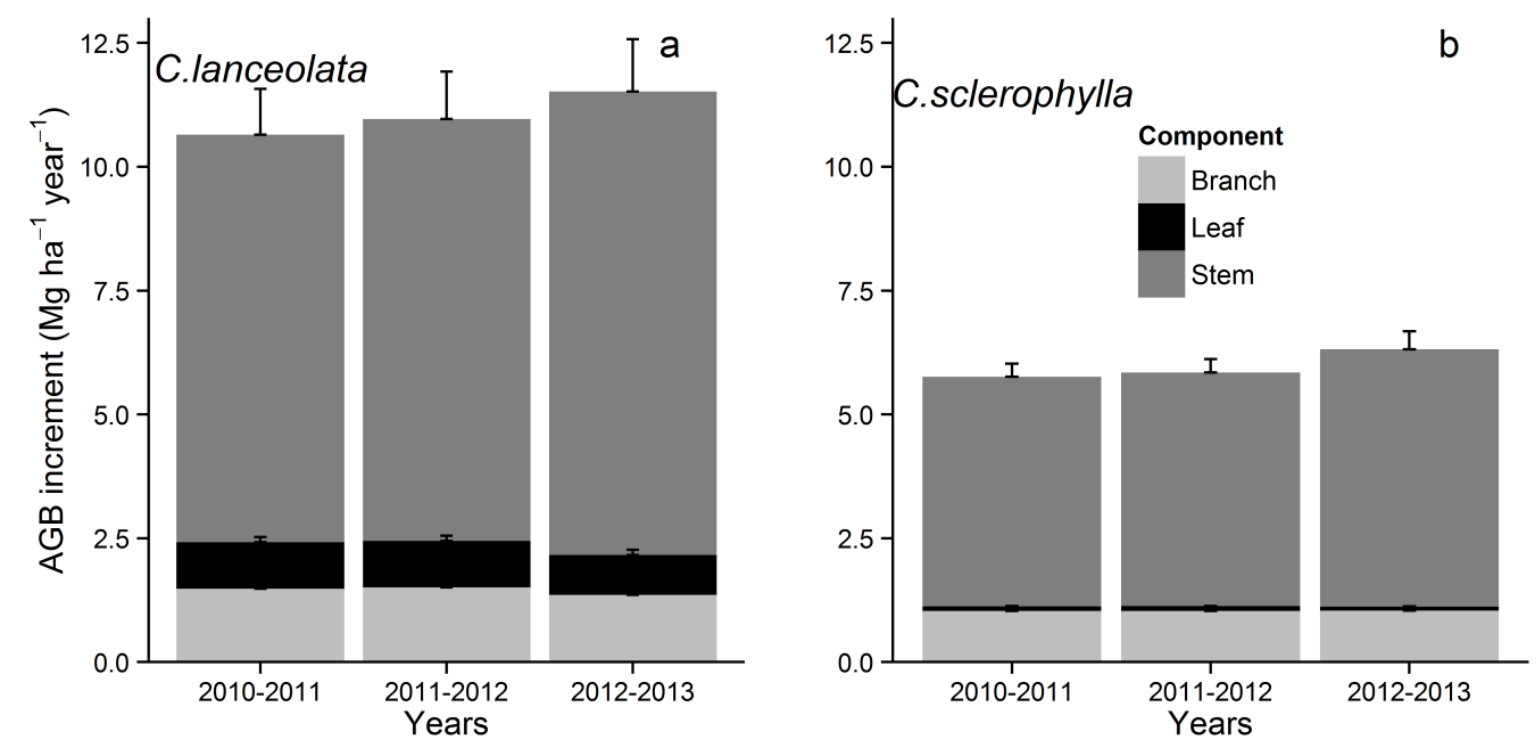

Fig. 4 Inter-annual biomass increment of stem, branch and leaf from 2011 to 2013 for C. lanceolata and C. sclerophylla forests.

AGB increment showed a reverse trend of AGB such that AGB increment of $C$. lanceolata was significantly higher $(p<0.05)$ than that of $C$. sclerophylla for the three-year period (Fig. 4). AGB increment of $C$. lanceolata was 10.6 \pm 1.2 for 2010-2011, $11.0 \pm 1.2$ for 2011-2012 and $11.5 \pm 1.3 \mathrm{Mg}$ $\mathrm{ha}^{-1}$ year $^{-1}$ for 2012-2013, respectively, compared to $5.8 \pm 0.3,5.9 \pm 0.3$ and $6.3 \pm 0.4 \mathrm{Mg} \mathrm{ha}^{-1}$ year $^{-1}$ for the $C$. sclerophylla stand. Stem biomass increment was the main contributor to AGB increment. As expected, leaf biomass increment contributed least to AGB increment with a value of $8 \%$ for $C$. lanceolata and $1.5 \%$ for $C$. sclerophylla. There was no significant inter-annual variability in compartment-wise biomass increment and total AGB increment for the two stands. Again, strong relationships between AGB increment and stand basal area were found with values of the adjusted $\mathrm{R}^{2}$ of 0.96 for C. lanceolata and 0.69 for C. sclerophylla (Fig. 5).

The production efficiency is defined as the ratio of stem production and leaf area index because the carbon sequestration in stem biomass is much larger than that of other compartments (Nunes et al., 2013). As expected, stem production efficiency of $C$. lanceolata, ranging from 1.8 to 2.0, was significantly higher than that of the C. sclerophylla stand for the three years observed $(p<0.001)$ ( about 0.8 , Fig. 6), indicating that $C$. lanceolata is a fast growing and efficient species. This can be confirmed by the mean stand biomass (Table 1) and AGB increment (Fig. 4). 


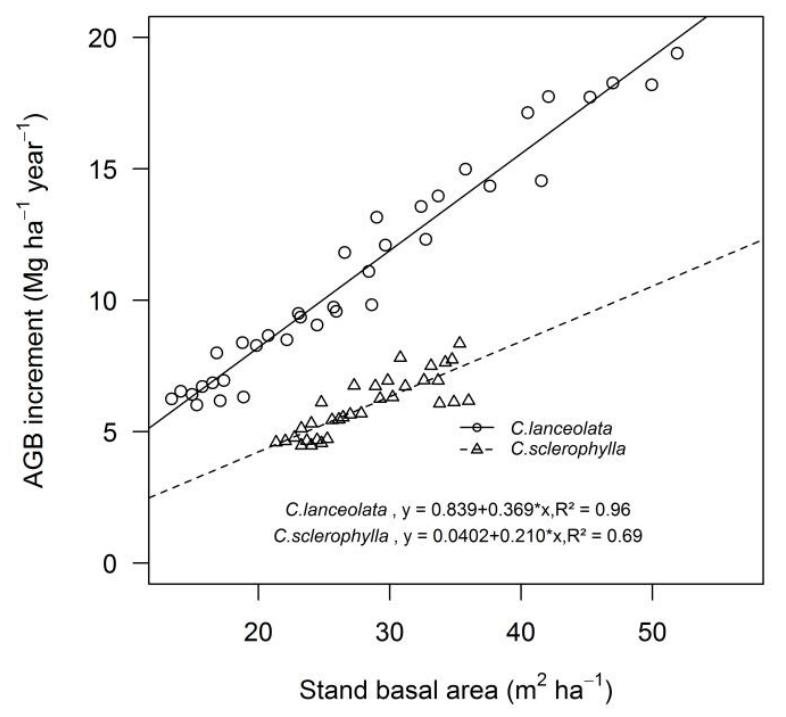

Fig. 5 Relationships between AGB increment and (a) leaf area index and (b) stand basal area.

\subsection{Discussion}

\subsubsection{Development of GADA model}

In our study, GADA model were developed based on data from tree ring analyses to predict $d b h$ at any age for each individual tree. The GADA models were flexible enough to predict diameter increment at any time interval, such as two- or five-year intervals, which allowed us to reconstruct historical diameters. By using tree-individual allometric biomass models to estimate tree compartment biomass combined with the GADA model, AGB dynamics and annual AGB increment were successfully estimated from 2010 to 2013. Such estimates of AGB increment were urgently needed to reduce uncertainties in ecosystem production and associated feedback to climate change (Frank et al., 2010). The dynamic GADA models could overcome the limitations of within-stand competition and limited biometric data, and by that improve our understanding of net primary production in these forest ecosystems.

To develop the GADA model, there are two basic approaches to gain the tree ring data: collecting increment cores (Babst et al., 2014; Foster et al., 2014; Groenendijk et al., 2014) or complete discs from destructive sampling (Brienen and Zuidema, 2006; Mbow et al., 2013; Groenendijk et al., 2014). Collecting the increment cores is quicker and less destructive than sampling complete discs. However, caution is needed with tree ring analyses from increment cores because the difficulty in separating true year rings and false rings what can lead to a significant bias. This is especially important for $C$. lanceolata where false rings are frequent so that there is a high probability of incorrectly classifying false rings from increment cores. Another problem that arises from increment cores is associated with no-pith cores because stems are not always round when the trees are growing on a slope, or due to competition and other stressors, although there are many approaches applied to predict the missing 
rings (Brienen and Zuidema, 2006; Groenendijk et al., 2014). Therefore, as for many other species (Maingi, 2006; Liu et al., 2012), complete discs are preferred.

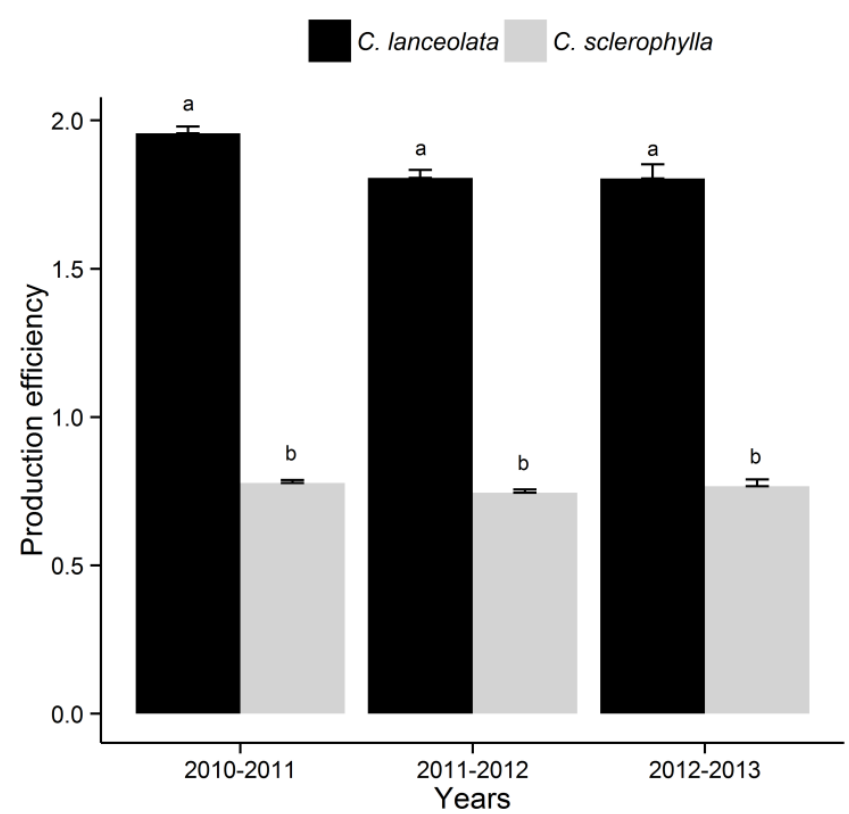

Fig.6 Production efficiency (stem production/leaf are index) for C. lanceolata and C. sclerophylla forests. Different letters above the error bars indicate significant differences between the tree species $(p<0.05)$.

\subsubsection{Leaf area index}

LAI is strongly related to carbon uptake, transpiration, leaf respiration, light variability and stand growth and structure (Chen et al., 1997; Moser et al., 2007; Olivas et al., 2013), and therefore affects many biological and physical processes in plant canopies (Chen et al., 1997). The average LAI in 2013 was $5.4 \pm 0.6 \mathrm{~m}^{2} \mathrm{~m}^{-2}$ for the C. lanceolata stand, which is close to the world average leaf area index $\left(5.55 \pm 4.14 \mathrm{~m}^{2} \mathrm{~m}^{-2}\right)$ based on a meta-analysis of 809 field plots in a literature review by Luo et al. (2002). Other authors have reported lower leaf area indices for this species, for example, $4.3 \mathrm{~m}^{2} \mathrm{~m}^{-}$ ${ }^{2}$ in Qianyanzhou, subtropical China (Li et al., 2007). The leaf area index of the C. sclerophylla stand $\left(6.9 \mathrm{~m}^{2} \mathrm{~m}^{-2}\right)$ was significantly higher than for the $C$. lanceolata stand $(p=0.049)$. This is consistent with Luo et al. (2002) who report that the LAI in China commonly $>6 \mathrm{~m}^{2} \mathrm{~m}^{-2}$ for tropical rainforest, subtropical evergreen broad-leaved forest and temperate mixed forest.

\subsubsection{AGB}

As expected, AGB increased with age for both stands, which agrees with other studies (Chen, 1998; Chen et al., 2013). The AGB of C. sclerophylla was significantly higher than that of C. lanceolata. Similar results were found for Castanopsis kawakamii forests that had a significantly higher AGB 
compared to nearby $C$. lanceolata forests (Yang et al., 2006). This was firstly due to the differences in wood density of the two species. Although the stand volume was similar (Table 1), the wood density was $0.40 \mathrm{~g} \mathrm{~m}^{-3}$ for $C$. lanceolata and $0.64 \mathrm{~g} \mathrm{~m}^{-3}$ for C. sclerophylla according to our measured data. Difference in ages was another important reason for the differences in AGB. It is generally recognized that AGB increases with stand age for young forests (Chen et al., 2013; Foster et al., 2014). In our study, C. lanceolata was 17 years old, which was 33 years younger than C. sclerophylla (Table 1). However, at a similar stand age, AGB of $C$. lanceolata is not necessarily lower than in a broadleaved forest, but $C$. lanceolata is commonly harvested at a rotation age of 25 years (Wu, 1984), whereas in China many broadleaved forests are not allowed to be cut due to ecological reasons. For example, AGB of a 40-year C. lanceolata forest in subtropical China with similar climate conditions to our study area was $222 \mathrm{Mg} \mathrm{ha}^{-1}$ (Chen et al., 2013), which was significantly higher than that of $C$. sclerophylla in our study. AGB of our C. lanceolata stand was $102.5 \pm 11.4 \mathrm{Mg} \mathrm{ha}^{-1}$ in 2013 (Table 3), which was comparable to a $C$. lanceolata stand with similar stand age in Huitong, Hunan Province (106 $\mathrm{Mg} \mathrm{ha}^{-1}$ ) (Xiao et al., 2007). But it was higher than inventory-based national average biomass $\left(80 \mathrm{Mg} \mathrm{ha}^{-1}\right.$ ) of C. lanceolata (Guo et al., 2010) and a C. lanceolata stand in Guangxi Province (86 $\mathrm{Mg} \mathrm{ha}^{-1}$ ) (Bing et al., 2009). Other authors observed higher values with an average of $155.3 \mathrm{Mg} \mathrm{ha}^{-1}$ in a 17-year C. lanceolata stand in Tongdao County (Chen, 1998) and $160 \mathrm{Mg} \mathrm{ha}^{-1}$ in Nanping City (Chen et al., 2013). Similarly, AGB of C. sclerophylla was $154.8 \pm 8.0 \mathrm{Mg} \mathrm{ha}^{-1}$ in 2013, which lies in the range of reported biomass of the main forest types in China (48.8-215.8 $\mathrm{Mg} \mathrm{ha}^{-1}$ ) (Guo et al., 2010). It is higher than that of natural Castanopsis carlesii - Schima superba mixed stands in the Xiaokeng region of the Nanling Mountains, in subtropical China (115.2 $\mathrm{Mg} \mathrm{ha}^{-1}$ ) (Xie et al., 2013), but lower than the mean AGB in Castanopsis, Camphortree and Schima superba forests in China (256.4 $\mathrm{Mg} \mathrm{ha}^{-1}$ ) (Jiang et al., 1999). These differences in AGB are mainly related to inherent variations in growth rates, stand age, stand density and starting $d b h$ (Pan et al., 2004; Houghton, 2005; Jandl et al., 2007). For example, AGB of C. lanceolata with a stand age of 40 years was doubled compared to a 21-year-old stand (Chen et al., 2013). Besides, with similar stand age, site and climate conditions, AGB of C. lanceolata in our study was lower than that reported by Chen et al. (2013) due to the high stand density of the latter study (2800-3875 trees $\cdot$ ha $^{-1}$ versus 1553 trees $\cdot$ ha $^{-1}$ in our study), indicating that stand density could maximize the tree biomass (Jandl et al., 2007).

Stem mass was the dominant AGB compartment for every stand, and contributed $76 \%$ to total AGB on average. This is consistent with C. lanceolata forests in Taiwan (80\%, Yen and Lee, 2011), the Huitong national research station of forest ecosystems (78\%, Wang et al., 2013) and the northwest Fujian Province in subtropical China (72\%, Huang et al., 2013). This value is also very similar to the mean ratio of stem biomass to AGB in forest ecosystems across China (79\%, Cheng et al., 2007). 


\subsubsection{Annual AGB increment}

AGB increment of the C. lanceolata stand was $10.6 \pm 1.2$ for $2010-2011,11.0 \pm 1.2$ for 2011-2012 and $11.5 \pm 1.3 \mathrm{Mg} \mathrm{ha}^{-1}$ year $^{-1}$ for 2012-2013. These values were significantly higher than those of the C. sclerophylla stand (Fig. 5). This can be explained by the tree physiology, structural characteristics of individual trees and the stand age (McMurtrie et al., 1994; Nunes et al., 2013). The young age in $C$. lanceolata could potentially lead to a higher AGB increment because it is generally accepted that the biomass accumulation reaches its maximum relatively early in the life of a stand, and thereafter declines with forest age (Ryan et al., 1997; Acker et al., 2002). In this study, AGB increment of $C$. lanceolata was higher than the average net primary production of main forest types in China (3.5 - 6.7 $\mathrm{Mg} \mathrm{ha}^{-1}$ year $^{-1}$ ) (Fang et al., 2003). Moreover, stem biomass contributed most to total AGB increment with an average of $76 \%$, which is similar to other studies (Acker et al., 2002). These results indicate that $C$. lanceolata is a fast-growing and efficient species with high biomass accumulation rates and that planting C. lanceolata is a good selection for timber production, as well as carbon sequestration (Zhao et al., 2009).

AGB increment of the C. sclerophylla stand ranged from 5.8 $\pm 0.3 \mathrm{Mg} \mathrm{ha}^{-1}$ year $^{-1}$ for 2010-2011 to 6.3 $\pm 0.4 \mathrm{Mg} \mathrm{ha}^{-1}$ year $^{-1}$ for 2010-2011. It was comparable to AGB increment of Spruce, secondary birch and secondary conifer-broadleaved forests (about $6 \mathrm{Mg} \mathrm{ha}^{-1}$ year $^{-1}$ ) at ages from 30 to 50 years in Sichuan province, subtropical China (Zhang et al., 2012), and higher than the mixed Schima superba - Castanopsis carlesii forests in subtropical China (3.9 $\mathrm{Mg} \mathrm{ha}^{-1} \mathrm{year}^{-1}$ ) (Yang et al., 2010). However, the value was lower than the national average AGB increment of the evergreen broadleaved forests in China (Fang et al., 2003).

Average AGB increment of $C$. sclerophylla from 2011 to 2013 was twice that of the mean biomass increment over the 52 years (3.0 $\mathrm{Mg} \mathrm{ha}^{-1}$ year $^{-1}$, Table 1$)$, which could be explained by the thinning operation in 2010. This result suggests that thinning is a good management practice to stimulate growth of standing trees, and could potentially improve the carbon sequestration capability and maintain a fast biomass accumulation rate even in the mature stand.

Converting secondary forests into $C$. lanceolata plantations is one of the most common land use changes driven by economic benefits (Guan et al., 2015). However, 17 years after the conversion soil organic carbon (SOC) stock was significantly reduced by $76 \mathrm{Mg} \mathrm{ha}^{-1}$ in C. lanceolata forests compared to $C$. sclerophylla forests due to prescribed burning and site preparation according to the results from Guan et al. (2015) in the same stands. It is generally accepted that SOC stocks decrease in the early establishment phase of plantations and recover to initial levels after about 30 - 40 years (Guo and Gifford, 2002; Paul et al., 2002; Cook et al., 2014). For example, after the conversion of natural forests to Abies fabri and Picea asperata plantations in subtropical China, SOC stock decreased about more than $50 \%$ in the first ten years, and then the SOC stock increased again with 
plantation age until the initial stage after 50 years in both types of plantations (Liu et al., 2002). Similarly, the SOC stock of conifer plantation recovered in 34 years after the conversion from broadleaved forest, and maintained similar levels thereafter (Cook et al., 2014). These results indicate on the ecosystem level, that increasing the rotation age of $C$. lanceolata could not only increase timber dimensions, subsequently carbon stocks of tree layers and economic benefits, but also increase SOC stocks. C. lanceolata plantations are commonly harvested at an age of 25 years with variations from 20 to 30 years depending on the site quality ( $\mathrm{Wu}, 1984)$. This suggests, in combination with a high biomass accumulation rate, a considerable potential to increase carbon sequestration in $C$. lanceolata plantations through extending the rotation period.

\subsection{Conclusions}

Understanding biomass dynamics is a fundamental requirement for evaluating the carbon sequestration capabilities and potentials of forest ecosystems. In this study, AGB dynamics and AGB increment from 2010 to 2013 of C. lanceolata and C. sclerophylla were successfully estimated by using GADA models and allometic biomass models. Stand AGB of C. sclerophylla was significantly higher than that of $C$. lanceolate, and stem contributed $76 \%$ to total AGB in both stand types, highlighting the importance of stem production in carbon sequestration of forest ecosystems. In contrast, AGB increment and production efficiency were significantly higher in the $C$. lanceolata forest than in the $C$. sclerophylla forest, indicating $C$. lanceolata is a fast-growing and efficient species with high biomass accumulation rates. AGB increment of $C$. sclerophylla after thinning was doubled compared to mean biomass increments over the 52 years, indicating that thinning operations are still a good management practice to stimulate growth of standing trees even in a mature stand, and could potentially improve the carbon sequestration capability and maintain a high biomass accumulation rate.

The high determination coefficients of GADA models for both stands indicated that GADA models were a powerful tool to predict the diameter dynamics. These dynamic models can overcome the limitations of within-stand competition and limited biometric data, and can be applied to study the biomass dynamics. If mortality data are given, the GADA models could contribute to long-term biomass dynamics without repeated measurements in the field, and improve our understanding of the net primary production in forest ecosystems.

\section{Acknowledgements}

This study was supported by the project of Sino-German Cooperation on Innovative Technologies and Service Capacities of Multifunctional Forest Management ( $\operatorname{Lin}^{2}$ Value 033L049-CAFYBB2012013), funded by the Federal Ministry of Education and Research (BMBF, Bundesministerium für Bildung und Forschung) and the Chinese Academy of Forestry, and special research fund of International 
Centre for Bamboo and Rattan (NO. 1632013010) supported by International Centre for Bamboo and Rattan (ICBR) in China. We thank Hans Fuchs, Sabine Schreiner, Haijun Yang and Dengkui Mo from the Georg-August-Universität Göttingen for plot design and fieldwork support. We also thank Director An'guo Fan, Mr. Bailing Ding, Miss Yue'e Chu from the Shitai Forest bureau for kindly organizing the fieldwork. Lastly, special thanks to Mr. Xiaozhu Wang and Mr. Hongbing Ruan for fieldwork support.

\section{References}

Acker SA, Halpern CB, Harmon ME, et al. 2002. Trends in bole biomass accumulation, net primary production and tree mortality in Pseudotsuga menziesii forests of contrasting age. Tree Physiology 22: 213-217.

Álvarez-González JG, Zingg A, Klaus Von G. 2010. Estimating growth in beech forests: a study based on long term experiments in Switzerland. Annals of Forest Science 67: 307-307.

An S, Liu M, Wang Y, et al. 2001. Forest plant communities of the Baohua Mountains, eastern China. Journal of Vegetation Science 12: 653-658.

Babst F, Bouriaud O, Alexander R, et al. 2014. Toward consistent measurements of carbon accumulation: A multi-site assessment of biomass and basal area increment across Europe. Dendrochronologia 32: 153-161.

Barrio-Anta M, Castedo-Dorado F, Diéguez-Aranda U, et al. 2006. Development of a basal area growth system for maritime pine in northwestern Spain using the generalized algebraic difference approach. Canadian Journal of Forest Research 36: 1461-1474.

Bertalanffy VL. 1957. Quantitative laws in metabolism and growth. Quarterly Review of Biology 32: 217-231.

Bing K, ShiRong L, DaoXiong C, et al. 2009. Characteristics of biomass, carbon accumulation and its spatial distribution in Cunninghamia lanceolata forest ecosystem in low subtropical area. Scientia Silvae Sinicae 45: 147-153 (in Chinese with English abstract).

Bonan GB. 2008. Forests and climate change: forcings, feedbacks, and theclimate benefits of forests. Science 320: 1444-1449.

Brienen RJW, Zuidema PA. 2006. The use of tree rings in tropical forest management: Projecting timber yields of four Bolivian tree species. Forest Ecology and Management 226: 256-267.

Bush R, Brand G. 2008. Lake States (LS) variant overview: Forest Vegetation Simulator. USDA Forest Service, Forest Management Service Center. Fort Collins, CO.

Chen GS, Yang ZJ, Gao R, et al. 2013. Carbon storage in a chronosequence of Chinese fir plantations in southern China. Forest Ecology and Management 300: 68-76. 
Chen H. 1998. Biomass and nutrient distribution in a Chinese-fir plantation chronosequence in Southwest Hunan, China. Forest Ecology and Management 105: 209-216.

Chen JM, Black TA. 1992. Defining leaf area index for non-flat leaves. Plant, Cell \& Environment 15: 421-429.

Chen JM, Rich PM, Gower ST, et al. 1997. Leaf area index of boreal forests: Theory, techniques, and measurements. Journal of Geophysical Research: Atmospheres 102: 29429-29443.

Cheng DL, Wang GX, Li T, et al. 2007. Relationships among the stem, aboveground and total biomass across Chinese forests. Journal of Integrative Plant Biology 49: 1573-1579.

Cieszewski C, Bailey RL. 2000. Generalized algebraic difference approach: Theory based derivation of dynamic site equations with polymorphism and variable asymptotes. Forest Science 46: 116126.

Cieszewski CJ. 2002. Comparing fixed- and variable-base-age site equations having single versus multiple asymptotes. Forest Science 48: 7-23.

Cook RL, Binkley D, Mendes JCT, et al. 2014. Soil carbon stocks and forest biomass following conversion of pasture to broadleaf and conifer plantations in southeastern Brazil. Forest Ecology and Management 324: 37-45.

Diéguez-Aranda U, Castedo-Dorado F, Álvarez-González JG, et al. 2006. Compatible taper function for Scots pine plantations in northwestern Spain. Canadian Journal of Forest Research 36: 11901205.

Fang J, Piao S, Field CB, et al. 2003. Increasing net primary production in China from 1982 to 1999. Frontiers in Ecology and the Environment 1: 293-297.

Foster JR, D'Amato AW, Bradford JB. 2014. Looking for age-related growth decline in natural forests: unexpected biomass patterns from tree rings and simulated mortality. Oecologia 175: 363-374.

Frank DC, Esper J, Raible CC, et al. 2010. Ensemble reconstruction constraints on the global carbon cycle sensitivity to climate. Nature 463: 527-530.

Gea-Izquierdo G, Cañellas I, Montero G. 2008. Site index in agroforestry systems: age-dependent and age-independent dynamic diameter growth models for Quercus ilex in Iberian open oak woodlands. Canadian Journal of Forest Research 38: 101-113.

Geng TS, Wang HH. 2011. Research on the water and soil conservation in Shitai County of Anhui Province. Journal of Anhui Agriculture Science 39: 451-452, 482 (in Chinese with English abstract).

González-García M, Hevia A, Majada J, et al. 2013. Above-ground biomass estimation at tree and stand level for short rotation plantations of Eucalyptus nitens (Deane \& Maiden) Maiden in Northwest Spain. Biomass and Bioenergy 54: 147-157.

Gower ST, Vogel JG, Norman JM, et al. 1997. Carbon distribution and aboveground net primary production in aspen, jack pine, and black spruce stands in Saskatchewan and Manitoba, Canada. Journal of Geophysical Research: Atmospheres 102: 29029-29041. 
Groenendijk P, Sass-Klaassen U, Bongers F, et al. 2014. Potential of tree-ring analysis in a wet tropical forest: A case study on 22 commercial tree species in Central Africa. Forest Ecology and Management 323: 65-78.

Guan F, Tang X, Fan S, et al. 2015. Changes in soil carbon and nitrogen stocks followed the conversion from secondary forest to Chinese fir and Moso bamboo plantations. CATENA 133: 455-460.

Guisasola-Rodríguez R. 2014. Allometric biomass equations and crown architecture in mixed-species forests of subtropical China. Fakultät für Umwelt and Natürliche Ressourcen. Freiburg: AlbertLudwigs Universität Freiburg, p48.

Guo LB, Gifford RM. 2002. Soil carbon stocks and land use change: a meta analysis. Global Change Biology 8: 345-360.

Guo ZD, Fang JY, Pan YD, et al. 2010. Inventory-based estimates of forest biomass carbon stocks in China: A comparison of three methods. Forest Ecology and Management 259: 1225-1231.

Houghton RA. 2005. Aboveground forest biomass and the global carbon balance. Global Change Biology 11: 945-958.

Huang S, Price D, J. Titus S. 2000. Development of ecoregion-based height-diameter models for white spruce in boreal forests. Forest Ecology and Management 129: 125-141.

Huang ZQ, He ZM, Wan XH, et al. 2013. Harvest residue management effects on tree growth and ecosystem carbon in a Chinese fir plantation in subtropical China. Plant and Soil 364: 303-314.

IPCC. 2007. Climate Change 2007: Synthesis Report. Contribution of Working Groups I, II and III to the Fourth Assessment Report of the Intergovernmental Panel on Climate Change. 36-41p.

Jandl R, Lindner M, Vesterdal L, et al. 2007. How strongly can forest management influence soil carbon sequestration? Geoderma 137: 253-268.

Jia Z, Zhang J, Wang X, et al. 2009. Report for Chinese forest resource-The $7^{\text {th }}$ national forest inventory. Beijing(in Chinese): China Forestry Publishing House.

Jiang H, Apps MJ, Zhang Y, et al. 1999. Modelling the spatial pattern of net primary productivity in Chinese forests. Ecological Modelling 122: 275-288.

Jonckheere I, Fleck S, Nackaerts K, et al. 2004. Review of methods for in situ leaf area index determination: Part I. Theories, sensors and hemispherical photography. Agricultural and Forest Meteorology 121: 19-35.

Landsberg JJ, Gower ST. 1997. Applications of physiological ecology to forest management. San Diego, CA, USA: Academic Press. 601-602p.

Li K, Jang H, You M, et al. 2011. Effect of simulated nitrogen deposition on soil respiration of Lithocarpus glaber and Castanopsis sclerophylla. Acta Ecologica Sinaca 31: $82-89$ (in Chinese with English abstract). 
Li X, Liu Q, Cai Z, et al. 2007. Specific leaf area and leaf area index of conifer plantations in Qianyanzhou station of subtropical China. Journal Plant Ecolcogy 31: 93-101 (in Chinese with English abstract).

Liu SL, Fu BJ, Chen LD, et al. 2002. Effects of land use changes on soil properties in Wolong Nature Reserve. Geographical Research 21: 682-688.

Liu YC, Zhang YD, Liu SR. 2012. Aboveground carbon stock evaluation with different restoration approaches using tree ring chronosequences in Southwest China. Forest Ecology and Management 263: 39-46.

Lu CM. 2010. Rock-soil geochemical features for Dashan Area, Shitai, Anhui. Geology of Anhui 20: 120-125 (in Chinese with English abstract).

Luo T, Neilson RP, Tian H, et al. 2002. A model for seasonality and distribution of leaf area index of forests and its application to China. Journal of Vegetation Science 13: 817-830.

Maingi JK. 2006. Growth rings in tree species from the Tana river floodplain, Kenya. Journal of East African natural history 95: 181-211.

Mbow C, Chhin S, Sambou B, et al. 2013. Potential of dendrochronology to assess annual rates of biomass productivity in savanna trees of West Africa. Dendrochronologia 31: 41-51.

McMurtrie RE, Gholz HL, Linder S, et al. 1994. Climatic factors controlling the productivity of pine stands: a model-based analysis. Ecological Bulletins 43: 173-188.

Moser G, Hertel D, Leuschner C. 2007. Altitudinal change in LAI and stand leaf biomass in tropical Montane Forests: a transect study in Ecuador and a pan-tropical meta-analysis. Ecosystems 10: 924-935.

Mund M, Kummetz E, Hein M, et al. 2002. Growth and carbon stocks of a spruce forest chronosequence in central Europe. Forest Ecology and Management 171: 275-296.

Nunes L, Lopes D, Rego FC, et al. 2013. Aboveground biomass and net primary production of pine, oak and mixed pine-oak forests on the Vila Real district, Portugal. Forest Ecology and Management 305: 38-47.

Ogawa K. 2012. Mathematical analysis of age-related changes in leaf biomass in forest stands. Canadian Journal of Forest Research 42: 356-363.

Olivas PC, Oberbauer SF, Clark DB, et al. 2013. Comparison of direct and indirect methods for assessing leaf area index across a tropical rain forest landscape. Agricultural and Forest Meteorology 177: 110-116.

Palahí M, Pukkala T, Kasimiadis D, et al. 2008. Modelling site quality and individual-tree growth in pure and mixed Pinus brutia stands in north-east Greece. Annals of Forest Science 65: 501-501.

Pan YD, Luo TX, Birdsey R, et al. 2004. New estimates of carbon storage and sequestration in China's forests: Effects of age-class and method on inventory-based carbon estimation. Climatic Change 67: 211-236. 
Paul KI, Polglase PJ, Nyakuengama JG, et al. 2002. Change in soil carbon following afforestation. Forest Ecology and Management 168: 241-257.

R Core Team. 2014. R: A language and environment for statistical computing. R Foundation for Statistical Computing, Vienna, Austria. URL http://www.R-project.org/.

Ryan MG, Binkley D, Fownes JH. 1997. Age-related decline in forest productivity: pattern and process. Begon M, Fitter AH editors. Advances in Ecological Research: Academic Press, p213262.

SAS Institute Inc. 2007. SAS user's guide, version 9.2. SAS Institute Cary, NC.

Sharma RP, Brunner A, Eid T, et al. 2011. Modelling dominant height growth from national forest inventory individual tree data with short time series and large age errors. Forest Ecology and Management 262: 2162-2175.

Stokes MA. 1996. An introduction to tree-ring dating: University of Arizona Press.

Tomé J, Tomé M, Barreiro S, et al. 2006. Age-independent difference equations for modelling tree and stand growth. Canadian Journal of Forest Research 36: 1621-1630.

Wang QK, Wang SL, Zhong MC. 2013. Ecosystem carbon storage and soil organic carbon stability in pure and mixed stands of Cunninghamia lanceolata and Michelia macclurei. Plant and Soil 370: 295-304.

Woolley TJ, Harmon ME, O’Connell KB. 2015. Inter-annual variability and spatial coherence of net primary productivity across a western Oregon Cascades landscape. Forest Ecology and Management 335: 60-70.

Wu C, Hong W, Jiang Z. 2001. Simulation of Cunninghamia lanceolata growth by wave-type time series analysis. The journal of applied ecology 12: 659-662 (in Chinese with English abstract).

Wu ZL. 1984. Chinese-fir Beijing: China Forestry Publishing House (in Chinese). 583p.

Xiang W, Liu S, Deng X, et al. 2011. General allometric equations and biomass allocation of Pinus massoniana trees on a regional scale in southern China. Ecological Research 26: 697-711.

Xiao FM, Fan SH, Wang SL, et al. 2007. Carbon storage and spatial distribution in Phyllostachy pubescens and Cunninghamia lanceolata plantation ecosystem. Acta Ecologica Sinica 27: 27942801 (in Chinese with English abstract).

Xie TT, Li G, Zhou GY, et al. 2013. Aboveground biomass of natural Castanopsis carlesii-Schima superba community in Xiaokeng of Nanling Mountains, South China. The journal of applied ecology 24: 2399-2407 (in Chinese with English abstract).

Yang T, Song K, Da L, et al. 2010. The biomass and aboveground net primary productivity of Schima superba-Castanopsis carlesii forests in east China. Science China Life Sciences 53: 811-821.

Yang Y, Chen G, Wang Y, et al. 2006. Carbon storage and allocation in Castanopsis kawakamii and Cunninghamia lanceolata plantations in subtropical China. Scientia Silvae Sinicae 42: 43-47 (in Chinese with English abstract). 
Yen T, Lee J. 2011. Comparing aboveground carbon sequestration between moso bamboo (Phyllostachys heterocycla) and China fir (Cunninghamia lanceolata) forests based on the allometric model. Forest Ecology and Management 261: 995-1002.

Zhang XQ, Kirschbaum MUF, Hou ZH, et al. 2004. Carbon stock changes in successive rotations of Chinese fir (Cunninghamia lanceolata (lamb) hook) plantations. Forest Ecology and Management 202: 131-147.

Zhang Y, Liu Y, Liu S, et al. 2012. Dynamics of stand biomass and volume of the tree layer in forests with different restoration approaches based on tree-ring analysis. Chinese Journal of Plant Ecology 36: 117-125.

Zhao MF, Xiang WH, Peng CH, et al. 2009. Simulating age-related changes in carbon storage and allocation in a Chinese fir plantation growing in southern China using the 3-PG model. Forest Ecology and Management 257: 1520-1531.

Zianis D, Mencuccini M. 2005. Aboveground net primary productivity of a beech (Fagus moesiaca) forest: a case study of Naousa forest, northern Greece. Tree Physiology 25: 713-722. 
Chapter III: Estimation of aboveground biomass dynamics

Appendix

Table 1 Allometric models of height, stem, branch and leaf biomass and leaf area

\begin{tabular}{|c|c|c|c|c|c|c|c|c|c|c|c|c|}
\hline Species & Variable & $\mathrm{a}$ & $p$ & $\mathrm{~b}(d b h)$ & $p$ & $\mathrm{c}(h)$ & $p$ & $\mathrm{~d}\left(d b h^{2} \cdot h\right)$ & $p$ & $\mathrm{R}_{\text {adj }}^{2}$ & $\mathrm{n}$ & RMSE \\
\hline \multirow{5}{*}{$\begin{array}{l}\text { Cunninghamia } \\
\text { lanceolata }\end{array}$} & $h$ & -10.224 & $<0.001$ & 7.768 & $<0.001$ & & & \multirow{5}{*}{0.967} & \multirow{5}{*}{$<0.001$} & 0.7642 & 327 & 1.732 \\
\hline & Stem & 0.0202 & $<0.001$ & & & & & & & 0.9764 & 12 & 0.0179 \\
\hline & Branch & 0.0118 & $<0.001$ & 3.742 & $<0.001$ & -1.603 & 0.0013 & & & 0.9722 & 12 & 0.0294 \\
\hline & Leaf & 0.0319 & $<0.001$ & 3.207 & $<0.001$ & -1.511 & 0.003 & & & 0.9522 & 12 & 0.0363 \\
\hline & Leaf area & 0.164 & 0.0198 & 3.253 & $<0.001$ & -1.533 & 0.003 & & & 0.9500 & & \\
\hline \multirow{4}{*}{$\begin{array}{l}\text { Castanopsis } \\
\text { sclerophylla }\end{array}$} & $h$ & 0.00951 & 0.00696 & 5.307 & $<0.001$ & & & \multirow{4}{*}{1.0123} & \multirow{4}{*}{$<0.001$} & 0.4347 & 103 & 2.207 \\
\hline & Branch & 0.0471 & $<0.001$ & 2.187 & $<0.001$ & \multirow{3}{*}{-0.731} & \multirow{3}{*}{$<0.001$} & & & 0.8889 & 24 & 0.0863 \\
\hline & Leaf & 0.102 & $<0.001$ & 1.873 & $<0.001$ & & & & & 0.8138 & 24 & 0.0735 \\
\hline & Leaf area & 0.404 & 0.07 & 1.419 & $<0.001$ & & & & & 0.7501 & 24 & 0.0969 \\
\hline
\end{tabular}

$h$ is the total tree height $(\mathrm{m}) ; d b h$ is the diameter at breast height $(1.3 \mathrm{~m})$ in $\mathrm{cm}$. The allometric model are expressed: $h=\mathrm{a}+\mathrm{b} \cdot \ln (d b h) ; B i o m a s s=\mathrm{a} \cdot d b h^{\mathrm{b}}$ or $\mathrm{a} \cdot d b h^{\mathrm{b}} \cdot h^{\mathrm{c}}$ or $\mathrm{a} \cdot\left(d b h^{2} \cdot h\right)^{\mathrm{d}}$. The coefficients for these allometric models were taken from (Guisasola Rodríguez 2014) and the coefficients for $h$ were fitted based on the measured trees in the field and felled trees for stem analysis. 


\section{Chapter IV}

\section{Development of a compatible taper function and stand-level merchantable volume model for Chinese fir plantations}

Xiaolu Tang ", César Pérez-Cruzado, Lutz Fehrmann, Juan Gabriel Álvarez-González, Yuanchang Lu, Christoph Kleinn

Status: submitted to "PloS one" (under review)

Contribution by Xiaolu Tang: $85 \%$

- Design the manuscript

- Collect data

- Analyze and model data

- Write and revise manuscript

\footnotetext{
*Corresponding author: xtang@gwdg.de
} 
Chapter IV: Development of a taper function and stand-level merchantable volume model 


\title{
Development of a compatible taper function and stand-level merchantable volume model for Chinese fir plantations
}

\author{
Xiaolu Tang ${ }^{1}$, César Pérez-Cruzado ${ }^{1}$, Lutz Fehrmann ${ }^{1}$, Juan Gabriel Álvarez-González ${ }^{2}$, \\ Yuanchang $\mathrm{Lu}^{3}$, Christoph Kleinn ${ }^{1}$ \\ ${ }^{1}$ Chair of Forest Inventory and Remote Sensing, Georg-August-Universität Göttingen, Büsgenweg 5, \\ 37077 Göttingen, Germany \\ ${ }^{2}$ Departamento de Ingeniería Agroforestal, Universidad de Santiago de Compostela. Escuela \\ Politécnica Superior, Campus Universitario, 27002 Lugo, Spain \\ ${ }^{3}$ Department of Forest Management and Statistics, Institute of Forest Resource Information \\ techniques, Chinese Academy of Forestry, Dongxiaofu 2, Xiangshan Road, 100091 Haidian, Beijing, \\ PR of China
}

\begin{abstract}
Chinese fir (Cunninghamia lanceolata [Lamb.] Hook) is one of the most important plantation tree species in China with good timber quality and fast growth. It covers an area of 8.54 million hectare, which corresponds to $21 \%$ of the total plantation area and $32 \%$ of total plantation tree volume in China. With the increasing market demand, an accurate estimation and prediction of merchantable volume at tree- and stand-level is becoming important for plantation owners. Although there are many studies on the total tree volume estimation from allometric models, these allometric models cannot predict tree- and stand-level merchantable volume at any merchantable height, and the stand-level merchantable volume model was not seen yet in Chinese fir plantations. This study aimed to develop (1) a compatible taper function proposed by Fang et al. (2000) for tree-level merchantable volume estimation, and (2) a stand-level merchantable volume model for Chinese fir plantations. This "taper function system" consisted in a taper function, a merchantable volume equation and a total tree volume equation. 46 Chinese fir trees were felled to develop the taper function in Shitai County, Anhui province, China. A second-order continuous autoregressive error structure corrected the inherent serial autocorrelation of different observations in one tree. The taper function and volume equations were fitted simultaneously after autocorrelation. The model developed by Fang et al. (2000) fitted well to our data and had very good performances in diameter and total tree volume prediction. The stand-level merchantable volume equation based on the ratio approach was developed using basal area, dominant height, quadratic mean diameter and top diameter (ranging from 0 to $30 \mathrm{~cm}$ ) as independent variables. The high correlation between measured and predicted total and merchantable stand volume from this model highlighted the efficiency of stand-level merchantable volume as well
\end{abstract}


as total stand volume estimation. At last, a total stand-level volume table using stand basal area and dominant height was proposed for local forest managers to simplify the stand volume estimation.

Keywords: taper function system, basal area, dominant height, volume prediction, diameter prediction

\subsection{Introduction}

As an important plantation species, Chinese fir (Cunninghamia lanceolata [Lamb.] Hook) has been widely planted throughout Southern China for more than one thousand years history and is famous for its fast growth and good quality (Zhao et al., 2009; Chen et al., 2013). Currently, Chinese fir plantations have an area of 8.54 million ha, amounting for $21 \%$ of the China's total plantation area and $32 \%$ of total plantation tree volume according to the $7^{\text {th }}$ national forest inventory (Jia et al., 2009). With the changes of market and the increasingly local economic dependence, timber production has become the most important object in Chinese fir plantations not only for plantation owners, but also for local governments. Chinese fir plantations are usually managed in a clear cutting system with a rotation period of 20 to 30 years depending on the site quality (Wu, 1984). Accurate prediction of volume in such rotation period is a matter of interest for plantation owners and forest managers.

To estimate the total tree volume, allometic models using diameter at breast height $(1.3 \mathrm{~m}, d b h)$ and tree height have been widely used (Bi and Hamilton, 1998; Turski et al., 2008; Cutini et al., 2013). However, these models cannot predict the volume to any height limits and merchantable volumes to any merchantable height or diameter limits (Menéndez-Miguélez et al., 2014). Instead, taper functions have been well developed to solve such problems. Taper functions do not only describe the stem shapes (Kozak, 1988), but also provide the estimation of: (1) diameter at any height of the stem; (2) total tree volume; (3) merchantable volume and merchantable height at any top diameter and (4) individual volumes for logs between any two heights (Kozak, 2004; Barrio Anta et al., 2007).

Ideally, a taper function should be compatible. For example, the volume calculation from the estimation of taper function should be equal to that computed from a total volume model (Demaerschalk, 1972; Clutter, 1980; Fang et al., 2000). It is also desirable to achieve the compatibility that the merchantable volume to any merchantable height calculated from taper function should be equal to that from a merchantable volume model (Barrio Anta et al., 2007). Many compatible taper functions have been proposed for different tree species with different forms, as reviewed by Diéguez-Aranda et al. (2006). These taper functions are classified into three types: single taper models, segmented taper models and variable-form taper models. Through comparing different taper functions for different tree species, the segmented taper function developed by Fang et al. (2000) 
is regarded as one of the most accurate and flexible functions that has been used for different tree species (Diéguez-Aranda et al., 2006; Barrio Anta et al., 2007; Menéndez-Miguélez et al., 2014).

Some direct and indirect approaches have been developed to estimate the merchantable volume. Direct approaches measure the diameter at different heights and calculate the section volume upto the merchantable height or diameter of interest. Indirect approaches focus on (i) the development of a volume equation to a fixed merchantable diameter or merchantable height; (ii) the development of a taper function that is compatible to estimate the merchantable volume (Barrio Anta et al., 2007; Navar et al., 2013); (iii) the development of a merchantable volume that is proportional to the total stem volume using a merchantable diameter or height (Tasissa et al., 1997; Teshome, 2005). Among these methods, volume-ratio equations that predict merchantable volume as a percentage of total volume and taper functions are the most widely used to estimate merchantable volume (Clutter, 1980; Reed and Green, 1984; Diéguez-Aranda et al., 2006). This method can use the top diameter or the merchantable height as independent variable, combining with $d b h$, total tree height and stump height (Cao et al., 1980; Tasissa et al., 1997; Teshome, 2005). However, although great progress has been made to estimate the merchantable volume as mentioned above, the majority of the existing models have been developed to estimate tree-level merchantable volume and to date very few studies have been carried out concerning stand-level volume-ratio equations (Barrio-Anta et al., 2008).

Although many taper functions have been developed for different tree species, the taper function for Chinese fir is still rare despite a generalized taper function was developed about 20 years ago using a single taper model (Hui and von Gadow, 1997). However, this taper function cannot estimate the merchantable volume. Recent evidence further indicates that segmented taper models are more accurate and flexible to describe the stem taper (Fang et al., 2000; Diéguez-Aranda et al., 2006). To our knowledge, no such taper function was developed for Chinese fir plantation. This study attempts to make up this gap using the taper function developed by Fang et al. (2000). The objectives of this study are to: (i) develop a taper function that can correctly describe the stem taper, estimate stem volume and tree merchantable volume as a baseline in China; (ii) develop a stand-level merchantable volume model to simplify the stand merchantable volume estimation for Chinese fir plantations.

\subsection{Materials and methods}

\subsubsection{Study area}

The study was conducted in Shitai county $\left(29^{\circ} 59^{\prime}-30^{\circ} 24^{\prime} \mathrm{N}, 117^{\circ} 12^{\prime}-117^{\circ} 59^{\prime} \mathrm{E}\right.$, Fig.1), Anhui province, China. It is a very mountainous area with an average slope of $66 \%$. It has a forest cover of $80 \%$ with an elevation varying between $50 \mathrm{~m}$ and $1000 \mathrm{~m}$ above the sea level. The region has a mid-subtropical, humid, mountainous climate with seasonal variability (Geng and Wang, 2011). The annual average temperature is $16{ }^{\circ} \mathrm{C}$, ranging from $40.9{ }^{\circ} \mathrm{C}$ in July to $-13.2{ }^{\circ} \mathrm{C}$ in January $(\mathrm{Lu}, 2010)$. The mean annual 
precipitation is about $1668 \mathrm{~mm}$ with high inter-annual variability, and with about $70 \%$ of the precipitation occurring during flooding seasons (Geng and Wang, 2011). The average annual sunshine duration is 1704 hours and evaporative capacity is $1256 \mathrm{~mm}(\mathrm{Lu}, 2010)$.

\subsubsection{Plot design}

This study is a part of the $\mathrm{Lin}^{4}$ carbon project, in which three different types of inventories were established: (1) a land use and forest inventory (LUI/FI) that produces information over the whole extent of the sampling frame based on the systematic grids of $3 \times 3 \mathrm{~km}$; (2) a forest management inventory (FMI) for those stands with forest management information with a $500 \times 500 \mathrm{~m}$ systematic grid, and (3) a stand inventory of selected stands (SI) with a 100×100 m systematic grid. Altogether 74 nested circular plots in the Chinese fir plantations were established. Trees with a $d b h$ within 10 $20 \mathrm{~cm}$ were measured in the $6 \mathrm{~m}$ radius circular subplots with a diameter tape to the nearest $0.1 \mathrm{~cm}$. While trees with a $d b h>20 \mathrm{~cm}$ were measured in the $10 \mathrm{~m}$ radius subplots. In each plot, heights of one or two dominant, one co-dominant and one suppressed trees were measured, respectively. A height-diameter relationship was fitted to the subsample of trees with diameter and height measurements using the model proposed by Pretzsch (2009):

$$
H=1.3+\left(\frac{d b h}{2.0208+0.3461 \cdot d b h}\right)^{3} \quad \mathrm{R}^{2}=0.7286, \mathrm{RMSE}=1.6006
$$

Where $H$ is the total height of the tree in meter, $d b h$ is the diameter at breast height $(1.3 \mathrm{~m})$ in $\mathrm{cm}, \mathrm{R}^{2}$ is the coefficient of determination and RMSE is the root mean square error in meter.
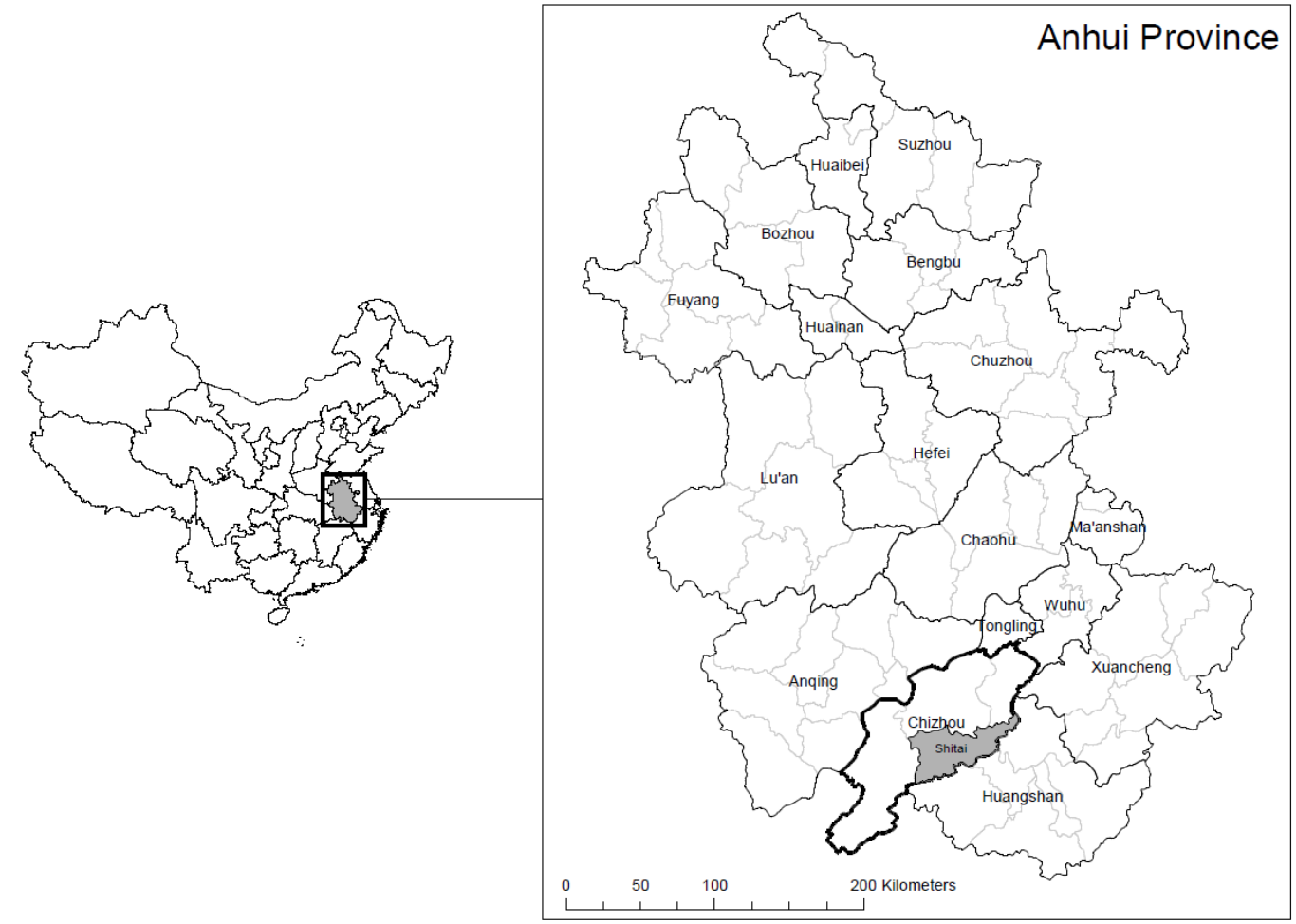

Fig. 1 Location of Shitai County in the southern part of Anhui Province, South-East China. 


\subsubsection{Data set}

A total of 46 non-forked sample trees were felled throughout the study area, covering the existing range of age, diameter, stand density and site quality. $d b h$ was measured for each tree to the nearest $0.1 \mathrm{~cm}$ with a diameter tape before felling. The trees were felled with an average stump height of 0.1 $\mathrm{m}$, and the total tree height was measured to the nearest $0.1 \mathrm{~m}$ using a measuring tape. The stem was cut into sections at heights of $0.3 \mathrm{~m}, 1.3 \mathrm{~m}, 3 \mathrm{~m}$ and $2 \mathrm{~m}$ intervals up to a top diameter of $5 \mathrm{~cm}$. Smalian formula was used to calculate the log volumes (Diéguez-Aranda et al., 2006; MenéndezMiguélez et al., 2014). The treetop was treated as a cone. Total stem volume with bark was obtained by summing the log volumes and treetop volume. The relative diameter against relative height are plotted to detect the anomalies in the data (Fig. 2). More summary statistics of the felled trees used for fitting the taper function are given in Table 1.

Table 1 Summary statistics of the 46 trees used for developing the taper function

\begin{tabular}{lrrc}
\hline & \multicolumn{1}{l}{$\begin{array}{l}d b h \\
(\mathrm{~cm})\end{array}$} & $H(\mathrm{~m})$ & $V\left(\mathrm{~m}^{3}\right)$ \\
\hline Mean & 18.1 & 12.3 & 0.1926 \\
Min & 8.8 & 6.2 & 0.0251 \\
Max & 39.4 & 22.7 & 1.0612 \\
S.D. & 6.5 & 3.2 & 0.1962 \\
\hline
\end{tabular}

$d b h$ is the diameter at breast height; $H$ is the total tree height; $V$ is the total tree volume.

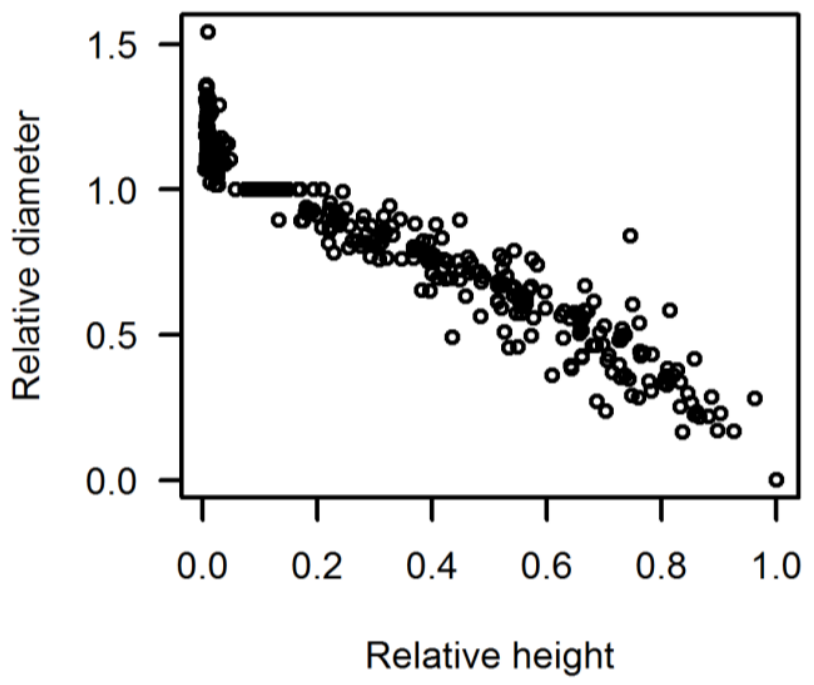

Fig. 2 Data points of relative diameter and relative height. 


\subsubsection{Taper function proposed by Fang et al (2000)}

The exponential-segmented-compatible model assumes that the tree stem has three sections with different form factors. The compatible function has three equations: a taper function, a total stem volume equation and a merchantable volume equation. They are expressed:

Taper function:

$d=c_{1} \sqrt{H^{\left(k-b_{1}\right) / b_{1}} \cdot(1-q)^{(k-\beta) / \beta} \cdot \alpha_{1}^{I_{1}+I_{2}} \cdot \alpha_{2}^{I_{2}}}$

where $I_{1}=1$, if $p_{1} \leq q \leq p_{2} ; 0$ otherwise;

$$
I_{2}=1 \text {, if } p_{2} \leq q \leq 1 ; 0 \text { otherwise }
$$

$p_{1}$ and $p_{2}$ are the relative height from the ground level where the two inflection points assumed in the model occur.

$$
\begin{aligned}
& \beta=b_{1}^{1-\left(I_{1}+I_{2}\right)} \cdot b_{2}^{I_{1}} \cdot b_{3}^{I_{2}}, \alpha_{1}=\left(1-p_{1}\right)^{\frac{\left(b_{2}-b_{1}\right) \cdot k}{b_{1} \cdot b_{2}}}, \alpha_{2}=\left(1-p_{2}\right)^{\frac{\left(b_{3}-b_{2}\right) \cdot k}{b_{2} \cdot b_{3}}} \\
& r_{0}=\left(1-h_{s t} / H\right)^{k / b_{1}}, r_{1}=\left(1-p_{1}\right)^{k / b_{1}}, r_{2}=\left(1-p_{2}\right)^{k / b_{2}} \\
& c_{1}=\sqrt{\frac{a_{0} \cdot D^{a_{1}} \cdot H^{a_{2}-k / b_{1}}}{b_{0}\left(r_{0}-r_{1}\right)+b_{2}\left(r_{1}-\alpha_{1} \cdot r_{2}\right)+b_{3} \cdot \alpha_{1} \cdot r_{2}}}
\end{aligned}
$$

Merchantable volume equation:

$$
v=c_{1}^{2} \cdot H^{k / b_{1}} \cdot\left[b_{1} \cdot r_{0}+\left(I_{1}+I_{2}\right) \cdot\left(b_{2}-b_{1}\right) \cdot r_{1}+I_{2} \cdot\left(b_{3}-b_{2}\right) \cdot \alpha_{1} \cdot r_{2}-\beta \cdot(1-q)^{k / \beta} \cdot \alpha_{1}^{I_{1}+I_{2}} \cdot \alpha_{2}^{I_{2}}\right]
$$

Total volume equation:

$$
V=a_{0} \cdot D^{a_{1}} \cdot H^{a_{2}}
$$

Where $d=$ top diameter with bark at height $h(\mathrm{~cm})$;

$D$ is the diameter at breast height $(1.3 \mathrm{~m}$ aboveground, $\mathrm{cm})$;

$H=$ total tree height (m);

$h=$ height aboveground to top diameter $d(\mathrm{~m})$;

$h_{s t}=$ stump height $(\mathrm{m})$;

$v=$ merchantable volume with bark from the stump to the height $h\left(\mathrm{~m}^{3}\right)$; 
$V=$ total tree volume $\left(\mathrm{m}^{3}\right)$

$k=\pi / 40000$, a metric constant for converting from the diameter squared in $\mathrm{cm}^{2}$ to cross-section area in $\mathrm{m}^{2}$;

$q=h / H$.

\subsubsection{Modelling}

The compatible system of Fang et al. (2000) has two components: a taper function and a total volume equation. The system is composed by the endogenous variables (variables included on the left-hand side of the equations) $d$ and $v$, which are assumed to be determined by the model structure. The remaining variables - $D, H, h$, and $h_{s t}$ - are exogenous, i.e., they are independent variables. An endogenous variable in one equation of the system can also appear on the right-hand side of the other equation.

The compatibility between the taper and the total volume equation does not depend on the process of parameter estimation, so different methodologies can be used to fit the systems. For the Fang et al. (2000) function, there are three possibilities: (i) estimation of the parameters of the taper function, and recovery of the implied total volume equation; (ii) estimation of the parameters of the total volume equation using the total volume observations, substitution of the estimated parameters in the system, and fitting the remaining parameters; or (iii) estimation of all the parameters of the system simultaneously. With options i) and ii), it is easier to achieve convergence on the parameter estimates, and provide the best estimate of diameter at a certain height or of total volume, depending on which equation is prioritized; however, this may increase the bias and the standard error of the other equation. Option iii) reduces the total system squared error, that is, they simultaneously minimize both diameter at different heights and volume prediction errors. The selection of the fitting option will depend on the forest manager, who should decide if the major use for the system will be for estimating total volume, followed by volumes in size assortments (or vice versa), or a mixture between them. In this study, we selected the simultaneous fitting option.

The number of observations in each equation are not equal because there is more than one diameter observation for each tree but only one observation for total stem volume. However, the simultaneous fitting of both equations requires the number of observations of the two endogenous variables ( $d$ and $v)$ to be equal. To solve this problem we created a special structure for the data: the total volume of the tree was assigned to each diameter observation on the same tree. The inverse of the number of observations in each tree $\left(n_{i}\right)$ was then used as weight of the total volume in the fitting process.

Estimation of the parameters was carried out with the MODEL procedure of SAS/ETS ${ }^{\circledR}$ (SAS Institute Inc, 2007), in which several methods of parameter estimation are available. We used the nonlinear 
seemingly unrelated regression (NSUR) technique, in which the random errors of the equations are correlated but the equations are not really simultaneous (none of the endogenous variables in one equation of the system appears as dependent on the left-hand side of the other equation).

\subsubsection{Stand-level volume model construction}

To simplify the stand-level volume estimation, the volume ratio approach was used. This approach was firstly introduced by Burkhart (1977) and its use requires fitting a total stand volume equation $\left(V_{s}\right)$ and a stand volume ratio equation $\left(R_{i}\right)$. As Gregoire and Schabenberger (1996) pointed out, both terms $\left(R_{i}\right.$ and $\left.V_{s}\right)$ should be included in the same expression, in which case the total volume becomes a special case of the volume ratio equation when the top diameter limit is equal to zero. Therefore, a composite model including stand total volume and a volume ratio equation to estimate merchantable stand volume to a top diameter limit was fitted.

The commonly used allometric model, which includes stand basal area $\left(G, \mathrm{~m}^{2} \cdot \mathrm{ha}^{-1}\right)$ and dominant height $\left(H_{d}, \mathrm{~m}\right.$, the average height of the 100 largest trees per hectare) as independent variables, was selected to determine the total stand volume. A modification of the exponential ratio model originally developed by Van Deusen et al. (1981) was selected as volume ratio equation. This model was developed for individual trees; therefore, the original tree variables were replaced by equivalent stand variables (tree height was replaced by dominant height and diameter at breast height by quadratic mean diameter).

$V_{s}=c_{0} \cdot G^{c_{1}} \cdot H_{d}^{c_{2}} \cdot \exp \left(c_{3} \cdot d_{i}^{c_{4}} \cdot d_{g}^{c_{5}}\right)$

Where $V_{s}$ is the merchantable stand volume $\left(\mathrm{m}^{3} \cdot \mathrm{ha}^{-1}\right)$ to a top diameter $d_{i} ; G$ is the stand basal area $\left(\mathrm{m}^{2} \cdot \mathrm{ha}^{-1}\right) ; H_{d}$ is the dominant height $(\mathrm{m}) ; d_{g}$ is the quadratic mean diameter $(\mathrm{cm})$ and $c_{i}$ are parameters to be fitted.

Total and merchantable stand volumes were calculated by aggregating tree volumes (upper limit diameters ranging between 0 and $30 \mathrm{~cm}$ ) calculated by using the fitted model proposed by Fang et al. (2000) (equations 3 and 4) for each tree in each one of the 74 nested circular plots.

\subsubsection{Multicollinearity, autocorrelation and heteroscedasticity}

There are several problems associated with stem taper and volume equation analysis that violate the fundamental least squares assumption of independence and equal distribution of errors with zero mean and constant variance: multicollinearity, autocorrelation and heteroscedasticity are three of the most important. Although the least squares estimates of regression coefficients remain unbiased and consistent under the presence of multicollinearity, autocorrelation and heteroscedasticity, they are no longer efficient. These problems may seriously affect the standard errors of the coefficients, invalidating statistical tests using $t$ or $F$ distributions and confidence intervals. Thus, appropriate 
statistical procedures should be used in model fitting to avoid the problems of heteroscedasticity and autocorrelated errors, and models with low multicollinearity should be selected whenever possible.

Multicollinearity refers to the existence of high intercorrelations among the independent variables in multiple linear or nonlinear regression analysis, because some of the variables represent or measure similar phenomena. One of the main sources of multicollinearity is the use of overcomplicated models that include several polynomial and cross-product terms. However, the model of Fang et al. (2000) does not include these terms, so multicollinearity is not a real problem.

Since the database contains multiple observations for each tree (i.e., hierarchical data), one many expect autocorrelation within the residuals of each individual, which violates the assumption of independent error terms. We have corrected the autocorrelation using a modified continuous autoregressive error structure $(\operatorname{mCAR}(x))$, which accounted for the distance between measurements and the relative position on the stem they were taken from. To account for first-order autocorrelation, a mCAR(1) model form which expands the error terms in the following way can be used:

$e_{i j}=d_{1} \rho_{1}^{h_{i j}-h_{i j-1}} e_{i j-1}+\varepsilon_{i j}$

where $e_{i j}$ is the $j$ th ordinary residual on the $i$ th individual (i.e., the difference between the observed and the estimated diameters of the tree $i$ at height measurement $j$ ), $d_{1}=1$ for $j>1$ and it is zero for $j=1$, $\rho_{1}$ is the first-order continuous autoregressive parameter to be estimated, and $h_{i j}-h_{i j-1}$ is the distance separating the $j$ th from the $j$ th-1 observations within each tree, $h_{i j}>h_{i j-1}$. The $\rho_{1}$ parameter was expanded in the following way using dummy variables to account for the position of the measurements along the stem: $\rho_{1}+\rho_{11} d_{11}+\rho_{12} d_{12}$, where $d_{11}$ and $d_{12}$ are either 1 or 0 , depending on the relative position of the measurements. The relative positions were analyzed graphically for each model before correcting for autocorrelation by calculating the correlations between raw residuals and residuals from previous observations within each tree, for relative height classes.

In mCAR(2) the error terms are expanded as:

$e_{i j}=d_{1} \rho_{1}^{h_{i j}-h_{i j-1}} e_{i j-1}+d_{2} \rho_{2}^{h_{i j}-h_{i j-2}} e_{i j-2}+\varepsilon_{i j}$

And consequently, $d_{2}=1$ for $j>2$ and it is zero for $j \leq 2, \rho_{2}$ is the second-order continuous autoregressive parameter to be estimated, and $h_{i j}-h_{i j-2}$ is the distance separating the $j$ th from the $j$ th- 2 observations within each tree, $h_{i j}>h_{i j-2}$. The autocorrelation parameters were expanded in the same way as in mCAR(1). In both cases $\varepsilon_{i j}$ are independent normal random variables with a mean value of zero. 
To test for the presence of autocorrelation we have used the Durbin-Watson test. The modified $\operatorname{mCAR}(x)$ error structure was programmed in the MODEL procedure of SAS/ETS ${ }^{\circledR}$ (SAS Institute Inc, 2007), which allows for dynamic updating of the residuals.

Forest modellers are often faced with the problem of heteroscedasticity in their data, which would lead to non-minimum variance parameter estimates and unreliable predictor intervals. This is especially true in the construction of volume equations. The solution to the problem is to weight each observation during the fitting process by the inverse of its variance $\left(\sigma_{i}^{2}\right)$. If the variance is unknown, the problem becomes one of estimating the proper weight for each observation. Although several assumptions about the nature of the heteroscedasticity problem in the construction of volume equations that depend on two variables were suggested, it is often assumed that the variance of the error of the $i$ th individual can be modelled as a power function of $D_{i}^{2} H_{i}$ for individual tree volumes (e.g. Furnival, 1961; Alder, 1980), i.e., $\sigma_{i}^{2}=\left(D_{i}^{2} H_{i}\right)^{k_{1}}$ and $G H_{d}$ for stand volumes, i.e., $\sigma_{i}^{2}=\left(G_{i} H_{d_{i}}\right)^{k_{2}}$. The most reasonable values of the exponential terms $k_{j}$ should provide the most homogeneous studentized residual plot. It can be obtained by iteratively testing different values of $k$ (e.g., from 0.1 to 2), or optimizing the value using the method suggested by Harvey (Harvey, 1976), which consists of using the estimated errors of the unweighted model $\left(\hat{e}_{i}\right)$ as the dependent variable in the error variance model.

The $k_{j}$ parameters were estimated using linear regression. The weighting factor for heteroscedasticity $1 /\left(X_{i}\right)^{k_{j}}$, along with the correction for the special structure of the data that we used, were multiplied and programmed in the MODEL procedure of SAS/ETS ${ }^{\circledR}$ by specifying resid.V $=\operatorname{resid.V} / \sqrt{n_{i}\left(X_{i}\right)^{k_{j}}}$, where $n_{i}$ is the number of observations in each tree (note that the residual - resid.V - is multiplied by $1 / \sqrt{n_{i}\left(X_{i}\right)^{k_{j}}}$ because the latter is acting on the residual before it is squared).

\subsection{Results and discussion}

\subsubsection{Taper function}

First, the taper function was fitted without autocorrelation. Strong linear relationships between the residuals in diameter and lag 1-residuals and lag 2-residuals were found (Fig. 3a, 3b). This indicates that there is a strong autocorrelation among the multiple observations from each tree. Therefore, a second-order continuous autoregressive error structure (mCAR2) was conducted to correct the autocorrelation. After the correction, the linear trend between the residuals in diameter and lag 1residuals and lag 2-residucals disappeared (Fig. 3c, 3d). Although the fitted curve shapes were not significantly different from the model without autocorrelation, the autocorrelation correction could improve the interpretation of the statistical properties of the model (Diéguez-Aranda et al., 2006). 
The coefficient estimates after autocorrelation and their approximated standard errors are given in Table 2, and the goodness-of-fit statistics of the taper function and the total stem volume are shown in Table 3. All the coefficients were significant at a 0.001 level. The fitted system proposed by Fang et al. (2000) showed very good fitness of the data, and could explain more than $98 \%$ of the total variations of $d$ and $V$.

Table 2 Coefficient estimates for the taper functions

\begin{tabular}{llll}
\hline Coefficients & Estimates & $\begin{array}{l}\text { Standard } \\
\text { error }\end{array}$ & $p$ \\
\hline$a_{0}$ & $7.1 \times 10^{-5}$ & $3.5 \times 10^{-6}$ & $<0.001$ \\
$a_{1}$ & 1.7512 & 0.0288 & $<0.001$ \\
$a_{2}$ & 1.0417 & 0.0402 & $<0.001$ \\
$b_{1}$ & $4.2 \times 10^{-6}$ & $3.4 \times 10^{-7}$ & $<0.001$ \\
$b_{2}$ & $3.1 \times 10^{-5}$ & $5.3 \times 10^{-7}$ & $<0.001$ \\
$b_{3}$ & $3.2 \times 10^{-5}$ & $1.3 \times 10^{-6}$ & $<0.001$ \\
$p_{1}$ & 0.0202 & 0.0012 & $<0.001$ \\
$p_{2}$ & 0.6577 & 0.1548 & $<0.001$ \\
$\rho_{1}$ & 0.7483 & 0.0443 & $<0.001$ \\
$\rho_{2}$ & 0.3900 & 0.0680 & $<0.001$ \\
\hline
\end{tabular}

Table 3 Goodness-of-fit statistics of the taper function and volume model

\begin{tabular}{lllc}
\hline & RMSE & $\mathrm{R}_{\text {adj }}^{2}$ & $\begin{array}{l}\text { Weighting } \\
\text { factor }\end{array}$ \\
\hline Eq. (2) & 1.0481 & 0.9856 & --- \\
Eq. (4) & 0.0243 & 0.9878 & $1 /\left(D_{i}^{2} H_{i}\right)^{1.2987}$ \\
\hline
\end{tabular}

Although the goodness-of-fit could reflect the behavior of the data evaluated, they may not indicate the best practical uses because the larger residuals compensated the smaller residuals (DiéguezAranda et al., 2006). Therefore, the goodness should be determined based on the analysis of the model's behavior for different stem sections. For this purpose, the residuals of diameter were plotted against the relative height classes with an interval of $10 \%$, and the residuals of volume were plotted against the diameter classes with an interval of $5 \mathrm{~cm}$ (Fig. 4). The residuals in diameter ranged from $4.1 \mathrm{~cm}$ to $5.6 \mathrm{~cm}$ with an average of $0.02 \mathrm{~cm}$. This demonstrates that on average the Fang et al. (2000) function performed well in the prediction of bole diameter. As expected, the prediction of diameter for lower section closest to the ground was less precise than that of upper sections. This has also been observed in other tree species using different taper functions (Rojo et al., 2005; Diéguez-Aranda et al., 2006). This is mainly due to the irregular shape of the stem section close to the ground level. The taper function had the most accurate prediction in diameter for relative height classes between $15 \%$ 
and $35 \%$ because of regular stem shape between these heights. For relative height classes higher than $35 \%$, the precision decreased with the increase of the relative height.

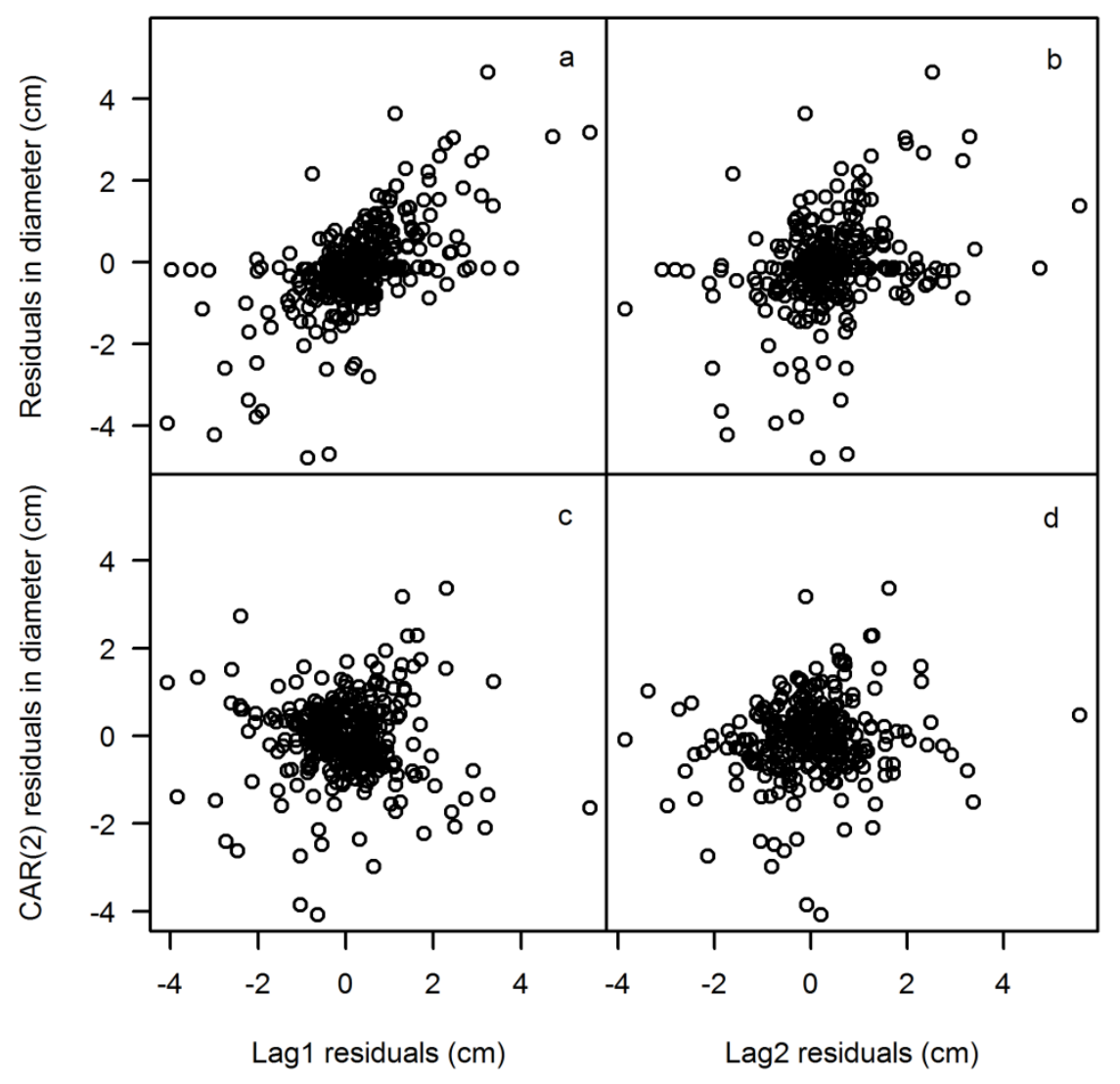

Fig. 3 Residuals in diameter plotted against lag1 and lag2 without autocorrelation (a, b), and against lag 1 and lag2 with continuous time autoregressive error structure of second order (CAR2).

The taper function also performed well in total tree volume prediction, with the average residuals ranging from $-6 \%$ to $8 \%$ for different diameter classes (Fig. 4b). However, we do not recommend the application of our model for trees with diameter larger than $30 \mathrm{~cm}$ due to the small sample size for trees of these dimensional classes. Moreover, the Chinese fir plantations in our study area are commonly harvested at the age of 20-30 years old, when only few trees larger than $30 \mathrm{~cm}$ can be found. Therefore, our model is dimensionally valid for most of the dimensional classes during the rotation period in the study area.

\subsubsection{Stand-level merchantable volume model}

The composite Eq. (5) was fitted to estimate stand-level merchantable volume. All the coefficients were significant at 0.001 level (Table 5). The model explained more than $99 \%$ of the variance of stand volume with a RMSE of $4.3 \mathrm{~m}^{3} \cdot \mathrm{ha}^{-1}$. When $d_{i}$ equals to zero, the stand merchantable volume equals to the total stand volume. The results highlighted the efficiency of total stand-level volume estimation by using the stand-level model developed here, as $G$ can efficiently be estimated by using angle-count 
techniques (i.e., with a dendrometer) and, similarly, the dominant height can be more efficiently acquired than individual tree heights. For example, the average measuring time of forest inventory among the 74 plots was about 33 minutes, not including tree harvest in some plots. However, it took just 7 minutes to measure stand basal area using dendrometer and dominant heights.

Boxplot of residuals against the volume classes were drawn in Fig. 5. The residuals of different volume classes ranged from $-1.8 \mathrm{~m}^{3} \cdot \mathrm{ha}^{-1}$ to $2.9 \mathrm{~m}^{3} \cdot \mathrm{ha}^{-1}$ with a mean value of $0.03 \mathrm{~m}^{3} \cdot \mathrm{ha}^{-1}$ (Fig. 5). Eq. (5) had the most accurate prediction for volume class $50-100 \mathrm{~m}^{3} \cdot \mathrm{ha}^{-1}$, while it had the least accurate prediction for volume class $0-50 \mathrm{~m}^{3} \cdot \mathrm{ha}^{-1}$. Eq. (5) overestimated stand merchantable volume for volume class $150-200 \mathrm{~m}^{3} \cdot \mathrm{ha}^{-1}$, but slightly underestimated merchantable volume for other volume classes.
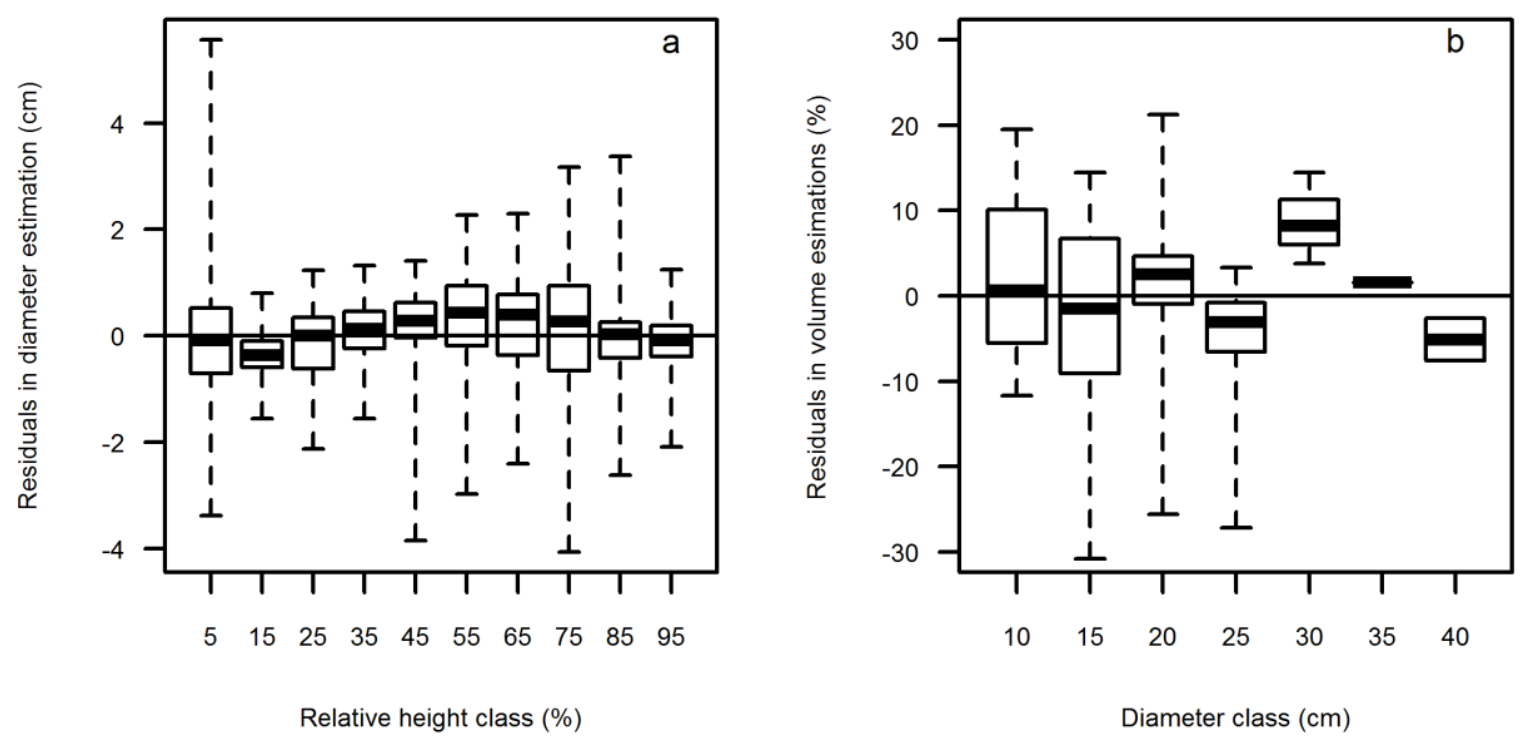

Fig. 4 Boxplot of: (a) residuals in diameter against relative height classes and (b) residuals in volume estimations against diameter classes. The horizontal line represents 0 in residuals.

Table 4 Coefficient estimates of stand-level volume model Eq. (5).

\begin{tabular}{lrlllll}
\hline Coefficients & Estimates & $\begin{array}{l}\text { Approx. } \\
\text { S.E. }\end{array}$ & $p$ & $\mathrm{R}^{2}$ adj & RMSE & $\begin{array}{l}\text { Weighting } \\
\text { factor }\end{array}$ \\
\hline$c_{0}$ & 1.2936 & 0.0361 & $<0.001$ & & & \\
$c_{1}$ & 0.9808 & 0.0029 & $<0.001$ & & & \\
$c_{2}$ & 0.5846 & 0.0119 & $<0.001$ & & & \\
$c_{3}$ & -0.7332 & 0.0736 & $<0.001$ & 0.9953 & 4.2997 & $1 /\left(G_{i} H_{d_{i}}\right)^{0.7761}$ \\
$c_{4}$ & 3.8938 & 0.0308 & $<0.001$ & & & \\
$c_{5}$ & -3.8075 & 0.0466 & $<0.001$ & & & \\
\hline
\end{tabular}

S.E. is standard error and RMSE is root mean square error. 


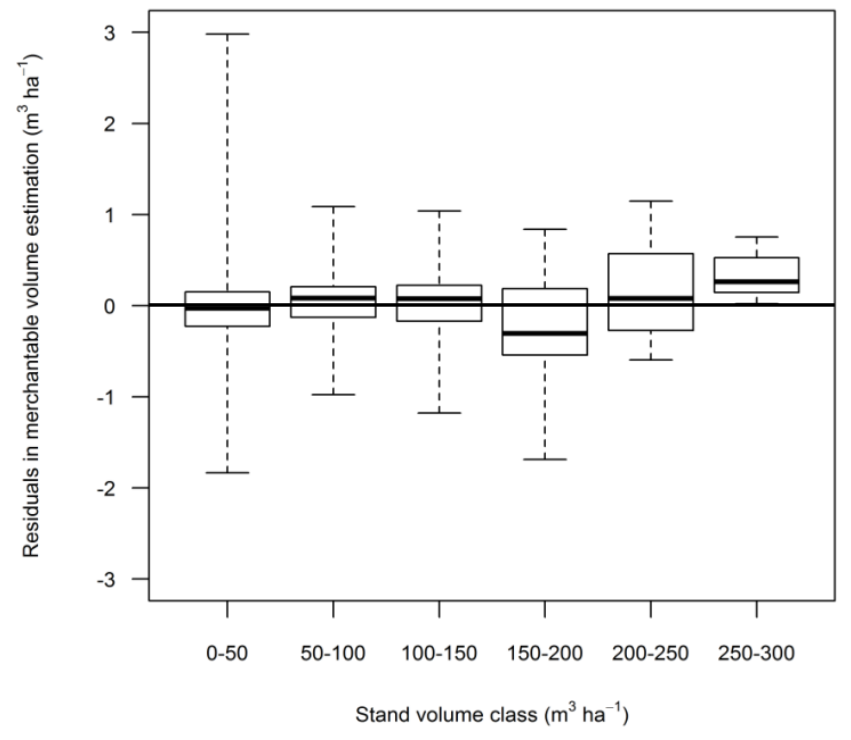

Fig. 5 Boxplot of residuals of Eq. (5) in stand volume estimation against stand volume classes.

\subsubsection{Model performance comparisons in the estimation of stand level merchantable volume}

Two practical examples are presented to test the performance of the stand level model in predicting the stand merchantable volume. The first example defines the top diameter as zero, in which case, the merchantable volume equals total stand volume, which was presented in the $x$-axis (Fig.6 a). The measured stand volume calculated using Eq. (4) for each individual tree considering the expansion factors was presented in $y$-axis. High correlation was found between the two estimates $\left(\mathrm{R}^{2}>0.99\right)$. The second example was to predict the merchantable volume according to the local top diameter of 7 $\mathrm{cm}$. Similarly, there was a strong relationship between the measured merchantable and predicted merchantable volume $\left(\mathrm{R}^{2}>0.99\right.$, Fig.6 b). These results highly demonstrated the wide application of Eq. (5) in predicting stand merchantable volume for different top diameters. The results also highlighted the simplification of using Eq. (5) to total stand volume by setting top diameter to zero. The calculated ratio of merchantable stand volume and total stand volume was $94.5 \%$ (range from $88.0 \%$ to $99.0 \%$ ) based on the 74 plots if the top diameter was set to $7 \mathrm{~cm}$.

\subsubsection{Construction of stand-level volume table}

To make our models more applicable, a stand-level volume table was constructed for Chinese fir plantation for local study area using stand basal area and dominant height based on the Eq. (5). As mentioned above, stand basal area could be easily measured using a dendrometer without moving up and down in the stand, and just measure few heights of dominant trees based different plot sizes. Afterwards, local forest manager could "read" the stand volume directly from Table 5. Stand merchantable volume could be also estimated by multiplying the ratio of stand merchantable volume and total stand volume $(94.5 \%)$. 

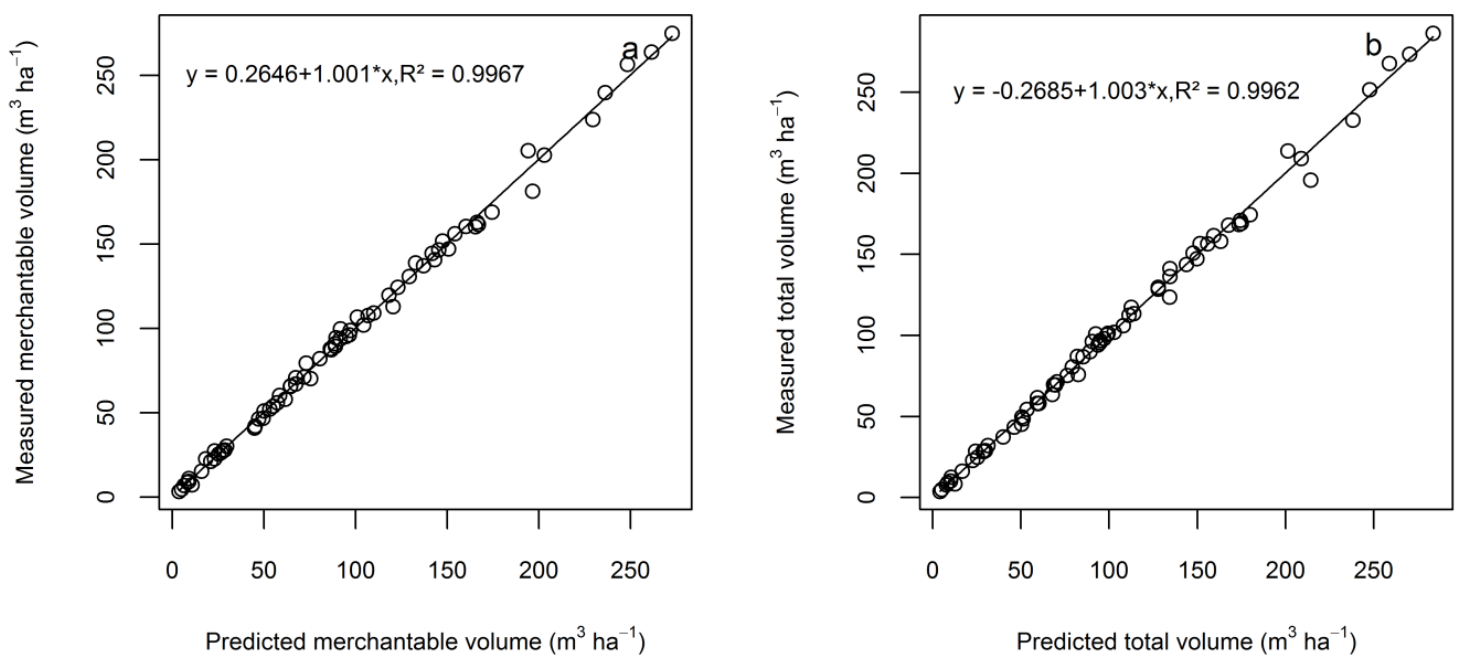

Fig. 6 The relationship between (a) measured total stand volume and predicted total stand volume, (b) measured stand merchantable volume and predicted stand merchantable volume for local top diameter of $7 \mathrm{~cm}$.

\subsection{Conclusions}

The compatible taper function proposed by Fang et al. (2000) was analysed in this study and it fitted well to our data. A modified second-order continuous autoregressive error structure corrected the inherent serial autocorrelation of different observations in one tree. The diameter and volume were fitted simultaneously after autocorrelation correction. Fang et al. (2000) performed well in diameter and total stem volume prediction. A modified stand-level merchantable volume (Eq. 5) based on the volume ratio approach was developed including basal area, dominant height, quadratic mean diameter and top diameter as regressors. One quarter of the measuring time of total trees in each inventory plot was used when measuring base area and dominant height for total stand volume, demonstrating the efficiency of using the stand-level volume model to estimate stand merchantable volume and total stand volume. A stand volume table was also proposed for local forest managers to "read" stand volume. This could be a useful tool for local forest managers to increase their work efficiency and simplify the fieldwork. 
Table 5 Stand-level volume table for Chinese fir plantations

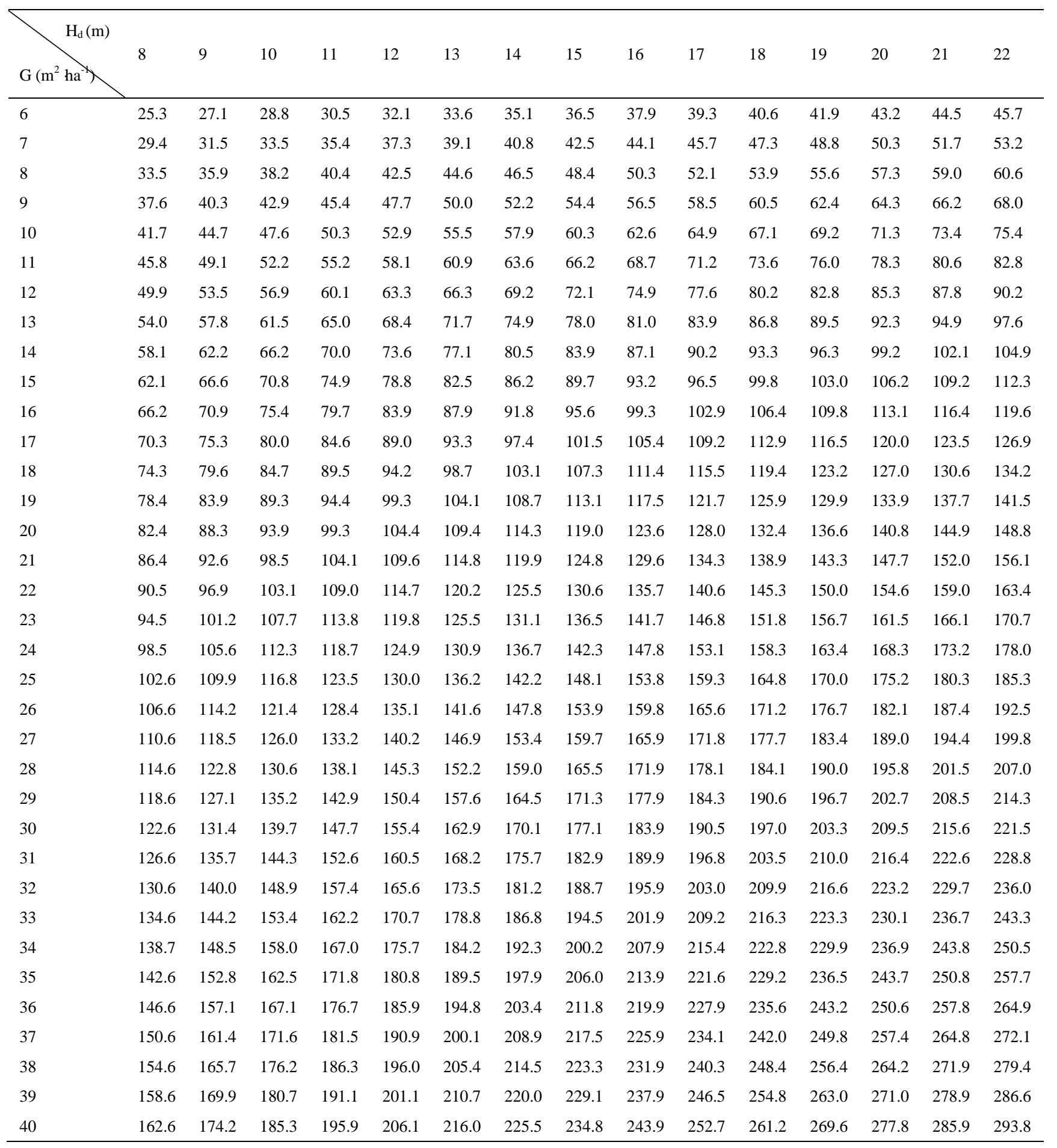

$\mathrm{G}$ is stand basal area $\left(\mathrm{m}^{2} \cdot \mathrm{h}^{-1}\right), \mathrm{H}_{\mathrm{d}}$ is the dominant height of the 100 largest tree per hectare $(\mathrm{m})$. 


\section{Acknowledgements}

The study was supported by a project of Sino-German Cooperation on Innovative Technologies and Service Capacities of Multifunctional Forest Management (Lin ${ }^{2}$ Value 033L049-CAFYBB2012013), funded by the Federal Ministry of Education and Research (BMBF) and the Chinese Academy of Forestry. We would like to thank Dr. Hans Fuchs, Dr. Tosten Vor, M.Sc. Sabine Schreiner, Dr. Haijun Yang and M.sc. Dengkui Mo from the Georg-August-University Göttingen for the plot design and fieldwork support. We would like to thank prof. Yuanchang Lu from Chinese Academy of Forestry for financial support for fieldwork. Furthermore, we want to thank Director An'guo Fan, Mr. Bailing Ding, Miss Yue'e Chu from the Shitai Forest bureau for their kind organization of the fieldwork. Thanks also to Mr. Xiaozhu Wang and Mr. Hongbing Ruan for their fieldwork support.

\subsection{References}

Alder D. 1980. Estimación del volumen forestal y predicción del rendimiento. Estudio FAO: Montes 22: 80 .

Barrio-Anta M, Sixto-Blanco H, Viñas IC-RD, et al. 2008. Dynamic growth model for I-214 poplar plantations in the northern and central plateaux in Spain. Forest Ecology and Management 255: 1167-1178.

Barrio Anta M, Diéguez-Aranda U, Castedo-Dorado F, et al. 2007. Merchantable volume system for pedunculate oak in northwestern Spain. Annals of Forest Science 64: 511-520.

Bi H, Hamilton F. 1998. Stem volume equations for native tree species in southern New South Wales and Victoria. Australian Forestry 61: 275-286.

Burkhart HE. 1977. Cubic-foot volume of loblolly pine to any merchantable top limit. Southern Journal of Applied Forestry 1: 7-9.

Cao QV, Burkhart HE, Max TA. 1980. Evaluation of two methods for cubic-volume prediction of Loblolly Pine to any merchantable limit. Forest Science 26: 71-80.

Chen GS, Yang ZJ, Gao R, et al. 2013. Carbon storage in a chronosequence of Chinese fir plantations in southern China. Forest Ecology and Management 300: 68-76.

Clutter JL. 1980. Development of Taper Functions from Variable-Top Merchantable Volume Equations. Forest Science 26: 117-120.

Cutini A, Chianucci F, Manetti MC. 2013. Allometric relationships for volume and biomass for stone pine (Pinus pinea L.) in Italian coastal stands. Iforest-Biogeosciences and Forestry 6: 331-337.

Demaerschalk JP. 1972. Converting volume equations to compatible taper equations. Forest Science 18: 241-245. 
Diéguez-Aranda U, Castedo-Dorado F, Álvarez-González JG, et al. 2006. Compatible taper function for Scots pine plantations in northwestern Spain. Canadian Journal of Forest Research 36: 11901205.

Fang ZX, Borders BE, Bailey RL. 2000. Compatible volume-taper models for loblolly and slash pine based on a system with segmented-stem form factors. Forest Science 46: 1-12.

Furnival GM. 1961. An index for comparing equations used in constructing volume tables. Forest Science 7: 337-341.

Geng TS, Wang HH. 2011. Research on the water and soil conservation in Shitai County of Anhui Province. Journal of Anhui Agriculture Science 39: 451-452, 482 (in Chinese with English abstract).

Gregoire TG, Schabenberger O. 1996. A non-linear mixed-effects model to predict cumulative bole volume of standing trees. Journal of Applied Statistics 23: 257-272.

Harvey AC. 1976. Estimating regression models with multiplicative heteroscedasticity. Econometrica 44: 461-465.

Hui GY, von Gadow K. 1997. A generalized taper function for Cunninghamia lanceolata. Forstwissenschaftliches Centralblatt 116: 315-321.

Jia Z, Zhang J, Wang X, et al. 2009. Report for Chinese forest resource-The $7^{\text {th }}$ national forest inventory. Beijing(in Chinese): China Forestry Publishing House. 2p.

Kozak A. 1988. A variable-exponent taper equation. Canadian Journal of Forest Research 18: 13631368.

Kozak A. 2004. My last words on taper equations. The Forestry Chronicle 80: 507-515.

Lu CM. 2010. Rock-soil geochemical features for Dashan Area, Shitai, Anhui. Geology of Anhui 20: 120-125 (in Chinese with English abstract).

Menéndez-Miguélez M, Canga E, Álvarez-Álvarez P, et al. 2014. Stem taper function for sweet chestnut (Castanea sativa Mill.) coppice stands in northwest Spain. Annals of Forest Science 71: 761-770.

Navar J, Rodriguez-Flores FdJ, Dominguez-Calleros PA. 2013. Taper functions and merchantable timber for temperate forests of northern Mexico. Annals of Forest Research 56: 165-178.

Pretzsch H. 2009. Forest Dynamics, Growth, and Yield: Springer Berlin Heidelberg. 187p.

Reed DD, Green EJ. 1984. Compatible stem taper and volume ratio equations. Forest Science 30: 977-990.

Rojo A, Perales X, Sanchez-Rodriguez F, et al. 2005. Stem taper functions for maritime pine (Pinus pinaster Ait.) in Galicia (Northwestern Spain). European Journal of Forest Research 124: 177186.

SAS Institute Inc. 2007. SAS user's guide, version 9.2. SAS Institute Cary, NC. 
Tasissa G, Burkhart HE, Amateis RL. 1997. Volume and Taper Equations for Thinned and Unthinned Loblolly Pine Trees in Cutover, Site-Prepared Plantations. Southern Journal of Applied Forestry 21: $146-152$.

Teshome T. 2005. A ratio method for predicting stem merchantable volume and associated taper equations for Cupressus lusitanica, Ethiopia. Forest Ecology and Management 204: 171-179.

Turski M, Beker C, Kazmierczak K, et al. 2008. Allometric equations for estimating the mass and volume of fresh assimilational apparatus of standing scots pine (Pinus sylvestris L.) trees. Forest Ecology and Management 255: 2678-2687.

Van Deusen PC, Sullivan AD, Matvey TG. 1981. A Prediction System for Cubic Foot Volume of Loblolly Pine Applicable Through Much of Its Range. Southern Journal of Applied Forestry 5: 186-189.

Wu ZL. 1984. Chinese-fir Beijing: China Forestry Publishing House (in Chinese). 583p.

Zhao MF, Xiang WH, Peng CH, et al. 2009. Simulating age-related changes in carbon storage and allocation in a Chinese fir plantation growing in southern China using the 3-PG model. Forest Ecology and Management 257: 1520-1531. 
Chapter IV: Development of a taper function and stand-level merchantable volume model 


\section{Chapter V}

\section{Development of stand density management diagrams for Chinese fir plantations}

Xiaolu Tang ${ }^{*}$, César Pérez-Cruzado, Torsten Vor, Lutz Fehrmann, Juan Gabriel Álvarez-González, Christoph Kleinn

Status: in press in "Forestry"

Contribution by Xiaolu Tang: $80 \%$

- Design the manuscript

- Collect the data

- Analyze and model the data

- Write and revise the manuscript

*Corresponding author: xtang@gwdg.de 
Chapter IV: Development of a taper function and stand-level merchantable volume model 


\title{
Development of stand density management diagrams for Chinese fir plantations
}

Xiaolu Tang ${ }^{1, *}$, César Pérez-Cruzado ${ }^{1}$, Torsten Vor $^{2}$, Lutz Fehrmann ${ }^{1}$, Juan Gabriel ÁlvarezGonzález $^{3}$, Christoph Kleinn ${ }^{1}$

${ }^{1}$ Chair of Forest Inventory and Remote Sensing, Georg-August-Universität Göttingen, Büsgenweg 5, 37077 Göttingen, Germany

${ }^{2}$ Department of Silviculture and Forest Ecology of the Temperate Zones, Georg-August-Universität Göttingen, Büsgenweg 1, 37077 Göttingen, Germany

${ }^{3}$ Departamento de Ingeniería Agroforestal, Universidad de Santiago de Compostela. Escuela Politécnica Superior, Campus Universitario, 27002 Lugo, Spain

\begin{abstract}
Stand density management diagrams (SDMDs) are powerful tools for the design, display and evaluation of different density management regimes derived without long-term thinning trials in the field. The SDMDs can be used to predict the future stand development based on specific thinning schedules and to optimize the forest management. Even though Chinese fir (Cunninghamia lanceolata [Lamb.] Hook) covers the first largest area in the China's plantations with an area of 8.54 million ha, there is no management tool for a proper optimization of different management regimes. In this study, SDMDs, generated from common one-time inventory data, provided information about the evolution of quadratic mean diameter, stand volume, stem and aboveground biomass with stand development for the widely planted Chinese fir plantations in southern China. A system of four equations was fitted simultaneously to the data collected from 74 inventory plots. The relative spacing index was used to characterize the growing stock. These SDMDs can be easy tools for local forest managers to estimate the stand volume, stem and aboveground biomass, and could be the reference to determine optimum thinning schedules.
\end{abstract}

Keywords: stand density management diagrams, stand volume, biomass, forest management

\subsection{Introduction}

With the development of society and economy and the improvement of people's life, an increasing number of forest products, such as timber and bio-energy, are demanded. To meet these demands,

\footnotetext{
* Corresponding author at: Department of Forest Inventory and Remote Sensing, Georg-August-Universität Göttingen, Büsgenweg 5, 37077 Göttingen, Germany. Tel.: +49 (551) 39 9835; Fax: +49 (551) 39 9787. E-mail address: xtang@gwdg.de (X. Tang)
} 
large-scale afforestation and reforestation activities have been conducted in China during the past decades, resulting in large plantation areas constituting nowadays about one-third of the global forest plantation area (SFA 2008). Chinese fir (Cunninghamia lanceolata [Lamb.] Hook) is one of the most important plantation tree species with good timber quality, fast growth and more than 1000 years of cultivation history in southern China (Chen, et al. 2013; Zhao, et al. 2009). Currently, Chinese fir plantations cover an area of 8.54 million ha, which corresponds to $21 \%$ of the total plantation area in China according to the $7^{\text {th }}$ national forest inventory (Jia, et al. 2009). Chinese fir plantations are usually managed in a clear cutting system with a rotation period of 25 years, with variations from 20 to 30 years depending on the site quality (Wu 1984). Chinese fir is now one of the most important timber species in the Chinese forest product industry. The country has committed to increase its total forest area by 40 million hectare in the next decades, and the number and area of Chinese fir plantations will likely increase as well ( $\mathrm{Hu}$, et al. 2014; $\mathrm{Xu}$ 2011). In order to improve the timber output and economic benefits, as well as ecological functions, a suitable forest management is needed.

Thinning plans are essential to control for tree competition, resulting in an improvement in stand stability and wood quality. To achieve these goals, stand density management diagrams (SDMDs) have widely been used in forest plantation management (Castaño-Santamaría, et al. 2013; CastedoDorado, et al. 2009; Schnell, et al. 2012).

Stand density management, conceptually, is the process to control for tree competition through density regulation to meet different management targets (Newton 1997). Normally, the stand development is displayed by the increase of tree dimensions and the decrease of the number of trees per hectare (Long, et al. 2004). One useful approach to describe the stand development is the application of SDMDs, which integrate the relationship between stand density, stand structure, canopy dynamics and production efficiency. This application links the quantitative silviculture to ecology (Jack and Long 1996). In contrast to long-term observation plots, SDMDs can quickly be adapted to different site conditions and management objectives, overcoming the restrictions of complex and time-consuming measurement series in the field that are commonly focused on specific site conditions and silvicultural targets (Schnell, et al. 2012). Therefore, the application of SDMDs can be considered as one of the most effective methods for the design, display and evaluation of different density management regimes in even-aged stands (Jack and Long 1996). Nevertheless, real observations of field thinning experiments that look into cause-effects mechanisms are certainly the best and most reliable way to determine the thinning design (Schnell, et al. 2012). On the other hand, in absence of long-term observations or experiments, SDMDs offer the possibility of deriving basic stand growth models whenever immediate results with limited resources are needed.

SDMDs represent a system of empirical quantitative functions that illustrate the cumulative effects of various competition processes on tree and stand yield parameters (Newton and Amponsah 2005). The 
main axes usually are the average size of tree attributes (e.g. the height of dominant trees, diameter or volume) and stand density. The first SDMDs was proposed by Ando (1962), who presented competition and yield functions (based on the stand density) and the self-thinning rule in a twodimensional graphical format. Afterwards, yield parameters in the form of stem biomass, total aboveground biomass (Barrio-Anta, et al. 2006), empirical-based volume functions (Newton and Weetman 1994), aboveground bioenergy and cellulose production (Pérez-Cruzado, et al. 2011), have been included in the SDMDs for different forest types. SDMDs were also used to control the shrub growth in early stages of the stand development (Smith 1989), reduce stand susceptibility to pests (Long and Shaw 2005), assess the crown fire potential (Gómez-Vázquez, et al. 2014) and optimize wildlife habitats (Sturtevant, et al. 1996).

Although the importance of stand management in Chinese fir plantations has been highlighted for several decades, there is no realistic, simple and easy-follow operating guidance to implement the management. Thinning is consider as a good management practice to improve stand production in Chinese fir plantations based on some case studies (Liu and Yang 2008; Bingshuan 1989), unfortunately, these approaches remain at a theoretical level. As a result, forest managers and owners are difficult to apply these silvicultural treatments because of the lack of forest decision support tools to design, display, evaluate and optimize stand management according to different purposes. On the other hand, SDMDs can overcome these limitations and allow to simulate different silvicultural alternatives. However, to our knowledge, no SDMD was proposed for Chinese fir plantations yet. Thus, the objective of this study was to develop SDMDs for Chinese fir plantations based on the relative spacing index to characterize stand volume, stem and aboveground biomass. These SDMDs allow the forest managers to estimate the growth and yield parameters of Chinese fir plantations under several management regimes, and implement thinning schedules for a wide range of site qualities and management targets. This study can also fill the gap between the theoretical and practical management in Chinese fir plantations and can be a reference tool to optimize stand management.

\subsection{Materials and methods}

\subsubsection{Study area}

The study was conducted in Shitai county $\left(29^{\circ} 59^{\prime}-30^{\circ} 24^{\prime} \mathrm{N}, 117^{\circ} 12^{\prime}-117^{\circ} 59^{\prime}\right.$ E, Fig.1), Anhui province, China. $80 \%$ of this county is covered by forest. It is a mountainous area with an elevation range of $50 \mathrm{~m}$ to $1000 \mathrm{~m}$ and steep slopes with an average of $66 \%$. The region has a mid-subtropical, humid, mountainous climate with distinct seasonality (Geng and Wang 2011). The annual average temperature is $16{ }^{\circ} \mathrm{C}$ with an annual mean maximum of $40.9{ }^{\circ} \mathrm{C}$ and an annual mean minimum of $13.2{ }^{\circ} \mathrm{C}$ (Lu 2010). The mean annual precipitation is about $1668 \mathrm{~mm}$ with high inter-annual variability, and with about $70 \%$ of the precipitation occurring in flooding seasons (Geng and Wang 2011). The average annual sunshine duration is 1704 hours and evaporative capacity is $1256 \mathrm{~mm}$ (Lu 2010). 

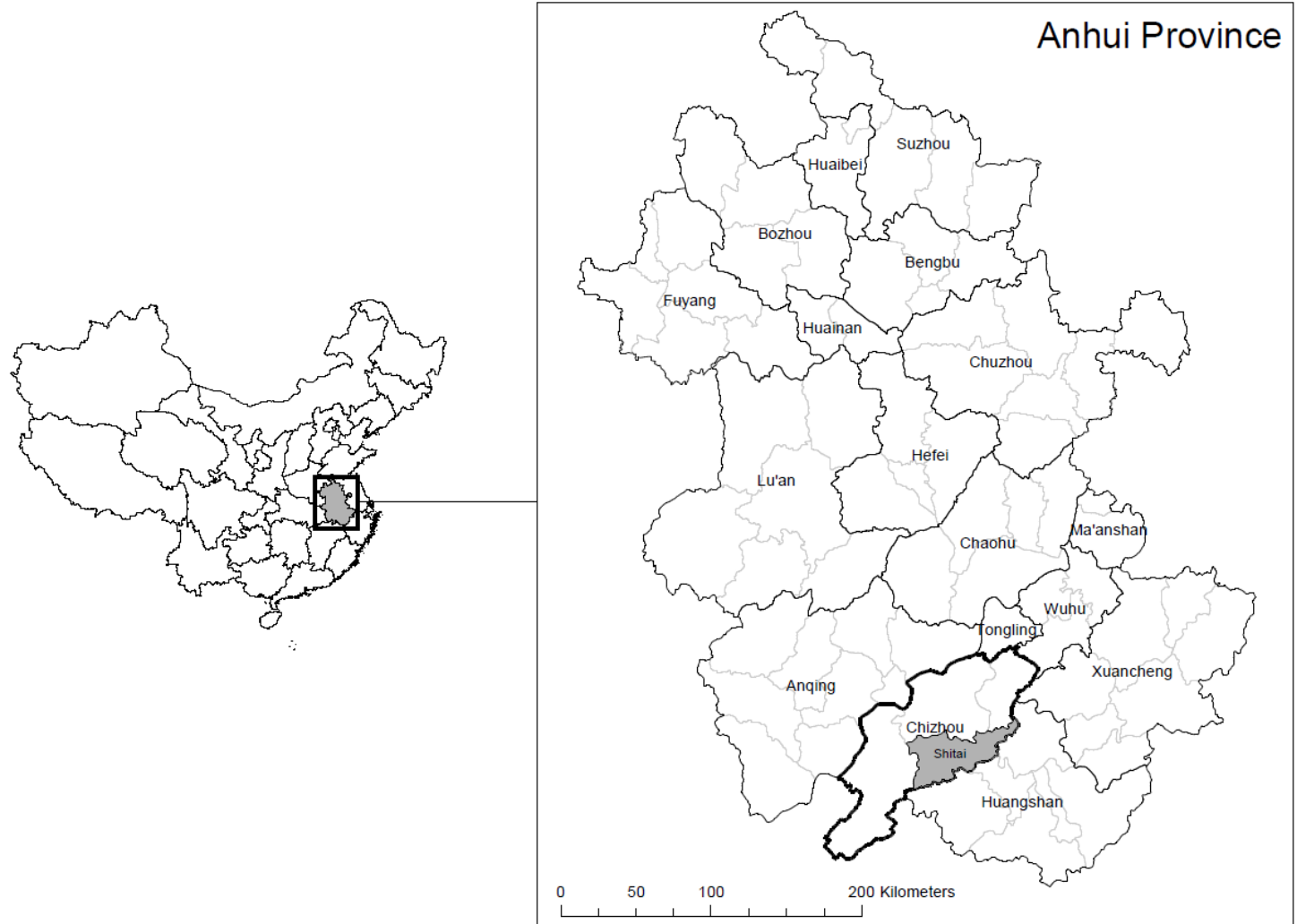

Fig. 1 Location of Shitai County in the southern part of Anhui Province, South-East China.

\subsubsection{Plot design}

This study is a part of the $\operatorname{Lin}^{4}$ carbon project (http://www.lin2value.uni-goettingen.de/), in which three different scales of inventories are distinguished: (1) land use and forest inventory (LUI/FI) that produce information over the whole extent of the sampling frame based on systematic grids $3 \times 3 \mathrm{~km}$; (2) forest management inventory (FMI) for those stands with forest management information with a $500 \times 500 \mathrm{~m}$ systematic grid, which is also part of a Sustainable Forest Management (SFM) Cooperation Project between the Shitai Forest Bureau and the German Development Bank (KfW); and (3) stand inventory of selected stands (SI) with a 100×100 m systematic grid. In the end, 74 nested circular plots in the Chinese fir plantations were established. In circular plots of $6 \mathrm{~m}$ radius, trees were measured for $10 \mathrm{~cm}<\mathrm{dbh}<20 \mathrm{~cm}$ while in $10 \mathrm{~m}$ radius plots, trees with $\mathrm{dbh}>20 \mathrm{~cm}$ were measured. The slope correction was conducted automatically using Vertex III (Haglöf Sweden AB) during forest inventory. Tree diameters were measured with a diameter tape to the nearest $0.1 \mathrm{~cm}$ and heights of one or two dominant, one co-dominant and one suppressed trees were measured in each plot, respectively. A height-diameter relationship was fitted to the subsample of trees with height measurements using the model proposed by Pretzsch (2009): 


$$
h=1.3+\left(\frac{d}{2.0208+0.3461 \cdot d}\right)^{3} \quad \mathrm{R}^{2}=0.7286, \mathrm{RMSE}=1.6006
$$

Where $h$ is the total height of the tree $(\mathrm{m})$ and $d$ is the diameter at breast height $(1.3 \mathrm{~m})$ in $\mathrm{cm}$.

\section{Biomass and volume estimation}

The following stand variables were calculated for each plot: the number of trees per hectare $(N)$, quadratic mean diameter $\left(d_{g}\right)$, mean height $\left(H_{m}\right)$, dominant height $\left(H_{d}\right.$, defined as the mean height of 100 thickest trees per hectare), stand volume $(V)$, stem biomass $\left(B_{s}\right)$ and aboveground biomass $\left(B_{a g b}\right)$.

The allometric models (Eq. 2-4), developed in the same study area in Shitai county (GuisasolaRodríguez 2014), were used to estimate stem, branch and leaf biomass. The total aboveground biomass was calculated as the sum of these components $\left(B_{s}+B_{b}+B_{l}\right)$. Eq. 5 , developed by a compatible taper function for this species (Tang, et al. 2015), was used to calculated individual tree volume. Individual tree-level biomass and volume were scaled to stand-level in terms of expansion factors of 31.8 for $10 \mathrm{~m}$ radius plots and 88.4 for $6 \mathrm{~m}$ radius plots.

$$
\begin{array}{ll}
B_{s}=0.020232 \cdot\left(d^{2} \cdot h\right)^{0.9674} & \mathrm{R}^{2}=0.9764, \mathrm{RMSE}=0.0179 \\
B_{b}=0.011774 \cdot d^{3.7416} \cdot h^{-1.6029} & \mathrm{R}^{2}=0.9722, \mathrm{RMSE}=0.0294 \\
B_{l}=0.031911 \cdot d^{3.207} \cdot h^{-1.5105} & \mathrm{R}^{2}=0.9522, \mathrm{RMSE}=0.0363 \\
V_{s}=0.000071 \cdot d^{1.7512} \cdot h^{1.0417} & \mathrm{R}^{2}=0.9878, \mathrm{RMSE}=0.0243
\end{array}
$$

Where $B_{s}, B_{b}, B_{l}$ and $V_{s}$ represent stem biomass, branch biomass, leaf biomass $(\mathrm{kg})$ and stem volume $\left(\mathrm{m}^{3}\right)$ of the individual tree, respectively. $d$ is the diameter at breast height at $1.3 \mathrm{~m}(\mathrm{~cm}) ; h$ is the total tree height (m), $\mathrm{R}^{2}$ is the coefficient of determination, and RMSE is the root mean square error.

\subsubsection{Development of SDMDs}

In our study, SDMDs consist of four equations and the relative spacing index $(R S)$ as the basic components. The $R S$ is used to characterize the growing stock level and is calculated as the ratio between the average distance among the trees and the dominant height, expressed as a percentage (Castedo-Dorado, et al. 2009; Pérez-Cruzado, et al. 2011):

$$
R S(\%)=\frac{100}{\sqrt{N} \cdot H_{d}} \times 100
$$

Where $R S$ is the relative spacing index $(\%), N$ is the number of trees per hectare, and $H_{d}$ is the dominant tree height $(\mathrm{m})$. 
To describe stand stability, the slenderness coefficient (SC) is often used (Wang, et al. 1998; Wilson and Oliver 2000). In this study, $S C$ is defined as the ratio of mean stand height $\left(H_{m}\right)$ to the mean diameter at breast height $\left(d_{m}\right)$, expressed as:

$$
S C=\frac{H_{m}}{d_{m}}
$$

The first step to model the SDMDs is to fit the non-linear system of the following equations (Eq.) (8) to (11). In the system, $N$ and $H_{d}$ are the exogenous variables (defined as independent of the system), while $V, B_{s}$ and $B_{a g b}$ are endogenous variables (variables that the model predicts), and $d_{g}$ is the endogenous instrumental variable (Castaño-Santamaría, et al. 2013; Pérez-Cruzado, et al. 2011). These equations are very flexible and have already been successfully applied in different tree species, such as Eucalyptus species (Pérez-Cruzado, et al. 2011) and Quercus pyrenaica forests (CastañoSantamaría, et al. 2013).

$$
\begin{aligned}
& d_{g}=a_{1} \cdot N^{a_{2}} \cdot H_{d}^{a_{3}} \\
& V=a_{4} \cdot d_{g}^{a_{5}} \cdot H_{d}^{a_{6}} \cdot N^{a_{7}} \\
& B_{S}=a_{8} \cdot d_{g}^{a_{9}} \cdot H_{d}^{a_{10}} \cdot N^{a_{11}} \\
& B_{a g b}=a_{12} \cdot d_{g}^{a_{13}} \cdot H_{d}^{a_{14}} \cdot N^{a_{15}}
\end{aligned}
$$

Where $a_{1}, a_{2} \ldots a_{15}$ are the fitted coefficients; $d_{g}$ is the quadratic mean diameter $(\mathrm{cm}), H_{d}$ is the mean height of the 100 thickest trees per hectare (m); $N$ is the number of the trees per hectare (trees $\cdot \mathrm{ha}^{-1}$ ); $V$ is the stand volume $\left(\mathrm{m}^{3} \cdot \mathrm{ha}^{-1}\right) ; B_{S}$ is the stem biomass and $B_{a g b}$ is the aboveground biomass $\left(\mathrm{t} \cdot \mathrm{ha}^{-1}\right)$.

Because of the correlations between error components of the independent variables and dependent variables, the full information maximum likelihood method (FIML) was used in the fitting process (Pérez-Cruzado, et al. 2011). Eq. (8-11) were fitted simultaneously using the MODEL procedure in SAS 9.2 (SAS Institute Inc 2007). The convergence level was set at 0.001. Some more characteristics of the inventory stands are given in Table 1.

Construction of the SDMDs involves the following steps: i) the height of dominant trees are plotted on the $\mathrm{x}$-axis and the number of trees per hectare on the y-axis (logarithmic scale); ii) representation of isolines of the relative spacing index $(R S)$; iii) representation of isolines for quadratic mean diameter using equation (7) by setting $d_{g}$ constant and solving for the number of trees $(N)$ through a range of dominant heights $\left(H_{d}\right)$; and iv) representing isolines for additional variables $\left(V, B_{S}\right.$ and $\left.B_{a g b}\right)$. These isolines were determined by substituting $d_{g}$ in the equations (9) to (11) by equation (8) and solving for the number of trees $(N)$ through a range of dominant height $\left(H_{d}\right)$ by setting the additional variables ( $V, B_{S}$ and $\left.B_{a g b}\right)$ constant. The SDMDs were drawn in R 3.0.2 (R Core Team 2014). 
Table 1. Main stand characteristics in the sample plots.

\begin{tabular}{lllll}
\hline Variables & Mean & Min & Max & SD \\
\hline$d_{m}(\mathrm{~cm})$ & 15.4 & 7.4 & 25.9 & 3.1 \\
$d_{g}(\mathrm{~cm})$ & 15.7 & 7.5 & 26.0 & 3.2 \\
$B A\left(\mathrm{~m}^{2} \cdot \mathrm{ha}^{-1}\right)$ & 18.6 & 1.0 & 50.8 & 12.3 \\
$N\left(\mathrm{trees} \cdot \mathrm{ha}^{-1}\right)$ & 1021 & 32 & 2741 & 679 \\
$H_{d}(\mathrm{~m})$ & 12.0 & 6.3 & 16.2 & 2.3 \\
$H_{m}(\mathrm{~m})$ & 9.6 & 5.7 & 14.9 & 1.7 \\
$S C$ & 63.2 & 49.0 & 81.0 & 4.6 \\
$R S(\%)$ & 37.9 & 14.2 & 177.2 & 30.4 \\
$V\left(\mathrm{~m}^{3} \cdot \mathrm{ha}^{-1}\right)$ & 100 & 4 & 286 & 70 \\
$B_{S}\left(\mathrm{t} \cdot \mathrm{ha}^{-1}\right)$ & 38 & 1 & 111 & 27 \\
$B_{a g b}\left(\mathrm{t} \cdot \mathrm{ha}^{-1}\right)$ & 52 & 2 & 146 & 36 \\
\hline
\end{tabular}

Where $d_{g}$ is the quadratic mean diameter, $d_{m}$ is the mean diameter; $B A$ is the stand basal area; $N$ is the number of the trees $>10 \mathrm{~cm} d b h$ per hectare, $H_{d}$ is the dominant height, $H_{m}$ is the stand mean height, $S C$ is the slenderness coefficient, $R S$ is the relative spacing index; $V$ is the stand volume, $B_{S}$ is the stand stem biomass per hectare, $B_{a g b}$ is the total aboveground biomass per hectare and SD is the standard deviation of means.

\subsection{Results and discussion}

The coefficients and statistics of non-linear regressions (Eq.8-11) are shown in Table 2. All coefficients were significant at the level of 0.05 . These equations explained $79 \%$ of the observed variability for the quadratic mean diameter and $99 \%$ for $V, B_{S}$ and $B_{a g b}$. As expected, the quadratic mean diameter was least accurate. These results are common for static stand-level models (CastañoSantamaría, et al. 2013; Schnell, et al. 2012; Pérez-Cruzado, et al. 2011). The high variability explained by the stand volume, stem biomass and aboveground biomass models is consistent with other studies (Castaño-Santamaría, et al. 2013; Barrio-Anta, et al. 2006).

\subsubsection{Construction of SDMDs}

Three SDMDs are constructed for stand volume, stem biomass and aboveground biomass (Fig. 2, 3 and 4) by superimposing the expected size-density trajectories. The dominant height is set on the $x$ axis while the number of trees per hectare is set on the $y$-axis. The tree height axis ranges from $6 \mathrm{~m}$ to $24 \mathrm{~m}$, while the number of trees ranges from 30 to 3000 according to the observed sample plots (Table 1). The stand stability (expressed by the slenderness coefficient, $S C$ ), relative spacing $(R S)$ and the quadratic mean diameter $\left(d_{g}\right)$ are shown in isolines. 
Some studies have only focused on the stability of the largest 100-250 trees per hectare because these trees tend to have the highest timber, aesthetic and habitat values (Cremer, et al. 1982). However, some other studies also consider stand stability aspects using $S C$ as the ratio of the mean stand height and mean stand diameter, therefore including suppressed trees as well (Castedo-Dorado, et al. 2009; Hinze and Wessels 2002). They defined that the average $S C$ of 90 is a reasonable stability threshold for e.g. Pinus radiata forests. When the $S C$ was above 90, the stand was unstable for wind or snow damage, while a mean $S C$ below 60 indicate stable conditions. The inclusion of the average stand $S C$ is conditioned by the other variables represented in the diagram (Castedo-Dorado, et al. 2009; Hinze and Wessels 2002). In our study, if we take a $S C$ of 90 as a reference threshold, the $S C$ ranging from 49 to 81 (Table 1) indicates that the Chinese fir plantations in our study area are relatively stable against wind or snow damage. However, there is no more information available about critical $S C$ values in Chinese fir plantations, which is necessary for future Chinese fir plantation management.

Table 2 Coefficients (including standard errors) and goodness-of-fit statistics obtained with non-linear regression models using simultaneous fitting of the four equations system predicting quadratic mean diameter (Eq. 8, $d_{g}$ ), stand volume (Eq. 9, V), stem biomass (Eq. 10, $B_{s}$ ) and aboveground biomass (Eq. 11, $B_{a g b}$ ).

\begin{tabular}{|c|c|c|c|c|c|c|c|}
\hline Equations & Coefficients & & & & df & $\mathrm{R}_{\text {adj }}^{2}$ & RMSE \\
\hline (8) & $a_{1}=3.3739(0.552)$ & $a_{2}=-0.1079(0.00922)$ & $a_{3}=0.9023(0.059)$ & & 71 & 0.7921 & 1.4546 \\
\hline (9) & $a_{4}=0.000063(0.0000074)$ & $a_{5}=2.4941(0.0568)$ & $a_{6}=0.1520(0.0509)$ & $a_{7}=1.0214(0.00826)$ & 70 & 0.9986 & 2.7485 \\
\hline (10) & $a_{8}=0.000015(0.0000046)$ & $a_{9}=2.5760(0.0762)$ & $a_{10}=0.2230(0.0751)$ & $a_{11}=1.0299(0.011)$ & 70 & 0.9974 & 1.4452 \\
\hline (11) & $a_{12}=0.000029(0.0000029)$ & $a_{13}=2.5968(0.0515)$ & $a_{14}=0.1375(0.0498)$ & $a_{15}=1.0037(0.00808)$ & 70 & 0.9992 & 1.1025 \\
\hline
\end{tabular}




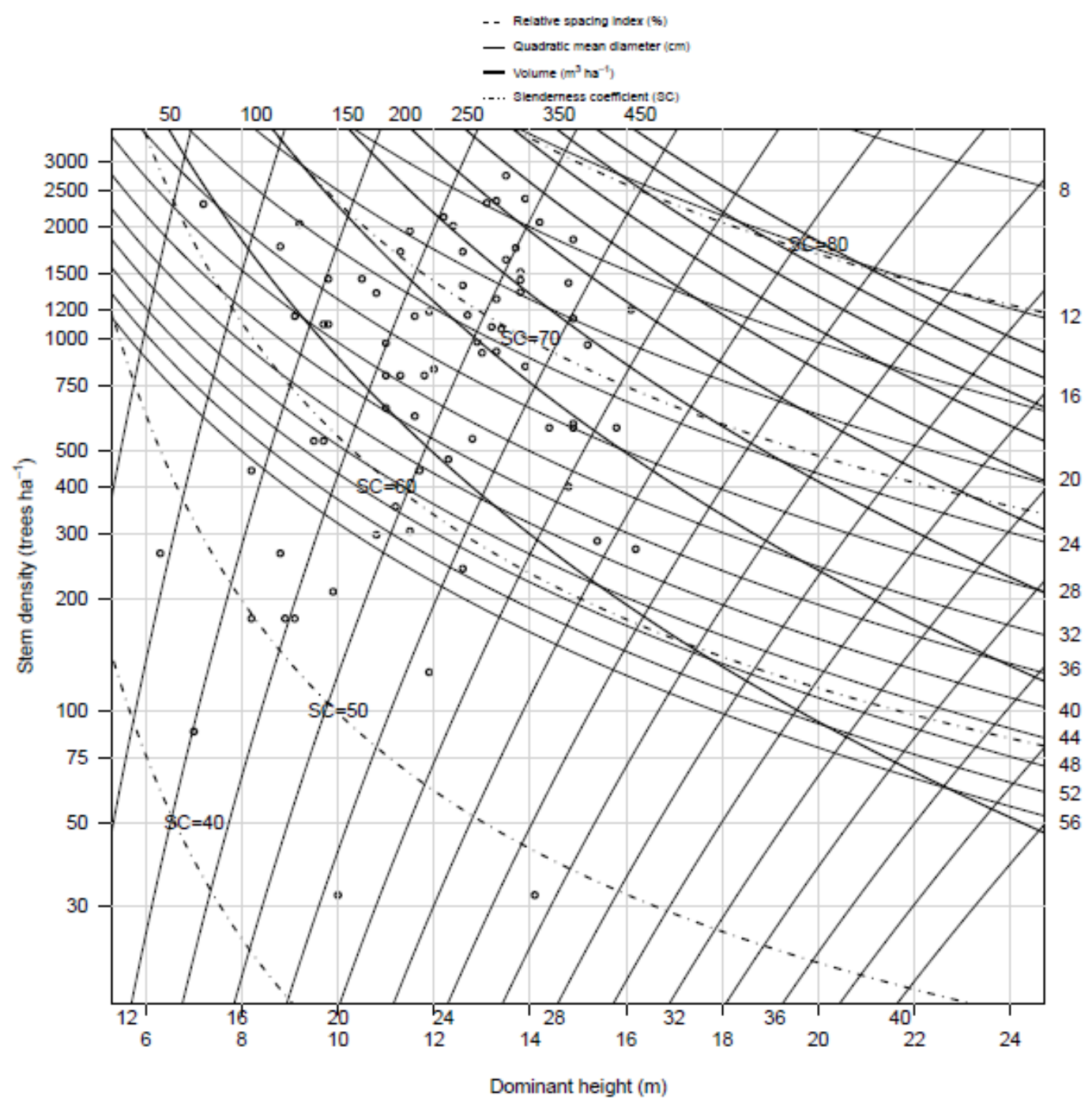

Fig. 2 Stand density diagram for Chinese fir plantations in relation to stand volume. The open circles represent the measured field data used to fit the models. Dominant height is the mean height of the 100 thickest trees. Other variables are explained in the text.

The open circular dots in in Fig. 2, 3 and 4 represent the field measured data based on $N$ and $H_{d}$, demonstrating the range of applicability of the models. The $R S$ isolines drawn in black lines slope down from left to right with values of $8 \%-56 \%$, which is similar to other studies (Castedo-Dorado, et al. 2009; Barrio-Anta 2005). The $d_{g}$ is represented in red lines and runs upward sloped from right to left. As confirmed by other authors (Schnell, et al. 2012), the $d_{g}$ is highly sensitive to stand density, ranging from $6 \mathrm{~cm}$ to $40 \mathrm{~cm}$. For constant $H_{d}$, the $d_{g}$ decreased with the increase of $N$ because of the increase of competition for resources in the stands, leading to a smaller average tree dimension (Pérez-Cruzado, et al. 2011; Curtis 1970; Dean and Long 1992). The observed values ranging from 4 to $286 \mathrm{~m}^{3} \cdot \mathrm{ha}^{-1}$ for $V$, from 1 to $111 \mathrm{t} \cdot \mathrm{ha}^{-1}$ for $B_{S}$ and 2 to $146 \mathrm{t} \cdot \mathrm{ha}^{-1}$ for $B_{a g b}$ represented in blue lines slope downward from left to right (Fig. 2, 3 and 4). For a constant N, the growing stock (expressed by 
$V, B_{S}$ and $\left.B_{a g b}\right)$ increases with an increase of $H_{d}$. This result is consistent to the principle that the stand productivity is strongly related to the tree height development (Schnell, et al. 2012).

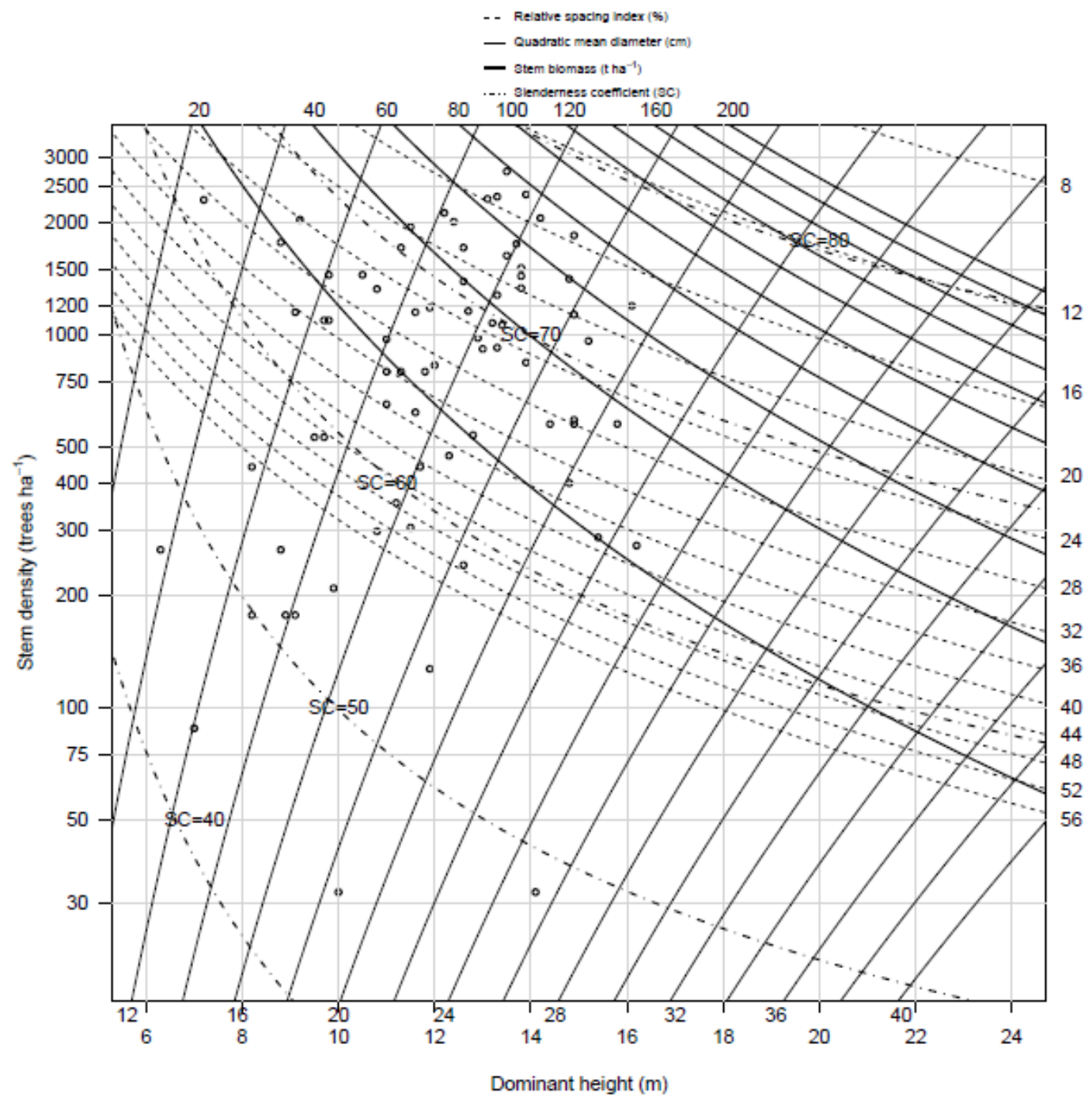

Fig.3 Stand density management diagram for Chinese fir plantation in relation to stem biomass $\left(\mathrm{t} \cdot \mathrm{ha}^{-1}\right)$. The open circles represent the measured field data used to fit the models. Dominant height is the mean height of the 100 thickest trees. Other variables are explained in the text.

\subsubsection{Comparisons with yield tables}

Statistically, yield tables are constructed from a large monitoring data, long-term experimental data or permanent inventory plots, and allow to estimation of site-dependent volume production (Pretzsch 2009). This makes the volumes from yield table and SDMDs comparable. Since there was a lack of yield table of our study area, a yield table built on similar stand and climate conditions as ours for Chinese fir plantations was taken to compare our results (Jiang, et al. 1996). A strong relationship between predicted volume from our models and volume from yield table up to a dominant height of $22 \mathrm{~m}$ was observed (Fig. 5). The result illustrated the reliability of SDMDs to estimate the stand 
volume, even for a dominant height above $17 \mathrm{~m}$ where contained no observed data. However, predicted volume from our study was lower than some other studies (e.g. Li, et al. 1988; Jiang, et al. 1997). This could be due to the differences of site quality, climatic conditions and threshold diameters used in the forest inventory. For example, the threshold diameter was $10 \mathrm{~cm}$ in our study, compared to $5 \mathrm{~cm}$ for other researches ( $\mathrm{Li}$, et al. 1988; Jiang, et al. 1997). Therefore, the SDMDs developed in this study should be preferably applied in local study area or the stands with similar site and climatic conditions as this study.

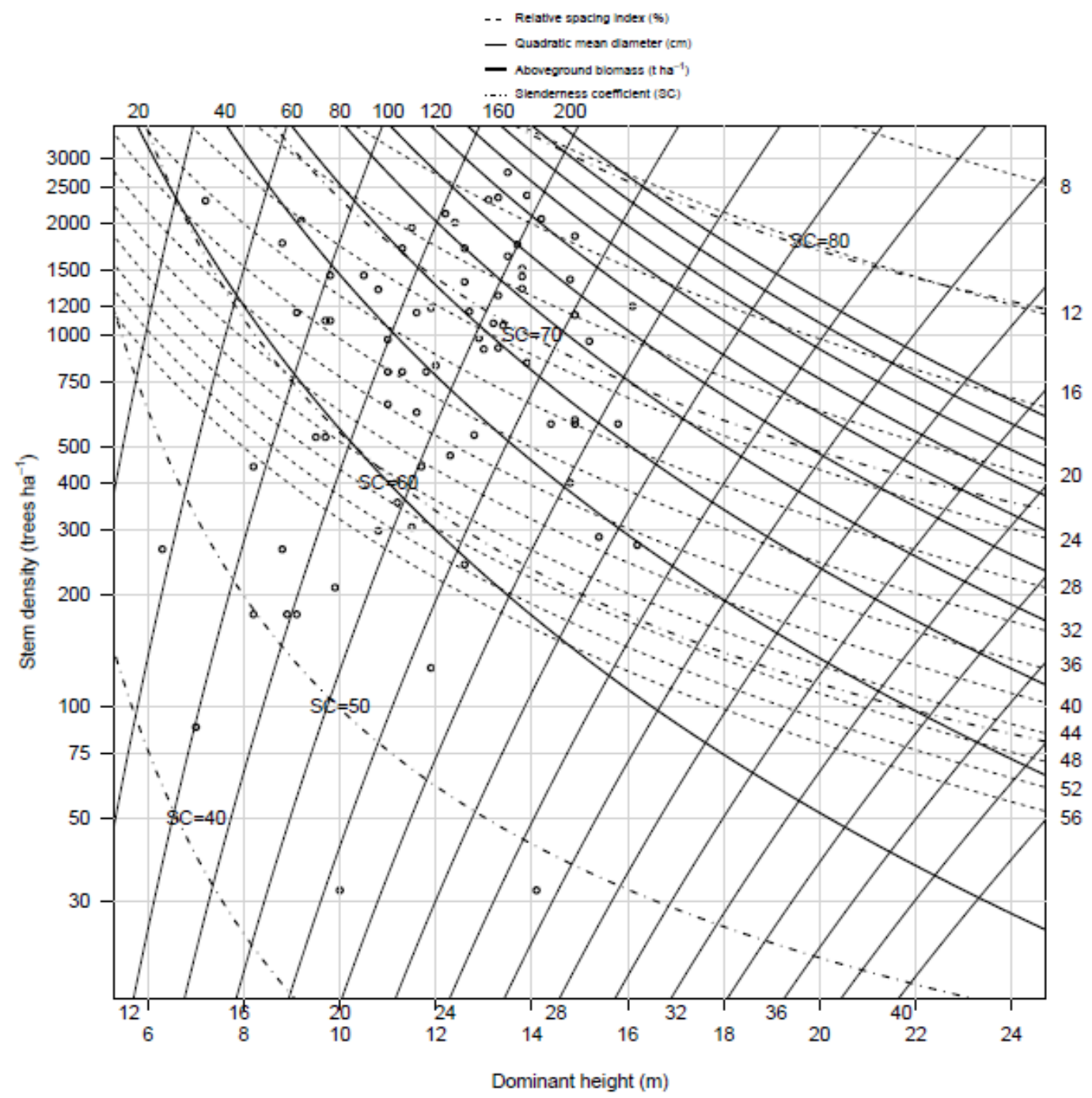

Fig. 4 Stand density management diagram for Chinese fir plantation in relation to aboveground biomass $\left(\mathrm{t} \cdot \mathrm{ha}^{-1}\right)$. The open circles represent the measured field data used to fit the models. Dominant height is the mean height of the 100 thickest trees. Other variables are explained in the text. 


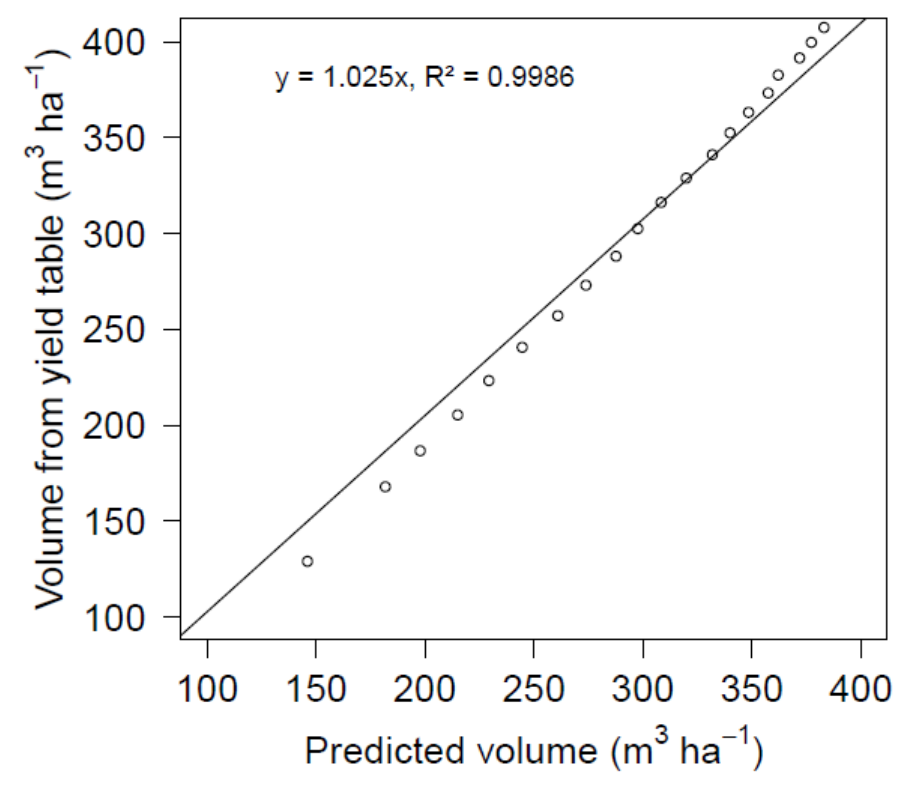

Fig. 5 Relationship between volume from our models and volume from yield table proposed by Jiang et al. (1997) for Chinese fir plantations.

\subsubsection{Practical examples}

Stand management is recognized as an important practice to increase stand productivity (Gao, et al. 2014; Liu, et al. 2013). However, management in Chinese fir plantations commonly associate with the application of short rotations, monoculture, clear-cut and high-level removal of biomass or volume driven by economic benefits. With the expansion of plantation area, repeated establishing plantation by sprouts or new seedlings on the same sites become normal with a short rotation of 25 years (Wu 1984; Wei, et al. 2012). Continuous cultivation of plantation on the same sites or monoculture has resulted in a decline in production ( $\mathrm{Bi}$, et al. 2007), increased susceptibility to insect and diseases (Ye, et al. 2010) and decreased stand stability (Zhou, et al. 2011). Although thinning trials are observed in some case studies in China (Cheng, et al. 2014), the lacking of management knowledge and technical trainings has limited expansion of thinning treatments. It is expected that the proposed SDMDs could propose a basal theoretical guideline for the management of Chinese fir plantations. Therefore, two thinning trials with same target were presented as follows to illustrate how to use SDMDs.

In the practical application of SDMDs, two factors determine the thinning schedules: the target stand dimension at rotation age and the upper and the lower growing stock limits (Schnell, et al. 2012; Barrio-Anta, et al. 2006; Barrio-Anta 2005). The first factor could be defined by any logical combination of two of the following variables: dominant height, quadratic mean diameter, number of the trees per hectare, total stand volume, aboveground biomass depending on the final management target or stand variable used to develop in the SDMDs (Castaño-Santamaría, et al. 2013; Schnell, et al. 2012). 


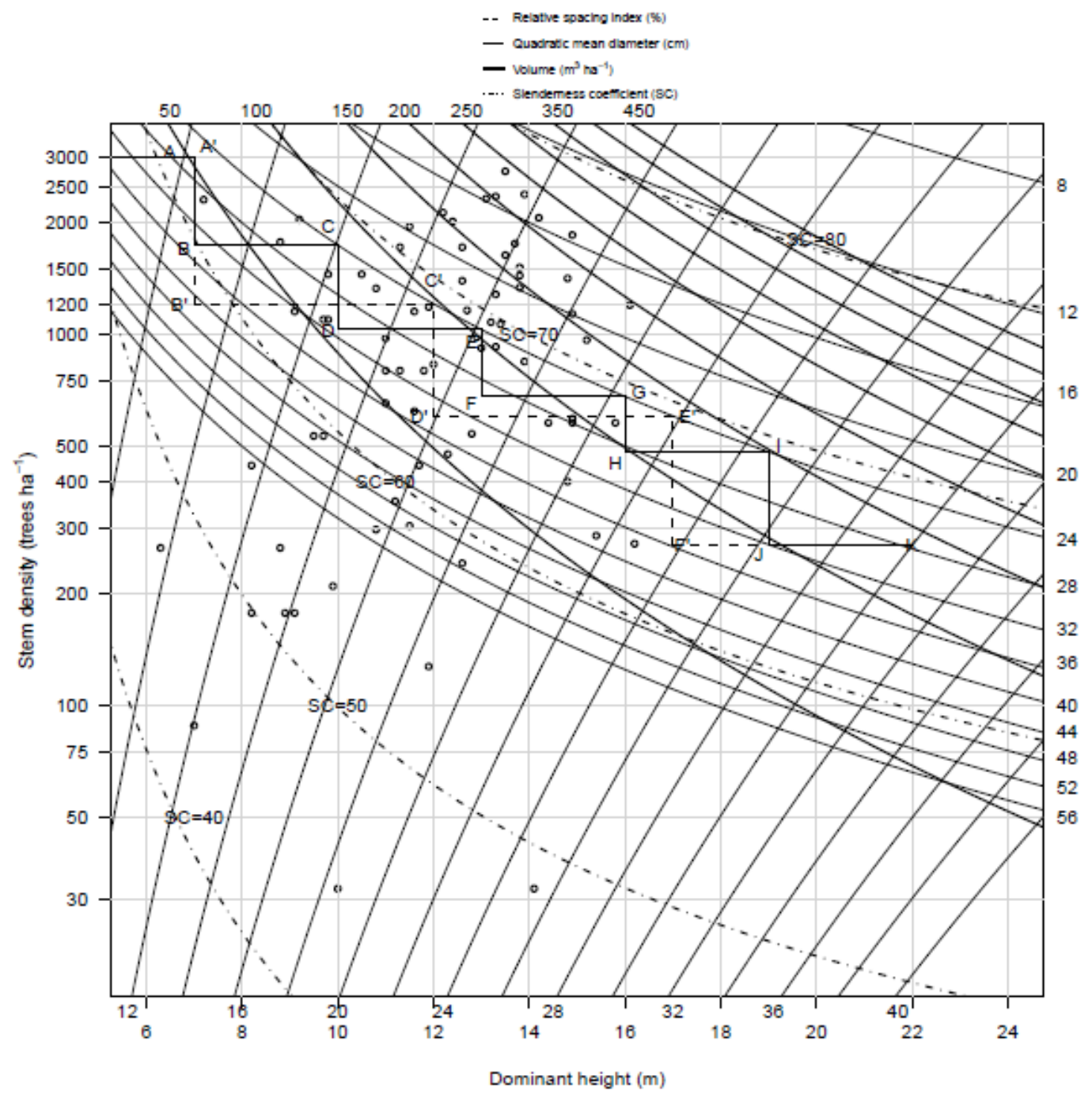

Fig. 6 Examples for two different thinning schedules in Chinese fir plantations. Open circles represent the measured field data used to fit the models. Dark lines (Example 1) and dash lines (Example 2) show describe the simulated thinning schedules, respectively.

The second factor should consider the maximum growth on the stand or on the tree level, but cannot be maximized simultaneously (Schnell, et al. 2012). Therefore, the selection of the upper and lower stocking limits represents a compromise between the stand growth and individual tree growth (Long 1985), as well as stand stability. The upper growing stock limit can be set higher than the determined $R S$ to avoid density-caused mortality and maintain an adequate live-crown ratio for good tree vigour, while the lower growing stock limit could be set to maintain adequate site occupancy using the $R S$. For example, $R S$ of $16 \%$ seems a reasonable upper growing stock limit to maintain live crown ratio for good tree vitality and avoid density-dependent mortality in radiate pine (Pinus radiata) plantations in temperate regions (Rodríguez, et al. 2002). An alternative method of setting the constant $R S$ values is to define the thinning trials considering height growth combined with an upper growing stock limit, 
or with a thinning intensity defined as the increment of the $R S$ values that ensure the stand stability (Barrio-Anta 2005).

When applying the SDMDs to describe the thinning schedules, there are two assumptions. The first assumption is that no mortality happens during the stand development after the first thinning. If the upper and lower stock limits are selected in the way that natural mortality does not occur, this assumption seems to be reasonable. However, mortality caused by incidents, such as wind, snow, ice or lightning damage is not included. To account for such issues, a mortality model could be included in the SDMDs (Castedo-Dorado, et al. 2009; Pérez-Cruzado, et al. 2011). However, in our study, density-independent mortality was not considered due to a lack of information. The second assumption is that thinning has no effect on the dominant height, as this variable is site dependant.

Table 3 Stand data modelled for two different thinning scenarios (see also Fig. 6).

\begin{tabular}{lllllllllllll}
\hline Example 1 & \multicolumn{3}{l}{ Before thinning } & \multicolumn{3}{c}{ Thinning } & \multicolumn{3}{c}{ After thinning } & Total \\
\hline$H_{d}$ & $N$ & $d_{g}$ & $B A$ & $V_{b}$ & $N$ & $B A$ & $V_{t}$ & $N$ & $d_{g}$ & $B A$ & $V_{a}$ & $V_{\text {total }}$ \\
\hline 7 & 3000 & 8.2 & 16.0 & 58 & 1264 & 5.6 & 20 & 1736 & 8.7 & 10.4 & 38 & 58 \\
10 & 1736 & 12.0 & 19.8 & 90 & 709 & 6.7 & 69 & 1027 & 12.7 & 13.1 & 61 & 110 \\
13 & 1027 & 16.2 & 21.0 & 114 & 349 & 5.9 & 31 & 678 & 16.9 & 15.2 & 84 & 163 \\
16 & 678 & 20.4 & 22.1 & 138 & 197 & 5.2 & 31 & 481 & 21.1 & 16.9 & 106 & 217 \\
19 & 481 & 24.7 & 23.0 & 161 & 212 & 8.4 & 57 & 269 & 26.3 & 14.6 & 104 & 272 \\
22 & 269 & 28.0 & 16.6 & 125 & & & & & & & & 292 \\
\hline Example 2 & & & & & & & & & & & \\
\hline 7 & 3000 & 8.2 & 16.0 & 58 & 1794 & 8.1 & 29 & 1206 & 9.1 & 7.8 & 29 & 58 \\
12 & 1206 & 14.8 & 20.7 & 106 & 605 & 8.7 & 43 & 601 & 15.9 & 12.0 & 63 & 135 \\
17 & 601 & 21.8 & 22.4 & 146 & 332 & 10.5 & 66 & 269 & 23.8 & 11.9 & 80 & 218 \\
22 & 269 & 30.0 & 19.0 & 149 & & & & & & & & 287 \\
\hline
\end{tabular}

$N$ is the number of the trees per ha, $d_{g}$ is the quadratic mean diameter $(\mathrm{cm}), B A$ is the basal area $\left(\mathrm{m}^{2} \cdot \mathrm{ha}^{-1}\right), V_{b}$ is the stand volume $\left(\mathrm{m}^{3} \cdot \mathrm{ha}^{-1}\right)$ before thinning, $V_{t}$ is the thinning volume $\left(\mathrm{m}^{3} \cdot \mathrm{ha}^{-1}\right), V_{a}$ is the stand volume $\left(\mathrm{m}^{3} \cdot \mathrm{ha}^{-1}\right)$ after thinning, $V_{\text {total }}$ is the total stand volume $\left(\mathrm{m}^{3} \cdot \mathrm{ha}^{-1}\right)$.

The sequence of thinning was plotted by a backwards stair-stepping procedure considering the upper growth limit and thinning interval. Therefore, the vertical ( $y$-axis) and horizontal segments ( $x$-axis) of the steps represent the thinning and post-thinning stages. The theoretic development of a Chinese fir plantation under a particular management is shown in Fig. 6. Assumed target dimensions were $22 \mathrm{~m}$ (dominant height) and $30 \mathrm{~cm}$ (quadratic mean diameter) (Fig. 6, K). The lower growing stock limit was defined by a relative space index of $24 \%$, similar to other studies (e.g. Castaño-Santamaría, et al. 2013). Because the average space index in our study was $38 \%$ and no dead trees were found in the 
sample plots (Table 1), $36 \%$ was defined as the upper stock limit in our study. The starting density of the plantations was defined at 3000 trees per hectare with a dominant height of $7 \mathrm{~m}$ because the planting distance between each seedling was $2 \mathrm{~m} \times 1.5 \mathrm{~m}$ with about $90 \%$ survival rate in our study area according to reports from the local forest administration (unpublished data).

Theoretically, in order to achieve the target harvest stage (Point K, Fig. 6), two thinning schedules are simulated based on the observed stand characteristics and on the standard silvicultural practice for Chinese fir in the region. The first example (dark green) shows a thinning schedule based on low intensity interventions which may maximize site occupancy and production with an increment of dominant height of $3 \mathrm{~m}$ within one thinning interval. The stair stepping procedure is drawn in Fig. 6 taking the stand volume as an example. Therefore, the thinning related $V_{t}, N$ and $d_{g}$ can be read directly from the different SDMDs. For example, during the five thinning operations, 20, 30, 31, 31 and $57 \mathrm{~m}^{3} \cdot \mathrm{ha}^{-1}$ were theoretically removed, respectively. Until the rotation age, the stand volume reached $125 \mathrm{~m}^{3} \cdot \mathrm{ha}^{-1}$ (Table 3). Including the thinning volume, a total yield of $292 \mathrm{~m}^{3} \cdot \mathrm{ha}^{-1}$ was produced in the Chinese fir plantation.

The second alternative responds mainly to economic aspects (dash blue, Fig. 6), as the lower number of interventions indicates that all removals have commercial value either because of the size of the extracted trees or because of the total amount of extracted biomass. Similarly, including the thinning volume, a total yield of $287 \mathrm{~m}^{3} \cdot \mathrm{ha}^{-1}$ was produced in the Chinese fir plantation until the harvest stage (pion K, Fig. 6), which was similar to the first thinning example. However, the stand stability resistant to natural disaster, such as wind and snow damage, should be considered because each thinning removes half or even more than half of the standing trees.

In our SDMDs, aside from stand volume, the aboveground biomass through thinning schedules can be optimized as well. Combing the parameters in Table 2, the stand level biomass could easily be estimated based on the knowledge of the stand basal area and dominant height. This could be an alternative to individual-tree biomass estimations.

\subsection{Conclusions}

To our knowledge, this is the first study, where SDMDs of stand volume, stem and aboveground biomass were developed for Chinese fir plantations. SDMDs could be a useful tool to support and optimize the forest management according to different owner targets. These diagrams also allow for rapid estimations of stand volume, stem and aboveground biomass for a range of planting densities and rotation ages. This information may help to control for several indicators of sustainable forest management (e.g. stand volume, stand biomass). Further risk indices depending on stand characteristics are easy to superimpose the proposed diagrams, allowing forest managers to make better technical decisions. The fitted stand-level volume and biomass models can be used as an 
alternative to the individual-tree models for making predictions at stand level. This study could fill the gap between theoretical and practical management in Chinese fir plantations and the SDMDs proposed could be a reference decision support tool to optimize stand management of these forests according to different management purposes.

\section{Acknowledgements}

We would like to thank Dr. Hans Fuchs, MSc. Sabine Schreiner, Dr. Haijun Yang and Msc. Dengkui Mo from the Georg-August-University Göttingen for the plot design and fieldwork support. Furthermore, we want to thank Director An'guo Fan, Mr. Bailing Ding, Miss Yue'e Chu from the Shitai Forest bureau for their kind organization of the fieldwork. Thanks also to Mr. Xiaozhu Wang and Mr. Hongbing Ruan for their fieldwork support.

\section{Conflict of interest statement}

None declared.

\section{Funding}

The study was supported by a project of Sino-German Cooperation on Innovative Technologies and Service Capacities of Multifunctional Forest Management (Lin ${ }^{2}$ Value 033L049-CAFYBB2012013), funded by the Federal Ministry of Education and Research (BMBF) and the Chinese Academy of Forestry.

\subsection{References}

Barrio-Anta M. 2005. Development of a stand density management diagram for even-aged pedunculate oak stands and its use in designing thinning schedules. Forestry 78: 209-216.

Barrio-Anta M, Balboa-Murias MA, Castedo-Dorado F, Dieguez-Aranda U, Alvarez-Gonzalez JG. 2006. An ecoregional model for estimating volume, biomass and carbon pools in maritime pine stands in Galicia (northwestern Spain). Forest Ecology and Management 223: 24-34.

Bi J, Blanco JA, Seely B, Kimmins JP, Ding Y, Welham C. 2007. Yield decline in Chinese-fir plantations: a simulation investigation with implications for model complexity. Canadian Journal of Forest Research 37: 1615-1630.

Bingshuan W. 1989. A preliminary experiment report about effect of different intensity of thinning out Chinese-fir stand. Journal of Fujian College of Forestry 9: 58-66.

Castaño-Santamaría J, Barrio-Anta M, Álvarez-Álvarez P. 2013. Regional-scale stand density management diagrams for Pyrenean oak (Quercus pyrenaica Willd.) stands in north-west Spain. iForest - Biogeosciences and Forestry 6: 113-122. 
Castedo-Dorado F, Crecente-Campo F, Álvarez-Álvarez P, Barrio-Anta M. 2009. Development of a stand density management diagram for radiata pine stands including assessment of stand stability. Forestry 82: 1-16.

Chen GS, Yang ZJ, Gao R, Xie JS, Guo JF, Huang ZQ, Yang YS. 2013. Carbon storage in a chronosequence of Chinese fir plantations in southern China. Forest Ecology and Management 300: 68-76.

Cheng X, Umeki K, Honjo T, Mizusaki D. 2014. Basal area growth rates of five major species in a Pinus-Cunninghamia forest in eastern China affected by asymmetric competition and spatial autocorrelation. Journal of Forest Research 19: 86-96.

Cremer K, Borough C, McKinnell F, Carter P. 1982. Effects of stocking and thinning on wind damage in pine plantations. New Zealand journal of forestry science 12: 244-268.

Curtis RO. 1970. Stand density measures: an interpretation. Forest Science 16: 403-414.

Dean TJ, Long JN. 1992. Influence of leaf area and canopy structure on size-density relations in evenaged lodgepole pine stands. Forest Ecology and Management 49: 109-117.

Gao GL, Ding GD, Zhao YY, Bao YF, Yu MH. 2014. Short Communication. Forestry solutions for mitigating climate change in China. Forest Systems 23: 183-186.

Geng TS, Wang HH. 2011. Research on the water and soil conservation in Shitai County of Anhui Province. Journal of Anhui Agriculture Science 39: 451-452, 482 (in Chinese with English abstract).

Gómez-Vázquez I, Fernandes P, Arias-Rodil M, Barrio-Anta M, Castedo-Dorado F. 2014. Using density management diagrams to assess crown fire potential in Pinus pinaster Ait. stands. Annals of Forest Science 71: 473-484.

Guisasola-Rodríguez R. 2014. Allometric biomass equations and crown architecture in mixed-species forests of subtropical China. Fakultät für Umwelt and Natürliche Ressourcen. Freiburg: AlbertLudwigs Universität Freiburg, p48.

Hinze WHF, Wessels NO. 2002. Stand stability in pines: An important silvicultural criterion for the evaluation of thinnings and the development of thinning regimes. The Southern African Forestry Journal 196: 37-40.

Hu Z, He Z, Huang Z, Fan S, Yu Z, Wang M, Zhou X, Fang C. 2014. Effects of harvest residue management on soil carbon and nitrogen processes in a Chinese fir plantation. Forest Ecology and Management 326: 163-170.

Jack SB, Long JN. 1996. Linkages between silviculture and ecology: an analysis of density management diagrams. Forest Ecology and Management 86: 205-220.

Jia Z, Zhang J, Wang X, Xu J, Li Z. 2009. Report for Chinese forest resource-The $7^{\text {th }}$ national forest inventory. Beijing(in Chinese): China Forestry Publishing House. 2p. 
Jiang X, Cai Lj, Lan J, Cheng Y, Wu Z, Jian X. 1997. On drawing up the variable-density yield table for Chinese fir plantation. Journal of Fujian College of Forestry 17: 84-87 (in Chinese with English abstract).

Jiang X, Huang Y, Zhang M. 1996. Study on drawing up variable-density yield table with the control chart of stand density. Journal of Fujian College of Forestry 16: 242-246 (in Chinese with English abstract).

Li X, Tang S, Wang S. 1988. The Establishment of variable density yield table for Chinese fir plantation in Dagangshan Experiment Bureau. Forest Research 4: 382-389 (in Chinese with English abstract).

Liu S, Innes J, Wei X. 2013. Shaping forest management to climate change: An overview. Forest Ecology and Management 300: 1-3.

Liu Z, Yang Q. 2008. Research on the intermediate felling model of planted Cunnighamia lanceolata. Jiangxi Forestry Science and Technology 6: 19-20.

Long JN. 1985. A practical approach to density management. The Forestry Chronicle 61: 23-27.

Long JN, Dean TJ, Roberts SD. 2004. Linkages between silviculture and ecology: examination of several important conceptual models. Forest Ecology and Management 200: 249-261.

Long JN, Shaw JD. 2005. A density management diagram for even-aged ponderosa pine stands. Western Journal of Applied Forestry 20: 205-215.

Lu CM. 2010. Rock-soil geochemical features for Dashan Area, Shitai, Anhui. Geology of Anhui 20: 120-125 (in Chinese with English abstract).

Newton PF. 1997. Stand density management diagrams: Review of their development and utility in stand-level management planning. Forest Ecology and Management 98: 251-265.

Newton PF, Amponsah IG. 2005. Evaluation of Weibull-based parameter prediction equation systems for black spruce and jack pine stand types within the context of developing structural stand density management diagrams. Canadian Journal of Forest Research 35: 2996-3010.

Newton PF, Weetman GF. 1994. Stand density management diagram for managed black spruce stands. The Forestry Chronicle 70: 65-74.

Pérez-Cruzado C, Merino A, Rodríguez-Soalleiro R. 2011. A management tool for estimating bioenergy production and carbon sequestration in Eucalyptus globulus and Eucalyptus nitens grown as short rotation woody crops in north-west Spain. Biomass and Bioenergy 35: 2839-2851.

Pretzsch H. 2009. Forest Dynamics, Growth, and Yield: Springer Berlin Heidelberg. 187p.

R Core Team. 2014. R: A language and environment for statistical computing. R Foundation for Statistical Computing, Vienna, Austria. URL http://www.R-project.org/.

Rodríguez R, Sánchez F, Gorgoso J, Castedo F, López C, Gadow Kv. 2002. Evaluating standard treatment options for Pinus radiata plantations in Galicia (north-western Spain). Forestry 75: 273-284.

SAS Institute Inc. 2007. SAS user's guide, version 9.2. SAS Institute Cary, NC. 
Schnell S, Kleinn C, Gonzalez JGA. 2012. Stand density management diagrams for three exotic tree species in smallholder plantations in Vietnam. Small-Scale Forestry 11: 509-528.

SFA. 2008. The Bulletin of Forestry and Ecological Construction in China. Beijing (in Chinese): State Forestry Administration of China. 6-10p.

Smith NJ. 1989. A stand-density control diagram for western red cedar, Thuja plicata. Forest Ecology and Management 27: 235-244.

Sturtevant BR, Bissonette JA, Long JN. 1996. Temporal and spatial dynamics of boreal forest structure in western Newfoundland: silvicultural implications for marten habitat management. Forest Ecology and Management 87: 13-25.

Tang X, Pérez-Cruzado C, Fehrmann L, Álvarez-González JG, Lu Y, Kleinn C. 2015. Development of a compatible taper function and stand-level merchantable volume model for Chinese fir plantations. Plos one (submitted manuscript).

Wang Y, Titus SJ, LeMay VM. 1998. Relationships between tree slenderness coefficients and tree or stand characteristics for major species in boreal mixedwood forests. Canadian Journal of Forest Research 28: 1171-1183.

Wei X, Blanco JA, Jiang H, Kimmins JP. 2012. Effects of nitrogen deposition on carbon sequestration in Chinese fir forest ecosystems. Science of The Total Environment 416: 351-361.

Wilson JS, Oliver CD. 2000. Stability and density management in Douglas-fir plantations. Canadian Journal of Forest Research 30: 910-920.

Wu ZL. 1984. Chinese-fir Beijing: China Forestry Publishing House (in Chinese). 583p.

Xu JC. 2011. China's new forests aren't as green as they seem. Nature 477: 370-370.

Ye S-m, Wen Y-g, Yang M, Liang H-w. 2010. Correlation analysis on biodiversity and soil physical $\&$ chemical properties of Eucalyptus spp. plantations under successive rotation. Journal of Soil and Water Conservation 24: 246-250,256.

Zhao MF, Xiang WH, Peng CH, Tian DL. 2009. Simulating age-related changes in carbon storage and allocation in a Chinese fir plantation growing in southern China using the 3-PG model. Forest Ecology and Management 257: 1520-1531.

Zhou B, Gu L, Ding Y, Shao L, Wu Z, Yang X, Li C, Li Z, Wang X, Cao Y. 2011. The great 2008 Chinese ice storm: its socioeconomic-ecological impact and sustainability lessons learned. Bulletin of the American Meteorological Society 92: 47-60. 
Chapter IV: Development of a taper function and stand-level merchantable volume model 


\section{Chapter VI}

\section{Changes in soil carbon and nitrogen stocks followed the conversion from secondary forest to Chinese fir and Moso bamboo plantations}

Fengying Guan ${ }^{*, c}$, Xiaolu Tang ${ }^{c}$, Shaohui Fan", Jiancheng Zhao, Chao Peng

Status: Guan F, Tang X, Fan S, Zhao J and Peng C (2015) Changes in soil carbon and nitrogen stocks followed the conversion from secondary forest to Chinese fir and Moso bamboo plantations. Catena 133: $455-460$

Contribution by Xiaolu Tang: $40 \%$

- Design the manuscript

- Analyze the data

- Write and revise the manuscript

Contribution by Fengying Guan: 40\%

- Design the manuscript

- Collect data

- Analyze the data

- Write and revise the manuscript

\footnotetext{
* Corresponding author: guanfy@icbr.ac.cn (F. Guan); fansh@icbr.ac.cn (S. Fan)

${ }^{c}$ Those authors contributed equally to this work.
} 
Chapter IV: Development of a taper function and stand-level merchantable volume model 


\title{
Changes in soil carbon and nitrogen stocks followed the conversion from secondary forest to Chinese fir and Moso bamboo plantations
}

\author{
Fengying Guan ${ }^{\mathrm{a},{ }^{*, c}}$, Xiaolu Tang ${ }^{\mathrm{b}, \mathrm{c}}$, Shaohui Fan ${ }^{\mathrm{a},{ }^{,}}$, Jiancheng Zhao ${ }^{\mathrm{a}}$, Chao Peng ${ }^{\mathrm{a}}$ \\ ${ }^{a}$ Key laboratory of Bamboo and Rattan, International Centre for Bamboo and Rattan, Beijing 100102, \\ P.R. China \\ ${ }^{\mathrm{b}}$ Chair of Forest Inventory and Remote Sensing, Georg-August-Universität Göttingen, Büsgenweg 5, \\ 37077 Göttingen, Germany
}

\begin{abstract}
Land use change is the second main reason for carbon (C) emissions after fossil fuel combustion, and it is recognized as an important driving force for soil organic carbon (SOC) and soil nitrogen (N) dynamics. Conversion of the secondary forest to Chinese fir (Cunninghamia lanceolata [Lamb.] Hook) and Moso bamboo (Phyllostachys heterocycla [Carr] Mitford cv. Pubescens) plantations represents one of the most important land use changes in subtropical China. However, the effects of these land use changes on the SOC and N stocks were not well documented. Therefore, in this study soil samples were collected in a secondary forest, a 17-year Chinese fir and a 18-year Moso bamboo plantation after the conversion from the secondary forest in November 2013, and total SOC and $\mathrm{N}$ concentrations were measured. Total SOC and N concentrations decreased with soil depth over the 0$50 \mathrm{~cm}$ in three land uses, and they were significantly higher in the secondary forest than those of Chinese fir and Moso bamboo plantations; however, these concentrations were not significantly different between Chinese fir and Moso bamboo plantations. Top soil $(0-10 \mathrm{~cm})$ accumulated one third of total SOC and N stocks. SOC and N stocks in the secondary forest were significantly higher than those of Chinese fir and Moso bamboo plantations with values of 203.68, 127.34 and 118.25 $\mathrm{t} \cdot \mathrm{ha}^{-1}$ for SOC stock and $9.24,5.10$ and $6.35 \mathrm{t} \cdot \mathrm{ha}^{-1}$ for $\mathrm{N}$ stock. The results indicated converting the secondary forest to Chinese fir and Moso bamboo plantations significantly decreased the SOC and N stocks over $0-50 \mathrm{~cm}$.
\end{abstract}

Keywords: land use change, soil carbon and nitrogen stocks, $\mathrm{C} / \mathrm{N}$ ratio, secondary forest, plantation

\subsection{Introduction}

The carbon $(\mathrm{C})$ and nitrogen $(\mathrm{N})$ cycles in the terrestrial ecosystems have gained an increasing attention over past decades because their oxides have great impacts on climate change (Fu et al.,

\footnotetext{
* Corresponding author: guanfy@icbr.ac.cn (F. Guan); fansh@icbr.ac.cn (S. Fan)

${ }^{\mathrm{c}}$ Those authors contributed equally to this work.
} 
2010). Soil contains the largest $C$ pools with the amount of $3150 \operatorname{Pg~C}\left(1 \mathrm{Pg} \mathrm{C}=10^{15} \mathrm{~g} \mathrm{C}\right)$, which is more than four times of that in plants (650 Pg C) and atmosphere (750 Pg C) (Luo and Zhou, 2006). In 2008, C emissions from soil respiration are estimated to be $98 \mathrm{Pg} \mathrm{C}$ (Bond-Lamberty and Thomson, 2010), which is more than 10 times of that from fossil fuel combustion (IPCC, 2007). Therefore, small changes in soil $\mathrm{C}$ could directly and significantly affect atmospheric $\mathrm{CO}_{2}$ concentrations.

Land use change is the second main reason for $\mathrm{C}$ emissions after fossil fuel combustion and has significant impacts on soil organic carbon (SOC) and N dynamics (Watson et al., 2000; Fu et al., 2010; Lozano-García and Parras-Alcántara, 2013). China, the largest developing country, has experienced wide land use changes from natural forests to plantations, forests to croplands or intensive land uses due to fast growing of human population and changing lifestyles in the past several decades (Fu et al., 2010). The land use change has caused a dramatic decline of SOC stock. According to the second national soil inventory in China, SOC stock in $1 \mathrm{~m}$ depth decreased by $7 \mathrm{Pg} \mathrm{C}$ due to the cultivation of natural soil, which represents $9.5 \%$ of world's SOC decline caused by land use change (Wu et al., 2003). However, the large $\mathrm{C}$ pool and significant changes of SOC related land use change also suggest a considerable potential to increase soil $\mathrm{C}$ pool through the management of human activities and forest management to decrease atmospheric $\mathrm{CO}_{2}$ concentrations (Post and Kwon, 2000; Wu et al., 2003). For example, restoring agro-pastoral ecotone to shrub land increases SOC concentration by $122-163 \%$ in topsoil $(0-10 \mathrm{~cm})$ (Fu et al., 2010).

In many areas in southern China, to meet the increasing demand of the timber market, fuel material and other forest products, larger areas of native forests have been converted to pure plantations followed by prescribed burning (Yang et al., 2009). One of the most important examples is the establishment of Chinese fir (Cunninghamia lanceolata [Lamb.] Hook) and Moso bamboo (Phyllostachys heterocycla [Carr.] Mitford cv. Pubescens) plantations. Chinese fir is one of the most popular plantation timber species in China due to its good timber quality, fast growth, straight stem and high resistance of bending (Zhao et al., 2009). Chinese fir plantations are commonly harvested at age 25 years (Zhang et al., 2004). Moso bamboo forest is an important forest type in southern China and has expanded very rapidly in recent decades because of fast and high income (Zhou et al., 2006). Moso bamboo is a fast growing species with fast biomass accumulation (Zhou et al., 2011) that it is normally harvested 4 or 5 years with wide uses, such as process bamboo flooring, scaffolding, supporting pillars, wall-decoration and laminated beams (Liu et al., 2011). According to the $7^{\text {th }}$ national forest inventory, Chinese fir plantations cover an area of 8.54 million hectares, equaling $21 \%$ of total China's plantation area, meanwhile bamboo forests have an area of 5.38 million hectares, $70 \%$ of which was Moso bamboo (Jia et al., 2009).

In the past 20 years, intensive studies have been conducted to estimate the contribution of land use change on $\mathrm{C}$ and $\mathrm{N}$ cycles at both the regional (Wu et al., 2003) and global scales (Nilsson and 
Schopfhauser, 1995; Guo and Gifford, 2002). Many of these studies focus on the conversion of native forests to agricultural systems (Lozano-García and Parras-Alcántara, 2013; Twongyirwe et al., 2013; Gelaw et al., 2014) or pastures (Matos et al., 2010; Fang et al., 2012). However, studies on the SOC and $\mathrm{N}$ stocks after the conversion of the secondary forest to the Chinese fir and Moso bamboo plantations are still rare, although few observed studies have reported soil fertility (Wang et al., 2011), soil labile organic carbon fractions and aggregate stability after the conversion of native forest to Chinese fir plantations (Yang et al., 2009), and soil respiration after the conversion of the Chinese fir plantations to Moso bamboo plantations (Song et al., 2013). Besides, some studies have also focused on the SOC and $\mathrm{N}$ stocks after the conversion of native forest to other plantations, such as rubber plantations (Yang et al., 2004; de Blecourt et al., 2013), Prince Rupprecht's larch and Chinese pine plantations (Wang et al., 2012). Therefore, in this study, we concentrated on a secondary forest, a Chinese fir plantation and a Moso bamboo plantation that converted from the secondary forest to exam the effects of forest conversion on SOC and N stocks. We hypothesized that SOC and N stocks would be higher in the secondary forest compared to the Chinese fir and Moso bamboo plantations because of significant prescribed burning, site preparation in both plantations and one-sixth selective harvest of Moso bamboo plantation every year (Zhou et al., 2011).

\subsection{Materials and methods}

\subsubsection{Study area}

The study was conducted in Shitai County $\left(29^{\circ} 59^{\prime}-30^{\circ} 24^{\prime} \mathrm{N}, 117^{\circ} 12^{\prime}-117^{\circ} 59^{\prime} \mathrm{E}\right)$, which is located in the southern part of Anhui province, China (Fig. 1). The region is characterized by a distinctly seasonal mid-subtropical, humid, mountainous climate. The annual average temperature is $16{ }^{\circ} \mathrm{C}$ with significant seasonality (Lu, 2010). The mean annual precipitation is $1626 \mathrm{~mm}, 71 \%$ of which occurs between April and September (Geng and Wang, 2011). The average annual sunshine duration is 1704 hours and the mean annual solar radiation is $3.08 \mathrm{MJ} \cdot \mathrm{m}^{-2}(\mathrm{Lu}, 2010)$.

\subsubsection{Current and past land use}

According to local plantation owners, the major trajectories of land use change were: (1) secondary forests-Chinese fir plantations, (2) secondary forests-Moso bamboo plantations and (3) secondary forests-tea plantations. Planting Chinese fir and bamboo plantations was more common in 1990s under the financial support of local government, World Bank and German Development Bank (KfW) in study area. Nowadays, $80 \%$ timber output comes from Chinese fir and bamboo plantations. A secondary forest, a Chinese fir and a Moso bamboo plantation with similar site conditions were selected (the distance between the three stands was less than $1 \mathrm{~km}$ ). The secondary forest started from natural regeneration after the primary forest harvest in 1960s. The main species of the secondary forest were Castanopsis sclerophylla (Lindl.) Schott, Liquidambar formosana Hance, Cyclobalanopsis glauca (Thunb.) Oerst. The Chinese fir and Moso bamboo plantations were planted 
in 1996 and 1995 after a clear cutting of a secondary forest, which was same type of the selected secondary forest, by hand without heavy machine in 1996 and 1995, respectively. After clear cutting, the sites were burnt and soils were prepared by digging holes. In the first three-year of the establishment of Chinese fir plantation, understory and weeds were felled to ensure enough sun light for seedlings to improve seedling survival. At year of 2010 and 2013, 10\% (volume) thinning was conducted. The suppressed and weak trees were felled and then moved out of the stand four months later. Branch and leaves of felled trees were left in the stand. In the first two years after planting Moso bamboo plantation, the understory and weeds were removed. Five years later, first selective cutting was implemented. The years later, one-sixth selective cutting of stand bamboos was conducted every year. The whole bamboo stem was removed out of stand and the branches and leaves were left in the stand. In addition, digging bamboo shoots occurred in every winter and early spring. More stand information was shown in Table 1.
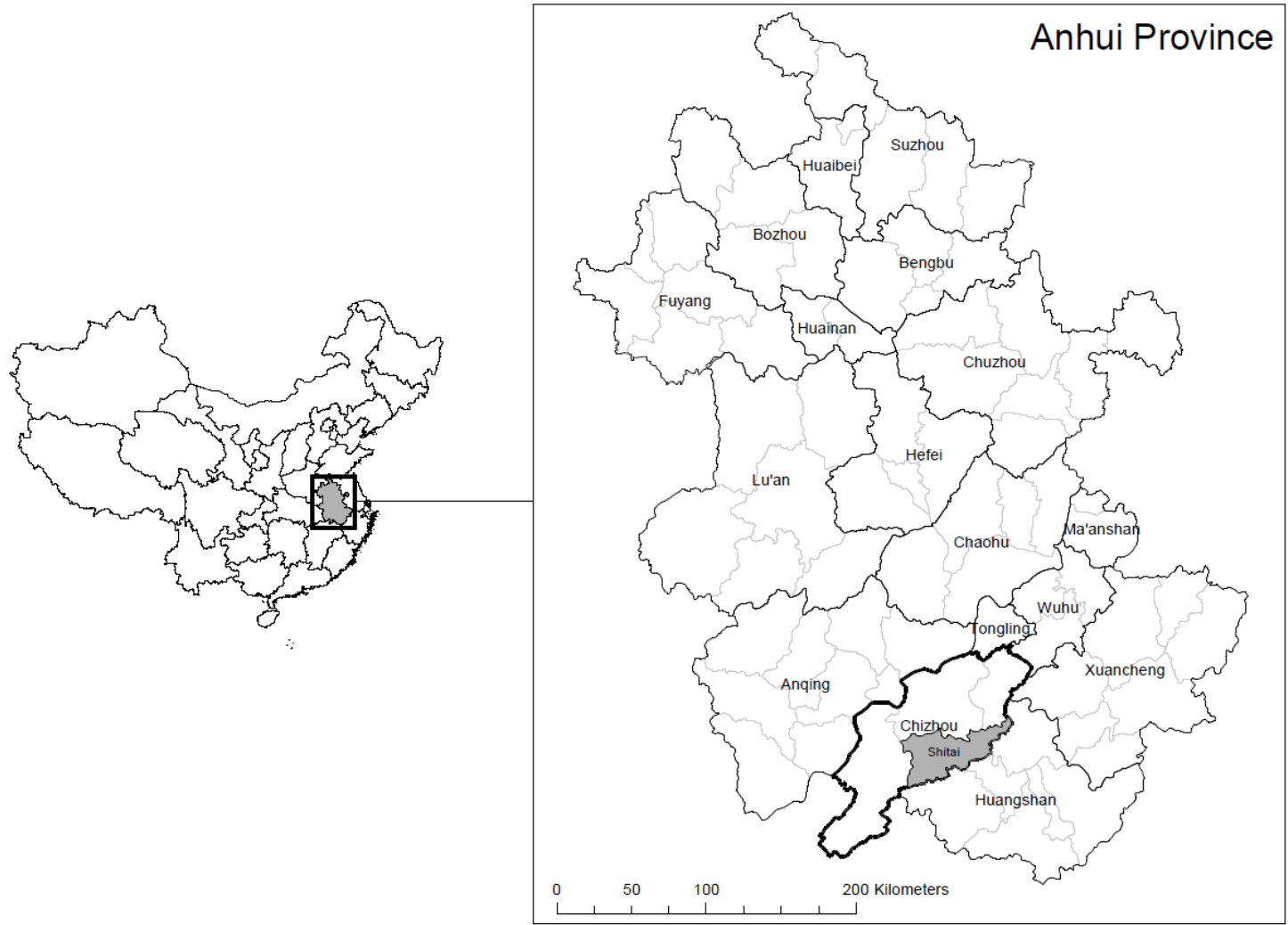

Fig. 1. Location of Shitai County in the southern part of Anhui Province, South-Eastern China.

\subsubsection{Study design}

In the selected stands, systematic grids of $100 \mathrm{~m} \times 100 \mathrm{~m}$ were established, among which, 6 grids in the secondary, 5 grids in the Chinese fir plantation and 3 grids in the Moso bamboo plantation depends on stand area were selected for permanent plots. A temporary plot was located $25 \mathrm{~m}$ north of each permanent plot. In both permanent and temporary plots, nested circular plots with an inner radius of $6 \mathrm{~m}$ and an outer radius of $10 \mathrm{~m}$ radius were established. 
Table 1 Brief descriptions of the secondary forest, Chinese fir and Moso bamboo plantations.

\begin{tabular}{llll}
\hline Variables & Secondary forest & Chinese fir & Moso bamboo \\
\hline Elevation $(\mathrm{m})$ & 137 & 202 & 163 \\
Slope $\left({ }^{\circ}\right)$ & 27 & 30 & 28 \\
Planted year & $1960 \mathrm{~s}$ & 1996 & 1995 \\
Density $\left(\right.$ trees $\left.\cdot \mathrm{ha}^{-1}\right)$ & 894 & 1593 & 2210 \\
Basal area $\left(\mathrm{m}^{2} \cdot \mathrm{ha}^{-1}\right)$ & 28 & 32 & 23 \\
Mean DBH $(\mathrm{cm})$ & 21.9 & 18.3 & 11.5 \\
Mean Height $(\mathrm{m})$ & 12.3 & 13.4 & 10.1 \\
Number of plots & 6 & 5 & 3 \\
Area (ha) & 9.6 & 22 & 7.2 \\
Soil type & Alfisol & Alfisol & Alfisol \\
Soil texture & silty clay loam & silty clay loam & silty clay loam \\
\hline
\end{tabular}

$\mathrm{DBH}$ is the diameter at breast height $(1.3 \mathrm{~m})$.

\subsubsection{Soil sampling and analysis}

Soil samples were collected in three profiles in November, 2013, lying at $0^{\circ}, 120^{\circ}$ and $240^{\circ}$, starting from north direction and $3 \mathrm{~m}$ distance to plot center in each temporary plot (Fig. 2). Soil samples were collected down to $50 \mathrm{~cm}$ in four layers: $0-10 \mathrm{~cm}, 10-20 \mathrm{~cm}, 20-30 \mathrm{~cm}$ and $30-50 \mathrm{~cm}$. In the field, soil samples from the same layer were mixed within each plot. In the lab, mineral soil was air-dried in the room temperature and sieved through 2-mm and $0.15-\mathrm{mm}$ for total SOC and $\mathrm{N}$ concentration analysis. Identifiable plant residues, root materials, and stones were removed during sieving. The soil was cored in the depth layers to take volumetric samples for bulk density determination (Zhang et al., 1999a). $20 \%$ of bulk density samples were randomly selected for stones or rock content determination, however, there were very few stones or rock fragments in the core samples, thus we did not correct for gravel content.

SOC concentration was determined using the $\mathrm{K}_{2} \mathrm{Cr}_{2} \mathrm{O}_{7}-\mathrm{H}_{2} \mathrm{SO}_{4}$ wet oxidation method. Briefly, first, 0.1-0.5 g air dried soil samples passed by $0.15 \mathrm{~mm}$ were digested by $5 \mathrm{ml}$ of $0.8 \mathrm{~mol} \cdot \mathrm{L}^{-1} \mathrm{~K}_{2} \mathrm{Cr}_{2} \mathrm{O}_{7}$ and $5 \mathrm{ml}$ concentrated $\mathrm{H}_{2} \mathrm{SO}_{4}\left(1.84 \mathrm{~g} \cdot \mathrm{mL}^{-1}\right)$ for $5 \mathrm{~min}$ at $170-180{ }^{\circ} \mathrm{C}$. Second, digested solution samples was titrated with standardized $0.2 \mathrm{~mol} \cdot \mathrm{L}^{-1} \mathrm{FeSO}_{4}$ solution mixed with $15 \mathrm{ml}$ concentrated $\mathrm{H}_{2} \mathrm{SO}_{4}$ per liter to prevent oxidization (Zhang et al., 1999c). N content was analysed using the Kjeldahl digestion procedure. Shortly, $1.0 \mathrm{~g}$ air-dried soil samples passed by $0.15 \mathrm{~mm}$ was digested with $5 \mathrm{ml}$ concentrated $\mathrm{H}_{2} \mathrm{SO}_{4}$ in a Kjeldahl flask by heating for one hour. An aliquot of digested solution was titrated with $0.2 \mathrm{~mol} \cdot \mathrm{L}^{-1}$ standardized $\mathrm{Na}_{2} \mathrm{~B}_{4} \mathrm{O}_{7}$ using automatic Kjeltec (FOSS, Denmark) (Zhang et al., 1999b). 


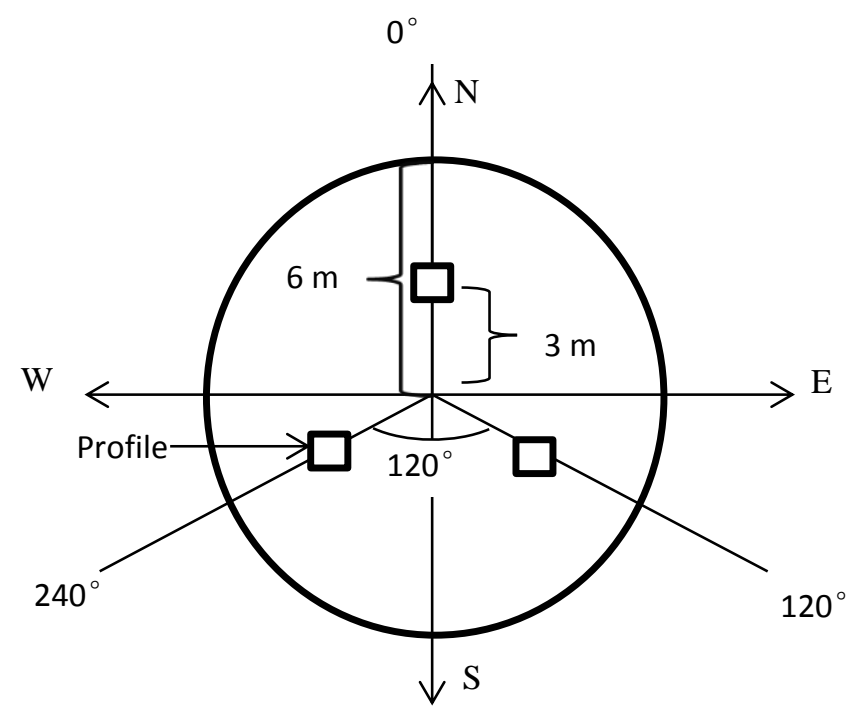

Fig. 2. The distributions of soil profiles in the temporary plots.

\subsubsection{Total SOC and TN stock}

The total SOC and TN stocks for each layer were calculated using the following formula (Xie et al., 2007):

$$
\operatorname{TSOC}(T N)=\operatorname{SOC}(N) \times B D \times D / 10
$$

Where TSOC is total SOC stock $\left(\mathrm{t} \cdot \mathrm{ha}^{-1}\right)$; TN is total $\mathrm{N}$ stock $\left(\mathrm{t} \cdot \mathrm{ha}^{-1}\right)$; SOC is the soil organic C concentration $\left(\mathrm{g} \cdot \mathrm{kg}^{-1}\right)$; $\mathrm{N}$ is the nitrogen content $\left(\mathrm{g} \cdot \mathrm{kg}^{-1}\right)$; BD is bulk density $\left(\mathrm{g} \cdot \mathrm{cm}^{-3}\right)$; D is the depth of soil layer $(\mathrm{cm})$.

\subsubsection{Statistical analysis}

One-way analysis of variance (ANOVA) was used to test the significant difference. Tukey-HSD was applied to test the significance of multiple comparisons. The difference level was set at $P<0.05$. All statistical analyses were performed in R 3.0.2 (Kabacoff, 2011).

\subsection{Results}

\subsubsection{SOC and $\mathbf{N}$ concentrations across soil depths and land use systems}

The soil bulk density showed an increasing trend with the soil depth among the three land uses (Table 2). The soil bulk density was lowest in top $0-10 \mathrm{~cm}$ in the secondary forest, and it was significantly lower $(P<0.05)$ than that of Chinese fir plantation. The soil bulk density was not statistically significant difference in the sub-layers $(10-50 \mathrm{~cm})$ for the three land uses. In the same land use, significant difference of soil bulk density was observed among different layers $(P<0.05)$; meanwhile, the soil bulk density at $30-50 \mathrm{~cm}$ was significantly higher than that of $0-10 \mathrm{~cm}$ for the three land uses $(P<0.05)$; however, it did not differ significantly between $0-10 \mathrm{~cm}$ and $10-20 \mathrm{~cm}$. 
Table 2 Soil bulk density $\left(\mathrm{g} \cdot \mathrm{cm}^{-3}\right)$, SOC concentration $\left(\mathrm{g} \cdot \mathrm{kg}^{-1}\right), \mathrm{N}$ concentration $\left(\mathrm{g} \cdot \mathrm{kg}^{-1}\right)$ and C:N in the secondary forest, Chinese fir and Moso bamboo plantations (Mean \pm Standard Error).

\begin{tabular}{llllll}
\hline Forest type & Soil depth & Bulk density & SOC & $\mathrm{N}$ & $\mathrm{C}: \mathrm{N}$ \\
\hline \multirow{3}{*}{ Secondary } & $0-10 \mathrm{~cm}$ & $1.10 \pm 0.03 \mathrm{Aa}$ & $60.36 \pm 3.57 \mathrm{Bc}$ & $2.89 \pm 0.27 \mathrm{Bc}$ & $21.20 \pm 0.94 \mathrm{Ba}$ \\
forest & $10-20 \mathrm{~cm}$ & $1.22 \pm 0.03 \mathrm{Aab}$ & $38.90 \pm 3.16 \mathrm{Bb}$ & $1.87 \pm 0.22 \mathrm{Bb}$ & $21.61 \pm 1.65 \mathrm{Aa}$ \\
& $20-30 \mathrm{~cm}$ & $1.29 \pm 0.03 \mathrm{Abc}$ & $28.33 \pm 3.50 \mathrm{Bab}$ & $1.21 \pm 0.14 \mathrm{Bab}$ & $23.68 \pm 1.60 \mathrm{Aa}$ \\
& $30-50 \mathrm{~cm}$ & $1.35 \pm 0.04 \mathrm{Ac}$ & $20.50 \pm 2.80 \mathrm{Ba}$ & $0.86 \pm 0.13 \mathrm{Ba}$ & $25.26 \pm 2.93 \mathrm{Aa}$ \\
\hline \multirow{3}{*}{ Chinese fir } & $0-10 \mathrm{~cm}$ & $1.23 \pm 0.01 \mathrm{Ba}$ & $36.03 \pm 1.97 \mathrm{Ac}$ & $1.57 \pm 0.17 \mathrm{Ab}$ & $23.80 \pm 1.92 \mathrm{Ba}$ \\
& $10-20 \mathrm{~cm}$ & $1.24 \pm 0.04 \mathrm{Aa}$ & $21.67 \pm 2.24 \mathrm{Ab}$ & $0.98 \pm 0.15 \mathrm{Aab}$ & $23.39 \pm 2.61 \mathrm{Aa}$ \\
& $20-30 \mathrm{~cm}$ & $1.33 \pm 0.05 \mathrm{Ab}$ & $17.71 \pm 2.19 \mathrm{Aab}$ & $0.61 \pm 0.21 \mathrm{Aa}$ & $39.22 \pm 9.54 \mathrm{Aa}$ \\
& $30-50 \mathrm{~cm}$ & $1.39 \pm 0.05 \mathrm{Ab}$ & $11.93 \pm 0.67 \mathrm{Aa}$ & $0.43 \pm 0.16 \mathrm{Aa}$ & $40.15 \pm 9.56 \mathrm{Aa}$ \\
\hline \multirow{2}{*}{ Moso } & $0-10 \mathrm{~cm}$ & $1.14 \pm 0.04 \mathrm{ABa}$ & $35.94 \pm 4.79 \mathrm{Ac}$ & $2.33 \pm 0.29 \mathrm{ABc}$ & $15.39 \pm 0.33 \mathrm{Aa}$ \\
bamboo & $10-20 \mathrm{~cm}$ & $1.19 \pm 0.01 \mathrm{Aab}$ & $26.40 \pm 3.50 \mathrm{Abc}$ & $1.37 \pm 0.17 \mathrm{ABb}$ & $19.75 \pm 3.16 \mathrm{Aa}$ \\
& $20-30 \mathrm{~cm}$ & $1.26 \pm 0.03 \mathrm{Aab}$ & $14.26 \pm 2.34 \mathrm{Aab}$ & $0.74 \pm 0.10 \mathrm{ABab}$ & $19.44 \pm 2.11 \mathrm{Aa}$ \\
& $30-50 \mathrm{~cm}$ & $1.32 \pm 0.04 \mathrm{Ab}$ & $10.70 \pm 1.79 \mathrm{Aa}$ & $0.43 \pm 0.08 \mathrm{Aa}$ & $27.63 \pm 7.16 \mathrm{Aa}$
\end{tabular}

Different upper-case letters or lower-case letters indicated significantly different among different forest types for the same soil layer or different soil layers within the same forest type by Tukey-HSD $(P<0.05)$.

SOC concentration decreased with the soil depth in the three land uses (Table 2). SOC concentration measured in the secondary forest was significantly higher than that of Chinese fir and Moso bamboo plantations for all soil layers $(P<0.01)$, but it was not significantly different between Chinese fir and Moso bamboo plantations. SOC concentration in $0-10 \mathrm{~cm}$ was significantly higher than that of sublayers $(P<0.05)$, except $0-10 \mathrm{~cm}$ and $10-20 \mathrm{~cm}$ in the Moso bamboo plantation. There was no significant difference in SOC concentration between $10-20 \mathrm{~cm}$ and $20-30 \mathrm{~cm}$, as well as $20-30 \mathrm{~cm}$ and $30-50 \mathrm{~cm}$.

The distribution of $\mathrm{N}$ concentration with depth followed a similar trend to that of SOC concentration (Table 2). Significantly higher $N$ concentration was measured in secondary forest for the four soil layers compared to the Chinese fir and Moso bamboo plantations $(P<0.05)$. The measured $\mathrm{N}$ concentration in the Chinese fir plantation was not significantly lower than that of the Moso bamboo plantation for all soil layers. The $\mathrm{N}$ concentration in $0-10 \mathrm{~cm}$ was significantly higher $(P<0.05)$ than that of deeper soil for the three land uses, except $10-20 \mathrm{~cm}$ in the Chinese fir plantation. The $\mathrm{N}$ concentration between $10-20 \mathrm{~cm}$ and $20-30 \mathrm{~cm}, 20-30 \mathrm{~cm}$ and $30-50 \mathrm{~cm}$ was not significantly different, but it reached a statistically significantly different level between $10-20 \mathrm{~cm}$ and $30-50 \mathrm{~cm}$ in the secondary forest and Moso bamboo plantation $(P<0.05)$. 
Although the $\mathrm{C} / \mathrm{N}$ ratio showed an increasing trend with the soil depth, except $20-30 \mathrm{~cm}$ in the Moso bamboo plantation, the ratios did not differ significantly for the three land uses (Table 2). In the top 0$10 \mathrm{~cm}, \mathrm{C} / \mathrm{N}$ ratio in secondary forest was significant higher $(P<0.05)$ than that of Chinese fir and Moso bamboo plantations, but not for deeper layers.

\subsubsection{SOC and N stock across soil depths and land use systems}

Above $30 \mathrm{~cm}$, SOC stock decreased with soil depths (Table 3), but not for 30-50 cm because the soil depth was different. Measured SOC stock in the secondary forest in all layers were significantly higher than that of Chinese fir and Moso bamboo plantations $(P<0.01)$, but it was not significantly different between the Chinese fir and Moso bamboo plantations. SOC stock up to $50 \mathrm{~cm}$ was 203.68 $\mathrm{t} \cdot \mathrm{ha}^{-1}$ in the secondary forest, which was $37 \%$ and $42 \%$ higher than that of Chinese fir and Moso bamboo plantations, and the difference was significant $(P<0.01)$. SOC stock in $0-10 \mathrm{~cm}$ was significantly higher than that of deeper depths under the secondary forest and Chinese fir plantation $(P$ $<0.05$ ); however, the difference of SOC stock between $10-20 \mathrm{~cm}$ and $20-30 \mathrm{~cm}$ were not statistically different. The percentage of SOC of each layer showed a similar trend for all land uses. On average, SOC stock at 0-10 cm accounted for one third of total SOC stock, while SOC in $10-20 \mathrm{~cm}$ and $30-50$ $\mathrm{cm}$ amounted one quarter.

The distribution of $\mathrm{N}$ stock with depth had a similar trend to that of SOC stock (Table 3). $\mathrm{N}$ stock in $0-10 \mathrm{~cm}, 10-20 \mathrm{~cm}$ and $20-30 \mathrm{~cm}$ in secondary forest were significantly higher $(P<0.05)$ than that of the Chinese fir and Moso bamboo plantations. Although N stock in $30-50 \mathrm{~cm}$ in the secondary forest was double to that of the Chinese fir and Moso bamboo plantations, the difference was not statistically different. $\mathrm{N}$ stock was $9.24 \mathrm{t} \cdot \mathrm{ha}^{-1}$ in the secondary forest, which was significantly higher $(P<0.05)$ than that of Chinese fir plantation $\left(5.10 \mathrm{t} \cdot \mathrm{ha}^{-1}\right)$ and Moso bamboo plantation $\left(6.35 \mathrm{t} \cdot \mathrm{ha}^{-1}\right)$. N stock in 0-10 cm significantly differed from that of $20-30 \mathrm{~cm}$ for the three land uses $(P<0.05)$. Calculated $\mathrm{N}$ stock in $10-20 \mathrm{~cm}$ was not significantly different from that of $20-30 \mathrm{~cm}$ and $30-50 \mathrm{~cm}$ for the three land uses, except $20-30 \mathrm{~cm}$ in the secondary forest $(P<0.05)$.

\subsection{Discussion}

The three adjacent sites had the same forest type prior to planting Chinese fir and Moso bamboo plantations in this study, and the soil developed from the same basaltic parent materials, therefore, differences in SOC and N stock were assumed to the results of land use changes as well as the effects of the changes in tree species. It has been recognized that such pseudo-replication is the limitation of such studies (Yang et al., 2009).

\subsubsection{SOC and N concentrations across soil depths and land use systems}

Concentrations of SOC and N decreased with the soil depth in the secondary forest, Chinese fir and Moso bamboo plantations (Table 2). This result agreed with Wang et al. (2012), who observed a declining trend in SOC and N concentrations in Larch and Liaodong oak plantations. De Blécourt et al. 
(2013) also found a decreasing trend of SOC in a rubber plantation and a secondary forest. However, this result was inconsistent with a reported negatively correlation between SOC, N concentrations and soil depth in Kafa, Southwest Ethiopia (Aticho, 2013), as well as Faidherbia albida based agroforestry (Gelaw et al., 2014). Gelaw et al. (2014) attributed the difference to the mixed effects of tillage of top soil in the agroforestry.

Table $3 \mathrm{SOC}$ and $\mathrm{N}$ stocks $\left(\mathrm{t} \cdot \mathrm{ha}^{-1}\right)$ in the secondary forest, Chinese fir and Moso bamboo plantations (Mean \pm Standard Error).

\begin{tabular}{clllll}
\hline Forest type & Soil depth & SOC stock & Percent & N stock & Percent \\
\hline & $0-10 \mathrm{~cm}$ & $66.06 \pm 2.89 \mathrm{Bc}$ & $32 \%$ & $3.16 \pm 0.25 \mathrm{Bb}$ & $34 \%$ \\
Secondary & $10-20 \mathrm{~cm}$ & $46.96 \pm 3.11 \mathrm{Bab}$ & $23 \%$ & $2.25 \pm 0.25 \mathrm{Bab}$ & $24 \%$ \\
forest & $20-30 \mathrm{~cm}$ & $36.25 \pm 4.07 \mathrm{Ba}$ & $18 \%$ & $1.55 \pm 0.16 \mathrm{Ba}$ & $17 \%$ \\
& $30-50 \mathrm{~cm}$ & $54.41 \pm 6.33 \mathrm{Bbc}$ & $27 \%$ & $2.27 \pm 0.32 \mathrm{Aab}$ & $25 \%$ \\
& Total & $203.68 \pm 14.27 \mathrm{~B}$ & $100 \%$ & $9.24 \pm 0.78 \mathrm{~B}$ & $100 \%$ \\
\hline \multirow{5}{*}{ Chinese fir } & $0-10 \mathrm{~cm}$ & $44.38 \pm 2.50 \mathrm{Ac}$ & $35 \%$ & $1.94 \pm 0.23 \mathrm{ABb}$ & $38 \%$ \\
& $10-20 \mathrm{~cm}$ & $26.76 \pm 2.60 \mathrm{Aab}$ & $21 \%$ & $1.21 \pm 0.17 \mathrm{Aab}$ & $24 \%$ \\
& $20-30 \mathrm{~cm}$ & $23.27 \pm 2.43 \mathrm{Aa}$ & $18 \%$ & $0.78 \pm 0.23 \mathrm{ABa}$ & $15 \%$ \\
& $30-50 \mathrm{~cm}$ & $32.93 \pm 1.64 \mathrm{Ab}$ & $26 \%$ & $1.17 \pm 0.42 \mathrm{Aab}$ & $23 \%$ \\
\hline \multirow{5}{*}{ Total } & $127.34 \pm 7.75 \mathrm{~A}$ & $100 \%$ & $5.10 \pm 0.86 \mathrm{~A}$ & $100 \%$ \\
\hline bamboo & $0-10 \mathrm{~cm}$ & $40.98 \pm 5.34 \mathrm{Ab}$ & $35 \%$ & $2.66 \pm 0.35 \mathrm{Ab}$ & $42 \%$ \\
& $10-20 \mathrm{~cm}$ & $31.50 \pm 4.46 \mathrm{Aab}$ & $27 \%$ & $1.63 \pm 0.21 \mathrm{ABab}$ & $26 \%$ \\
& $20-30 \mathrm{~cm}$ & $17.86 \pm 2.46 \mathrm{Aa}$ & $15 \%$ & $0.93 \pm 0.11 \mathrm{Aa}$ & $15 \%$ \\
& $30-50 \mathrm{~cm}$ & $27.91 \pm 3.98 \mathrm{Aab}$ & $23 \%$ & $1.14 \pm 0.26 \mathrm{Aa}$ & $17 \%$ \\
& Total & $118.25 \pm 14.79 \mathrm{~A}$ & $100 \%$ & $6.35 \pm 0.77 \mathrm{~A}$ & $100 \%$
\end{tabular}

Different upper-case letters or lower-case letters indicated significantly different among different forest types for the same soil layer or different soil layers within the same forest type by Tukey-HSD $(\mathrm{P}<0.05)$.

The distribution of SOC and N concentrations with depth showed higher concentrations in the $0-10$ $\mathrm{cm}$ in all the three land uses, suggesting the high risks of large amounts of $\mathrm{C}$ loss from topsoil when significant soil disturbances occur. The relative contributions of each soil layer in this study were comparable with the observations in temperate forest in other regions (Yang et al., 2004).

The significant higher SOC and N concentrations in the secondary forest than the Chinese fir and Moso bamboo plantations indicated that converting secondary forest to Chinese fir and Moso bamboo plantations could decrease SOC and N concentrations. The result is similar to Yang et al. (2004), who found the conversion of secondary forests to rubber plantations decreased both SOC and $\mathrm{N}$ 
concentrations. Significant higher SOC and N concentrations was found in each layer in the secondary forest, demonstrating that the conversion of the secondary forest to the Chinese fir and Moso bamboo plantations did not only decrease soil surface SOC and N concentrations, but also decline SOC and N concentrations in sub-layers. This is comparable to a similar study that the conversion of native forest to popular plantation decreases SOC up to $55 \mathrm{~cm}$ (Ferré et al., 2014). However, our result does not agree with Yang et al. (2004), who observed that converting secondary forests to rubber plantations did not change SOC and N concentrations when soil was deeper than $40 \mathrm{~cm}$. Our result also differed Gelaw's et al. (2014) observation that no significant difference of SOC and N concentrations was detected in different land use changes when soil was deeper than $30 \mathrm{~cm}$ due the soil disturbances only happened in the top soil in these agroforestry ecosystems.

\subsubsection{SOC and N stocks across soil depths and land use systems}

If we take the secondary forest as a baseline, the conversion of the secondary forest decreased total SOC and N stocks. This agrees with our hypothesis. This result is consistent with Yang et al. (2004), who observed that the conversion of native forest to plantations and croplands lead 23\%-34\% and $20 \%-32 \%$ decline in SOC and N stocks, respectively. Similarly, the conversion of the secondary forest to Chinese fir plantations decreased SOC and N stocks in subtropical China (Wang et al., 2012). Additionally based on a meta-analysis, on average, the conversion of native forests to plantations decreases SOC stock by $13 \%$ (Guo and Gifford, 2002).

The factors attributed to these changes in SOC and N stocks are complex. First, the SOC and N stock loss may be partly responsible for prescribed burning. To improve seedling survival and growth rates, the sites were burnt before planting Chinese fir seedlings and mother Moso bamboo. This practice could direct decrease SOC and N stocks due to the lack of understory and soil bareness, which could increase soil erosion at soil surface. This can be obtained by the significant increase in the soil bulk density in Chinese fir planation compared to the secondary forest, leading to the significantly decrease the top layer SOC and N concentrations (Table 2), as well as their stocks (Table 3). Similar results were found in other studies. For example, harvest and prescribed burning decreased total SOC by $6.6 \%$, and four years later, SOC declined by another $10.1 \%$ due to soil erosion in Chinese fir plantations (Chen and Wang, 2007). Six years later followed prescribed burning, the total SOC and N stocks loss are 6.9 and 6.0 times higher compared the sites without burning (Ma et al., 1996).

Second, site preparation is another important factor for decreasing SOC and N stock. Site preparation after clear-cut aims to improve soil structure to improve survival rate and to promote growth of young seedlings. Planting holes with $20 \mathrm{~cm}$ to $30 \mathrm{~cm}$ depth were established when planting Chinese fir seedlings, and even deeper planting holes with $50 \mathrm{~cm}$ to $60 \mathrm{~cm}$ depth were established for planting mother Moso bamboo according to local residence descriptions. These significant soil disturbances resulted in decomposition of SOC and $\mathrm{N}$ loss occurring at different rates in different depths of soil 
profiles by breaking the physical protection SOC and N (Guo and Gifford, 2002; Wang et al., 2011), and increasing the frequency of erosion after rainfall, especially in the first year (Chen and Wang, 2007).

Third, SOC stock is also affected by tree species because some tree species can produce and accumulate more litter or root than other species affecting SOC (Lugo and Brown, 1993; Guo and Gifford, 2002). This has been confirmed by other studies that both SOC and N stocks decreased under conifer plantations compared to broadleaf forests (Wang et al., 2011), while planting broadleaf trees had no effect on SOC (Guo and Gifford, 2002). Besides, different tree species have different C allocation strategies that could lead to differences in pattern, rate, quality and quantity of $\mathrm{C}$ input to the soil (Lugo and Brown, 1993). These differences between conifer, bamboo and broadleaf forests may be responsible to their individual strategy to allocate $\mathrm{C}$ to belowground. In this study, one sixth of total standing biomass was harvested in Moso bamboo forest every year, which could lead a significant output of biomass from the stand and thereby decreased the $\mathrm{C}$ and litter input to belowground.

Fourth, root biomass and turnover may be another important driver for SOC accumulation, at least in the short-term (Lugo and Brown, 1993). Previous studies showed that biomass of fine roots in pine forest were only $2.9 \%$ of that of poplar plantation during three years study (Coleman et al., 2000).

Fifth, forest age after the conversion may be another important determinant for SOC and N stock. SOC and N stocks suffered from a decrease in new-planted plantations because: (1) destruction of existing litter when planting seedlings; (2) significant decrease in litter input before crown closure; (3) increasing SOC and N mineralization rate (Chen and Wang, 2007). The time span after the forest conversion was 17-year for Chinese fir plantation and 18-year Moso bamboo forest, which was relatively short, because SOC stock decreases in the early establishment of plantation and recovers to initial stage in 30-40 years (Guo and Gifford, 2002; Paul et al., 2002; Cook et al., 2014). For example, converting of native forests to Abies fabri and Picea asperata plantations decreased the SOC stock in the first few years, and the SOC stock in Abies fabri and Picea asperata plantations increases with plantation age (Liu et al., 2002). Similarly, after 34 years of the conversion of broadleaf forests to conifer plantations, the SOC stock did not change and maintained the similar levels (Cook et al., 2014). At the same time, the decrease in the litterfall due to the high frequency of thinning and selective cutting in relative young plantations could lead the decline in $\mathrm{C}$ input back into soil.

\subsection{Conclusions}

The study was conducted in a secondary forest, a Chinese fir and a Moso bamboo plantation, which could contribute the understanding of the effects of land use changes on the SOC and N stocks. The soil bulk density increased with soil depth, while the SOC and $\mathrm{N}$ concentrations decreased with soil 
depth in the three land uses. SOC and $\mathrm{N}$ concentrations in the secondary forest were significantly higher than that of Chinese fir and Moso bamboo plantations for all depths, suggesting the conversion of the secondary forest to Chinese fir and Moso bamboo planations did not only decrease the SOC and $\mathrm{N}$ concentrations in top layer, but also decrease the SOC and N concentrations in sub-layers. SOC and $\mathrm{N}$ concentrations in $0-10 \mathrm{~cm}$ were significantly higher than those of deeper layers, indicating the high risk of the SOC and N loss in the top layer after the land use changes, SOC and N stocks in the secondary forest were significantly higher in all soil layers compared with Chinese fir and Moso bamboo plantations. This result indicates that the conversion of the secondary forest to Chinese fir and Moso bamboo plantations significantly reduced SOC and $\mathrm{N}$ stocks over 0-50 cm. However, this study could not provide data evidence for the time required to reach equilibrium of SOC and $\mathrm{N}$ stock to the secondary forest due to one-time soil sampling in relatively short time period after the forest conversion.

\section{Acknowledgements}

This study was part of "948 project" of State Forest Administration (2013-4-70), special research fund of International Centre for Bamboo and Rattan (1632013010) supported by International Centre for Bamboo and Rattan (ICBR) and the Lin $^{2}$ Value project (033L049) supported by the Federal Ministry of Education and Research (BMBF, Bundesministerium für Bildung und Forschung). We thank two anonymous reviewers for valuable suggestions to improve the article. We thank Director An'guo Fan, Mr. Bailing Ding, Miss Yue'e Chu from Shitai Forest bureau for kind organization for fieldwork. Thanks to Mr. Xiaozhu Wang and Mr. Hongbing Ruan for fieldwork support.

\subsection{References}

Aticho A. 2013. Evaluating Organic Carbon Storage Capacity of forest soil: Case study in the Kafa Zone Bita District, South Western Ethiopia. American-Eurasian Journal of Agriculture and Environmental Science 13: 95-100.

Bond-Lamberty B, Thomson A. 2010. Temperature-associated increases in the global soil respiration record. Nature 464: 579-582.

Chen JN, Wang SL. 2007. Dynamic of soil carbon pool in Cunninghamia lanceolata plantation: recent advances and future prospects. Guangxi Forestry Science 36: 147-151 (in Chinese).

Coleman M, Dickson R, Isebrands J. 2000. Contrasting fine-root production, survival and soil $\mathrm{CO}_{2}$ efflux in pine and poplar plantations. Plant and Soil 225: 129-139.

Cook RL, Binkley D, Mendes JCT, Stape JL. 2014. Soil carbon stocks and forest biomass following conversion of pasture to broadleaf and conifer plantations in southeastern Brazil. Forest Ecology and Management 324: 37-45. 
de Blecourt M, Brumme R, Xu J, Corre MD, Veldkamp E. 2013. Soil carbon stocks decrease following conversion of secondary forests to rubber (Hevea brasiliensis) plantations. PloS one 8: e69357.

Fang X, Xue ZJ, Li BC, An SS. 2012. Soil organic carbon distribution in relation to land use and its storage in a small watershed of the Loess Plateau, China. CATENA 88: 6-13.

Ferré C, Comolli R, Leip A, Seufert G. 2014. Forest conversion to poplar plantation in a Lombardy floodplain (Italy): effects on soil organic carbon stock. Biogeosciences Discussions 11: 96019627.

Fu X, Shao M, Wei X, Horton R. 2010. Soil organic carbon and total nitrogen as affected by vegetation types in Northern Loess Plateau of China. Geoderma 155: 31-35.

Gelaw AM, Singh BR, Lal R. 2014. Soil organic carbon and total nitrogen stocks under different land uses in a semi-arid watershed in Tigray, Northern Ethiopia. Agriculture Ecosystems \& Environment 188: 256-263.

Geng TS, Wang HH. 2011. Research on the water and soil conservation in Shitai County of Anhui Province. Journal of Anhui Agriculture Science 39: 451-452, 482 (in Chinese with English abstract).

Guo LB, Gifford RM. 2002. Soil carbon stocks and land use change: a meta analysis. Global Change Biology 8: 345-360.

IPCC. 2007. Climate Change 2007: Synthesis Report. Contribution of Working Groups I, II and III to the Fourth Assessment Report of the Intergovernmental Panel on Climate Change. 36-41p.

Jia Z, Zhang J, Wang X, Xu J, Li Z. 2009. Report for Chinese forest resource-The $7^{\text {th }}$ national forest inventory. Beijing(in Chinese): China Forestry Publishing House. 2p.

Kabacoff RI. 2011. R in Action. R Daagw editor. Data analysis and graphics with R. New York, USA: Manning Publications Co., p219-243.

Liu J, Jiang PK, Wang HL, Zhou GM, Wu JS, Yang F, Qian XB. 2011. Seasonal soil $\mathrm{CO}_{2}$ efflux dynamics after land use change from a natural forest to Moso bamboo plantations in subtropical China. Forest Ecology and Management 262: 1131-1137.

Liu SL, Fu BJ, Chen LD, Lu YH, Ma KM. 2002. Effects of land use changes on soil properties in Wolong Nature Reserve. Geographical Research 21: 682-688.

Lozano-García B, Parras-Alcántara L. 2013. Land use and management effects on carbon and nitrogen in Mediterranean Cambisols. Agriculture, Ecosystems \& Environment 179: 208-214.

Lu CM. 2010. Rock-soil geochemical features for Dashan Area, Shitai, Anhui. Geology of Anhui 20: 120-125 (in Chinese with English abstract).

Lugo A, Brown S. 1993. Management of tropical soils as sinks or sources of atmospheric carbon. Plant and Soil 149: 27-41.

Luo Y, Zhou X. 2006. Soil respiration and the environment. San Diego, California: Academic press. 18-20p. 
Ma X, Yang Y, Lin K, Liu A, He Z. 1996. Effect of different ground clearance on Chinese fir plantation ecosystems. Acta Ecologica Sinica 17: 176-183.

Matos ES, Freese D, Mendonça ES, Slazak A, Hüttl RF. 2010. Carbon, nitrogen and organic C fractions in topsoil affected by conversion from silvopastoral to different land use systems. Agroforestry Systems 81: 203-211.

Nilsson S, Schopfhauser W. 1995. The carbon-sequestration potential of a global afforestation program. Climatic Change 30: 267-293.

Paul KI, Polglase PJ, Nyakuengama JG, Khanna PK. 2002. Change in soil carbon following afforestation. Forest Ecology and Management 168: 241-257.

Post WM, Kwon KC. 2000. Soil carbon sequestration and land-use change: processes and potential. Global Change Biology 6: 317-327.

Song X, Yuan H, Kimberley MO, Jiang H, Zhou G, Wang H. 2013. Soil $\mathrm{CO}_{2}$ flux dynamics in the two main plantation forest types in subtropical China. Science of The Total Environment 444: 363-368.

Twongyirwe R, Sheil D, Majaliwa JGM, Ebanyat P, Tenywa MM, van Heist M, Kumar L. 2013. Variability of soil organic carbon stocks under different land uses: A study in an afro-montane landscape in southwestern Uganda. Geoderma 193: 282-289.

Wang Q, Wang S, Yu X. 2011. Decline of soil fertility during forest conversion of secondary forest to Chinese Fir plantations in subtropical China. Land Degradation \& Development 22: 444-452.

Wang S, Wang X, Ouyang Z. 2012. Effects of land use, climate, topography and soil properties on regional soil organic carbon and total nitrogen in the Upstream Watershed of Miyun Reservoir, North China. Journal of Environmental Sciences 24: 387-395.

Watson RT, Noble IR, Bolin B, Ravindranath N, Verardo DJ, Dokken DJ. 2000. Land use, land-use change, and forestry: a special report of the intergovernmental panel on climate change: Cambridge University Press.

Wu H, Guo Z, Peng C. 2003. Land use induced changes of organic carbon storage in soils of China. Global Change Biology 9: 305-315.

Xie Z, Zhu J, Liu G, Cadisch G, Hasegawa T, Chen C, Sun H, Tang H, Zeng Q. 2007. Soil organic carbon stocks in China and changes from 1980s to 2000s. Global Change Biology 13: 1989-2007.

Yang JC, Huang JH, Pan QM, Tang JW, Han XG. 2004. Long-term impacts of land-use change on dynamics of tropical soil carbon and nitrogen pools. Journal of Environmental Sciences 16: 256261.

Yang Y, Guo J, Chen G, Yin Y, Gao R, Lin C. 2009. Effects of forest conversion on soil labile organic carbon fractions and aggregate stability in subtropical China. Plant and Soil 323: 153162. 
Zhang LH, Xie ZK, Zhao RF, Wang YJ. 2012. The impact of land use change on soil organic carbon and labile organic carbon stocks in the Longzhong region of Loess Plateau. Journal of Arid Land 4: $241-250$.

Zhang WR, Yang GY, Tu XN, Zhang P. 1999a. Determination of forest soil water-physical properties. Beijing: China Standard Press, p21-24 (in Chinese).

Zhang WR, Yang GY, Tu XN, Zhang P. 1999b. Determination of total nitrogen in forest soil. Beijing: China Standard Press, p74-77 (in Chinese).

Zhang WR, Yang GY, Tu XN, Zhang P. 1999c. Determinatlon of organic matter in forest soil and calculation carbon-nitrogen ratio. Zhang WR, Yang GY, Tu XN, Zhang P editors. Standards of forest soil measurement. Beijing, China: China Standard Press, p105-108 (in Chinese).

Zhang XQ, Kirschbaum MUF, Hou ZH, Guo ZH. 2004. Carbon stock changes in successive rotations of Chinese fir (Cunninghamia lanceolata (lamb) hook) plantations. Forest Ecology and Management 202: 131-147.

Zhao MF, Xiang WH, Peng CH, Tian DL. 2009. Simulating age-related changes in carbon storage and allocation in a Chinese fir plantation growing in southern China using the 3-PG model. Forest Ecology and Management 257: 1520-1531.

Zhou G, Meng C, Jiang P, Xu Q. 2011. Review of Carbon Fixation in Bamboo Forests in China. The botanical review 77: 262-270.

Zhou GM, Xu JM, Jiang PK. 2006. Effect of management practices on seasonal dynamics of organic carbon in soils under bamboo plantations. Pedosphere 16: 525-531. 


\section{Chapter VII}

\section{Inventory-based estimation of forest biomass in Shitai County, China - A comparison of five methods}

Xiaolu Tang ${ }^{*}$, Lutz Fehrmann, Fengying Guan, David I. Forrester, Rubén Guisasola, Christoph Kleinn

Status: submitted to Annals of Forest Research

Contribution by Xiaolu Tang: $80 \%$

- Design the manuscript

- Collect data

- Analyze data

- Write and revise manuscript

*Corresponding author: xtang@gwdg.de 
Chapter VII: Inventory-based biomass estimation 


\title{
Inventory-based estimation of forest biomass in Shitai County, China - A comparison of five methods
}

\author{
Xiaolu Tang ${ }^{1}$, Lutz Fehrmann ${ }^{1}$, Fengying Guan ${ }^{2}$, David I. Forrester ${ }^{3}$, Rubén Guisasola ${ }^{3}$, Christoph \\ Kleinn $^{1}$ \\ ${ }^{1}$ Chair of Forest Inventory and Remote Sensing, Georg-August-Universität Göttingen, Büsgenweg 5, \\ 37077 Göttingen, Germany \\ ${ }^{2}$ Key laboratory of Bamboo and Rattan, International Centre for Bamboo and Rattan, No.8, Futong \\ Dongdajie, Wangjing, Chaoyang District, Beijing 100102, P.R. China \\ ${ }^{3}$ Chair of Silviculture, Faculty of Environment and Natural Resources, Freiburg University, \\ Tennenbacherstr. 4, 79108 Freiburg, Germany
}

\begin{abstract}
Several comparative studies have reported that there can be great discrepancies between different methods used to estimate forest biomass. With the development of carbon markets, an accurate estimation at the regional scale (i.e. county level) is becoming increasingly important for local government. In this study, we applied five methodologies [continuous biomass expansion factor (CBEF) approach, mean biomass density (MB) approach, mean biomass expansion factor (MBEF) approach, national continuous biomass expansion factors (NCBEF) proposed by Fang et al (2002), standard IPCC approach] to estimate the total biomass for Shitai county, China. The CBEF is generally considered to be the most realistic estimates in term of regional biomass CBEF reflects the change of BEF to stand density, stand age and site conditions. The forests of the whole county were divided into four forest types, namely Chinese fir plantations (CF), hardwood broadleaved forests (HB), softwood-broadleaved forests (SB) and mason pine forests according to local forest management inventory in 2004. Generally, the MBEF approach overestimated forest biomass while the IPCC approach underestimated forest biomass for all forest types when CBEF derived biomass was used as a control. The MB approach provided the most similar biomass estimates for all forest types and could be an alternative approach when the CBEF equation is lacking in the study area. The total biomass derived from MBEF was highest at $1.44 \times 10^{7} \mathrm{t}$, followed by $1.32 \times 10^{7} \mathrm{t}$ from CBEF, 1.31 $\times 10^{7} \mathrm{t}$ from NCBEF, $1.25 \times 10^{7} \mathrm{t}$ from MB and $1.16 \times 10^{7} \mathrm{t}$ from IPCC. Our results facilitate method selection for regional forest biomass estimation and provide statistical evidence for local government planning to enter the potential carbon market.
\end{abstract}

Key words: biomass expansion factors (BEFs), forest type, forest inventory, carbon market 


\subsection{Introduction}

Forest biomass accounts for $80 \%$ of the global terrestrial vegetation biomass (Dixon et al., 1994), and it has become a core research interest due to the important role of forests with regards to mitigating global climate change (Guo et al., 2010; Seo et al., 2013). According to the United Nations Framework Convention on Climate Change (UNFCCC), signatory countries are obliged to report greenhouse gas emissions and removal (Bettelli et al., 1997). Forests act as a continuous carbon sink of 1.9-2.6 $\mathrm{Pg} \mathrm{C} \mathrm{a}^{-1}$, accounting for 33\% of carbon emission from fossil fuel and land use changes (Houghton, 2007; IPCC, 2007; Pan et al., 2011), thus forests play an important role in mitigating and alleviating global climate change (Bonan, 2008). However, different methods generate different biomass estimates (Guo et al., 2010). For example, based on the national forest inventory in 19992003, China's forest biomass carbon stock ranged from 5.7 Pg C (1 Pg C $\left.=10^{15} \mathrm{~g} \mathrm{C}\right)$ derived from the continuous biomass expansion factor (CBEF) approach to $7.7 \mathrm{Pg} \mathrm{C}$ derived from the mean biomass density (MB) approach. Thus, applying appropriate methods for regional forest biomass estimation are important for accurate estimation (Fang et al., 1998), which is itself essential when reporting data to the UNFCCC (IPCC, 2006) and an essential step to enter into the carbon market.

Some early efforts in the 1970s were made to estimate the regional, national and global scale forest biomass using the MB approach (Whittaker and Likens, 1973; Woodwell, 1978). This simplifying approach simply multiplies mean biomass observed from field measurement by forest area. However, direct field measurements with greater biomass than the mean biomass level in a region can lead an overestimation of forest biomass (Brown and Lugo, 1984; Fang et al., 2005; Guo et al., 2010). With the increasing cover of forest inventories, inventory data has been widely used to estimate the forest biomass at a large scale (Schroeder et al., 1997; Fang et al., 1998; Fang et al., 2005; Guo et al., 2010). Since most inventories record detailed information on stand volume by age class and tree species, it is possible and useful to calculate a biomass expansion factor (BEF) to convert stand volume to stand biomass, including the non-commercial biomass such as branches, leaves and roots (Fang and Wang, 2001; Guo et al., 2010). Sharp et al. (1975) estimated the regional forest biomass for Northern Carolina in the USA using a constant BEF of $2.0 \mathrm{Mg} \cdot \mathrm{m}^{-3}$. However, more recent studies have indicated that the BEF is not a constant value and varies with forest age, site class and stand density (Fang and Wang, 2001; Lehtonen et al., 2004; Teobaldelli et al., 2009; Correia et al., 2010). Thus, applying constant BEFs values across all age classes and site conditions within a forest type underestimates the forest biomass of younger and less productive stands and overestimates the forest biomass of older and more productive stands (Fang et al., 1998; Goodale et al., 2002). To reduce the bias of constant BEFs, BEF equations have been developed that include stand variables as predictors (Teobaldelli et al., 2009; Guo et al., 2010; González-García et al., 2013). Because it is difficult or inefficient to obtain BEFs for each age and site class at regional or national scales, Fang et al. (1998, 2001) and Fang and Wang (2001) derived a simple linear relationship between BEFs and stem volume 
using field inventory data across China. Since the stand volume could reflect the impacts of stand age, stand density and other factors on biomass, it can be used to calculate the forest biomass using forest area and volume derived from forest inventory data without information about age, site class, etc (Fang et al., 2002; Guo et al., 2010).

In order to establish an international standard estimation of forest biomass, IPCC (2003) proposed a similar approach using forest volume, wood density, BEF and the shoot/root ratio. Many reference values for wood density, BEF and shoot/root ratios for different forest types were also provided (IPCC, 2003). This simplifies the biomass estimation and comparison globally. Using the constant BEF proposed by IPCC (2003), the total forest biomass of five provinces in China reported by Li et al. (2012) was $1.79 \times 10^{9} \mathrm{t}$, but it was much lower than $2.42 \times 10^{9} \mathrm{t}$ as derived by the continuous BEF. Therefore, the IPCC proposed approach could not necessarily appropriate for a certain study area.

This study was conducted in a mountainous county of Anhui Province with a forest cover of $80 \%$. Timber and by-products from the forests are the main income for local residents. The increasingly important role of sequestrating $\mathrm{CO}_{2}$ by forests has attracted considerable political and scientific attention from the local government that is aiming to enter the carbon market. The first step to enter the carbon market is to quantify the biomass on the county level. Thus, in this study, five well-known methods, namely the continuous biomass expansion factor (CBEF) approach, the mean biomass density (MB) approach, the mean biomass expansion factor (MBEF) approach, national continuous biomass expansion factors (NCBEF) proposed by Fang et al (2002), and the standard IPCC approach, were used to estimate the forest biomass by four forest types. The objectives were to: (1) build a continuous BEF equation relating stand volume for each forest type; and (2) to compare the biomass estimation derived from the five methodologies. These results could contribute to the improved understanding of method selection of regional biomass estimation.

\subsection{Materials and methods}

\subsubsection{Study area}

The study was conducted in Shitai county $\left(29^{\circ} 59^{\prime}-30^{\circ} 24^{\prime} \mathrm{N}, 117^{\circ} 12^{\prime}-117^{\circ} 59^{\prime}\right.$ E, Fig.1), Anhui province, China. About $80 \%$ of this county is covered by forest. It is a mountainous area with an elevation range of $50 \mathrm{~m}$ to $1000 \mathrm{~m}$ and steep slopes with an average of $66 \%$. The region has a midsubtropical, humid, mountainous climate with distinct seasonality (Geng and Wang, 2011). The annual average temperature is $16{ }^{\circ} \mathrm{C}$ with an annual mean maximum of $40.9{ }^{\circ} \mathrm{C}$ and an annual mean minimum of $-13.2{ }^{\circ} \mathrm{C}(\mathrm{Lu}, 2010)$. The mean annual precipitation is about $1668 \mathrm{~mm}$ with high interannual variability, with about $70 \%$ of the precipitation occurring in flooding seasons (Geng and Wang, 2011). The average annual sunshine duration is 1704 hours and the pan evaporation is 1256 $\mathrm{mm}(\mathrm{Lu}, 2010)$. 

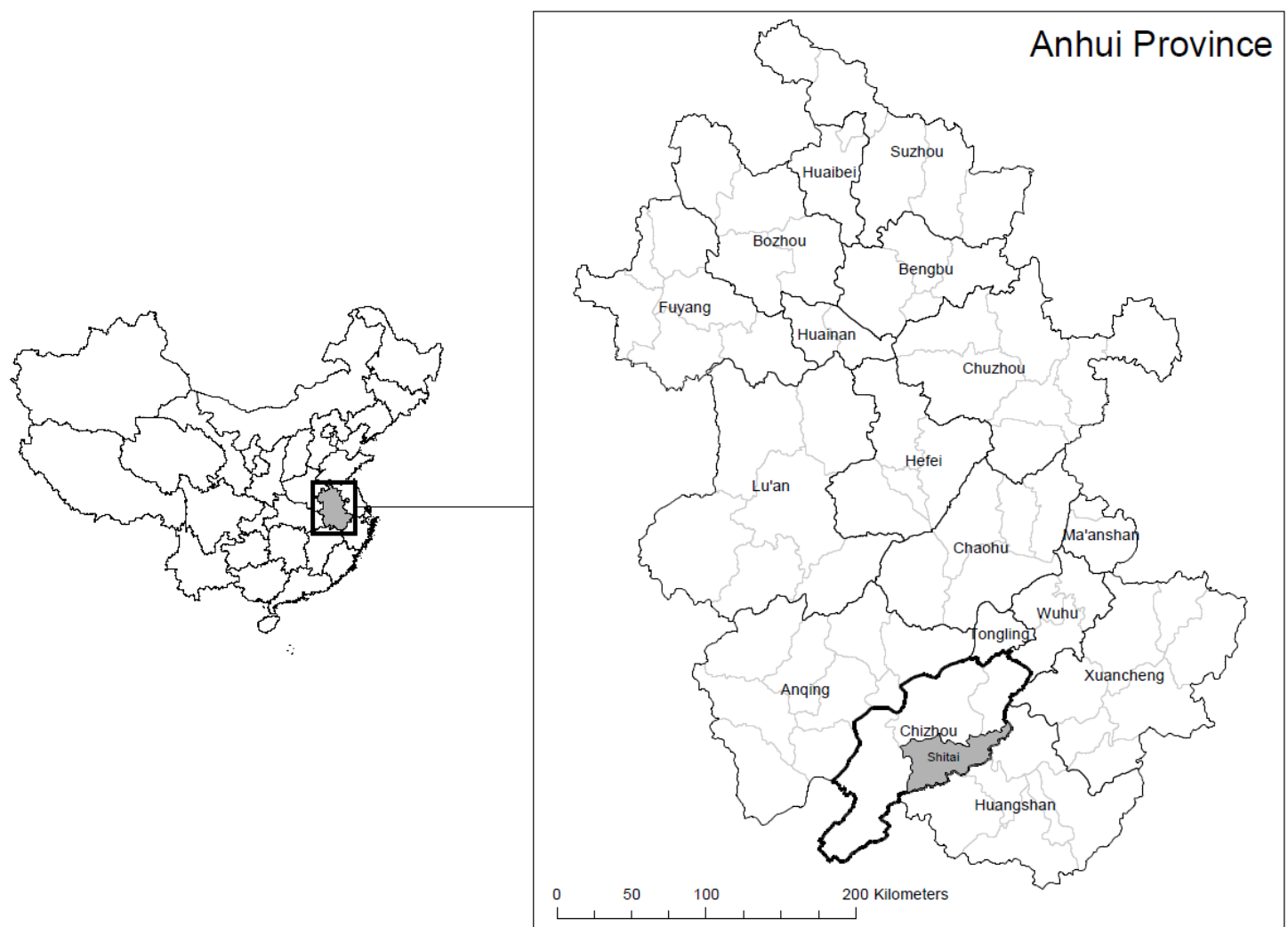

Fig. 1 Location of Shitai County in the southern part of Anhui Province, South-Eastern China.

\subsubsection{Plot design}

This study is a part of the $\operatorname{Lin}^{4}$ Carbon project, in which three different scales of inventories are distinguished: (1) land use inventory and forest inventory (LUI/FI) that produce information over the whole extent of the sampling frame based on systematic grids $3 \times 3 \mathrm{~km}$; (2) Forest management inventory (FMI) for those stands with forest management information with a $500 \times 500 \mathrm{~m}$ systematic grid, which is also part of a Sustainable Forest Management (SFM) Cooperation Project between the Shitai Forest Bureau and the German Development Bank (KfW); (3) Stand inventory of selected stands (SI) with a $100 \times 100 \mathrm{~m}$ systematic grid. This resulted in the establishment of 158 plots. Among these plots, 74 plots were dominated by Chines fir, 47 plots were dominated by hardwood broadleaved species, 28 plots were dominated by softwood broadleaved species and 9 plots were dominated by mason pine (MP) forests (Table 1). The main broadleaved species include Castanopsis sclerophylla, Cyclobalanopsis glauca, Castanopsis eyrei, Castanea mollissima, Cyclobalanopsis jenseniana, etc. Other broadleaved species (with lower wood basic density) included Liquidambar formosana, Rhus punjabensis, Rhus chinensis, Acer elegantulum, Cerasus pseudocerasus, etc. The bamboo forests were not included in this study. In circular plots of $6 \mathrm{~m}$ radius, trees were measured for $10 \mathrm{~cm}<\mathrm{dbh}<20 \mathrm{~cm}$, while in $10 \mathrm{~m}$ radius plots, trees with $\mathrm{dbh}>20 \mathrm{~cm}$ were measured. Tree diameters were measured with a diameter tape to the nearest $0.1 \mathrm{~cm}$ and heights of one or two dominant trees, one co-dominant trees and one suppressed tree were measured in each plot. If more 
than two plots were established in one stand, especially in well-managed stand, the average biomass was used to represent the stand because more plots in high production stand could overestimate the mean biomass of the whole county.

\subsubsection{Definition of a biomass expansion factor (BEF)}

In this study, BEF is defined as the ratio of total stand biomass (including above-, below-ground and understorey biomass) divided by stand stem volume:

$$
B E F=B / V
$$

Where $B$ is the total stand biomass $\left(\mathrm{Mg} \cdot \mathrm{ha}^{-1}\right)$, and $V$ is total stem volume $\left(\mathrm{m}^{3} \cdot \mathrm{ha}^{-1}\right)$.

The allometric models for volume and biomass of the main species in the study area are shown in appendix Table 1 (Guisasola-Rodríguez, 2014). Because we did not measure the belowground biomass, we used the ratios of below- and above-ground biomass for different species to estimate the belowground biomass (Fang et al., 1998; Wang et al., 2008).

\subsubsection{Understory biomass estimation}

Understory harvest was conducted in FMI and SI plots. In each plot, three systematic subplots of 40 $\mathrm{cm} \times 40 \mathrm{~cm}$ were established that were distributed in directions of $0^{\circ}, 120^{\circ}$ and $240^{\circ}$ from North and 3 meters away from the plot centre. All understory vegetation, including grass and shrubs, were harvested by uprooting in each plot and washed in the lab. The understorey samples were dried at 70 ${ }^{\circ} \mathrm{C}$ to constant weight. We also established a linear relationship between the aboveground biomass and understorey biomass to estimate the understorey biomass where the understorey was not collected.

\subsubsection{Descriptions of biomass estimation approaches}

In this study, five methods were used to estimate regional scale biomass as follows:

CBEF: $B_{t}=\sum_{i=1}^{4} A_{i} \cdot V_{m} \cdot B E F_{i}$

$\mathrm{MB}: B_{t}=\sum_{i=1}^{4} A_{i} \cdot B_{m}$

MBEF: $B_{t}=\sum_{i=1}^{4} V_{i} \cdot B E F_{m}$

NCBEF: $B_{t}=\sum_{i=1}^{4}\left(a \cdot V_{i}+b\right)$

IPCC: $B_{t}=\sum_{i=1}^{4} V_{i} \cdot D \cdot B E F 2 \cdot(1+R)$

Where $B_{t}$ is the total forest biomass of Shitai County; $i=1,2,3$ and 4, are the forest types; $V_{m}$ is the mean volume per hectare; $A_{i}$ is the total area, taken from the forest management inventory of Shitai County (Forest Bureau of Shitai County, 2004); $B E F_{i}$ is the biomass expansion factor; $B_{m}$ is the mean 
biomass of forest type $i ; B E F_{m}$ is the mean biomass expansion factor; $a$ and $b$ are the coefficients for each forest type at the national level (Fang et al. 1998); $D$ is the wood density proposed for these forests (IPCC, 2003); BEF2 is the biomass expansion factor proposed by the IPCC (2003); $R$ the shoot/root ratio (IPCC, 2003).

\subsubsection{Data analysis}

Statistical analyses were performed using R 3.0.2 (R Core Team, 2014). Non-linear regression analysis was used to model the relationship between BEF and volume for each forest type. The relationships between BEF and volume were expressed as follows:

$B E F=a+\frac{b}{V}$

Where $a$ and $b$ are coefficients.

\subsection{Results}

\subsubsection{Stand characteristics of different forest types}

The general characteristics of stand density, basal area, stand volume and biomass are displayed in Table 1. Stand density represented a wide changing range from 88 to 2416 tree ha $^{-1}$. The lowest basal area was found in SB with $13.3 \mathrm{~m}^{2} \mathrm{ha}^{-1}$, with the increase to $17.8 \mathrm{~m}^{2} \mathrm{ha}^{-1}$ for MP forests, $22.1 \mathrm{~m}^{2} \mathrm{ha}$ ${ }^{1}$ for CF plantations and $31.3 \mathrm{~m}^{2}$ ha ${ }^{-1}$ for HB forests. Similar trend was found for stand volume. Mean stand biomass ranged from $89.1 \mathrm{t} \mathrm{ha}^{-1}$ in MP forests to $236.7 \mathrm{t} \mathrm{ha}^{-1}$ in HB forests. Among different forest types, SB forest had the highest coefficients of variance.

Table 1 Descriptions of stand characteristics of different forest types

\begin{tabular}{|c|c|c|c|c|c|c|c|c|c|c|}
\hline \multirow{2}{*}{ Stand } & \multirow{2}{*}{$\begin{array}{l}\text { Mean } \\
\text { BEF }\end{array}$} & \multicolumn{2}{|c|}{ Density $\left(\right.$ tree $\left.\cdot \mathrm{ha}^{-1}\right)$} & \multicolumn{2}{|c|}{$\mathrm{BA}\left(\mathrm{m}^{2} \cdot \mathrm{ha}^{-1}\right)$} & \multicolumn{2}{|c|}{ Volume $\left(\mathrm{m}^{3} \cdot \mathrm{ha}^{-1}\right)$} & \multicolumn{2}{|c|}{ Biomass $\left(\mathrm{t} \cdot \mathrm{ha}^{-1}\right)$} & \multirow{2}{*}{$\begin{array}{l}\text { Number } \\
\text { of plots }\end{array}$} \\
\hline & & Mean(range) & $\mathrm{CV}(\%)$ & Mean(range) & $\mathrm{CV}(\%)$ & Mean & $\mathrm{CV}(\%)$ & Mean & $\mathrm{CV}(\%)$ & \\
\hline $\mathrm{CF}$ & 0.84 & $1025(88-2416)$ & 45.3 & $22.1(1.0-58.1)$ & 58.1 & $133.4(4.2-356.9)$ & 64.4 & $96.6(3.6-256.2)$ & 62.2 & 74 \\
\hline HB & 1.18 & $826(88-1920)$ & 49.1 & $31.3(0.7-85.3)$ & 65.7 & $220.2(2.4-816.8)$ & 76.0 & 236.7(4.1-1042.9) & 84.9 & 47 \\
\hline SB & 1.28 & 494(88-1316) & 69.4 & $13.3(0.8-41.8)$ & 97.6 & $91.4(3.1-313.1)$ & 108.3 & $94.1(4.7-382.0)$ & 107.3 & 28 \\
\hline MP & 0.84 & $540(177-1061)$ & 67.7 & $17.8(3.9-44.9)$ & 81.6 & $110.8(15.7-327.2)$ & 92.2 & $89.1(9.3-279.8)$ & 97.6 & 9 \\
\hline
\end{tabular}

$\mathrm{BA}=$ stand basal area; $\mathrm{CV}=$ coefficient of variation $(\%) ; \mathrm{CF}=$ Chinese fir plantation; $\mathrm{HB}=$ hardwood broadleaved forests; $\mathrm{SB}=$ softwood broadleaved forests, $\mathrm{MP}=$ mason pine forests. 

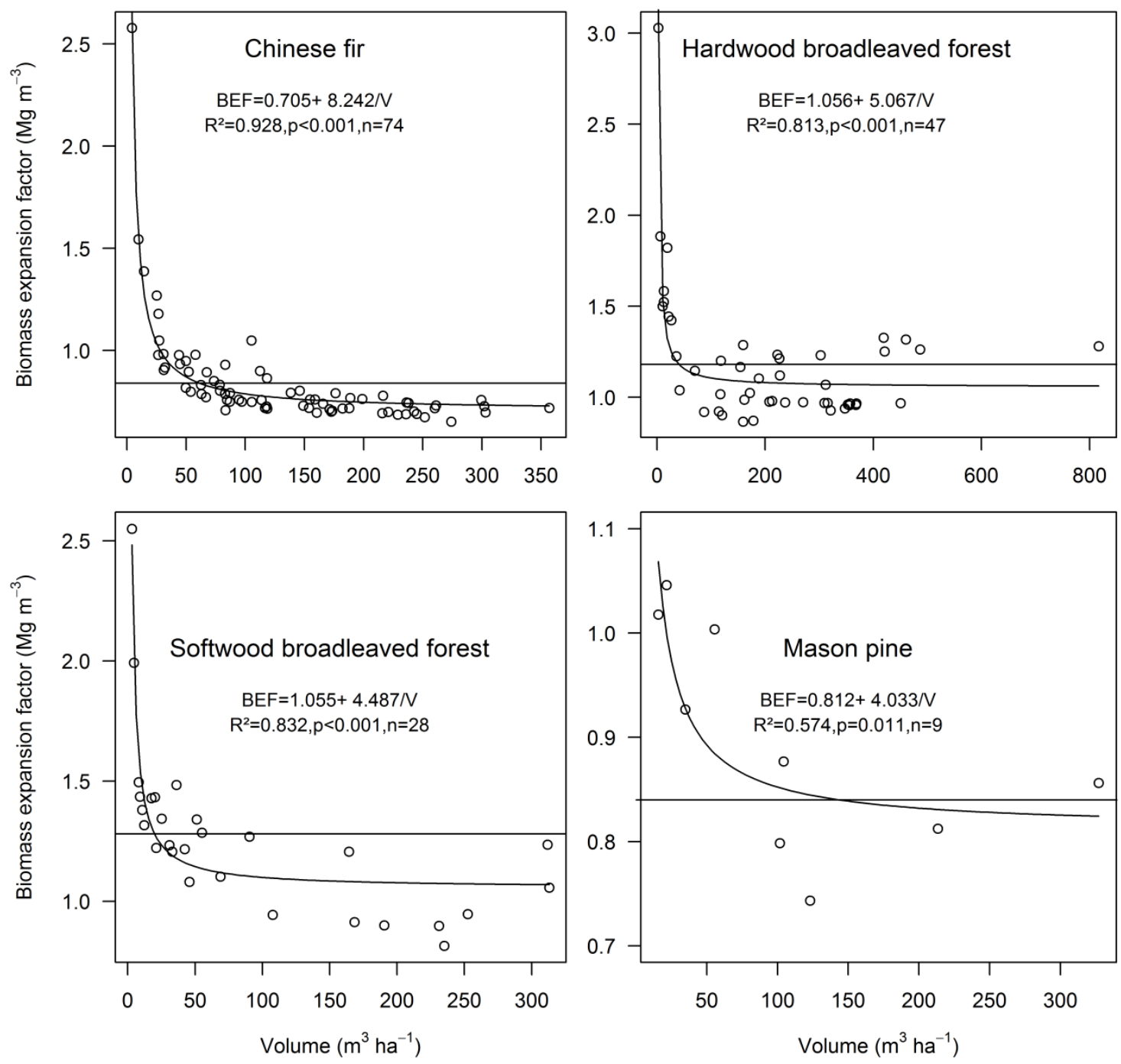

Fig.2 The relationship between biomass expansion factor and stand volume for different forest types. The horizontal lines mean mean biomass expansion factors.

\subsubsection{The relationship between BEF and stand volume}

$\mathrm{BEF}$ ranged from 0.65 to $2.58 \mathrm{Mg} \mathrm{m}^{-3}$ for $\mathrm{CF}$ plantations, compared to the values from 0.87 to 3.03 $\mathrm{Mg} \mathrm{m}^{-3}$ for $\mathrm{HB}$, from 0.82 to $2.55 \mathrm{Mg} \mathrm{m}^{-3}$ for $\mathrm{SB}$ and from 0.73 to $0.94 \mathrm{Mg} \mathrm{m}^{-3}$ for MP forests (Fig. 2). The average BEFs were $0.84 \mathrm{Mg} \mathrm{m}^{-3}$ for $\mathrm{CF}, 1.18 \mathrm{Mg} \mathrm{m}^{-3}$ for $\mathrm{HB}, 1.28 \mathrm{Mg} \mathrm{m}^{-3}$ for SB and $0.84 \mathrm{Mg} \mathrm{m}^{-}$

${ }^{3}$ for forests, respectively. BEF decreased with the increasing stand volume, and tended to level off for higher stand volumes.

We also calculated a threshold of stand volume for the continuous BEF and constant BEF by assuming those continuous BEFs equalled the constant BEF. If the stand volume was lower than this threshold, the constant BEF resulted in lower estimates of stand biomass compared to the continuous BEF method, and vice versa. The thresholds were 59, 39, 20 and $153 \mathrm{~m}^{3}$ for $\mathrm{CF}, \mathrm{HB}, \mathrm{SB}$ and MP forests, respectively. 


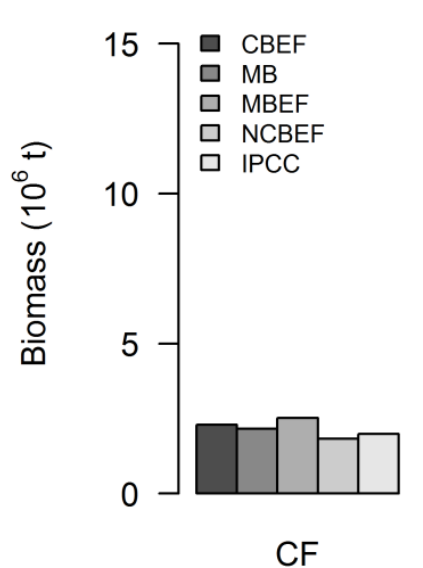

CF

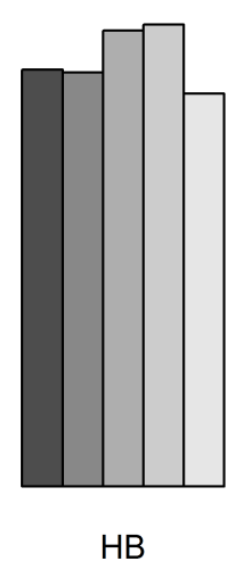

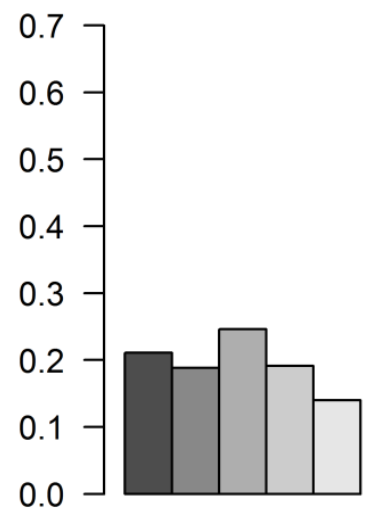

SB

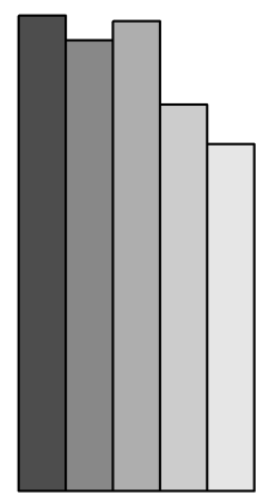

MP

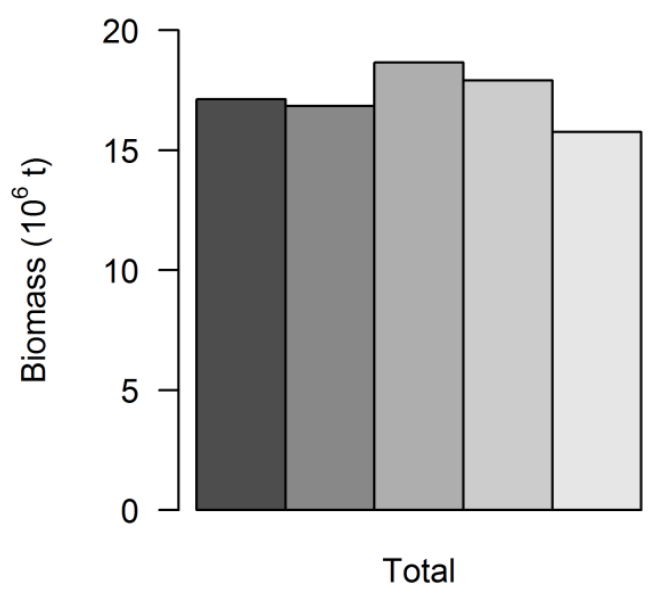

Fig. 3 Biomass of different forest types and total biomass in Shitai County estimated by different methods. $\mathrm{CF}=$ Chinese fir; $\mathrm{HB}=$ hardwood broadleaf forest; $\mathrm{SB}=$ softwood broadleaf forest; $\mathrm{MP}=$ mason pine; Total $=$ the total biomass of different forest types.

\subsubsection{Biomass estimation of different forest types}

Regardless of different approaches, biomass estimates in HB forests were highest, accounting for 83\% of total biomass, followed by CF forests, MP forests and SB forests. Within the same forest type, biomass estimates differed greatly depending on the method used (Fig. 3). For example, total biomass of $\mathrm{CF}$ plantations ranged from $1.83 \times 10^{6} \mathrm{t}$ calculated using NCBEF approach and $2.52 \times 10^{6} \mathrm{t}$ calculated using the MBEF approach (Fig. 3). First, we compared the first three methods that were developed in our study. In comparison to the CBEF derived biomass, the MB approach produced lower estimates of biomass while the MBEF approach led to higher biomass estimates for different forest type and total county biomass. Secondly, we compared the biomass estimation method proposed by Fang et al. (1998) and the IPCC (2003) approach. The NCBEF approach produced higher biomass estimates for HB forests and lower biomass estimates for CF, SB and MP forests. The IPCC approach generated the lowest biomass estimates for all forest types. The MBEF derived biomass was 
highest at $1.87 \times 10^{7} \mathrm{t}$, followed by $1.79 \times 10^{7} \mathrm{t}$ from NCBEF, $1.71 \times 10^{7} \mathrm{t}$ from CBEF, $1.68 \times 10^{7} \mathrm{t}$ from MB and $1.58 \times 10^{7} \mathrm{t}$ from IPCC.

In order to further qualify the effects of methodology selection on estimating the biomass of different forest types, we took the CBEF derived biomass estimation as a control and compared the ratios of biomass estimates from MB, MBEF, NCBEF and IPCC to that of CBEF (Fig. 4). The MB approach generated relatively stable biomass estimates of different forest types (89\%-98\%), generating the most accurate estimation of total biomass compared to the other methods, while NCBEF had the greatest variability in biomass estimation, varying from $80 \%$ in $\mathrm{CF}$ to $110 \%$ in $\mathrm{HB}$ forests. The IPCC approach underestimated 35\% for SB forests and 27\% for MP forests. Compared with different forest types, different methods generated the most accurate biomass estimates for $\mathrm{HB}$, varying from $94 \%$ for IPCC/CBEF and $110 \%$ for NCBEF/CBEF, and generated the least accurate estimates for SB forests, varying from $66 \%$ for IPCC/CBEF to $116 \%$ for MBEF/CBEF.

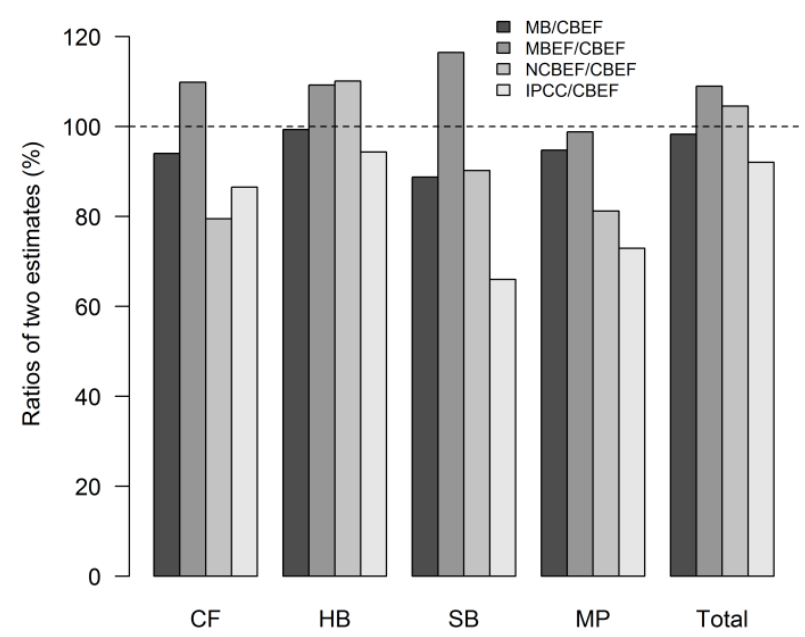

Fig.4 Comparison of biomass estimated of different methods, using the ratios of MB, MBEF, NCBEF and IPCC to CBEF. $\mathrm{CF}=$ Chinese fir forests; $\mathrm{HB}=$ hardwood broadleaf forests; $\mathrm{SB}=$ softwood broadleaved forests; $\mathrm{MP}=$ mason pine forests; Total = the total biomass of different forest types. The black dash line represents a constant ratio of $100 \%$.

\subsection{Discussion}

\subsubsection{Comparison of BEFs}

The mean BEFs were $0.84 \mathrm{Mg} \mathrm{m}^{-3}$ for $\mathrm{CF}$ and MP forests, $1.18 \mathrm{Mg} \mathrm{m}^{-3}$ for HB forests and $1.28 \mathrm{Mg} \mathrm{m}^{-}$ ${ }^{3}$ for SB forests, which were generally comparable to the reported values of these or similar forest types (Fang et al., 2007; Li et al., 2012). For example, Li et al. (2012) found BEFs of CF plantations that ranged from 0.705 to $0.954 \mathrm{Mg} \mathrm{m}^{-3}$ in different provinces, while Fang et al. (2007) reported a BEF value of $0.89 \mathrm{Mg} \cdot \mathrm{m}^{-3}$ for MP forests. However, the BEF of CF plantations was higher than the 
value calculated from Pan et al. (2004) and Fang et al. (2007) at the national level (Table 2). This deviation may have resulted from the sample size and the range of stand volume distributions. For instance, Pan et al.'s (2004) calculation was based on a sample size of $n=268$ and a volume range of $10-707 \mathrm{~m}^{3} \mathrm{ha}^{-1}$, which is much larger than our sample size $(\mathrm{n}=74)$ and has a wider spread of stand volume than our data set $\left(4-357 \mathrm{~m}^{3} \mathrm{ha}^{-1}\right)$.

Table 2 BEFs of different forest types

\begin{tabular}{|c|c|c|}
\hline Forest type & $\mathrm{BEF}$ & Sources \\
\hline \multirow{4}{*}{ Chinese fir } & 0.75 & (Fang et al., 2007) \\
\hline & 0.68 & $\begin{array}{l}\text { Calculated from Pan et al (2004) } \\
\text { using our data }\end{array}$ \\
\hline & 0.701-0.957 & (Li et al., 2012) \\
\hline & 0.84 & In this study \\
\hline Conifer forest & 1.30 & IPCC (2003) \\
\hline Abies fabri & 0.89 & (Fang et al., 2007) \\
\hline Deciduous oaks & 1.47 & (Fang et al., 2007) \\
\hline Cypress & 1.05 & (Fang et al., 2007) \\
\hline Betula & 1.26 & (Fang et al., 2007) \\
\hline $\begin{array}{l}\text { P. massoniana } \& P . \\
\text { yunnanensis }\end{array}$ & 0.69 & (Fang et al., 2007) \\
\hline Cupressus & $0.844-10.598$ & (Li et al., 2012) \\
\hline
\end{tabular}

In our study, BEF values varied with forest types, which has been illustrated by many other studies (Pan et al., 2004; Fang et al., 2007; Li et al., 2012). BEFs essentially represent specific weight in Mg $\mathrm{m}^{-3}$ and are influenced by the density of the tree canopy, stand wood volume, the wood density of the tree species and biomass allocation patterns (IPCC, 2003; Pajtík et al., 2008; Correia et al., 2010). Thus previous studies have demonstrated that the higher BEFs are related to species morphology such as the lack of apical dominance with a polyarchic ramification resulting in a crown shape that is wider than it is deep (Mutke et al., 2005), which leads to higher biomass allocation to the crown compared to the stem (and wood volume) (Correia et al., 2010). The age of the tree could also lead the variations in BEFs because the allocation of biomass to different functional parts of a tree changes with age (Petersson et al., 2012). The average BEFs for larger areas can only reflect the mean age structure in the respective forest types, and they are not expected to be well adapted to local conditions and/or a specific stand age or diameter distribution. Thus, it should be noted that the BEFs developed in our study are applicable to the study area, and should be only be used with caution to other forests. 
The BEFs declined with stand volume for all forest types (Fig. 2), which is highly consistent with previous studies (Fang et al., 1998; Teobaldelli et al., 2009; Correia et al., 2010; Guo et al., 2010). Therefore, using constant BEFs may underestimate or overestimate the forest biomass with different volume distributions. However, some researchers have determined a threshold for the use of a constant BEF based on a certain value of the predictor variables where the BEFs stabilize, and biomass estimation bias will be minimized (Brown et al., 1999). This could be a good way to simplify biomass calculation in mature and productive stands when the stand volume estimates are available, but it should be applied cautiously to young stands or stands with a low productivity (GonzálezGarcía et al., 2013).

\subsubsection{Comparison of biomass estimates from different methods}

In this study, the biomass was estimated using five well-known methods, and we found that different methods resulted in highly variable estimates of biomass for different forest types. CBEF uses stand volume as a function of BEF and accounts for the effects of forest age, stand density and site quality, allowing more realistic estimates of forest biomass than other methods (Fang et al., 2002; Teobaldelli et al., 2009). Therefore, the continuous BEF method is widely used to estimate forest biomass at regional or national scales (Fang et al., 2001; Guo et al., 2010; Li et al., 2012), because stand volume is usually the most reliable estimate in forest inventory (Petersson et al., 2012).

Because it is impossible to true value of regional biomass, CBEF derived biomass was taken as a control to compare the biomass estimation derived from the other methods (Fang et al., 2002, Guo et al., 2010). The ratio of MB/CBEF was $98 \%$ for total biomass, compared to $94 \%$ for $\mathrm{CF}, 99 \%$ for $\mathrm{HB}$, $89 \%$ SB and $95 \%$ for MP, indicating that the MB approach did not result in a substantial difference in the biomass estimate (Fig. 4). In contrast, the IPCC approach underestimated forest biomass of the different forest types and total biomass, suggesting that the IPCC approach is not suitable in our study area although it is a standard approach on a global level. A similar conclusion was found by Li et al. (2012) for regional biomass estimation using the IPCC approach. More interestingly, the NCBEF approach underestimated biomass of CF, SB and MP forests, but overestimated biomass of HB forests, subsequently leading the most accurate estimation of total biomass compared to other methods. The result indicates that using the national approach proposed by NCBEF could generate bias in the biomass estimation of certain forest types, but not in total biomass. If total biomass estimates were required by the carbon market, rather than estimates specific to a certain forest type, the NCBEF approach would have been a good choice when BEFs are lacking. However, if biomass estimates for a specific forest type, such as CF, were required for the carbon market, the NCBEF approach would have underestimated the forest biomass by $20 \%$.

Early approaches to simplify biomass estimation at the regional level applied the constant BEFs because only volume data was required (Sharp et al., 1975; Turner et al., 1995). However, more 
recent evidence shows that these constant BEFs are always the average values for a specific tree species, which are sometimes inaccurate given that stand age, stand density and site quality can change the BEFs (Lehtonen et al., 2004; Teobaldelli et al., 2009; Correia et al., 2010). Thus, applying constant BEFs values across all age classes and site conditions within a forest type underestimates the forest biomass of younger and less productive stands and overestimates the forest biomass of older and more productive stands (Fang et al., 1998; Goodale et al., 2002). In this study, the threshold stand volume where BEFs equal the constant BEF were 59, 39, 20 and $153 \mathrm{~m}^{3}$ for $\mathrm{CF}, \mathrm{HB}, \mathrm{SB}$ and $\mathrm{MP}$ forests, respectively. As expected, the constant BEFs overestimated the biomass of $\mathrm{CF}$, HB and SB forests because the average volume (Table 1) was higher than these thresholds. As a result, MBEF overestimated the total biomass by $9 \%$ (Fig. 4).

However, the data requirement of continuous BEFs, which can be determined using existing biomass and volume data, is stricter than other methods. When there is sufficient forest inventory data, including stand volume, forest area and a continuous BEF equation, the continuous BEFs method is a good choice to estimate regional forest biomass (Guo et al., 2010). Therefore, the continuous BEF equation proposed in this study could be directly used to estimate regional forest biomass in the study area.

\subsection{Conclusions}

Five methods were applied to estimate the forest biomass of Shitai County, China. The highest biomass estimate $\left(1.87 \times 10^{7} \mathrm{t}\right)$ was generated using the MBEF approach while the lowest biomass estimate $\left(1.58 \times 10^{7} \mathrm{t}\right)$ was generated using the IPCC approach. Because CBEF estimated biomass as a function of stand volume, which incorporated the effects of forest age, stand density and site quality, it was considered the most realistic estimate. The data requirement of CBEF is stricter than the other methods because it is based on sufficient forest inventory data, including the forest area and the continuous function of BEF. If there is not enough forest inventory data, the MB approach is another option in our study area because the MB derived biomass estimate had the lowest deviation from the CBEF approach for different forest types. The BEF equations developed in our study can directly be applied to estimate forest biomass for study area if the stand volume is given without destructively sampling. Our results further have a great significance for method selection of biomass estimation for regional carbon accounting.

\section{Acknowledgement}

The study was supported by a project of Sino-German Cooperation on Innovative Technologies and Service Capacities of Multifunctional Forest Management (Lin ${ }^{2}$ Value 033L049-CAFYBB2012013), funded by the Federal Ministry of Education and Research (BMBF) and the Chinese Academy of 
Forestry, and special research fund of the International Centre for Bamboo and Rattan (project number 1632013010) supported by the International Centre for Bamboo and Rattan (ICBR). We thank Hans Fuchs, Sabine Schreiner, Haijun Yang, Torsten Vor and Dengkui Mo from Georg-AugustUniversität Göttingen for plot design and fieldwork support. We also thank Director An'guo Fan, Mr. Bailing Ding, Miss Yue'e Chu from Shitai Forest bureau for kindly organizing the fieldwork. Lastly, special thanks to Mr. Xiaozhu Wang and Mr. Hongbing Ruan for fieldwork support.

\subsection{References}

Bettelli P, Carpenter C, Davenport D, et al. 1997. Report of the Third Conference of the Parties to the United Nations Framework Convention on Climate Change: 1-11 December 1997. Earth Negotiations Bulletin 12: 1-16.

Bonan GB. 2008. Forests and climate change: forcings, feedbacks, and theclimate benefits of forests. Science 320: 1444-1449.

Brown S, Lugo AE. 1984. Biomass of tropical forests: a new estimate based on forest volumes. Science 223: 1290-1293.

Brown SL, Schroeder P, Kern JS. 1999. Spatial distribution of biomass in forests of the eastern USA. Forest Ecology and Management 123: 81-90.

Correia AC, Tome M, Pacheco CA, et al. 2010. Biomass allometry and carbon factors for a Mediterranean pine (Pinus pinea L.) in Portugal. Forest Systems 19: 418-433.

Dixon RK, Solomon AM, Brown S, et al. 1994. Carbon Pools and Flux of Global Forest Ecosystems. Science 263: 185-190.

Fang J, Chen A, Peng C, et al. 2001. Changes in forest biomass carbon storage in China between 1949 and 1998. Science 292: 2320.

Fang J, Chen A, Zhao S. 2002. Calculating Forest Biomass Changes in China-response. Science 296: 1359.

Fang J, Guo Z, Piao S, et al. 2007. Terrestrial vegetation carbon sinks in China, 1981-2000. Science in China Series D: Earth Sciences 50: 1341-1350.

Fang J, Oikawa T, Kato T, et al. 2005. Biomass carbon accumulation by Japan's forests from 1947 to 1995. Global Biogeochemical Cycles 19: GB2004.

Fang JY, Wang GG, Liu GH, et al. 1998. Forest biomass of China: An estimate based on the biomassvolume relationship. Ecological Applications 8: 1084-1091.

Fang JY, Wang ZM. 2001. Forest biomass estimation at regional and global levels, with special reference to China's forest biomass. Ecological Research 16: 587-592.

Forest Bureau of Shitai County. 2004. Forest resources planning and design survey of Shitai County in 2004. Hefei. 5p. 
Geng TS, Wang HH. 2011. Research on the water and soil conservation in Shitai County of Anhui Province. Journal of Anhui Agriculture Science 39: 451-452, 482 (in Chinese with English abstract).

González-García M, Hevia A, Majada J, et al. 2013. Above-ground biomass estimation at tree and stand level for short rotation plantations of Eucalyptus nitens (Deane \& Maiden) Maiden in Northwest Spain. Biomass and Bioenergy 54: 147-157.

Goodale CL, Apps MJ, Birdsey RA, et al. 2002. Forest carbon sinks in the Northern Hemisphere. Ecological Applications 12: 891-899.

Guisasola-Rodríguez R. 2014. Allometric biomass equations and crown architecture in mixed-species forests of subtropical China. Fakultät für Umwelt and Natürliche Ressourcen. Freiburg: AlbertLudwigs Universität Freiburg, p48.

Guo ZD, Fang JY, Pan YD, et al. 2010. Inventory-based estimates of forest biomass carbon stocks in China: A comparison of three methods. Forest Ecology and Management 259: 1225-1231.

Houghton RA. 2007. Balancing the Global Carbon Budget. Annual Review of Earth and Planetary Sciences 35: 313-347.

IPCC. 2003. Good practice guidance for land use, land-use change and forestry: Institute for Global Environmental Strategies.

IPCC. 2006. IPCC guidelines for national greenhouse gas inventories. IGES, Japan. http://www.ipccnggip.iges.or.jp/public/2006gl/index.html.

IPCC. 2007. Climate Change 2007: Synthesis Report. Contribution of Working Groups I, II and III to the Fourth Assessment Report of the Intergovernmental Panel on Climate Change. 36-41p.

Lehtonen A, Mäkipää R, Heikkinen J, et al. 2004. Biomass expansion factors (BEFs) for Scots pine, Norway spruce and birch according to stand age for boreal forests. Forest Ecology and Management 188: 211-224.

Li HK, Zhao PX, Lei YC, et al. 2012. Comparison on estimation of wood biomass using forest inventory data. Scientia Silvae Sinicae 48: 44-52 (in Chinese with English abstract).

Lu CM. 2010. Rock-soil geochemical features for Dashan Area, Shitai, Anhui. Geology of Anhui 20: 120-125 (in Chinese with English abstract).

Mutke S, Sievänen R, Nikinmaa E, et al. 2005. Crown architecture of grafted Stone pine (Pinus pinea L.): shoot growth and bud differentiation. Trees 19: 15-25.

Pajtík J, Konôpka B, Lukac M. 2008. Biomass functions and expansion factors in young Norway spruce (Picea abies [L.] Karst) trees. Forest Ecology and Management 256: 1096-1103.

Pan Y, Birdsey RA, Fang J, et al. 2011. A large and persistent carbon sink in the world's forests. Science 333: 988-993.

Pan YD, Luo TX, Birdsey R, et al. 2004. New estimates of carbon storage and sequestration in China's forests: Effects of age-class and method on inventory-based carbon estimation. Climatic Change 67: 211-236. 
Petersson H, Holm S, Stahl G, et al. 2012. Individual tree biomass equations or biomass expansion factors for assessment of carbon stock changes in living biomass - A comparative study. Forest Ecology and Management 270: 78-84.

R Core Team. 2014. R: A language and environment for statistical computing. R Foundation for Statistical Computing, Vienna, Austria. URL http://www.R-project.org/.

Schroeder P, Brown S, Mo JM, et al. 1997. Biomass estimation for temperate broadleaf forests of the United States using inventory data. Forest Science 43: 424-434.

Seo YO, Lee YJ, Lumbres RIC, et al. 2013. Influence of stand age class on biomass expansion factor and allometric equations for Pinus rigida plantations in South Korea. Scandinavian Journal of Forest Research 28: 566-573.

Sharp DD, Lieth H, Whigham D. 1975. Assessment of regional productivity in North Carolina. Whittaker HLRH editor. Primary productivity of the biosphere: Springer, p131-146.

Teobaldelli M, Somogyi Z, Migliavacca M, et al. 2009. Generalized functions of biomass expansion factors for conifers and broadleaved by stand age, growing stock and site index. Forest Ecology and Management 257: 1004-1013.

Turner DP, Koerper GJ, Harmon ME, et al. 1995. A carbon budget for forests of the conterminous United States. Ecological Applications 5: 421-436.

Wang X, Fang J, Zhu B. 2008. Forest biomass and root-shoot allocation in northeast China. Forest Ecology and Management 255: 4007-4020.

Whittaker RH, Likens GE. 1973. Carbon in the biota. Woodwell GM, Pecan EV editors. Brookhaven symposia in biology. Springfield, VA, USA,: Technical Information Center, Office of Information Services, US Atomic Energy Commission, p281-302.

Woodwell GM. 1978. The carbon dioxide question. Scientific American 238: 34-43. 
Appendix

Table 1 Allometric models for height, aboveground biomass and volume of the main species in Shitai County

\begin{tabular}{|c|c|c|c|c|c|c|c|c|c|c|c|c|}
\hline Species & Variable & $\mathrm{a}$ & $p$ & $\mathrm{~b}(d b h)$ & $p$ & $\mathrm{c}(h)$ & $p$ & $\mathrm{~d}\left(d b h^{2} \cdot h\right)$ & $p$ & $\mathrm{R}_{\text {adj }}^{2}$ & $\mathrm{n}$ & RMSE \\
\hline \multirow{3}{*}{$\begin{array}{l}\text { Cunninghamia } \\
\text { lanceolata }\end{array}$} & Stem & 0.0202 & $<0.001$ & & & & & 0.967 & $<0.001$ & 0.9764 & 12 & 0.0179 \\
\hline & Branch & 0.0118 & $<0.001$ & 3.742 & $<0.001$ & -1.6029 & 0.0013 & & & 0.9722 & 12 & 0.0294 \\
\hline & Leaf & 0.0319 & $<0.001$ & 3.207 & $<0.001$ & -1.5105 & 0.003 & & & 0.9522 & 12 & 0.0363 \\
\hline \multirow{3}{*}{$\begin{array}{l}\text { Castanopsis } \\
\text { sclerophylla }\end{array}$} & Stem & 0.0240 & $<0.001$ & & & & & 1.012 & $<0.001$ & 0.9795 & 24 & 0.0213 \\
\hline & Branch & 0.0471 & $<0.001$ & 2.187 & $<0.001$ & & & & & 0.8889 & 24 & 0.0863 \\
\hline & Leaf & 0.102 & $<0.001$ & 1.873 & $<0.001$ & -0.7305 & $<0.001$ & & & 0.8138 & 24 & 0.0735 \\
\hline \multirow{2}{*}{$\begin{array}{l}\text { Cyclobalanopsis } \\
\text { glauca }\end{array}$} & branch & 0.0496 & $<0.001$ & 2.410 & $<0.001$ & & & & & 0.9488 & 9 & 0.0889 \\
\hline & leaf & 0.0911 & 0.005 & 1.565 & $<0.001$ & & & & & 0.8587 & 9 & 0.1140 \\
\hline \multirow{3}{*}{ Castanopsis eyrei } & wood & 0.101 & 0.0119 & 2.269 & $<0.001$ & & & & & 0.9284 & 8 & 0.0346 \\
\hline & branch & 0.321 & 0.1237 & 1.614 & $<0.001$ & & & & & 0.8714 & 8 & 0.0335 \\
\hline & leaf & 0.0918 & 0.0189 & 1.780 & 0.001 & & & & & 0.8554 & 8 & 0.0467 \\
\hline \multirow{2}{*}{$\begin{array}{l}\text { Liquidambar } \\
\text { formosana }\end{array}$} & wood & 0.0816 & $<0.001$ & & & & & 0.831 & $<0.001$ & 0.9315 & 13 & 0.0553 \\
\hline & leaf & 0.0208 & 0.00196 & & & & & 0.660 & $<0.001$ & 0.6939 & 13 & 0.2090 \\
\hline
\end{tabular}

$h$ is the total tree height $(\mathrm{m}) ; d b h$ is the diameter at breast height $(1.3 \mathrm{~m}) \mathrm{in} \mathrm{cm} ; A G B$ is the aboveground biomass $(\mathrm{kg})$. The allometric model are expressed: $h$ $=\mathrm{a}+\mathrm{b} \cdot \ln (d b h) ; A G B=\mathrm{a} \cdot d b h^{\mathrm{b}}$ or $\mathrm{a} \cdot d b h^{\mathrm{b}} \cdot h^{\mathrm{c}}$ or $\mathrm{a} \cdot\left(d b h^{2} \cdot h\right)^{\mathrm{d}}$. The coefficients for $A G B$ were taken from (Guisasola-Rodríguez 2014). 


\section{Chapter VIII}

\section{General discussion and conclusion}

Biomass and volume are two important targets for forest managers in terms of sustainable forest management, economical yield and carbon accounting purposes (Brandeis et al., 2006; Schröder et al., 2014). It is predicted that if the forest carbon stock in China can increase by $10 \%$ through forest management, the accumulated carbon sink is much higher than the Chinese official afforestation target of $0.683 \mathrm{Pg} \mathrm{C}$ by 2020 (Gao et al., 2011). Therefore, this thesis, as a case study, aimed to provide a methodological basis for stand management for one of the most important plantation species - Chinese fir, for different management purposes and to develop a method to efficiently estimate regional biomass in Shitai County, China. To realize these objectives, data on biomass and volume estimation and prediction and stand management tools are required, which are achieved through a combination of different chapters in this thesis.

To evaluate the potentials and capabilities of forests in carbon sequestration, data on biomass dynamics are required. Generally, biomass dynamics are measured as the difference between two time intervals by using repeated measurements on inventory plots or permanent plots (Foster et al., 2014; Nunes et al., 2013). However, repeated measurements require long-term planning and resources. To overcome this weakness, this thesis developed two GADA models for $C$. lanceolata and $C$. sclerophylla forests to predict the diameter of each individual tree at any age (chapter III). Although the GADA model has been widely used to model site index (Álvarez-González et al., 2010; Sharma et al., 2011) and basal area (Álvarez-González et al., 2010; Barrio-Anta et al., 2006), it was modified for $d b h$ prediction for $C$. lanceolata plantations and C. sclerophylla forests by replacing the dominant height or basal area with $d b h$ in this thesis. GADA models were flexible enough to predict diameter increment at any time interval, such as two- or five-year intervals, which allowed us to reconstruct historical diameters. Tree ring data can be obtained from complete discs or increment cores of sample trees. On the other hand, complete discs are preferred because the false boundaries between the real rings exist in $C$. lanceolata and $C$. sclerophylla. The dynamic GADA models can overcome the limitations of within-stand competition and limited biometric data, and improve our understanding of net primary production in forest ecosystems. However, as a case study based on a small number of inventory plots and sample trees, the results obtained should be considered with caution in making decisions about the management of these forests. In contrast, the results illustrated the possibility of the application of GADA model to estimate AGB dynamics.

Although allometric models using $d b h$ and total tree height are commonly used to estimate tree volume, these models cannot predict the volume at any merchantable height or any merchantable diameter, while the taper functions can overcome this limitation to predict the merchantable volume. 
Single taper models, segmented taper models and variable-form taper models are often used to model tree taper as reviewed by Diéguez-Aranda et al. (2006). Through comparing different taper functions for different tree species, the segmented taper function developed by Fang et al. (2000) is regarded as one of the most accurate and flexible functions that have been widely used for different tree species (Barrio Anta et al., 2007; Diéguez-Aranda et al., 2006; Menéndez-Miguélez et al., 2014). Therefore, the compatible taper function proposed by Fang et al. (2000) was developed for Chinese fir plantations and it performed quite well for diameter prediction. Regarding merchantable volume, the volume-ratio equation, which is first proposed by Burkhart (1977) and predicts merchantable volume as a percentage of total volume, was used to develop a stand-level merchantable model. In this thesis, top diameter, quadratic mean diameter, stand basal area and dominant height were used as independent variables, in which case the total volume becomes a special case of the volume ratio equation when the top diameter limit was equal to zero. With this method, a total stand-level volume table using stand basal area and dominant height was proposed for local forest managers, which can significantly contribute to the improvement of work efficiency in the field for stand volume estimation.

Because of the lack of management knowledge and technical training, local residents are afraid of conducting thinning. For example, local residents have no idea to design, display and evaluate different density management regimes. Instead they are distracted by the short-term volume reduction. As a result, they are not willing to conduct thinning trials in their stands, which leads to lower production, less stable and bad quality stands. Therefore, a suitable guideline for thinning trials and forest management is urgently needed because the mean stand biomass and volume in China's forests are far below the world average (Gao et al., 2011). The role of forest management in China is even more important than afforestation (Gao et al., 2011). A large area of Chinese fir plantations has been established, but managing the stands is still a big issue. In chapter V, SDMDs were proposed for Chinese fir plantations to optimize stand management, aiming to provide a theoretical guidance for forest management. Stand volume, stem biomass and AGB presented in the diagrams could meet different management purposes. Finally, two examples were presented to illustrate the application of the SDMDs. It should be noted that natural disasters, e.g. fire, thunderstorm, can be not included in the SDMDs. However, further data with larger tree dimensions and age ranges were recommended because our inventory plot constructed based on limited age ranges due to the short rotation age in the study area.

Land use change represents an important carbon emission after fossil fuel combustion and it is recognized as an important driving force for SOC and N dynamics (Fu et al., 2010). In subtropical China, the conversion of secondary forests to Chinese fir and Moso bamboo plantations represents an important land use change. Therefore, chapter VI focused on the effects of this conversion on SOC and $\mathrm{N}$ stocks. The results indicated a significant decrease in SOC and $\mathrm{N}$ stocks over $0-50 \mathrm{~cm}$ after the 
conversion. Stand age played an important role in the reduction in SOC and N stocks because the stands were just 17 years and 18 years after the conversion. This is consistent with the general agreement that SOC stocks decrease in the early establishment of plantations and recover to initial levels after about 30-40 years (Cook et al., 2014; Guo and Gifford, 2002; Paul et al., 2002). Chinese fir plantations are commonly harvested at age 25 years with the variation of 20-30 years (Wu, 1984; Zhang et al., 2004). However, the Chinese fir plantations still remain high-level of biomass accumulation rate during this age. Therefore, based on a view of ecosystem carbon sequestration, it is proposed that increasing rotation age in Chinese fir plantations could not only increase tree biomass accumulation, but also increase belowground SOC stock, and thus has great potentials to alleviate future climate change.

With the importance of forests being highlighted in alleviating climate change and the development of carbon markets, regional scale estimation of forest biomass is becoming a research interest for scientists and policy makers. Many approaches have been proposed for regional biomass estimation since the 1970s (Brown and Lugo, 1984; Fang et al., 2001; Fang et al., 1998; Guo et al., 2010; Whittaker and Likens, 1973; Woodwell, 1978). BEF approach is one of the most important approaches because stand volume is the most accurate estimate in the continuous forest inventory and it is possible to convert stand volume to stand biomass, including the non-commercial biomass such as branches, leaves and roots (Fang and Wang, 2001; Guo et al., 2010). Sharp et al. (1975) estimated the forest biomass for Northern Carolina in the USA using a constant BEF of $2.0 \mathrm{Mg} \mathrm{m}^{-3}$. In chapter VII, BEFs of different forest types showed a decreasing trend in BEF with an increase in stand volume. This is highly consistent with the recent reports that the BEF is not a constant value and varies with forest age, site class and stand density (Correia et al., 2010; Fang and Wang, 2001; Lehtonen et al., 2004; Teobaldelli et al., 2009). Thus, applying constant BEFs values across all age classes and site conditions within a forest type underestimates the forest biomass of younger and less productive stands and overestimates the forest biomass of older and more productive stands (Fang et al., 1998; Goodale et al., 2002). Subsequently, continuous BEF (CBEF) equations have been developed that include stand variables, e.g. stand volume, as predictors (González-García et al., 2013; Guo et al., 2010; Teobaldelli et al., 2009). Since the stand volume could reflect the impacts of stand age, stand density and other factors on biomass, it can be used to calculate the forest biomass using the data of forest area and volume derived from forest inventory without information about age, site class, and continuous BEF approach is recognized as the most accurate (Fang et al., 2002; Guo et al., 2010). Therefore, in this thesis, the biomass estimates derived from CBEF were treated as a control, and biomass estimates from MB, BEF, NCBEF and IPCC approaches for CF, HB, SB and MP forests were compared. Compared to $\mathrm{CBEF}$, the $\mathrm{MB}$ approach provided the most accurate biomass estimates for all forest types compared to other methods, which can be an alternative approach when a CBEF equation is lacking in the study area. While IPCC derived biomass is the least accurate. The BEF 
equations developed in this study can be directly applied to estimate forest biomass for study area if the stand volume is given. The results have a great significance for method selection of biomass estimation for regional carbon accounting, and provide evidence for local government planning to enter the potential carbon market.

\section{References}

Álvarez-González JG, Zingg A, Klaus Von G. 2010. Estimating growth in beech forests: a study based on long term experiments in Switzerland. Annals of Forest Science 67: 307-307.

Barrio-Anta M, Castedo-Dorado F, Diéguez-Aranda U, et al. 2006. Development of a basal area growth system for maritime pine in northwestern Spain using the generalized algebraic difference approach. Canadian Journal of Forest Research 36: 1461-1474.

Barrio Anta M, Diéguez-Aranda U, Castedo-Dorado F, et al. 2007. Merchantable volume system for pedunculate oak in northwestern Spain. Annals of Forest Science 64: 511-520.

Brandeis TJ, Delaney M, Parresol BR, et al. 2006. Development of equations for predicting Puerto Rican subtropical dry forest biomass and volume. Forest Ecology and Management 233: 133-142.

Brown S, Lugo AE. 1984. Biomass of tropical forests: a new estimate based on forest volumes. Science 223: 1290-1293.

Burkhart HE. 1977. Cubic-foot volume of loblolly pine to any merchantable top limit. Southern Journal of Applied Forestry 1: 7-9.

Cook RL, Binkley D, Mendes JCT, et al. 2014. Soil carbon stocks and forest biomass following conversion of pasture to broadleaf and conifer plantations in southeastern Brazil. Forest Ecology and Management 324: 37-45.

Correia AC, Tome M, Pacheco CA, et al. 2010. Biomass allometry and carbon factors for a Mediterranean pine (Pinus pinea L.) in Portugal. Forest Systems 19: 418-433.

Diéguez-Aranda U, Castedo-Dorado F, Álvarez-González JG, et al. 2006. Compatible taper function for Scots pine plantations in northwestern Spain. Canadian Journal of Forest Research 36: 11901205.

Fang J, Chen A, Peng C, et al. 2001. Changes in forest biomass carbon storage in China between 1949 and 1998. Science 292: 2320.

Fang J, Chen A, Zhao S. 2002. Calculating Forest Biomass Changes in China-response. Science 296: 1359.

Fang JY, Wang GG, Liu GH, et al. 1998. Forest biomass of China: An estimate based on the biomassvolume relationship. Ecological Applications 8: 1084-1091.

Fang JY, Wang ZM. 2001. Forest biomass estimation at regional and global levels, with special reference to China's forest biomass. Ecological Research 16: 587-592. 
Fang ZX, Borders BE, Bailey RL. 2000. Compatible volume-taper models for loblolly and slash pine based on a system with segmented-stem form factors. Forest Science 46: 1-12.

Foster JR, D'Amato AW, Bradford JB. 2014. Looking for age-related growth decline in natural forests: unexpected biomass patterns from tree rings and simulated mortality. Oecologia 175: 363-374.

Fu X, Shao M, Wei X, et al. 2010. Soil organic carbon and total nitrogen as affected by vegetation types in Northern Loess Plateau of China. Geoderma 155: 31-35.

Gao G, Ding G, Wang H, et al. 2011. China needs forest management rather than reforestation for carbon sequestration. Environmental science \& technology 45: 10292-10293.

González-García M, Hevia A, Majada J, et al. 2013. Above-ground biomass estimation at tree and stand level for short rotation plantations of Eucalyptus nitens (Deane \& Maiden) Maiden in Northwest Spain. Biomass and Bioenergy 54: 147-157.

Goodale CL, Apps MJ, Birdsey RA, et al. 2002. Forest carbon sinks in the Northern Hemisphere. Ecological Applications 12: 891-899.

Guo LB, Gifford RM. 2002. Soil carbon stocks and land use change: a meta analysis. Global Change Biology 8: 345-360.

Guo ZD, Fang JY, Pan YD, et al. 2010. Inventory-based estimates of forest biomass carbon stocks in China: A comparison of three methods. Forest Ecology and Management 259: 1225-1231.

Lehtonen A, Mäkipää R, Heikkinen J, et al. 2004. Biomass expansion factors (BEFs) for Scots pine, Norway spruce and birch according to stand age for boreal forests. Forest Ecology and Management 188: 211-224.

Menéndez-Miguélez M, Canga E, Álvarez-Álvarez P, et al. 2014. Stem taper function for sweet chestnut (Castanea sativa Mill.) coppice stands in northwest Spain. Annals of Forest Science 71: 761-770.

Nunes L, Lopes D, Rego FC, et al. 2013. Aboveground biomass and net primary production of pine, oak and mixed pine-oak forests on the Vila Real district, Portugal. Forest Ecology and Management 305: 38-47.

Paul KI, Polglase PJ, Nyakuengama JG, et al. 2002. Change in soil carbon following afforestation. Forest Ecology and Management 168: 241-257.

Schröder T, Arnoni Costa E, Felipe Valério A, et al. 2014. Taper Equations for Pinus elliottii Engelm. in Southern Paraná, Brazil. Forest Science 61: 311-319.

Sharma RP, Brunner A, Eid T, et al. 2011. Modelling dominant height growth from national forest inventory individual tree data with short time series and large age errors. Forest Ecology and Management 262: 2162-2175.

Sharp DD, Lieth H, Whigham D. 1975. Assessment of regional productivity in North Carolina. Whittaker HLRH editor. Primary productivity of the biosphere: Springer, p131-146. 
Teobaldelli M, Somogyi Z, Migliavacca M, et al. 2009. Generalized functions of biomass expansion factors for conifers and broadleaved by stand age, growing stock and site index. Forest Ecology and Management 257: 1004-1013.

Whittaker RH, Likens GE. 1973. Carbon in the biota. Woodwell GM, Pecan EV editors. Brookhaven symposia in biology. Springfield, VA, USA,: Technical Information Center, Office of Information Services, US Atomic Energy Commission, p281-302.

Woodwell GM. 1978. The carbon dioxide question. Scientific American 238: 34-43.

Wu ZL. 1984. Chinese-fir Beijing: China Forestry Publishing House (in Chinese). 583p.

Zhang XQ, Kirschbaum MUF, Hou ZH, et al. 2004. Carbon stock changes in successive rotations of Chinese fir (Cunninghamia lanceolata (lamb) hook) plantations. Forest Ecology and Management 202: 131-147. 


\title{
Curriculum Vitae
}

\author{
Georg-August-Universität Göttingen \\ Department of Forest Inventory and Remote Sensing \\ Büsgenweg 5, Göttingen, 37075, Germany \\ E-Mail: 1xtt2010@163.com; xtang@gwdg.de
}

\section{Xiaolu Tang, Ph.D}

https://www.researchgate.net/profile/Xiaolu_Tang

\section{Research interests}

Forest management for adaptation of Climate Change

Growth modelling

Remote sensing

Soil carbon

Sources and partitioning of soil $\mathrm{CO}_{2}$ fluxes

Forest inventory

\section{Educations}

2012.10-2015.07: PhD of Forest science in Georg-August-Universität Göttingen

Dissertation title: Estimation of biomass, volume and growth of subtropical forests in Shitai County, China

2009.09-2012.07: Master of Silvicultural in Chinese Academy of Forestry, International Centre for Bamboo and Rattan (ICBR)

Thesis title: Research on characteristics of soil respiration in different managed Phyllostachy edulis forests, Mufu Mountain, Southern Hubei, China

2005.09-2009.06: Bachelor of Forestry in Sichuan Agricultural University (SICAU)-211 Key University in China 


\section{Publications}

\section{5}

1. Tang X, Fan S, Qi L, Guan F, Cai C, Du M. 2015. Soil respiration and carbon balance in a Moso bamboo (Phyllostachys heterocycla (Carr.) Mitford cv. Pubescens) forest in subtropical China. iForest-Biogeosciences and Forestry (in press)

2. Tang X, Fan S, Qi L, Guan F, Liu G, Du M, Effect of understory removal on root production, turnover and total belowground carbon allocation in Moso bamboo forests, iForestBiogeosciences and Forestry (accepted)

3. Tang X, Pérez-Cruzado C, Vor T, Fehrmann L, Álvarez-González J G, Kleinn C. 2015, Development of stand density management diagrams for Chinese fir plantations. Forestry (accepted)

4. Guan F, Tang X (co-first author), Fan S, Zhao J, Peng C. 2015, Changes in soil carbon and nitrogen stocks followed the conversion from secondary forest to Chinese fir and Moso bamboo plantations. Catena 133: 455-460

5. Guisasola R, Tang X , Bauhus J, Forrester D. I. 2015, Intra- and inter-specific differences in crown architecture in subtropical mixed-species forests of Shitai County, China. Forest Ecology and Management, 353: 164-72

6. Forrester D. I. Tang $\mathbf{X}$. 2015, Analysing the spatial and temporal dynamics of species interactions in mixed-species forests and the effects of stand density using the 3-PG model. Ecological modelling (accepted)

\section{4}

7. Forrester D, Guisasola R, Tang X , Albrecht A, Dong T, le Maire G. 2014. Using a stand-level model to predict light absorption in stands with vertically and horizontally heterogeneous canopies. Forest Ecosystems 1: 1-19

\section{3}

8. Tang X, Fan S, Qi L, Liu G, Guan F, Du M, Xu Q. 2013, Effect of cutting on soil respiration in Phyllostachy edulis Forest, Mufu Area, China. Journal of Forest research, 26 (1): $52-57$ (in Chinese)

9. Du M, Fan S, Liu G, Qi L, Guo B, Tang X, Xiao F. 2013, Effects of land use change on soil labile organic carbon in Central Jiangxi of China. The journal of applied ecology, 24(10):28972904 (in Chinese)

10. Du M, Fan S, Liu G, Qi L, Tang X, Xiao F. 2013, Soil labile organic carbon in different types of Moso bamboo (Phyllostachys edulis) stands. Chinese Journal of Ecology, 32(3):571-576 (in Chinese) 
11. Du M, Fan S, Liu G, Qi L, Tang X, Xiao F. 2013, Effect of Mixed operating in Moso bamboo (Phyllostachys edulis) forest on soil labile carbon pool and carbon management index. Journal of Nanjing Forestry University (Natural Science Edition), 37(5):49-54 (in Chinese)

\section{2}

12. Tang X, Fan S, Qi L, Liu G, Guan F, Du M, Chen C. 2012: Effect of different managements on carbon storage and carbon allocation in Moso bamboo forest (Phyllostachys pubescen). Acta Agriculturae Universitatis Jiangxiensis, 34(4): 736-742 (in Chinese)

13. Fan S, Tang X, Qi L, Liu G, Guan F, Du M. 2012, Effect of different managements on temperature sensitivity of soil respiration in Phyllostachy edulis forest. Journal of Sichuan Agricultural University, 2012,30(3): 300-307 (in Chinese)

14. Qi L, Fan S, Ai W, Liu G, Meng Y, Du M, Tang X, 2012, Effects of Phyllostachy edulis and Cunninghamia lanceolata mixed forests on soil qualities in the hilly region, Central Hunan. Journal of Mountain Science, 30(3):314-320 (in Chinese)

\section{Conference Proceedings}

$\underline{\text { Tang X: }}$ : Aboveground stand biomass dynamics in a Chinese fir [(Cunninghamia lanceolata (Lamb.) Hook] plantation in Shitai County, China. Tropentag 2014-Bridging the gap between increasing knowledge and decreasing resources, Prague, Czech; September, 2014 (poster presentation)

$\underline{\text { Tang XX }}$, Fan S: A review of available phosphorus in soil. Abstract book of 9th Youth Academic Conference of Forestry in China, September, 2010 (oral presentation)

\section{Skills}

Fluency in statistical analysis and software (R and SAS)

Fluency in Quantum GIS and ENVI

\section{Participated Programs}

- 2011.03 - 2012.06 Spatial patterns and variation characteristics of soil carbon stock in typical forest (Project No.: 201104008)

* 2010.06 - 2011.10 The spatial patterns and stability mechanism of soil organic matter in Moso Bamboo (phyllostachys pubescen) forests (Project No.: 1632008005)

* 2010.06 - 2012.06 Research on carbon decreasing management and carbon morphometric parameters (Project No.: 163220100005)

* 2012.10 - 2015.09 Project of Sino-German Cooperation on Innovative Technologies and Service Capacities of Multifunctional Forest Management (Project No.: Lin²Value 033L049- 
CAFYBB2012013) funded by the Federal Ministry of Education and Research (BMBF) and the Chinese Academy of Forestry

\section{Honors}

2008: "Three good" student in bachelor study in Sichuan Agricultural University

First prize for scholarship and grants in Sichuan Agricultural University

Excellent member for summer social practice (Volunteer for "5.12" Wenchuan earthquake in July 2008)

* 2007: "Three good" student in bachelor study in Sichuan Agricultural University

First prize for scholarship and grants in Sichuan Agricultural University

Excellent member for summer social practice (Compulsory education for pupils in July 2007)

- 2006: First prize for scholarship and grants in Sichuan Agricultural University

Excellent member for summer social practice (Voluntary social survey of Leftover Children in Rural China in July 2006)

\section{Social Activities}

2006-2007: Minister of Love Organization of Sichuan Agricultural University

* 2007-2008: President of Love Organization of Sichuan Agricultural University 